\author{
UNIVERSIDADE DE SÃO PAULO \\ ESCOLA DE ENGENHARIA DE SÃO CARLOS \\ DEPARTAMENTO DE ENGENHARIA DE ESTRUTURAS
}

THOMAS NUNES SOMBRA

\begin{abstract}
Aplicação do ensaio de ressonância acústica na caracterização mecânica de unidades de alvenaria estrutural
\end{abstract}





\title{
Aplicação do ensaio de ressonância acústica na caracterização mecânica de unidades de alvenaria estrutural
}

\author{
VERSÃO CORRIGIDA \\ A versão original encontra-se na biblioteca da Escola de Engenharia de São Carlos
}

Dissertação apresentada ao Programa de PósGraduação em Engenharia Civil (Engenharia de Estruturas) da Escola de Engenharia de São Carlos da Universidade de São Paulo para obtenção do título de Mestre em Ciências.

Área de concentração: Estruturas

Orientador: Prof. Assoc. Vladimir Guilherme Haach 
AUTORIZO A REPRODUÇÃO TOTAL OU PARCIAL DESTE TRABALHO POR QUALQUER MEIO CONVENCIONAL OU ELETRÔNICO, PARA FINS DE ESTUDO E PESQUISA, DESDE QUE CITADA A FONTE.

Ficha catalográfica elaborada pela Biblioteca Prof. Dr. Sérgio Rodrigues Fontes da EESC/USP com os dados inseridos pelo(a) autor(a).

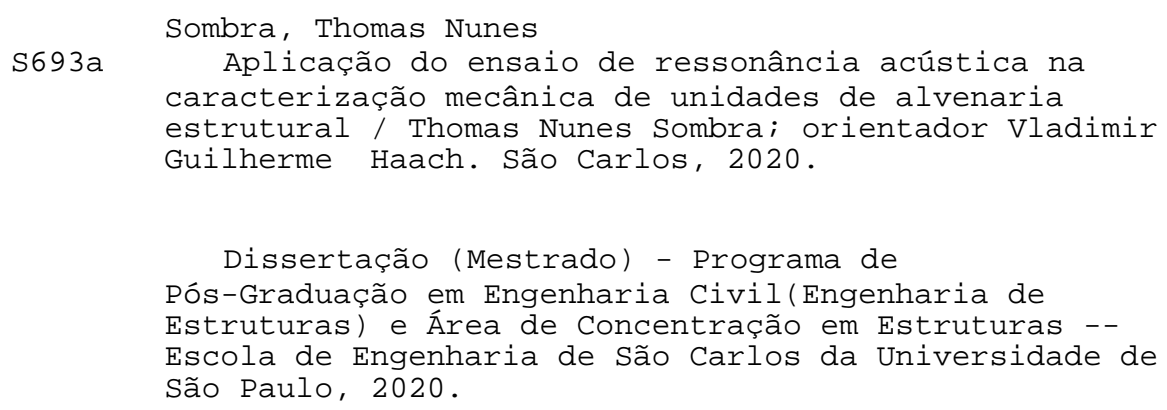

1. Alvenaria estrutural. 2. Análise modal. 3. Ensaios não destrutivos. 4. Frequências naturais. 5. Modelagem numérica. I. Título.

Eduardo Graziosi Silva - CRB - 8/8907 


\section{FOLHA DEJULGAMENTO}

Candida to: Engenheiro THOMAS NUNES SOMBRA.

Título da dissertação: "Aplicação do ensaio de ressonância acústica na caracterização mecânica de unidades de alvena ria estrutural".

Data da defesa: $31 / 07 / 2020$

Comissão J ulgadora

Prof. Associa do Vladimir Guilheme Haach

(Orientador)

(Escola de Engenharia de São Carlos - EESC/USP)

Prof. Dr. Gustavo Henrique Siqueira

(Universida de Esta dual de Campinas/UNICAMP)

\footnotetext{
Prof. Dr. Cláudius de Sousa Barbosa

(Escola Politécnica/EP-USP)
}

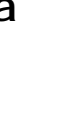

Resultado

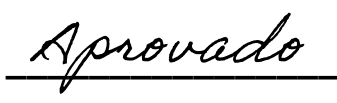

(Escola Poltécnica/EP-USP)

Aprovado

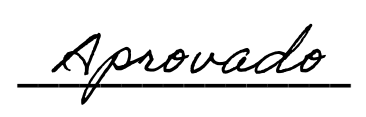

Coordenador do Programa de Pós-Graduação em Engenharia Civil (Engenharia de Estruturas):

Prof. Associa do Vladimir Guilherme Haach

Presidente da Comissão de Pós-Graduação:

Prof. Titular Murilo Araujo Romero 



\section{AGRADECIMENTOS}

Aos meus pais, Nilton e Aila, pela sabedoria transmitida, apoio incondicional, salvaguarda e afago. Os princípios adquiridos na criação se fizeram mister para a formação de meu caráter.

À Universidade Federal Rural do Semi-Árido (UFERSA), por me possibilitar obter uma formação em Engenharia Civil, conhecer profissionais esplêndidos e fazer amizades valiosas, sem as quais dificilmente teria chegado até aqui.

Ao meu orientador acadêmico, Vladimir Haach, pela paciência e disponibilidade ao longo dessa parceria, sempre em compromisso com a excelência.

Ao corpo docente da Escola de Engenharia de São Carlos, em especial aos professores Humberto Coda e Rodrigo Paccola, verdadeiros baluartes do conhecimento, por instigarem em mim a busca pelo saber.

Aos funcionários do Departamento de Engenharia de Estruturas (SET), pela solicitude e eficiência no desempenho de suas tarefas.

Aos colegas de mestrado Anchieta, Anne, Adriana, Camila, Danilo, Éverton, Felipe, Luan, Lucas, Matheus, Mariane, Tainá, Ray e Yury, pelo companheirismo caraterístico de grandes amizades e pelos momentos de descontração proporcionados, aliviando os altos níveis de estresse inerentes a uma pós-graduação.

Ao amigo Túlio Raunyr, pelas conversas que ajudaram a me manter motivado ao longo do mestrado.

Aos amigos Anderson, Eric, Herbert, Ingrid, Jefferson, Rafaelle e Rebecca, que mesmo distantes se fizeram presentes de alguma forma. Minhas conquistas se devem, de certa forma, a todos eles.

Ao Conselho Nacional de Desenvolvimento Científico e Tecnológico (CNPq), pela bolsa de mestrado concedida. 

“Aqueles de nós que não estão dispostos a expor suas ideias ao risco da refutação não tomam parte no jogo da ciência." 



\section{RESUMO}

SOMBRA, T. N. Aplicação do ensaio de ressonância acústica na caracterização mecânica de unidades de alvenaria estrutural. 2020. 161 p. Dissertação (Mestrado em Engenharia Civil - Estruturas) - Escola de Engenharia de São Carlos, Universidade de São Paulo. São Carlos, 2020.

A diversidade e complexidade das geometrias existentes para as unidades utilizadas no sistema construtivo em alvenaria estrutural (bloco inteiro, meio-bloco, entre outras) dificulta a determinação do módulo de elasticidade do material através dos métodos de ressonância, posto que tais elementos não dispõem de uma relação definida (expressa por meio de um coeficiente atrelado à geometria) entre aquela propriedade mecânica e suas frequências de vibração. Portanto, o estudo visa propor um procedimento experimental para aquisição do parâmetro geométrico que vincula o módulo de elasticidade dinâmico às frequências naturais da unidade, obtidas por meio do ensaio de ressonância acústica. A amostra experimental compreende blocos inteiros e meio-blocos (vazados) cerâmicos e de concreto com resistências variadas. Na etapa de caracterização, procederam-se a análise dimensional e a determinação da área líquida destas unidades, posteriormente submetidas ao ensaio de compressão axial para determinação da resistência à compressão característica e uma aproximação do módulo de elasticidade estático. Em outras unidades, foram conduzidos ensaios de velocidade de pulso ultrassônico e ressonância acústica (por meio da técnica de excitação por impulso) para angariar valores locais e globais do módulo de elasticidade dinâmico. Em paralelo, desenvolveu-se análise modal auxiliada pelo pacote de elementos finitos DIANA ${ }^{\circledR}$ com intuito de obter modos de vibrar, estimativas das frequências naturais e coeficientes geométricos para as diferentes unidades estudadas. Velocidades médias da propagação de ondas ultrassônicas longitudinais e transversais foram consideradas para estimar as propriedades elásticas dinâmicas requeridas pelos modelos numéricos. As frequências de ressonância identificadas experimentalmente apresentaram relações bastante razoáveis com aquelas previstas numericamente, especialmente nas unidades de concreto. Em todas as amostras, valores do módulo de elasticidade obtido a partir do ensaio de ultrassom superaram os providos pelo método acústico. Além disso, módulos de elasticidade aferidos pelas metodologias dinâmicas se mostraram mais elevados que o equivalente estático calculado na área bruta das unidades e próximos àquele calculado na área líquida. Os resultados experimentais e numéricos indicaram que o ensaio de ressonância acústica logrou êxito na caracterização do módulo de elasticidade dinâmico em unidades de alvenaria estrutural. Então, um procedimento baseado nesse método para estimar coeficientes geométricos de forma experimental foi enunciado e sua viabilidade discutida.

Palavras-chave: Alvenaria estrutural. Análise modal. Ensaios não destrutivos. Frequências naturais. Modelagem numérica. 



\begin{abstract}
SOMBRA, T. N. Application of acoustic resonance test on the mechanical characterization of structural masonry units. 2020. 161 p. Dissertation (MSc. in Civil Engineering Structures) - School of Engineering of São Carlos, University of São Paulo. São Carlos, 2020.

The diversity and complexity of existing geometries for the units used in structural masonry construction system (block, half-block, among others) hinder the determination of material elastic modulus through resonance methods, as such elements lack a defined relation (expressed in terms of a coefficient linked to geometry) between that mechanical property and their vibration frequencies. Therefore, this study proposes an experimental procedure for acquisition of the geometric parameter which relates dynamic elastic modulus to the natural frequencies of a unit, gathered by means of acoustic resonance testing. The experimental sample comprises hollow ceramic and concrete blocks and half-blocks with diverse strengths. During characterization phase, dimensional analysis and determination of net area were carried out for such units, which then underwent axial compression test in order to acquire characteristic compressive strength and an approximation of the static elastic modulus. On other units, ultrasonic pulse velocity and acoustic resonance (by impulse excitation of vibration) tests were conducted to obtain local and global values of dynamic elastic modulus. In parallel, modal analysis aided by finite element software DIANA ${ }^{\circledR}$ was developed to attain vibration modes, estimated natural frequencies and geometric parameters for the different units studied. Average propagation velocities of longitudinal and transverse ultrasonic waves were considered to estimate dynamic elastic properties required by the numerical models. Resonant frequencies identified via experimental setup showed very reasonable relations with those predicted numerically, notably for concrete units. Within all samples, values of elastic modulus obtained through ultrasonic test surpassed those provided by the acoustic test. Besides, elastic moduli measured with dynamic methodologies proved to be higher than their static counterparts calculated in the gross area of the units, and close to those measured in their net area. Experimental and numerical results indicated that the acoustic resonance test succeeded in characterizing the dynamic elastic modulus in structural masonry units. Thus, a procedure based on this method to estimate geometric coefficients in an experimental manner was enunciated and its feasibility discussed.
\end{abstract}

Keywords: Modal analysis. Natural frequencies. Nondestructive testing. Numerical modeling. Structural masonry. 



\section{LISTA DE FIGURAS}

Figura 1.1 - Fluxograma simplificado das etapas experimental e numérica da pesquisa..........25

Figura 2.1 - Modos naturais fundamentais: a) flexional; b) longitudinal; c) torcional ...........29

Figura 2.2 - Esquema do aparato para ensaio de ressonância forçada .................................... 30

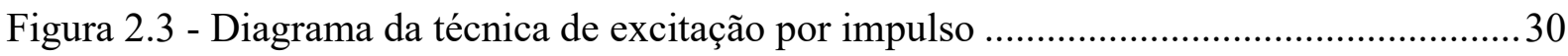

Figura 2.4 - Posição de impacto e captação para cada modo fundamental de vibração............31

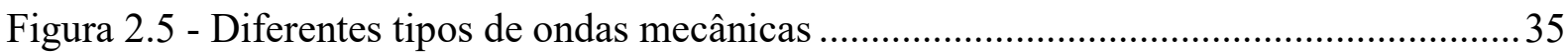

Figura 2.6 - Representação simplificada do ensaio de ultrassom ........................................... 36

Figura 2.7 - Formas de transmissão do pulso: $a$ ) direta; b) semidireta e $c$ ) indireta ................37

Figura 2.8 - Exemplo de FRF $\left(\mathrm{H}_{11}\right)$ para um sistema com 4 graus de liberdade..................... 42

Figura 2.9 - Transformada Rápida de Fourier (FFT): a) sinal original; b) sinal processado ...46

Figura 2.10 - Exemplos de geometria: a) bloco de concreto; b) bloco cerâmico 47

Figura 2.11 - Pontos indicados para efetuar medições: a) largura; b) altura; c) comprimento 48

Figura 2.12 - Esquemas de medição: a) desvio em relação ao esquadro; b) planeza das faces49

Figura 2.13 - Determinação da menor dimensão do furo ....................................................50

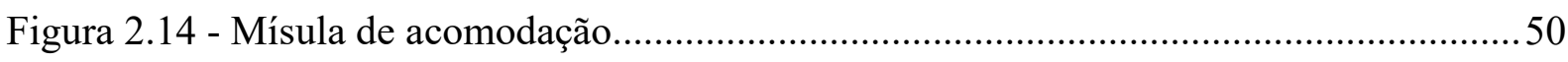

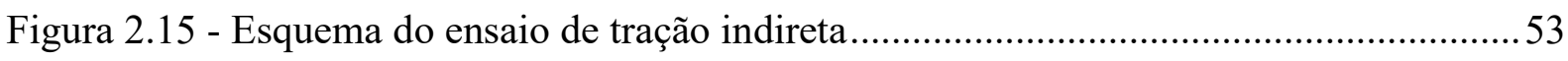

Figura 2.16 - Módulos de elasticidade: a) módulo tangente; b) módulo cordal.......................54

Figura 2.17 - Evolução das deformações na face do bloco ......................................................59

Figura 2.18 - Análise tensão-deformação: a) posicionamento dos transdutores de deslocamento; b) curvas tensão-deformação experimentais e teórica. 60

Figura 2.19 - Espectro de frequências gerado para as amostras prismáticas............................64

Figura 2.20 - Configurações de suporte: a) modo flexional; b) modo torcional ......................66

Figura 2.21 - Análise paramétrica: a) modo de vibrar selecionado; b) gráficos elaborados ....67

Figura 3.1 - Unidades componentes da amostra experimental ............................................. 71

Figura 3.2 - Determinação da área líquida: a) massa aparente; b) massa saturada ..................74

Figura 3.3 - Arranjo de extensômetros para ensaio de compressão (unidades cerâmicas) .......77

Figura 3.4 - Curvas tensão-deformação das unidades cerâmicas: a) blocos; b) meio-blocos .. 78

Figura 3.5 - Arranjo de extensômetros para ensaio de compressão (unidades de concreto) .... 79

Figura 3.6 - Curvas tensão-deformação das unidades de concreto: a) blocos; b) meio-blocos 80

Figura 3.7 - Equipamento para ensaios ultrassônicos Pundit Lab+ ......................................... 81

Figura 3.8 - Interface utilizada na identificação do tempo de percurso da onda transversal.... 82

Figura 3.9 - Exemplos de malha auxiliar para o ensaio de ultrassom 


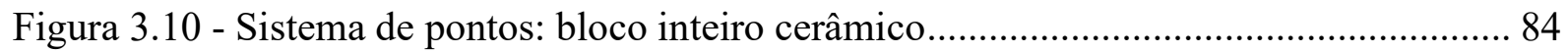

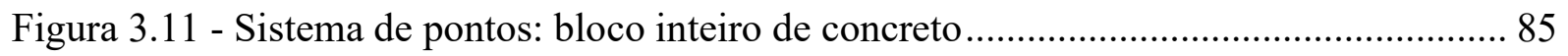

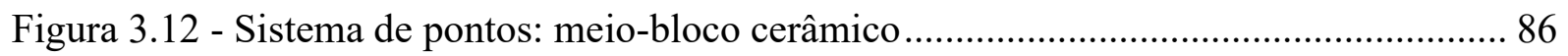

Figura 3.13 - Sistema de pontos: meio-bloco de concreto ................................................. 86

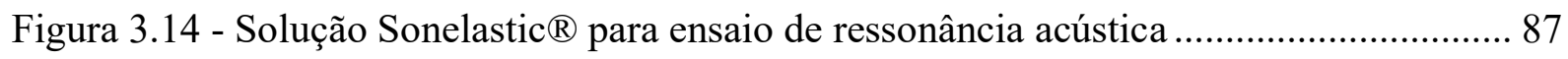

Figura 3.15 - Aparato para execução do ensaio de ressonância acústica................................ 88

Figura 3.16 - Exemplo de configuração de ensaio baseada em análise modal numérica ........ 89

Figura 3.17 - Exemplo de uma mesma configuração de ensaio para bloco e meio-bloco ........ 89

Figura 3.18 - Combinações impacto/captação: a) bloco inteiro; b) meio-bloco....................... 90

Figura 4.1 - Dimensões do modelo de bloco inteiro cerâmico (milímetros) ............................ 94

Figura 4.2 - Dimensões do modelo de meio-bloco cerâmico (milímetros) ............................. 95

Figura 4.3 - Dimensões do modelo de bloco inteiro de concreto (milímetros) ....................... 95

Figura 4.4 - Dimensões do modelo de meio-bloco de concreto (milímetros)........................... 96

Figura 4.5 - Elementos finitos hexaédricos: a) HX24L; b) CHX60 ...................................... 98

Figura 4.6 - Discretizações: a) modelo "BICE"; b) modelo "MBCO" .................................... 98

Figura 4.7 - Elementos finitos pentaédricos: a) TP18L; b) CTP45 ....................................... 99

Figura 4.8 - Discretizações: a) modelo "BICO"; b) modelo "MBCE" .................................... 99

Figura 4.9 - Bloco inteiro cerâmico: modos e frequências naturais....................................... 101

Figura 4.10 - Bloco inteiro de concreto: modos e frequências naturais................................ 103

Figura 4.11 - Meio-bloco cerâmico: modos e frequências naturais ......................................... 104

Figura 4.12 - Meio-bloco de concreto: modos e frequências naturais .................................... 105

Figura 4.13 - Determinação de $\alpha$ e $\beta$ via análise paramétrica: bloco cerâmico, $6^{\circ}$ modo ...... 107

Figura 4.14 - Determinação de $\alpha$ e $\beta$ via análise paramétrica: meio-bloco cerâmico, $3^{\circ}$ modo

Figura 4.15 - Determinação de $\alpha$ e $\beta$ via análise paramétrica: bloco de concreto, $2^{\circ}$ modo .. 107

Figura 4.16 - Determinação de $\alpha$ e $\beta$ via análise paramétrica: meio-bloco de concreto, $9^{\circ}$ modo 108

Figura 5.1 - Elaboração dos gráficos amplitude versus frequência analisados...................... 122

Figura 5.2 - Frequências ressonantes: experimental versus numérico.................................. 123

Figura 5.3 - Espectros totais e previsões numéricas: blocos cerâmicos................................ 124

Figura 5.4 - Espectros totais e previsões numéricas: blocos de concreto ............................. 126

Figura 5.5 - Espectros totais e previsões numéricas: meio-blocos cerâmicos ....................... 128

Figura 5.6 - Espectros totais e previsões numéricas: meio-blocos de concreto ...................... 130

Figura 5.7 - Configurações de ensaio e modos de vibrar recomendados para cada unidade. 140 


\section{LISTA DE TABELAS}

Tabela 3.1 - Dimensões efetivas para blocos e meio-blocos cerâmicos 73

Tabela 3.2 - Espessura das paredes e septos, desvio em relação ao esquadro (D) e planeza das

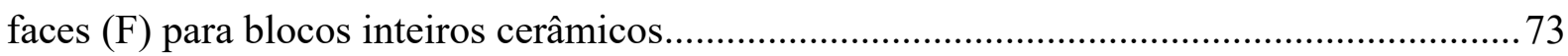

Tabela 3.3 - Área bruta e área líquida para blocos e meio-blocos cerâmicos ...........................74

Tabela 3.4 - Dimensões efetivas para blocos e meio-blocos de concreto …............................75

Tabela 3.5 - Espessura das paredes, dimensões dos furos e raio das mísulas para blocos inteiros

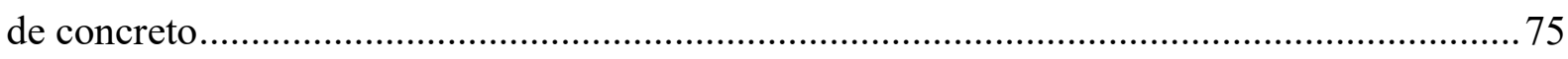

Tabela 3.6 - Área bruta e área líquida para blocos e meio-blocos de concreto ......................... 76

Tabela 3.7 - Resistência à compressão e módulo de elasticidade para blocos cerâmicos .........78

Tabela 3.8 - Resistência à compressão e módulo de elasticidade para meio-blocos cerâmicos

Tabela 3.9 - Resistência à compressão e módulo de elasticidade para blocos de concreto...... 80

Tabela 3.10 - Resistência à compressão e módulo de elasticidade para meio-blocos de concreto

Tabela 3.11 - Dados da amostra de blocos inteiros cerâmicos para ensaios não destrutivos ... 84

Tabela 3.12 - Dados da amostra de blocos inteiros de concreto para ensaios não destrutivos. 85

Tabela 3.13 - Dados da amostra de meio-blocos cerâmicos para ensaios não destrutivos........ 86

Tabela 3.14 - Dados da amostra de meio-blocos cerâmicos para ensaios não destrutivos........86

Tabela 4.1 - Modelagem numérica: propriedades dos materiais constituintes........................97

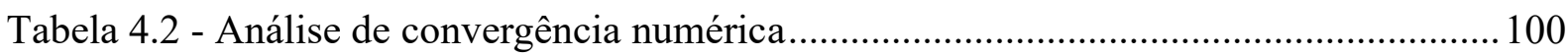

Tabela 4.3 - Constantes geométricas para os 10 primeiros modos: bloco cerâmico ............... 109

Tabela 4.4 - Constantes geométricas para os 10 primeiros modos: bloco de concreto ........... 110

Tabela 4.5 - Constantes geométricas para os 10 primeiros modos: meio-bloco cerâmico..... 110

Tabela 4.6 - Constantes geométricas para os 10 primeiros modos: meio-bloco de concreto. 111

Tabela 5.1 - Velocidade de propagação de ondas em blocos cerâmicos ................................ 114

Tabela 5.2 - Estimativa das propriedades elásticas dinâmicas: blocos cerâmicos .................. 114

Tabela 5.3 - Influência da não homogeneidade do material no módulo de elasticidade longitudinal dinâmico: blocos inteiros cerâmicos ............................................................... 115

Tabela 5.4 - Velocidade de propagação de ondas em blocos de concreto............................... 116

Tabela 5.5 - Estimativa das propriedades elásticas dinâmicas: blocos de concreto ................ 117

Tabela 5.6 - Velocidade de propagação de ondas em meio-blocos cerâmicos........................ 118

Tabela 5.7 - Estimativa das propriedades elásticas dinâmicas: meio-blocos cerâmicos .........118 
Tabela 5.8 - Influência da não homogeneidade do material no módulo de elasticidade longitudinal dinâmico: meio-blocos cerâmicos

Tabela 5.9 - Velocidade de propagação de ondas em meio-blocos de concreto 120

Tabela 5.10 - Estimativa das propriedades elásticas dinâmicas: meio-blocos de concreto ... 120

Tabela 5.11 - Frequências experimentais e módulo de elasticidade: blocos cerâmicos ......... 125

Tabela 5.12 - Frequências experimentais e módulo de elasticidade: blocos de concreto ...... 127

Tabela 5.13 - Frequências experimentais e módulo de elasticidade: meio-blocos cerâmicos 129

Tabela 5.14 - Frequências experimentais e módulo de elasticidade: meio-blocos de concreto

Tabela 5.15 - Módulos de elasticidade: blocos inteiros cerâmicos ...................................... 132

Tabela 5.16 - Módulos de elasticidade: meio-blocos cerâmicos .......................................... 132

Tabela 5.17 - Módulos de elasticidade: blocos inteiros de concreto ..................................... 133

Tabela 5.18 - Módulos de elasticidade: meio-blocos de concreto ......................................... 133

Tabela 5.19 - Estimativa dos resultados esperados para o procedimento experimental ........ 138

Tabela A.1 - Dimensões efetivas para blocos inteiros cerâmicos (individuais) .................... 151

Tabela A.2 - Espessura das paredes e septos, desvio em relação ao esquadro (D) e planeza das

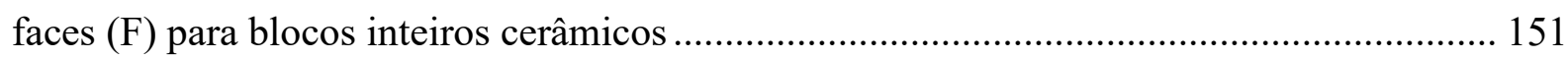

Tabela A.3 - Área bruta e área líquida para blocos inteiros cerâmicos (individuais) ............. 152

Tabela A.4 - Resistência à compressão e módulo de elasticidade para blocos inteiros cerâmicos

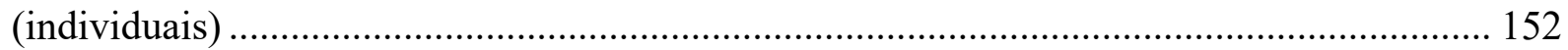

Tabela A.5 - Dimensões efetivas para meio-blocos cerâmicos (individuais) ......................... 153

Tabela A.6 - Área bruta e área líquida para meio-blocos cerâmicos (individuais)................. 153

Tabela A.7 - Resistência à compressão e módulo de elasticidade para meio-blocos cerâmicos

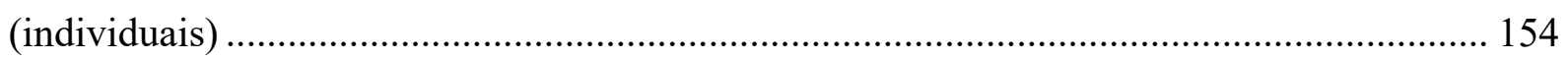

Tabela A.8 - Dimensões efetivas para blocos inteiros de concreto (individuais) .................. 154

Tabela A.9 - Espessura das paredes, dimensões dos furos e raio das mísulas para blocos inteiros

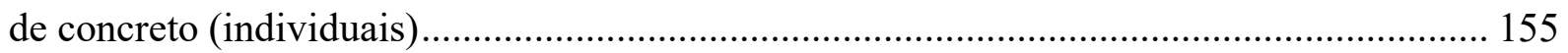

Tabela A.10 - Área bruta e área líquida para blocos inteiros de concreto (individuais)........ 155

Tabela A.11 - Resistência à compressão e módulo de elasticidade para blocos inteiros de

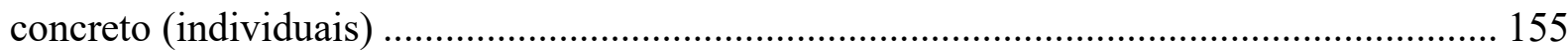

Tabela A.12 - Dimensões efetivas para meio-blocos de concreto (individuais).................... 156

Tabela A.13 - Área bruta e área líquida para meio-blocos de concreto (individuais) ........... 156

Tabela A.14 - Resistência à compressão e módulo de elasticidade para meio-blocos de concreto (individuais) 


\section{LISTA DE QUADROS}

Quadro 2.1 - Exemplos de END, seus princípios e aplicações...............................................28

Quadro 2.2 - Equações relacionando frequências ressonantes e módulos dinâmicos ...............33

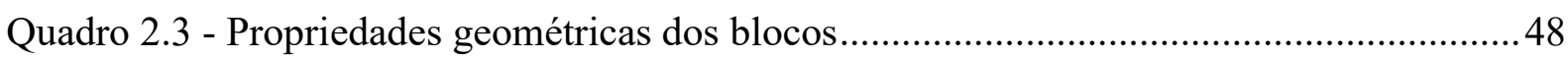

Quadro 2.4 - Algumas pesquisas envolvendo elementos de alvenaria estrutural....................56

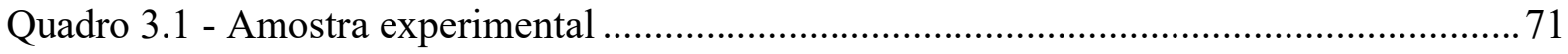

Quadro 3.2 - Parâmetros do software Sonelastic ${ }^{\circledR}$ utilizados no ensaio ................................91

Quadro 4.1 - Malhas de elementos finitos adotadas......................................................... 101

Quadro B.1 - Testes de hipóteses: blocos inteiros cerâmicos.............................................. 158

Quadro B.2 - Testes de hipóteses: blocos inteiros de concreto .......................................... 159

Quadro B.3 - Testes de hipóteses: meio-blocos cerâmicos .................................................. 160

Quadro B.4 - Testes de hipóteses: meio-blocos de concreto ............................................... 161 



\section{SUMÁRIO}

1 INTRODUÇÃO ...........................................................................................................21

1.1 Objetivos..........................................................................................................................23

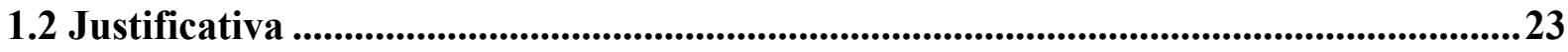

1.3 Metodologia ...................................................................................................................24

1.4 Estrutura da dissertação ...............................................................................................25

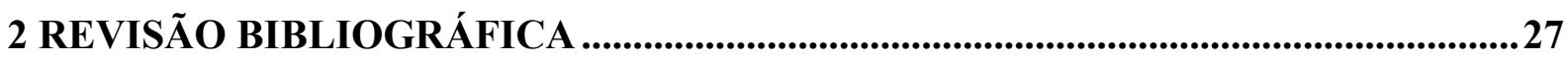

2.1 Ensaios não destrutivos .......................................................................................................27

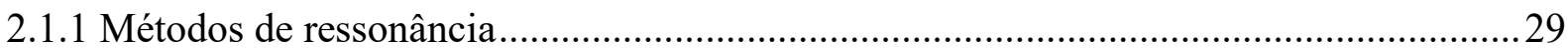

2.1.2 Velocidade de pulso ultrassônico (VPU).........................................................................

2.2 Análise modal das estruturas............................................................................................39

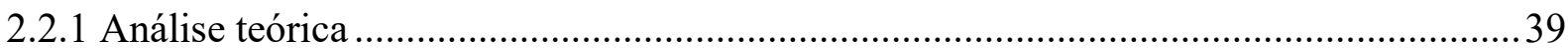

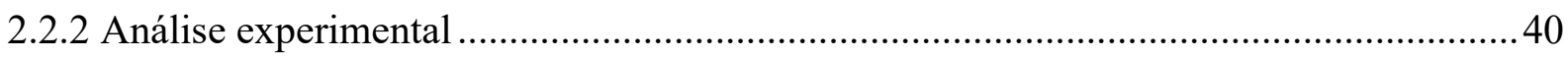

2.3 Caracterização das unidades de alvenaria estrutural.......................................................47

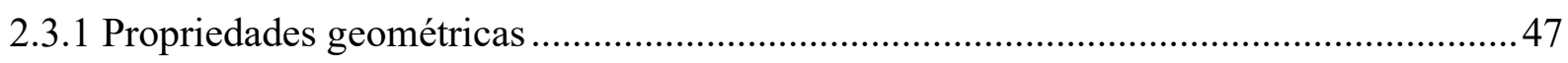

2.3.2 Propriedades mecânicas...................................................................................

2.4 Contextualização do estudo .............................................................................................55

2.4.1 Aspectos mecânicos da alvenaria estrutural ..............................................................55

2.4.2 Métodos de ressonância aplicados às estruturas........................................................61

2.4.3 Ensaio de ressonância acústica em blocos de alvenaria estrutural ..................................67

2.5 Síntese do capítulo .......................................................................................................................69

3 PROGRAMA EXPERIMENTAL ...............................................................................71

3.1 Caracterização geométrica e mecânica das unidades de alvenaria ...............................72

3.1.1 Propriedades geométricas: bloco e meio-bloco cerâmico .................................................72

3.1.2 Propriedades geométricas: bloco e meio-bloco de concreto …………………………....74

3.1.3 Propriedades mecânicas: bloco e meio-bloco cerâmico ………………………………......76

3.1.4 Propriedades mecânicas: bloco e meio-bloco de concreto ................................................79

3.2 Ensaio de ultrassom (VPU) ..............................................................................................81

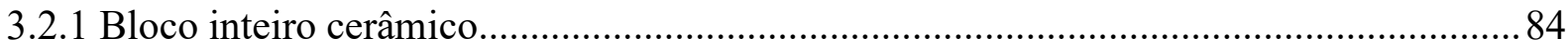

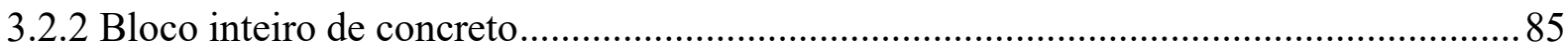

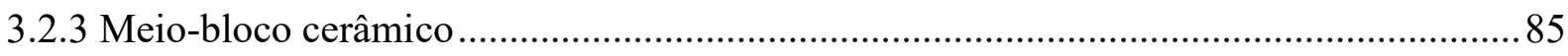

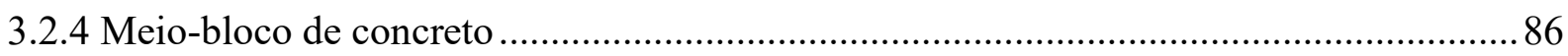




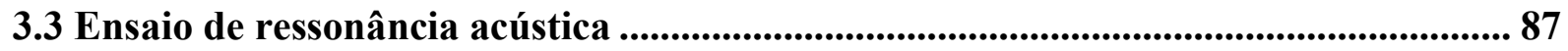

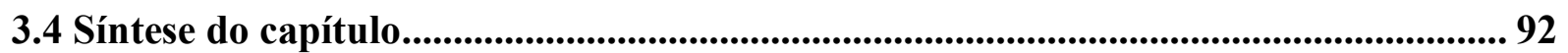

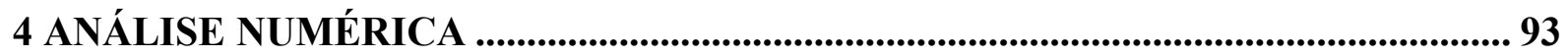

4.1 Definição dos modelos......................................................................................... 94

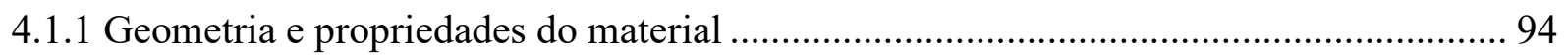

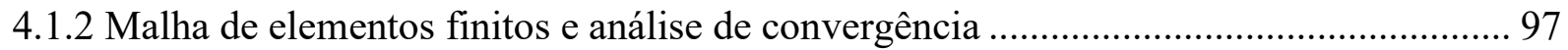

4.2 Modos de vibrar e frequências naturais ................................................................. 101

4.3 Determinação dos coeficientes geométricos ............................................................ 106

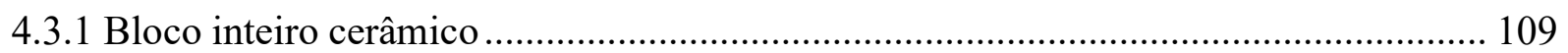

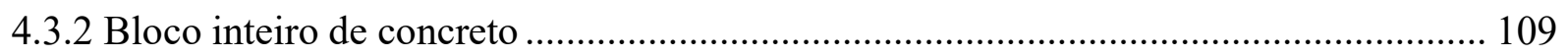

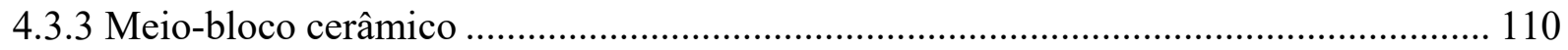

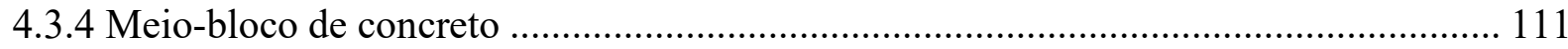

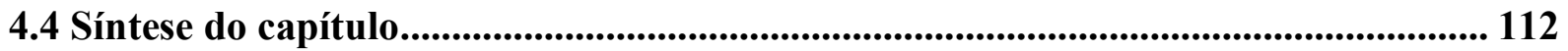

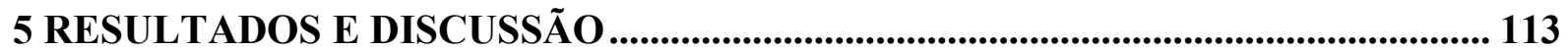

5.1 Estimativa de propriedades elásticas dinâmicas via VPU........................................... 113

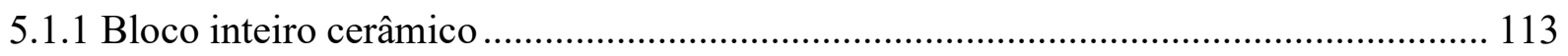

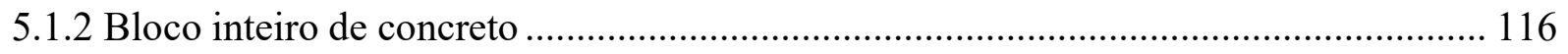

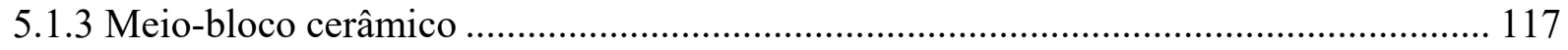

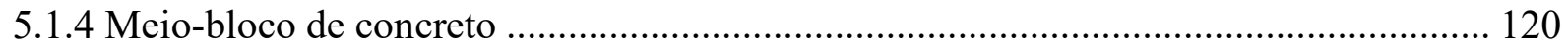

5.2 Ressonância acústica: resultados experimentais versus previsões numéricas.......... 122

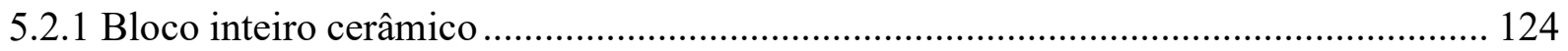

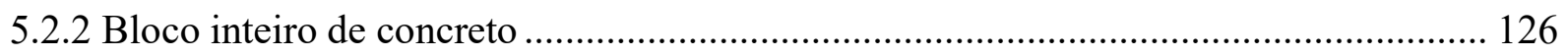

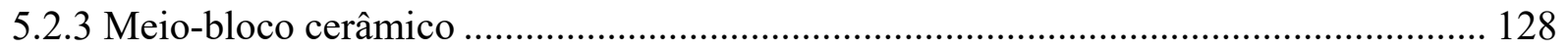

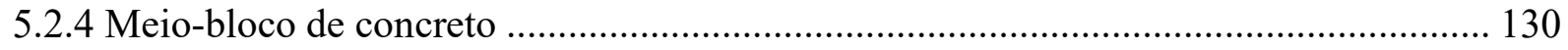

5.3 Módulo de elasticidade: comparativo entre metodologias de determinação............ 132

5.4 Proposta experimental para determinação da constante geométrica ....................... 136

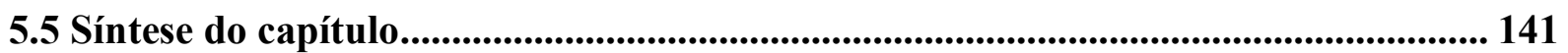

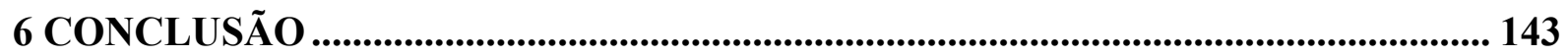

6.1 Sugestões para trabalhos futuros..................................................................................... 144

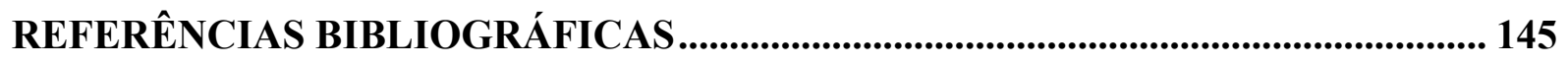

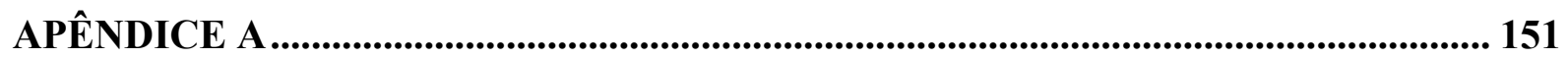

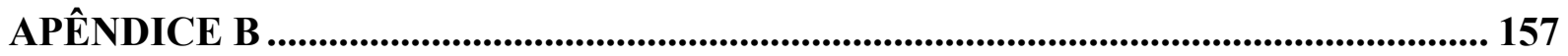




\section{INTRODUÇÃO}

A alvenaria estrutural é um sistema construtivo caracterizado pela presença de paredes que, além da habitual função de vedação, possuem capacidade portante. Outro aspecto a ele particular é a transmissão de ações, que ocorre por meio de tensões de compressão. É considerada uma técnica construtiva tradicional, podendo seus primeiros usos de forma rudimentar (empregando blocos de argila ou de rocha empilhados sem muito rigor técnico) serem datados de cerca de 2600 a.C. Nos últimos anos, esse processo construtivo experimentou avanços notáveis, muito em função da racionalização de materiais que o mesmo promove, da sua típica velocidade de execução, entre outros aspectos vantajosos em relação às edificações convencionais estruturadas em pórticos de concreto armado.

No viés de material, a alvenaria estrutural é atualmente composta por blocos (ou unidades) estruturais de concreto, cerâmicos ou sílico-calcários solidarizados por meio de argamassa de assentamento, podendo haver a presença de graute com função de preenchimento de vazios e acomodação de eventuais armaduras. É razoável imaginar o bloco estrutural como sendo o elemento básico desse compósito, definindo as características de resistência e deformabilidade do mesmo. Consequentemente, é o componente da alvenaria estrutural que costuma ser mais estudado, com especial interesse em sua caracterização mecânica, o que compreende a determinação experimental da resistência da unidade à diferentes tipos de solicitação e do seu módulo de elasticidade.

Em virtude da conformação geométrica das unidades de alvenaria, marcada pela presença de paredes e septos com diferentes espessuras, as curvas tensão-deformação extraídas de um ensaio de compressão axial (método destrutivo convencionalmente utilizado na obtenção de propriedades do material) representam o comportamento do bloco como estrutura. O que se consegue medir, nessas condições, é um módulo "aparente" ou de deformabilidade do bloco, e não a propriedade elástica intrínseca a seu material constituinte.

Soma-se a isso o fato de que a rigidez dos pratos da máquina de ensaio influencia a distribuição de tensões na superfície do corpo de prova, como constatado por Barbosa (2004) em blocos estruturais vazados de concreto. Não somente, o procedimento experimental é suscetível a fontes de imprecisão (como a dificuldade de se garantir a aplicação perfeitamente centrada do carregamento e a fixação de extensômetros para a aquisição de deformações) que promovem alta dispersão de resultados. Tais adversidades motivam a busca por métodos alternativos para aferir o módulo de elasticidade em unidades de alvenaria, bem como para a caracterização mecânica dos materiais de forma generalizada. 
A utilização de ensaios não destrutivos (ENDs) na determinação de parâmetros mecânicos de um material pode ser considerada uma metodologia já consolidada. Entre outras características, possibilita a execução de mais de um experimento na mesma amostra, diferentemente dos ensaios destrutivos tradicionais. Isso se deve ao fato de tais métodos permitirem relacionar fenômenos físicos como a propagação de ondas em um meio ou a frequência de vibração (ressonância) com as propriedades (estáticas ou dinâmicas) de interesse.

Nesse contexto, uma modalidade de END que vem sendo amplamente utilizada é a de ressonância, que consiste em investigar as frequências naturais de vibração de uma amostra mediante um impacto ou excitação, havendo captação e processamento da resposta por um aparato específico. Com esse procedimento e o auxílio de tratamento matemático é possível estimar, a partir da frequência natural (ou ressonante) associada a um modo de vibração, o módulo de elasticidade dinâmico do material, importante propriedade para a análise estrutural dinâmica, além de viabilizar correlações desta com o módulo de elasticidade estático, de maior interesse para fins de projeto.

A frequência natural referente a um modo de vibrar específico pode ser expressa, assumindo isotropia do material, em termos do módulo de elasticidade dinâmico $(E)$ e da massa $(M)$ do elemento por meio da relação

$$
f=\alpha \sqrt{\frac{E}{M}}
$$

sendo $\alpha$ uma constante que reúne aspectos geométricos relativos à rigidez, ao modo de vibrar em questão e à massa do elemento. Será tratada nesse texto como constante, coeficiente ou parâmetro geométrico.

Apesar de ser possível determinar as frequências naturais de uma amostra pelos métodos de ressonância, no instante do ensaio, em geral, não é possível enxergar a ocorrência dos modos de vibração. A importância da correta identificação do modo natural associado a uma frequência específica está na necessidade de se conhecer a rigidez que está sendo mobilizada para poder desenvolver modelos analíticos consistentes.

A análise modal conduzida junto a um programa computacional é uma solução para esse impasse, possibilitando a identificação das frequências naturais já vinculadas aos seus modos de vibração para estruturas de maior complexidade. Nesses casos, a faixa de frequências ressonantes é, a priori, desconhecida, a previsão analítica é, muitas vezes, impraticável e alguns dos modos de vibrar não são intuitivos, justificando o uso de uma ferramenta computacional. 


\subsection{Objetivos}

O estudo objetiva propor um procedimento experimental para obtenção do parâmetro geométrico que relaciona frequências ressonantes ao módulo de elasticidade dinâmico em unidades (blocos inteiros e meio-blocos cerâmicos e de concreto) utilizadas em alvenaria estrutural. Para tanto, os seguintes objetivos específicos devem ser cumpridos:

- Caracterizar as unidades a partir de suas propriedades geométricas e mecânicas;

- Estimar as propriedades elásticas dinâmicas do material das unidades por meio da velocidade de propagação de ondas (ensaio de ultrassom);

- Obter modos de vibrar e previsões das frequências naturais das unidades através de análise modal conduzida junto ao software de elementos finitos DIANA®;

- Identificar as frequências naturais das unidades mediante ensaio de ressonância acústica.

\subsection{Justificativa}

A relação entre o módulo de elasticidade dinâmico e as frequências ressonantes de uma estrutura qualquer pode ser expressa em termos de sua densidade (ou massa) e um coeficiente que é função da geometria do elemento e do modo de vibração. Os códigos ASTM C215-14 e ASTM E1876-15 estabelecem equações que relacionam frequências naturais associadas a determinados modos de vibrar às propriedades dinâmicas do material, sendo válidas para amostras prismáticas, cilíndricas e em formato de disco.

Nesse sentido, a aplicação dos métodos de ressonância para a obtenção de propriedades dinâmicas do material é limitada pela geometria da amostra ensaiada. Assim, por possuírem geometria complexa, as unidades de alvenaria estrutural ainda não dispõem de relações bem definidas entre suas frequências naturais e o módulo de elasticidade. Esse vínculo, estabelecido na forma de um coeficiente geométrico, pode ser obtido através de simulações numéricas, viabilizando o cálculo do módulo de elasticidade dos blocos pelos métodos de ressonância.

No entanto, a ocorrência de múltiplas geometrias (em função do processo de coordenação modular característico do sistema construtivo), bem como a existência de diferentes conformações (formato dos furos, paredes vazadas ou maciças etc.) para um mesmo padrão dimensional, tornam essa alternativa inviável para solução de todos os casos específicos. Assim, no contexto da caracterização mecânica das unidades de alvenaria, é de interesse prático determinar tal coeficiente de forma experimental, independentemente da geometria. 


\subsection{Metodologia}

Intentando atingir os objetivos definidos, foi proposta uma metodologia em etapas:

\section{a) Revisão bibliográfica}

Apresentou conceitos e métodos imprescindíveis para o entendimento das demais etapas do trabalho. Além disso, visando avaliar o estado da arte relativo ao emprego de metodologias não destrutivas na determinação de propriedades mecânicas dos materiais, bem como as relações entre o bloco e o seu material constituinte, foi feito um levantamento de trabalhos desenvolvidos nos últimos anos com temáticas afins. Para tanto, fez-se uso do acervo digital e físico da biblioteca da EESC - USP e da busca em bases de dados on-line.

\section{b) Programa experimental}

Contemplou a caracterização geométrica e mecânica das unidades de alvenaria estrutural com base nos seguintes ensaios: análise dimensional, determinação da área líquida e compressão axial. Além disso, incluiu a aplicação do ensaio de ressonância acústica na identificação dos modos de vibrar e frequências naturais das amostras e do ensaio de velocidade de pulso ultrassônico (ultrassom) para avaliar a variação das propriedades elásticas dinâmicas ao longo da estrutura. O programa foi realizado no Laboratório de Estruturas (LE) do Departamento de Engenharia de Estruturas.

\section{c) Simulações numéricas}

Consistiu na modelagem dos blocos ensaiados a fim de predeterminar os seus modos e frequências naturais de vibração, via análise modal assistida pelo pacote de elementos finitos DIANA ${ }^{\circledR}$. Essa etapa precedeu os ensaios de ressonância acústica, pois foi responsável por fornecer uma estimativa das frequências ressonantes esperadas para cada tipo de bloco, inicialmente desconhecidas, além das constantes geométricas necessárias para o cálculo do módulo de elasticidade dinâmico.

\section{d) Análise de resultados}

Mediante cumprimento das etapas anteriores, seguiu-se o processamento de dados (experimentais e numéricos), compreendendo a confecção de tabelas, obtenção de curvas e tratamento estatístico. À luz dessa análise, atestou-se a possibilidade de se obter o coeficiente geométrico experimentalmente. 
Uma vez que o programa experimental e a modelagem numérica dialogam entre si no objetivo de determinar o módulo de elasticidade dinâmico das unidades, julgou-se adequado detalhar essa parte da metodologia descrita, por entender que algumas das atividades realizadas se procederam de forma não convencional. A sequência desenvolvida é ilustrada na Figura 1.1.

Figura 1.1 - Fluxograma simplificado das etapas experimental e numérica da pesquisa

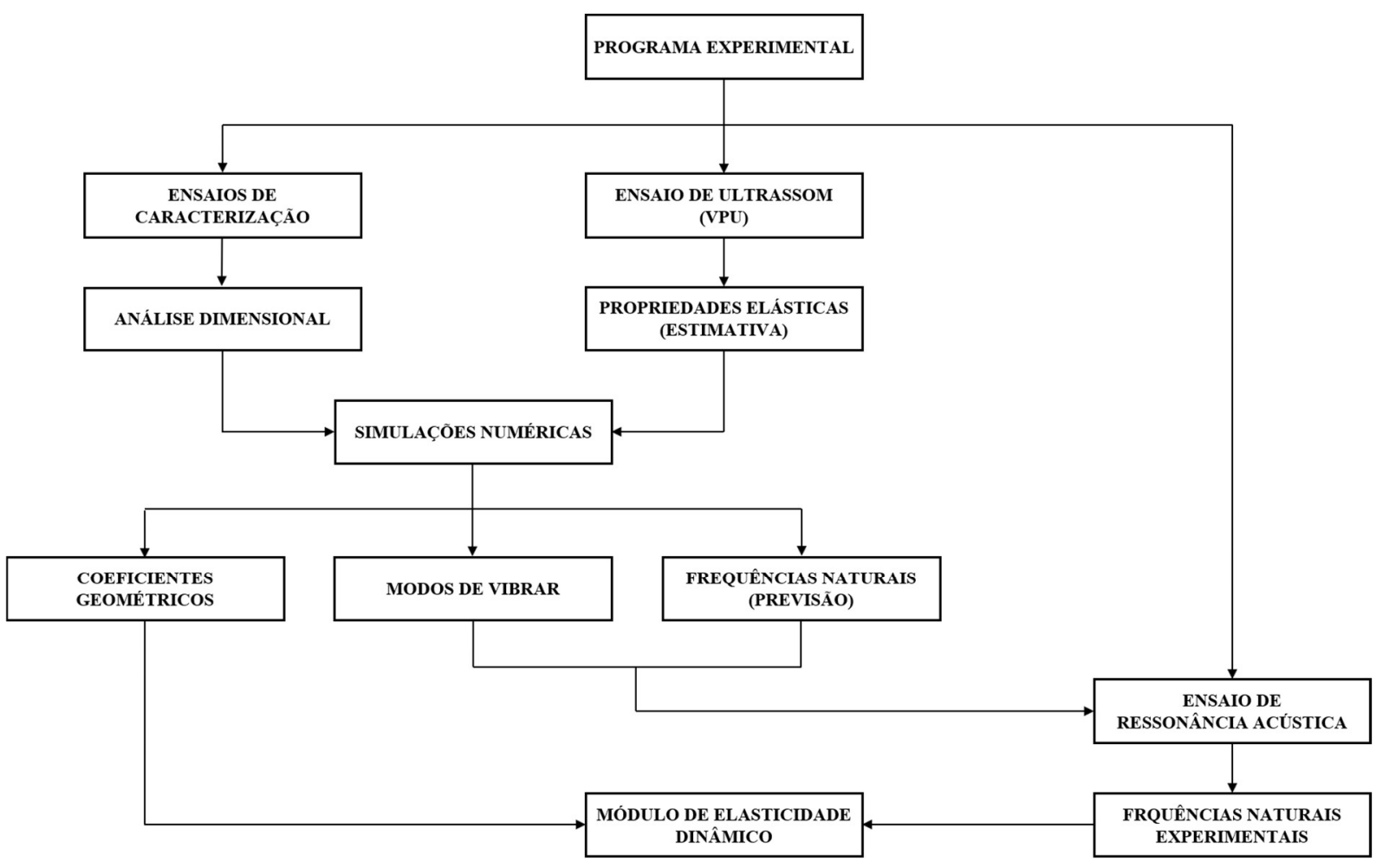

Fonte: Autor (2020)

\subsection{Estrutura da dissertação}

O Capítulo 2 (Revisão bibliográfica) fornece o embasamento teórico necessário para entendimento das demais etapas do estudo, além de prover o contexto em que este se insere.

No Capítulo 3 (Programa experimental) são descritos materiais e métodos empregados para a execução dos ensaios previstos, trazendo também alguns resultados preliminares.

O Capítulo 4 (Análise numérica) expõe o desenvolvimento dos modelos numéricos utilizados na previsão das frequências naturais e coeficientes geométricos das unidades.

No Capítulo 5 (Resultados e discussão) são tratados os resultados dos ensaios (ultrassom e ressonância acústica) e a proposta para determinação experimental de constantes geométricas.

Por fim, o Capítulo 6 (Conclusão) encerra o trabalho com perspectivas acerca dos principais resultados obtidos e sugestões para estudos futuros. 


\section{REVISÃO BIBLIOGRÁFICA}

\subsection{Ensaios não destrutivos}

Como o nome sugere, um ensaio não destrutivo (END) consiste em um procedimento para fornecer informações acerca de uma estrutura, equipamento ou material sem comprometer sua integridade ou funcionamento. Conforme Paiva (2017), possui aplicabilidade consagrada em materiais homogêneos (como o aço), mas para materiais compósitos e heterogêneos (caso do concreto) ainda é considerado uma novidade, apesar da gradual evolução nos últimos anos.

Alguns elementos básicos estão presentes em qualquer END, sendo eles: uma fonte com capacidade de provocar perturbações no meio de inspeção; um detector sensível às modificações produzidas nesse meio; uma forma de indicação ou registro das leituras do detector, de modo a possibilitar o processamento dos resultados; por fim, um observador apto ou dispositivo para interpretar as informações extraídas e associá-las à propriedade ou característica de interesse (SANTOS, 2014).

No contexto das estruturas, é importante ressaltar que as propriedades mecânicas do material só podem ser determinadas de forma direta pela extração de um corpo de prova e posterior ensaio destrutivo. Logo, não se pode lograr valores absolutos dessas propriedades a partir de um END. Conforme Malhotra e Carino (2004), tais métodos foram desenvolvidos para obter outras propriedades do material, por meio das quais pode-se inferir ou estimar as propriedades mecânicas e outras características relacionadas à performance estrutural, o que caracteriza uma medição indireta.

De maneira geral, há duas classes de ensaios não destrutivos para o concreto: a primeira consiste em métodos utilizados para estimar resistência, como os de dureza superficial (esclerometria), resistência à penetração, break-off, pull-off e de maturação. O ACI 228.1R-95 aborda com detalhes ensaios dessa classe. A segunda compreende métodos que medem outras características, como teor de umidade, densidade, espessura, resistividade e permeabilidade. Também se incluem nessa categoria as técnicas de propagação de ondas e de termografia infravermelha, utilizadas para localizar delaminações, vazios e fissuras. Tal classe de ensaios é escopo da ACI 228.2R-98.

Entre as principais vantagens dos ENDs, pode-se mencionar a possibilidade de reutilização das amostras e aplicação em condições de serviço, portabilidade e viabilidade econômica (HELLIER, 2003). Contudo, o ACI 228.2R-98 adverte que a aplicação bemsucedida de um END, de modo a prover resultados inequívocos, está vinculada a uma 
combinação favorável de metodologia de ensaio e condições de trabalho. Caso contrário, seu uso pode ser inconclusivo e demandar ensaios adicionais ou suplementares. Além disso, é impreterível que a análise de tais resultados seja executada por pessoas bem familiarizadas com os princípios e limitações de cada método (MALHOTRA; CARINO, 2004).

Juliani (2014) sumariza alguns métodos não destrutivos presentes na literatura, abordando brevemente seus princípios e aplicações. O Quadro 2.1 reproduz parte deles.

Quadro 2.1 - Exemplos de END, seus princípios e aplicações

\begin{tabular}{|c|c|c|}
\hline Método & Princípio & Aplicações \\
\hline Esclerometria & $\begin{array}{l}\text { Aplicar um impacto na superfície } \\
\text { do concreto através de uma massa } \\
\text { com dada energia cinética }\end{array}$ & $\begin{array}{l}\text { Medir a dureza do concreto e } \\
\text { correlacioná-la com a resistência }\end{array}$ \\
\hline $\begin{array}{l}\text { Ensaios de arrancamento } \\
\text { (pullout, break-off e pull-off) }\end{array}$ & $\begin{array}{l}\text { Medir a força necessária para } \\
\text { extrair corpos metálicos } \\
\text { incorporados no concreto fresco }\end{array}$ & $\begin{array}{c}\text { Determinar a resistência do } \\
\text { concreto nas primeiras idades e } \\
\text { determinar o melhor momento } \\
\text { para desforma }\end{array}$ \\
\hline Maturidade & $\begin{array}{c}\text { Medir o histórico de temperatura } \\
\text { do concreto fresco }\end{array}$ & $\begin{array}{l}\text { Acompanhar o desenvolvimento } \\
\text { da resistência nas idades iniciais } \\
\text { do concreto combinando os efeitos } \\
\text { de tempo e temperatura, } \\
\text { oferecendo uma base de quando } \\
\text { retirar formas e escoramento }\end{array}$ \\
\hline $\begin{array}{l}\text { Frequência de ressonância e } \\
\text { Eco-impacto }\end{array}$ & $\begin{array}{c}\text { Excitar o corpo de prova e } \\
\text { determinar suas frequências } \\
\text { naturais }\end{array}$ & $\begin{array}{c}\text { Estabelecer correlações com o } \\
\text { módulo de elasticidade dinâmico e } \\
\text { densidade, permitindo identificar } \\
\text { deterioração e corrosão ao longo } \\
\text { do tempo }\end{array}$ \\
\hline Métodos magnéticos & $\begin{array}{l}\text { Aparelhos que se baseiam no } \\
\text { princípio de que a presença do aço } \\
\text { afeta um campo eletromagnético }\end{array}$ & $\begin{array}{c}\text { Determinar a localização e } \\
\text { posicionamento da armadura, } \\
\text { informando cobrimento e diâmetro }\end{array}$ \\
\hline Métodos elétricos & $\begin{array}{l}\text { Mudanças nas propriedades } \\
\text { (resistência elétrica e de } \\
\text { polarização) e constante dielétrica } \\
\text { do concreto }\end{array}$ & $\begin{array}{l}\text { Determinar o teor de umidade, } \\
\text { espessuras de lajes e pavimentos e } \\
\text { avaliar a corrosão de armaduras }\end{array}$ \\
\hline Termografia infravermelha & $\begin{array}{l}\text { Baseia-se na condição de que } \\
\text { vazios e fissuras possuem baixa } \\
\text { condutividade térmica }\end{array}$ & $\begin{array}{l}\text { Detectar anomalias em camadas } \\
\text { inferiores da superfície do } \\
\text { elemento de concreto, vazios } \\
\text { internos e fissuras }\end{array}$ \\
\hline
\end{tabular}

Fonte: Adaptado de Juliani (2014)

A seguir, as duas modalidades de END praticadas neste trabalho são apresentadas com maior profundidade: métodos de ressonância (com ênfase à técnica de excitação por impulso) e a velocidade de pulso ultrassônico. 


\subsubsection{Métodos de ressonância}

As frequências naturais de vibração (ou frequências ressonantes) de um corpo estão relacionadas às propriedades do material constituinte, sua geometria e condições de contorno. Sendo assim, a partir da medição dessas frequências em amostras com geometria conveniente, condições de contorno conhecidas e de relações matemáticas, o módulo de elasticidade dinâmico do material pode ser determinado, o que constitui a essência dos métodos de ressonância (MALHOTRA; SIVASUNDARAM, 2004). Os tratamentos analíticos usuais admitem que o corpo de prova esteja vibrando em um de seus modos naturais fundamentais (primeiro modo flexional, longitudinal ou torcional), ilustrados na Figura 2.1.

Figura 2.1 - Modos naturais fundamentais: a) flexional; b) longitudinal; c) torcional

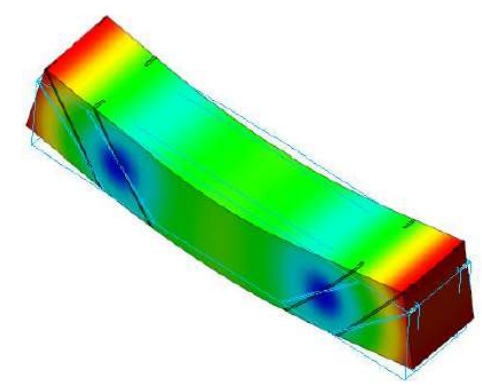

a)

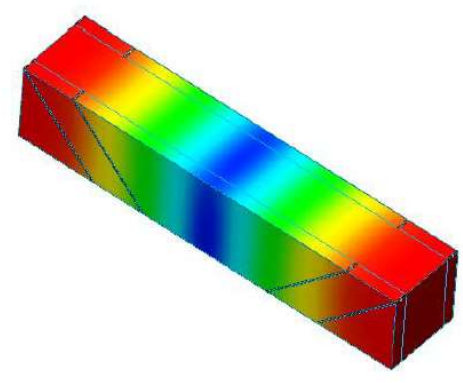

b)

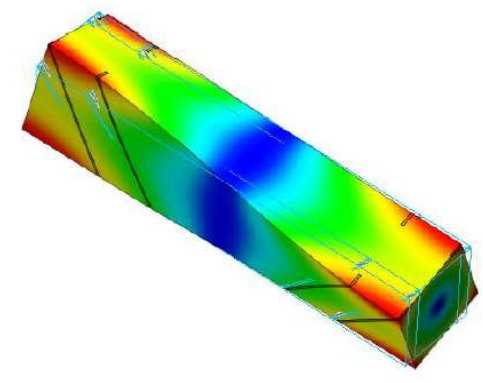

c)

Fonte: Adaptado de Prado (2016)

Diferentes métodos de ressonância foram padronizados por normas americanas, diferenciando-se pela forma de induzir a vibração na peça ensaiada e pela instrumentação utilizada para captar a resposta dinâmica e associá-la ao módulo de elasticidade.

A ASTM C215-14 apresenta o procedimento chamado de ressonância forçada (forced resonance), que faz uso de um oscilador eletrônico de áudio com frequência variável associado a um amplificador como forma de produzir vibrações mecânicas, sendo essas transmitidas à amostra pelo contato de uma unidade de excitação. A captação se dá por meio de um transdutor piezoelétrico ou magnético, responsável por transformar as vibrações mecânicas em corrente alternada de mesma frequência, posteriormente amplificadas para possibilitar a indicação da amplitude relativa do sinal por uma unidade específica. Um diagrama simples (Figura 2.2) ilustra o aparato descrito. 
Figura 2.2 - Esquema do aparato para ensaio de ressonância forçada

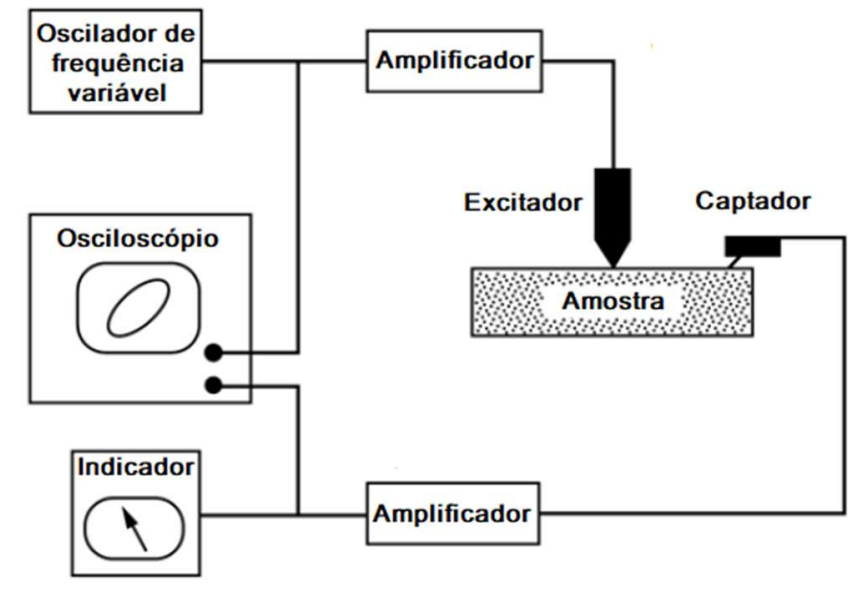

Fonte: ASTM C215-14

Conforme a frequência do conjunto oscilador-excitador é variada, identifica-se o instante em que a amostra entra em ressonância quando a amplitude de sinal lida no indicador for máxima. É comum lançar mão de uma unidade gráfica auxiliar (osciloscópio) para obter uma indicação visível dos modos fundamentais de vibração da amostra, o que é especialmente útil ao se ensaiar espécimes cuja faixa de frequências não é conhecida de antemão. A norma estabelece, ainda, as posições adequadas para se promover a excitação e captação de maneira a alcançar cada um dos modos fundamentais.

A ASTM E1876-15 contempla a técnica de excitação por impulso (impulse excitation of vibration), onde a amostra, situada sobre um suporte específico, é excitada por um golpe único de curta duração dado com uma ferramenta propícia (excitador). A captação pode ser feita por um transdutor de contato acoplado (como um acelerômetro) ou sem contato (usualmente um microfone), transformando a vibração mecânica em sinal elétrico processado por um sistema apropriado. A Figura 2.3 ilustra o esquema representativo desse ensaio.

Figura 2.3 - Diagrama da técnica de excitação por impulso

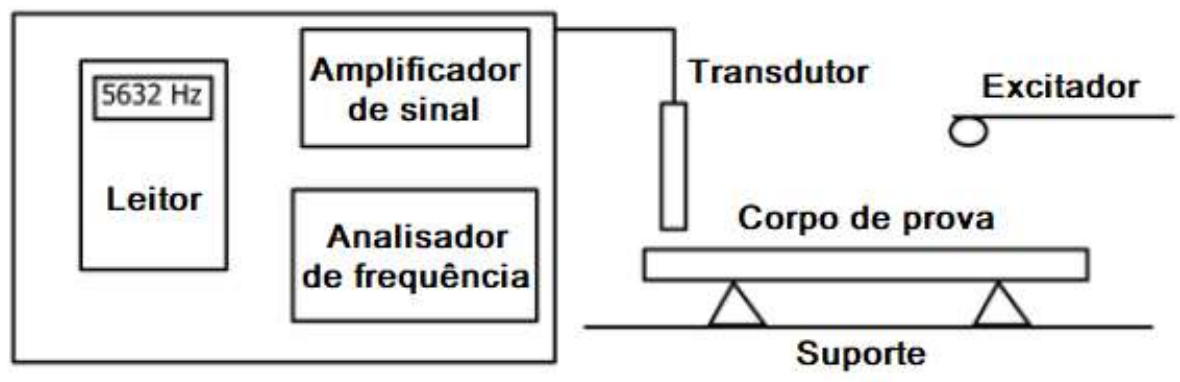

Sistema elétrico

Fonte: ASTM E1876-15 
Quando o registro das frequências de ressonância se dá a partir da resposta acústica (som emitido pela superfície) obtida por um captador de áudio, o procedimento costuma ser referido como ensaio de ressonância acústica (GIDRÃO, 2015). Esse método será discutido com maior detalhe por se tratar da modalidade a ser executada neste trabalho. A ASTM E1876-15 prescreve o arranjo conveniente de impacto e captação para cada modo fundamental de vibração, bem como especificações acerca do excitador utilizado, dos tipos de suporte a serem empregados e da geometria do corpo de prova, de modo a proporcionar resultados satisfatórios.

Quanto ao arranjo de impacto e captação, a norma ressalta sua importância para induzir e medir o modo de vibração desejado. As posições do golpe e do transdutor não devem ser modificadas ao longo de múltiplas leituras, visto que podem provocar e detectar modos de vibração alternativos. A Figura 2.4 explana a configuração ideal para a excitação de cada um dos modos fundamentais.

Figura 2.4 - Posição de impacto e captação para cada modo fundamental de vibração

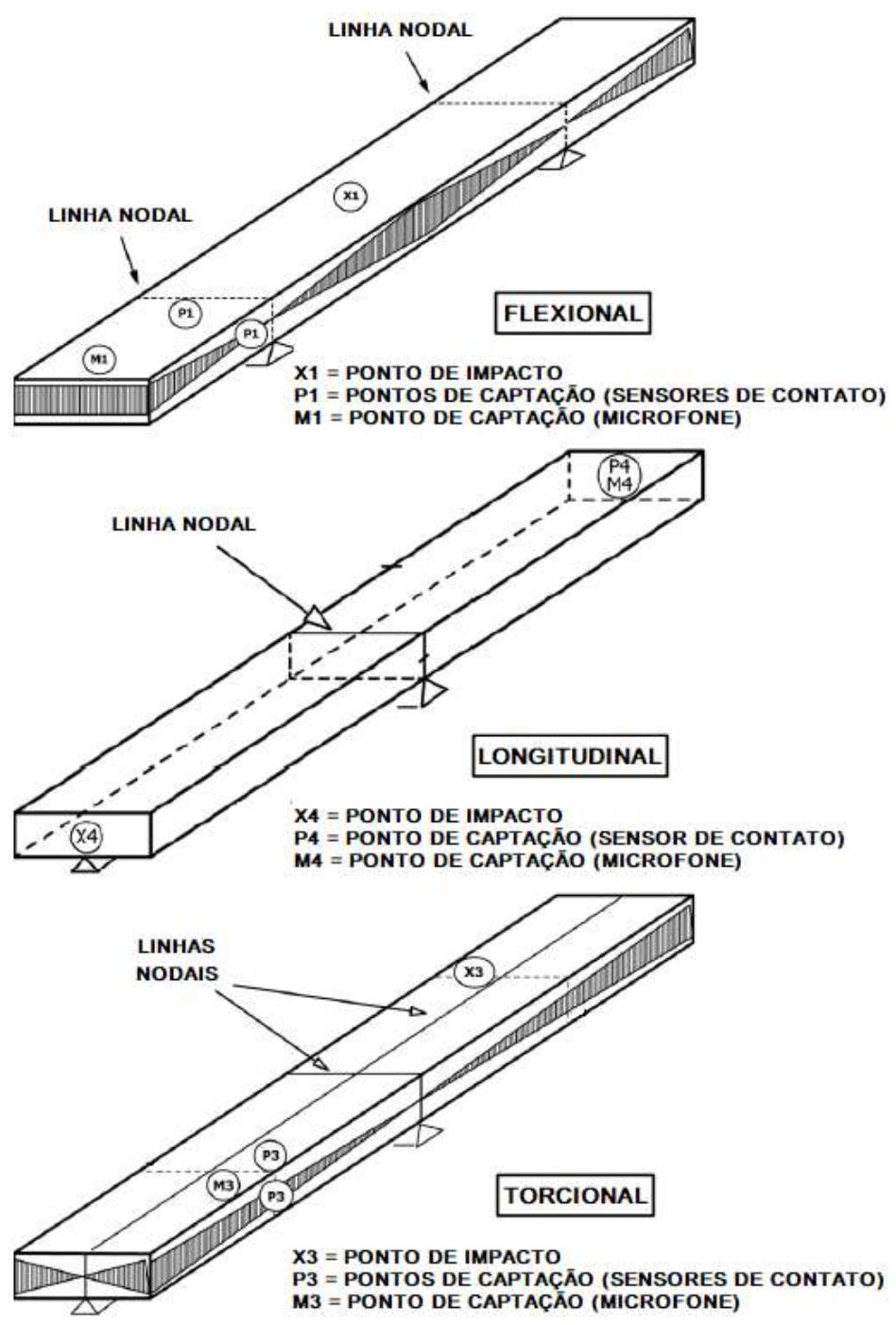

Fonte: Adaptado da ASTM E1876-15 
Nota-se, na figura, a menção às chamadas linhas nodais, que são regiões do elemento onde, ao vibrar em um modo específico, não ocorre qualquer deslocamento (amplitude nula), coincidindo com a posição do suporte para cada caso. Além disso, o impulso deve ser dado no local onde a amplitude de vibração é máxima. (COSSOLINO; PEREIRA, 2010).

De acordo com Malhotra e Sivasundaram (2004), é importante que os suportes sejam de material com frequências naturais fora da faixa de frequência do espécime investigado, bem como deve permitir que o mesmo vibre sem restrição significativa. Ainda segundo os autores, apesar da condição ideal ser a do corpo de prova apoiado sobre os pontos nodais relativos ao modo de vibrar estudado, uma base de material como espuma elastomérica é adequada. A ASTM E1876-15 também admite a suspensão por arames ou fios como forma de suporte.

Com relação ao excitador, a referida norma menciona que o mesmo deve possuir a maior parte de sua massa concentrada no ponto de impacto, devendo essa ser suficiente para induzir vibração mecânica, porém, não grande o bastante para danificar ou deslocar a amostra ensaiada. Na prática, a geometria e tamanho do excitador estão vinculadas ao tamanho e peso do espécime analisado. Para as geometrias consideradas pela norma, sugere-se o uso de dispositivo composto por uma esfera de aço $(0,5 \mathrm{~cm}$ de diâmetro) fixada a uma haste de material polimérico (com 10 cm de comprimento).

Para tornar possível o cálculo do módulo de elasticidade dinâmico a partir das equações presentes na ASTM E1876-15, o corpo de prova deve possuir seção transversal cilíndrica ou retangular. Em seu Anexo, ainda é descrito um procedimento para corpos de prova com formato de disco. É indicado que os melhores resultados são obtidos para amostras cujo comprimento é pelo menos 5 vezes maior que a menor dimensão de sua seção transversal, e, ainda, que uma relação de tais parâmetros entre 20 e 25 permite cálculos simplificados. Também são especificadas tolerâncias relativas à medição das dimensões.

Determinada a frequência natural desejada, pode-se proceder o cálculo do módulo de elasticidade dinâmico. O Quadro 2.2 resume parte das equações disponíveis na ASTM E187615 para cada modo natural e geometria, válidas para os dois métodos de ressonância citados. 
Diante da técnica de ressonância forçada, o ensaio de ressonância acústica se mostra vantajoso por não necessitar de excitação contínua. Além disso, conforme Prado (2016), a instalação da aparelhagem de ensaio torna-se mais simples por não exigir a fixação de sensores e o uso de hardwares adicionais, uma vez que as placas de áudio presentes nos computadores contemporâneos são suficientes.

No entanto, tais métodos também possuem limitações. A ASTM C215-14 adverte que diferentes modos de vibração ou diferentes geometrias para amostras do mesmo concreto podem resultar em valores distintos do módulo de elasticidade dinâmico. Além disso, como consta na ASTM E1876-15, o ensaio de ressonância acústica pode ser ineficiente em materiais com alto valor de amortecimento. Por fim, as equações analíticas para o cálculo do módulo dinâmico são válidas apenas para amostras de geometria regular, havendo introdução de erro nos cálculos caso haja presença de chanfros ou cantos arredondados.

\subsubsection{Velocidade de pulso ultrassônico (VPU)}

Esse método se baseia no princípio da propagação de ondas mecânicas com frequências superiores a $20 \mathrm{kHz}$ (fora da faixa de audibilidade humana) em um meio material. Resende (2018) comenta que sua utilização na avaliação estrutural se torna notável em vista do baixo custo operacional, da simplicidade do procedimento experimental e por não provocar qualquer dano à estrutura. Devido ao seu caráter não destrutivo, essa técnica possibilita que um corpo de prova seja ensaiado múltiplas vezes no mesmo local, o que é útil, por exemplo, na monitoração das modificações na estrutura interna do concreto ao longo do tempo (NAIK; MALHOTRA; POPOVICS, 2004). Trata-se de um procedimento aplicável tanto em laboratório como em campo, independentemente de dimensões e formas da estrutura.

Quando a superfície de um meio sólido e elástico é perturbada por cargas dinâmicas ou vibratórias, diferentes tipos de ondas mecânicas podem ser produzidas, entre elas: ondas longitudinais (também chamadas de ondas de compressão ou primárias - P), ondas transversais (cisalhantes ou ainda secundárias - S) e ondas superficiais (ou de Rayleigh, geradas a partir da combinação das anteriores). Estas se diferem pela maneira com que excitam o movimento das partículas em relação à direção de sua propagação, isto é, se paralelamente (ondas longitudinais) ou perpendicularmente (ondas transversais). De acordo com Mehta e Monteiro (2014), o comportamento provocado pelas ondas de Rayleigh é complexo, suscitando um movimento elíptico das partículas. A Figura 2.5 esclarece a diferença. 
Figura 2.5 - Diferentes tipos de ondas mecânicas
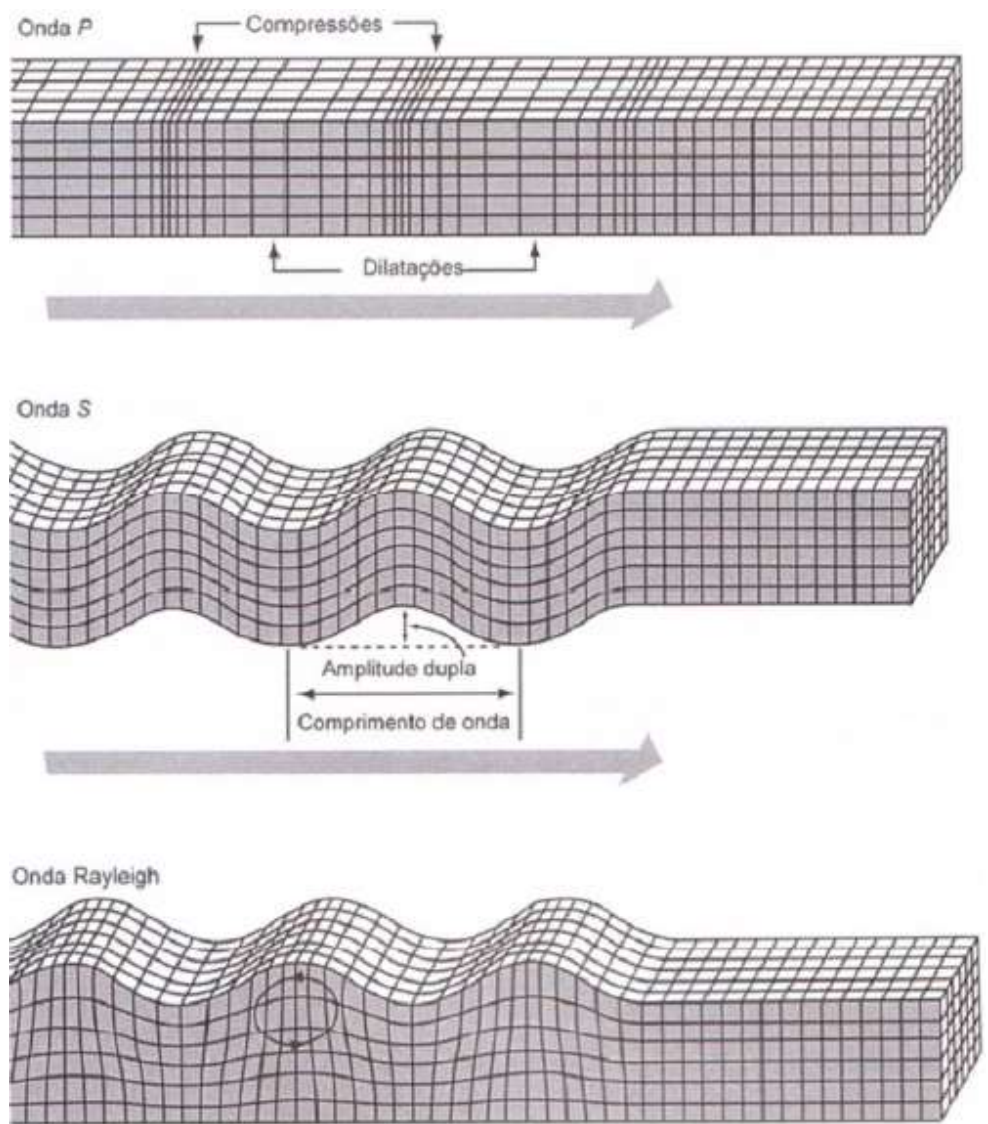

Fonte: Adaptado de Mehta e Monteiro (2014)

O ensaio, comumente referido como ultrassom, consiste em criar um pulso de onda ultrassônica (usualmente longitudinal) em um ponto da superfície da amostra e medir seu tempo de propagação até outro ponto. Sendo conhecida a distância entre pontos, a determinação da velocidade do pulso é imediata. A velocidade de propagação das ondas longitudinais $\left(V_{P}\right)$ e secundárias $\left(V_{S}\right)$ em um meio é dependente das propriedades elásticas e da densidade deste, com relações expressas pelas Equações 2.1 a 2.3, no caso de um material isótropo.

$$
\begin{gathered}
V_{P}=\sqrt{\frac{E(1-v)}{\rho(1+v)(1-2 v)}} \\
V_{S}=\sqrt{\frac{G}{\rho}} \\
\frac{V_{P}}{V_{S}}=\sqrt{\frac{2(1-v)}{1-2 v}}
\end{gathered}
$$


Nessas expressões, $E$ é o módulo de elasticidade dinâmico, $v$ é o coeficiente de Poisson dinâmico e $\rho$ representa a densidade. Naik, Malhotra e Popovics (2004) atestam que a influência das variações em $E$ e $\rho$ na velocidade é bem mais significante que o impacto provocado por variações de $v$.

O aparato experimental é composto por transdutores emissor e receptor, um circuito gerador-receptor, um circuito medidor de tempo e cabos coaxiais que permitem a conexão entre os transdutores e o circuito gerador-receptor. Conforme a ASTM C597-16, é vantajoso incorporar os dois circuitos em um mesmo dispositivo, usualmente provido de uma unidade de exibição do tempo. Dessa forma, a aparelhagem utilizada pode ser esquematizada como mostra a Figura 2.6.

Figura 2.6 - Representação simplificada do ensaio de ultrassom

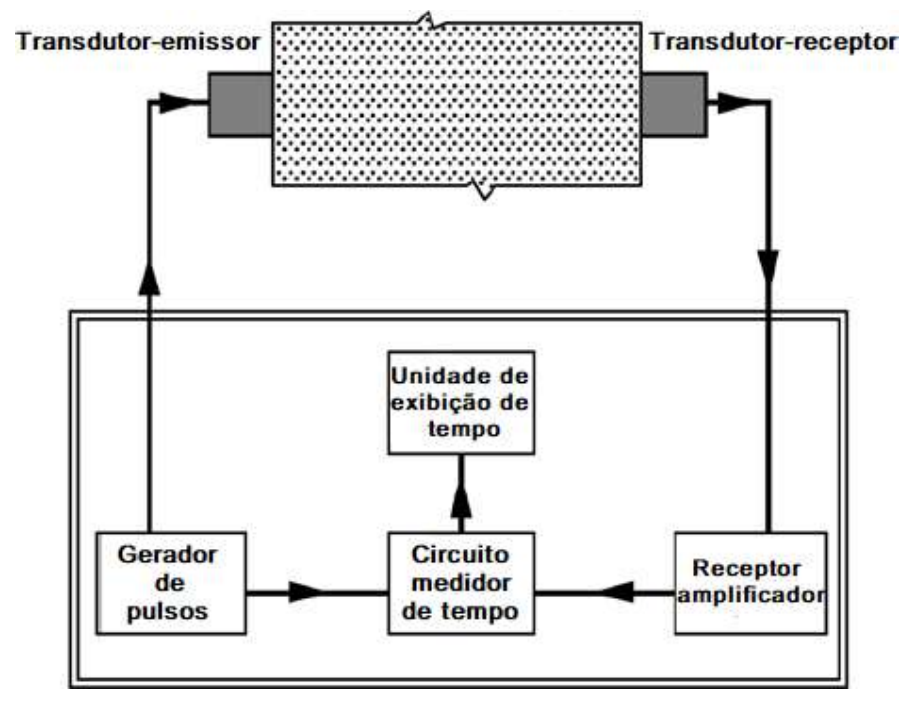

Fonte: ASTM C597-16

De modo a transmitir ou receber o pulso, os transdutores devem estar em pleno contato com o espécime em ensaio. Caso contrário, bolsas de ar entre o transdutor e a superfície do material podem introduzir erros no tempo de propagação indicado pelo aparelho. O uso de um agente acoplante (material viscoso, como gel à base d'água), em conjunto com a aplicação de certa pressão por parte do operador, são suficientes para garantir medições adequadas. Entre os três tipos de onda mencionados, as longitudinais são as que se propagam com maior velocidade, sendo estas as principais ondas captadas pelos transdutores. Schiavon (2015) relata que existem transdutores específicos para emitir ondas transversais, requerendo um agente acoplante de viscosidade substancialmente superior àquela dos utilizados para ondas longitudinais. 
É útil recordar que as características do pulso, isto é, frequência $(f)$ e comprimento de onda $(\lambda)$, se relacionam à velocidade de forma inversamente proporcional $(V=\lambda f)$ para um mesmo meio de propagação. Essa relação ajuda a compreender a utilidade das diferentes frequências de operação com que os transdutores podem ser encontrados.

Segundo Naik, Malhotra e Popovics (2004), para aplicações em concreto, normalmente são empregados transdutores com frequência de 25 a $100 \mathrm{kHz}$. No entanto, os autores mencionam aplicações especiais que requerem frequências diferentes da faixa habitual: para corpos de prova muito pequenos e concretos de alta resistência (alta taxa de finos), transdutores de alta frequência (acima de $100 \mathrm{kHz}$ ) são utilizados, enquanto que transdutores de baixa frequência (abaixo de $25 \mathrm{kHz}$ ) são necessários para ensaios em estruturas de maior porte ou em concretos com maior teor de agregados graúdos. A variação de frequência é necessária para controlar o comprimento de onda, pois há dispersão da energia do pulso original à medida que a onda percorre agregados, vazios e fissuras, denominada atenuação sônica (SCHIAVON, 2015). Esse fenômeno ocorre de forma drástica quando as heterogeneidades são de tamanho superior ou igual ao comprimento de onda.

No ensaio, três arranjos de medição são possíveis, definidos em função da posição relativa entre os transdutores: transmissão direta, transmissão semidireta e transmissão indireta. A Figura 2.7 ilustra tais configurações.

Figura 2.7 - Formas de transmissão do pulso: $a$ ) direta; $b$ ) semidireta e $c$ ) indireta

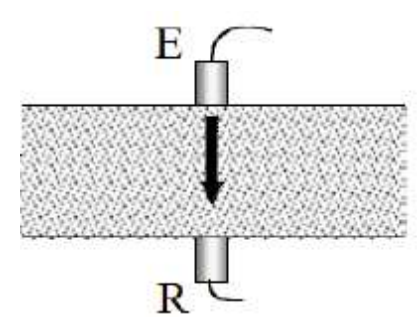

a)

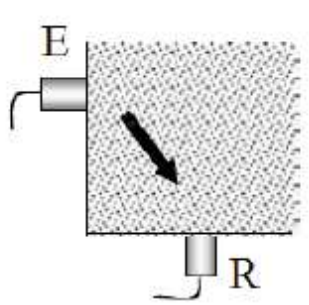

b)

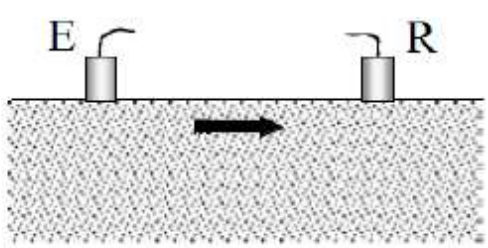

c)

Fonte: Adaptado de Naik, Malhotra e Popovics (2004)

A ABNT NBR8802:2013, em seu Anexo B, estabelece que a transmissão direta é a mais recomendada, por tornar bem definida a distância percorrida pela onda e propiciar maior intensidade na sua recepção. $\mathrm{O}$ arranjo indireto é útil quando se tem acesso a apenas uma face do corpo de prova, desde que esta possua comprimento suficiente para permitir o deslocamento do transdutor-receptor; em contrapartida, um procedimento especial é exigido para determinar a velocidade do pulso. A configuração semidireta pode ser empregada em situações onde não 
se tem acesso a duas faces opostas do corpo de prova e a face acessível não dispõe de extensão suficiente para utilizar o arranjo de transmissão indireta.

A técnica é especialmente profícua em amostras de concreto, possibilitando diversas aplicações. Entre elas, pode-se citar a estimativa da resistência à compressão, avaliação da uniformidade e durabilidade e a obtenção do módulo de elasticidade dinâmico.

No caso da resistência à compressão, apesar de não haver relação física entre esta propriedade e a velocidade do pulso ultrassônico, pode-se extrair estimativas admissíveis por meio de correlações gráficas preestabelecidas entre os dois parâmetros para um mesmo traço de concreto (PAIVA, 2017). A ASTM C597-16 salienta que a aplicação dessa técnica não deve ter intuito de medir resistência. Também não é adequada para estabelecer conformidade entre o módulo de elasticidade do concreto in situ com aquele assumido no projeto.

Com relação à uniformidade e durabilidade, é possível identificar heterogeneidades (como fissuração interna e nichos de concretagem) e deterioração (causada por fatores como exposição a sulfatos, reação álcali-agregado e corrosão de armaduras) a partir das variações na velocidade do pulso. A ABNT NBR8802:2013, em seu Anexo A, estipula um procedimento para verificação da homogeneidade do concreto que compreende a elaboração de um sistema de pontos (padrão de malha) e adoção de critérios estatísticos, viabilizando a obtenção de dados qualitativos acerca da velocidade de propagação de ondas.

Sendo conhecidos ou assumidos os valores da densidade e do coeficiente de Poisson, o cálculo do módulo de elasticidade dinâmico passa a ser imediato a partir da Equação 2.1. Porém, o uso do ultrassom para essa finalidade deve observar algumas condições: o erro resultante de uma estimativa pouco precisa do coeficiente de Poisson pode ser significativo; além disso, a Equação 2.1. foi desenvolvida considerando material sólido, isotrópico e homogêneo, tornando incerta a validade de sua aplicação para um compósito poroso e não homogêneo como o concreto. Todavia, Resende (2018) ressalta que a aproximação resulta em erro aceitável desde que as heterogeneidades (presença de agregados, vazios e fissuras) sejam de dimensão inferior ao comprimento de onda.

Pode-se concluir que, por se tratar de um procedimento normatizado e com aparelhagem portátil e digital, o ensaio ultrassônico oferece praticidade e eficiência ao controle de qualidade do concreto. Não obstante, sua aplicação na obtenção de parâmetros de resistência desse material deve ser conduzida prudentemente, em razão das diversas variáveis que afetam a relação entre tais propriedades e a velocidade de pulso. 


\subsection{Análise modal das estruturas}

Diz-se análise modal aquela que permite descrever a estrutura em termos de suas características ou parâmetros modais, isto é, frequências naturais, modos de vibração e fatores de amortecimento. Segundo Nóbrega (2004), esse tipo de análise contempla estratégias teóricas e experimentais que permitem elaborar um modelo matemático representativo da resposta dinâmica do sistema estudado.

De acordo com He e Fu (2001), a análise modal teórica baseia-se na descrição das propriedades físicas do sistema (suas matrizes de massa, de rigidez e de amortecimento) para obter os parâmetros modais e, em posse desses, avaliar a resposta dinâmica. Já a análise modal experimental parte da determinação da resposta dinâmica (dados medidos diretamente na estrutura ou sistema em estudo), com a qual os parâmetros modais são calculados, tornando possível a caracterização do sistema físico. As duas vias de análise são exploradas a seguir.

\subsubsection{Análise teórica}

Na via teórica, o modelo modal parte da equação de movimento de um sistema contínuo, consistindo na expressão diferencial de segunda ordem representada na Equação 2.4.

$$
M \ddot{x}(t)+C \dot{x}(t)+K x(t)=f(t)
$$

Sendo:

$M$ a matriz de massa do sistema, de ordem $n \times n$, em que $n$ equivale ao número de graus de liberdade do mesmo;

$C$ a matriz de amortecimento, da mesma ordem de $M$;

$K$ a matriz de rigidez, também de ordem $n \times n$;

$\ddot{x}$ o vetor de acelerações em coordenadas generalizadas, de ordem $n \times 1$;

$\dot{x}$ o vetor de velocidades em coordenadas generalizadas, de ordem $n \times 1$;

$x$ o vetor de deslocamentos em coordenadas generalizadas, de ordem $n \times 1$;

$f$ o vetor de forças externas, da mesma ordem dos demais vetores.

Assumindo que o sistema em questão apresenta vibração livre e não amortecida, a expressão anterior é simplificada para a forma exposta na Equação 2.5.

$$
M \ddot{x}(t)+K x(t)=0
$$


Trata-se de uma equação diferencial homogênea com solução conhecida, tal que

$$
x(t)=\phi e^{i \omega t}
$$

onde $\phi$ representa um vetor de elementos reais, dito vetor modal, que caracteriza um dos modos de vibração do sistema, enquanto $\omega$ é a frequência angular natural associada a esse modo.

A substituição de (2.6) em (2.5) resulta em

$$
\left[K-\omega^{2} M\right] \phi e^{i \omega t}=0
$$

cuja solução não trivial $(\phi \neq 0)$ requer

$$
\operatorname{det}\left[K-\omega^{2} M\right] \phi=0
$$

A Equação 2.8 constitui um problema de autovalores e autovetores generalizado. Para um sistema de $n$ graus de liberdade, a solução assume a forma de $n$ pares do tipo $\left(\omega_{r} ; \phi_{r}\right)$. Soriano (2014) comenta que é conveniente reunir as frequências naturais (autovalores) em uma matriz $\Omega$

$$
\Omega=\left[\begin{array}{cccc}
\omega_{1}^{2} & 0 & \cdots & 0 \\
0 & \omega_{2}^{2} & \cdots & 0 \\
\vdots & \vdots & \ddots & \vdots \\
0 & 0 & \cdots & \omega_{n}^{2}
\end{array}\right]
$$

e os modos de vibração (autovetores) em uma matriz $\Phi$

$$
\Phi=\left[\begin{array}{llll}
\phi_{1} & \phi_{2} & \cdots & \phi_{n}
\end{array}\right]=\left[\begin{array}{cccc}
\phi_{11} & \phi_{12} & \cdots & \phi_{1 n} \\
\phi_{21} & \phi_{22} & \cdots & \phi_{2 n} \\
\vdots & \vdots & \ddots & \vdots \\
\phi_{n 1} & \phi_{n 2} & \cdots & \phi_{n n}
\end{array}\right]
$$

para rearranjar o problema em (2.8) na configuração

$$
\mathrm{K} \Phi=\Omega \mathrm{M} \Phi
$$

cuja resolução é imediata desde que se disponha das matrizes de massa e rigidez do sistema, pressupostos da análise modal teórica.

\subsubsection{Análise experimental}

O interesse da análise modal experimental reside na extração de parâmetros modais a partir da medição direta da Função Resposta em Frequência (FRF), recurso que relaciona a resposta vibratória em um local à força aplicada em qualquer ponto como função da frequência de excitação introduzida. 
Para obter a FRF de um sistema, parte-se da solução das equações de movimento na situação de vibração forçada, especialmente sob uma excitação harmônica ou senoidal (EWINS, 2000). Assim, considerando um sistema sujeito a força externa de excitação com comportamento harmônico atuando em um único ponto da estrutura, pode-se reconsiderar a expressão em (2.5) como sendo

$$
M \ddot{x}(t)+K x(t)=F \operatorname{sen} \omega t
$$

de modo que

$$
F=\left\{\begin{array}{c}
0 \\
\vdots \\
F_{q} \\
\vdots \\
0
\end{array}\right\}
$$

onde $F_{q}$ é a amplitude da força harmônica aplicada na coordenada generalizada (ou grau de liberdade) $q$.

Como consequência da hipótese relativa à excitação do sistema, pode-se assumir solução do tipo

$$
x(t)=X \operatorname{sen} \omega t
$$

com $X$, vetor de ordem $n \times 1$, representando a amplitude máxima do movimento.

Portanto, realizando as derivações e substituindo (2.14) em (2.12), resulta

$$
\left[K-\omega^{2} M\right] X \operatorname{sen} \omega t=F \operatorname{sen} \omega t
$$

$\mathrm{Ou}$, rearranjando a igualdade em termos da amplitude, escreve-se

$$
X=\left[K-\omega^{2} M\right]^{-1} F
$$

A matriz à direita da igualdade corresponde à Função de Resposta em Frequência, usualmente representada por $H(\omega)$, de ordem $n \times n$. Representa-se um elemento dessa matriz como

$$
H_{p q}(\omega)=\frac{X_{p}}{F_{q}}
$$

em que $X_{p}$ é o deslocamento medido no grau de liberdade $p$ em função da força $F_{q}$, aplicada no grau de liberdade $q$. 
Uma combinação de excitações e respostas em diferentes locais propicia a obtenção de um conjunto de FRFs que coletivamente constituem a FRF do sistema (HE; FU, 2001). Nóbrega (2004) comenta que tal análise é usualmente conduzida considerando excitações normalizadas (ou seja, com valores unitários) em pontos específicos e para um intervalo de frequências de interesse, possibilitando a solução de casos particulares. A representação gráfica de uma FRF é ilustrada na Figura 2.8 .

Figura 2.8 - Exemplo de FRF $\left(\mathrm{H}_{11}\right)$ para um sistema com 4 graus de liberdade
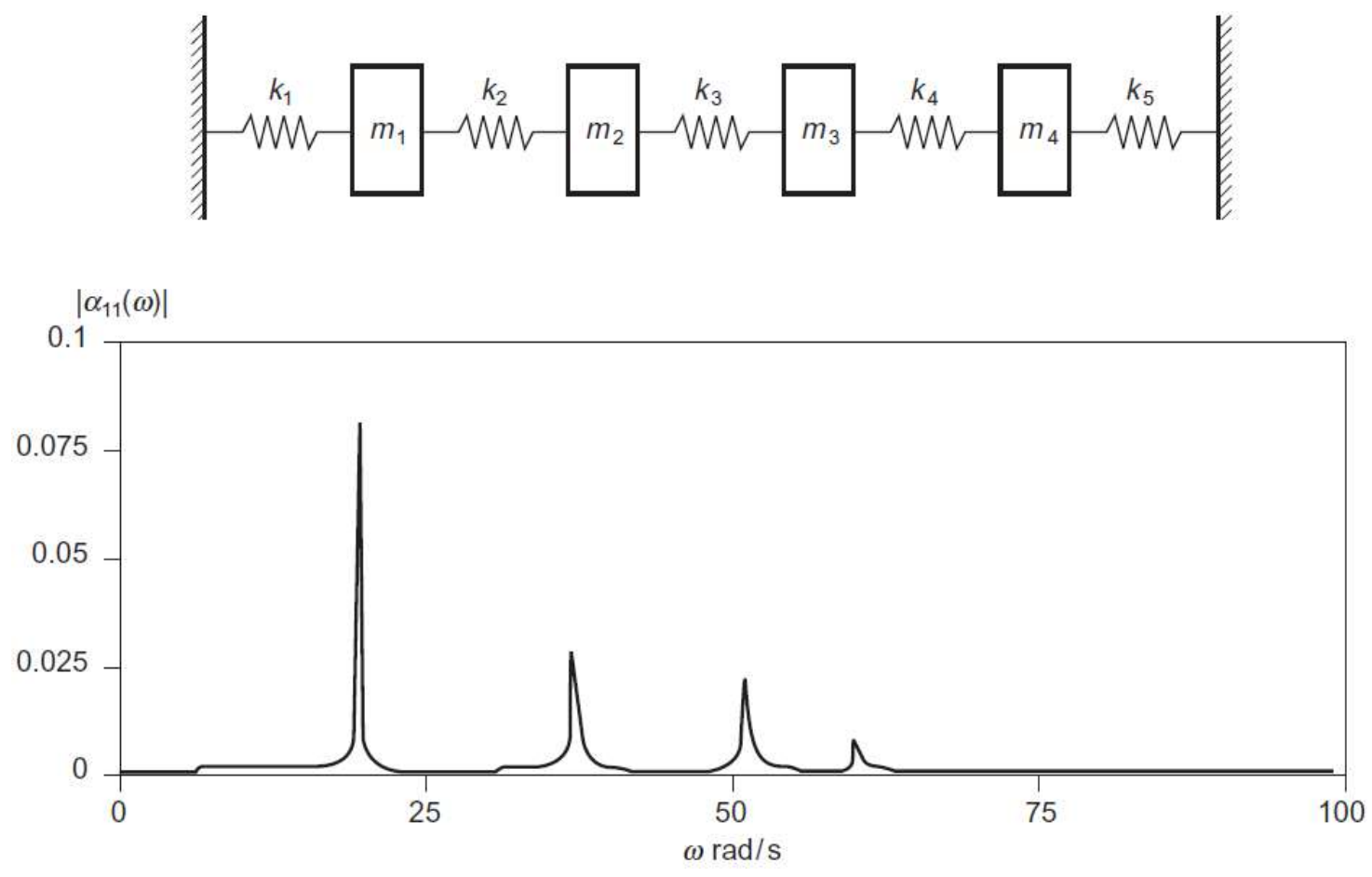

Fonte: Adaptado de He e Fu (2001)

$\mathrm{He}$ e Fu (2001) atentam ao fato de que, apesar de ser proveniente de um caso de vibração forçada, a FRF é independente da função de excitação externa. Chega-se a essa constatação com o emprego das propriedades de ortogonalidade dos modos de vibração que, segundo Craig Jr. e Kurdila (2006), relacionam o modelo espacial (matrizes de massa - $M$ e de rigidez - $K$ ) ao modelo modal (frequências e modos naturais), permitindo escrever

$$
\begin{gathered}
\Phi^{T} M \Phi=\mathrm{m} \\
\Phi^{T} K \Phi=k
\end{gathered}
$$

em que $m$ é chamada matriz modal de massa e $k$ é denominada matriz modal de rigidez, sendo ambas diagonais. Seus elementos, $m_{r}$ e $k_{r}$, representam a massa modal e a rigidez modal do $r$ ésimo modo de vibração, respectivamente. 
Outra manipulação conveniente é a normalização do vetor referente ao modo de vibração pela massa modal, isto é

$$
\hat{\phi}_{r}=\frac{\phi_{r}}{\sqrt{m_{r}}}
$$

com $r=1,2, \ldots, n$ ou, generalizando para a forma matricial

$$
\Psi=\Phi m^{-1 / 2}
$$

Trabalhando com modos de vibração normalizados pela massa (matriz $\Psi$ ), as expressões (2.18) e (2.19) resultam

$$
\begin{aligned}
& \Psi^{T} M \Psi=\mathrm{I} \\
& \Psi^{T} K \Psi=\Omega
\end{aligned}
$$

onde I é a matriz identidade de ordem $n \times n$ e $\Omega$ é a matriz das frequências naturais, já apresentada em (2.9).

Pelo visto em (2.14), pode-se depreender a seguinte relação para a FRF:

$$
H(\omega)^{-1}=\left[K-\omega^{2} M\right]
$$

Pré multiplicando por $\Psi^{\mathrm{T}}$ e pós multiplicando por $\Psi$ ambos os lados da Equação 2.24, tem-se

$$
\Psi^{T} H(\omega)^{-1} \Psi=\Psi^{T}\left[K-\omega^{2} M\right] \Psi
$$

Aplicando as propriedades de ortogonalidade expressas em (2.22) e (2.23), o lado direito da expressão anterior resulta

$$
\Psi^{T} H(\omega)^{-1} \Psi=\left[\Omega-\omega^{2} I\right]
$$

Recordando que a matriz $\Omega$ resulta diagonalizada e operando adequadamente as matrizes identidade e inversa, reescreve-se (2.26) como

$$
H(\omega)=\Psi\left[\omega_{r}^{2}-\omega^{2}\right]^{-1} \Psi^{T}
$$

Lima e Santos (2008) explicam que a vibração livre e não amortecida de um sistema com $n$ graus de liberdade pode ser expressa como sendo a superposição (combinação linear) dos $n$ modos de vibração individuais. Dessa forma, a expressão para a matriz FRF dada em (2.27) pode ser entendida da seguinte maneira 


$$
H(\omega)=\sum_{r=1}^{n} \frac{\hat{\phi}_{r} \hat{\phi}_{r}^{T}}{\left[\omega_{r}^{2}-\omega^{2}\right]}
$$

onde cada elemento pode ser expresso na forma

$$
H_{p q}(\omega)=\sum_{r=1}^{n} \frac{\hat{\phi}_{p r} \hat{\phi}_{q r}}{\left[\omega_{r}^{2}-\omega^{2}\right]}
$$

sendo $\hat{\phi}_{p r}$ e $\hat{\phi}_{q r}$ os $p$-ésimo e $q$-ésimo elementos, respectivamente, do vetor representativo do $r$-ésimo modo de vibrar (normalizado pela massa modal); $\omega_{\mathrm{r}}$ a frequência natural do $r$-ésimo modo; e $\omega$ a frequência de excitação do sistema.

Nota-se que a expressão (2.29) independe de força, como dito antes do desenvolvimento exposto. Ewins (2000) vê nela a essência da análise modal experimental, demonstrando a conexão explícita entre as propriedades modais do sistema e a sua resposta à vibração.

O projeto e construção de estruturas civis cada vez mais complexas e tecnicamente exigentes (barragens e pontes estaiadas, por exemplo), bem como a progressiva deterioração de estruturas já existentes, motivaram o desenvolvimento de metodologias para identificar com acurácia propriedades estáticas e dinâmicas pertinentes (CUNHA; CAETANO, 2006). As propriedades dinâmicas de uma estrutura podem ser determinadas experimentalmente a partir da análise de dados obtidos em ensaios de vibração conduzidos com a aparelhagem adequada.

A análise modal experimental se fundamenta em quatro hipóteses, como expostas por Nóbrega (2004):

1. O comportamento da estrutura é linear, de modo que uma combinação qualquer de forças aplicadas concomitantemente pode ser tratada como a soma das respostas de cada força atuando isoladamente;

2. Os parâmetros modais da estrutura são constantes, isto é, a mesma é invariante no tempo;

3. Há uma relação direta entre os deslocamentos generalizados provenientes de forças generalizadas atuantes em diferentes pontos da estrutura, independentemente da ordem de aplicação (teorema de reciprocidade de Maxwell);

4. As medidas de entrada e saída realizadas ao longo do tempo contém dados suficientes para elaborar um modelo de comportamento da estrutura. 
De acordo com Ewins (2000), três pontos da análise de vibrações demandam particular atenção a fim de garantir a qualidade da aquisição de dados: aspectos mecânicos relativos à fixação (preparação) da estrutura e à sua excitação; a transdução efetiva das grandezas medidas, ou seja, a entrada de força e a resposta em movimento; e o processamento de sinal adequado para cada técnica de ensaio utilizada.

Com relação à fixação, é de interesse identificar a condição de contorno a ser reproduzida na realização do ensaio. No contexto da medição de uma FRF, a escolha do tipo de suporte está associada à necessidade de se obter o comportamento da estrutura em condição isolada (o que corresponderia a um apoio sem restrições ou arranjo de suspensão, simulando condições de contorno do tipo livre-livre) ou em situação de trabalho, onde a mesma se encontra vinculada a elementos rígidos. Contudo, há casos em que a estrutura não pode ser ensaiada in situ (devido a inacessibilidade ou ineficácia das tecnologias de medição), de modo que seu comportamento deve ser simulado a partir de parâmetros obtidos considerando-a isolada. Da mesma forma, o porte de algumas estruturas não permite seu tratamento em laboratório, exigindo avaliações in situ (HE; FU, 2001).

No que concerne a excitação, esse texto trata sobre equipamentos destinados a aplicações em laboratório. Para tanto, Cunha e Caetano (2006) apresentam duas alternativas: a primeira consiste no martelo de impacto, que possui como principal vantagem a capacidade excitar uma larga faixa de frequências, induzindo diferentes modos de vibração. No entanto, alguns modos requerem uma quantidade de energia que não pode ser fornecida por esse equipamento. A alternativa pode ser o uso de um excitador eletrodinâmico (shaker), capaz de emitir diferentes tipos de sinal dinâmico. Essa característica permite a excitação da estrutura em sua frequência ressonante, tornando mais fácil a identificação dos modos de vibrar. Sua desvantagem reside na necessidade de se desacoplar o equipamento e reconectá-lo à estrutura sempre que se desejar alterar o ponto de excitação, resultando em gasto excessivo de tempo na execução do ensaio (JULIANI, 2014).

Os dispositivos empregados na aquisição de entradas (força) ou saídas (aceleração, por exemplo) do sistema são chamados transdutores. Na análise modal experimental, conforme Ewins (2000), o tipo mais comum de transdutor é o piezoelétrico, cujo princípio básico de operação consiste na geração de sinal elétrico por parte de um cristal piezoelétrico quando sujeito a uma tensão mecânica, sendo este incorporado a um dispositivo que provoca nele uma tensão elétrica proporcional à grandeza física de interesse. É um aparelho de custo relativamente baixo, alta sensibilidade e que opera em uma variada faixa de frequências (embora não seja o mais adequado para aplicações em baixa frequência), possuindo ainda a característica de não 
necessitar de uma fonte de energia. Um inconveniente desse tipo de equipamento é que o sinal elétrico produzido costuma ser baixo, exigindo o uso conjunto de unidades amplificadoras (CUNHA; CAETANO, 2006). Outra forma de transdução para aferir respostas dinâmicas consiste no uso de um captador acústico (microfone) em detrimento da solução convencional utilizada em ensaios não destrutivos, que é a fixação de um acelerômetro piezoelétrico ao corpo de prova (PRADO, 2016).

O sinal de vibração típico obtido experimentalmente compreende uma superposição de diversas funções senoidais com diferentes amplitudes e ângulos de fase. Esse resultado (amplitude ou aceleração versus tempo) não é tão esclarecedor, exigindo um processo de decomposição do sinal em suas diferentes funções, sendo a amplitude de cada uma delas plotada em função da respectiva frequência (COLEMAN, 2004). Isso é possível através do algoritmo de análise conhecido como Transformada Rápida de Fourier (Fast Fourier Transform - FFT). De forma simplificada, a FFT é responsável por transferir a análise do domínio do tempo para o domínio da frequência, conforme representado na Figura 2.9. Essa conversão permite identificar as frequências ressonantes do elemento, associadas aos picos de amplitude.

Figura 2.9 - Transformada Rápida de Fourier (FFT): $a$ ) sinal original; $b$ ) sinal processado

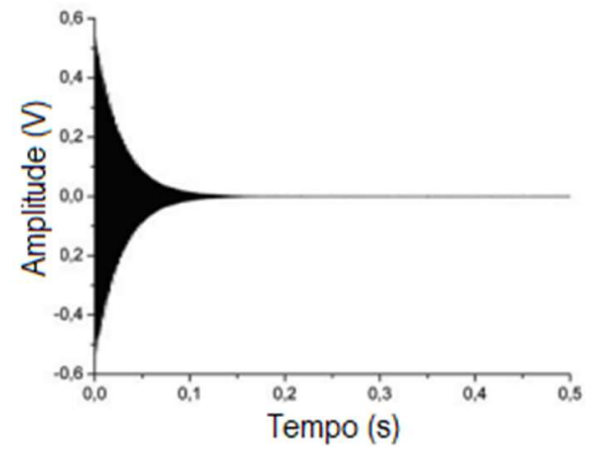

a)

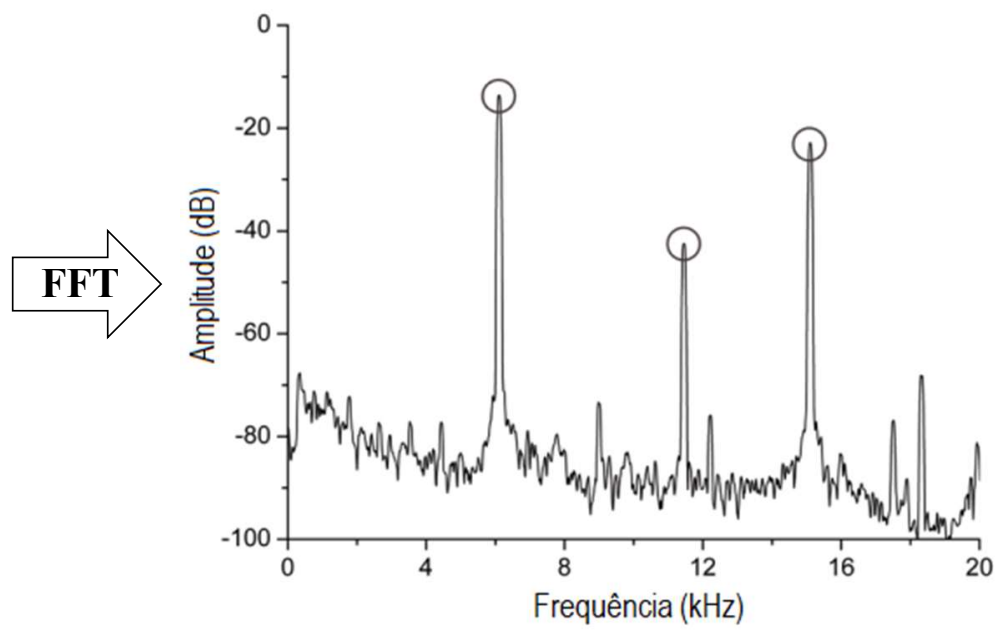

b)

Fonte: Adaptado da ATCP Engenharia Física [201-]

Entre as aplicações da análise modal experimental, Ewins (2000) destaca a verificação de integridade e o monitoramento das condições de serviço de uma estrutura, além de sua serventia na calibração de modelos computacionais teóricos. Cunha e Caetano (2006) comentam sobre sua utilidade na atualização e validação de programas em elementos finitos, bem como na implementação de estratégias para controle de vibrações. 


\subsection{Caracterização das unidades de alvenaria estrutural}

Os blocos de alvenaria estrutural são caracterizados a partir de três categorias de propriedades: geométricas, físicas e mecânicas. Estas são estabelecidas por normas específicas para cada material de bloco. Como a pesquisa tem objetivo de caracterizar unidades cerâmicas e de concreto, apenas as normas referentes a esses materiais serão tratadas. A caracterização dos blocos cerâmicos obedece às prescrições da ABNT NBR15270-2:2017, enquanto que a dos blocos de concreto é preconizada pela ABNT NBR12118:2013. Cada norma obedece a requisitos e tolerâncias, deliberadas pelas ABNT NBR15270-1:2017 e ABNT NBR6136:2016, respectivamente. Alguns desses requisitos são dependentes da classe de resistência do bloco.

Como o interesse do estudo reside na determinação do módulo de elasticidade do material dos blocos por uma metodologia cujo resultado é fortemente influenciado pela geometria, julgou-se oportuno omitir dessa seção as propriedades físicas dos blocos (absorção de água, retração por secagem, entre outras), prezando pela concisão. Entende-se que isso não acarretará prejuízo para a revisão de literatura ou para o desenvolvimento do estudo, muito porque algumas dessas propriedades não possuem caráter normativo, não sendo obrigatória sua determinação para a avaliação de conformidade do lote.

\subsubsection{Propriedades geométricas}

Dizem respeito à forma do bloco e a conformação de seus elementos (paredes, furos etc.). O procedimento de obtenção dessas propriedades é denominado análise dimensional. Algumas delas são comuns aos dois tipos de bloco, ao passo que outras são específicas. Isso se deve, principalmente, à diferença entre as faces de trabalho (onde serão argamassados e assentados) típicas de cada bloco, como exemplifica a Figura 2.10.

Figura 2.10 - Exemplos de geometria: a) bloco de concreto; b) bloco cerâmico

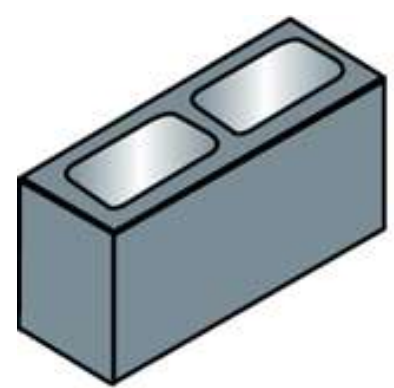

a)

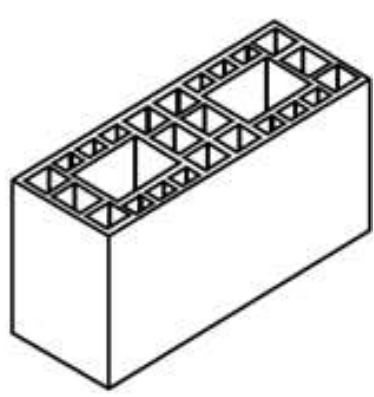

b)

Fonte: a) Adaptado da ABNT NBR12118:2013; b) ABNT NBR15270-1:2017 
Doravante neste tópico, exceto quando indicado, os procedimentos mencionados respeitam às orientações da ABNT NBR15270- 2:2017 quando concernir aos blocos cerâmicos e da ABNT NBR12118:2013 em referência aos blocos de concreto. O Quadro 2.3 apresenta todas as características de geometria e para quais tipos de bloco sua determinação se aplica.

Quadro 2.3 - Propriedades geométricas dos blocos

\begin{tabular}{|c|c|c|}
\hline Propriedade & Blocos cerâmicos & Blocos de concreto \\
\hline Dimensões efetivas & SIM & SIM \\
\hline Espessura dos septos e paredes externas & SIM & SIM \\
\hline Espessura equivalente & NÃO & SIM \\
\hline Desvio em relação ao esquadro & SIM & NÃO \\
\hline Planeza das faces & SIM & NÃO \\
\hline Dimensão dos furos & NÃO & SIM \\
\hline Mísulas de acomodação & NÃO & SIM \\
\hline Área bruta & SIM & SIM \\
\hline Área líquida & SIM & SIM \\
\hline
\end{tabular}

Fonte: Autor (2020)

As dimensões efetivas referem-se às medidas reais de largura $(L)$, altura $(H)$ e comprimento $(C)$ do bloco, não devendo ser confundidas com as dimensões nominais fornecidas pelo fabricante. Devem ser tomadas com precisão, preferencialmente por um paquímetro adequado às dimensões do bloco ou régua metálica com resolução mínima de 1 mm. No caso dos blocos de concreto, as medidas devem ser aferidas na face com maior espessura de parede, sendo necessárias três determinações em pontos distintos. Para os blocos cerâmicos, deve-se efetuar as medições em pontos apropriados nas duas faces correspondentes, como esclarece a Figura 2.11.

Figura 2.11 - Pontos indicados para efetuar medições: $a$ ) largura; b) altura; $c$ ) comprimento

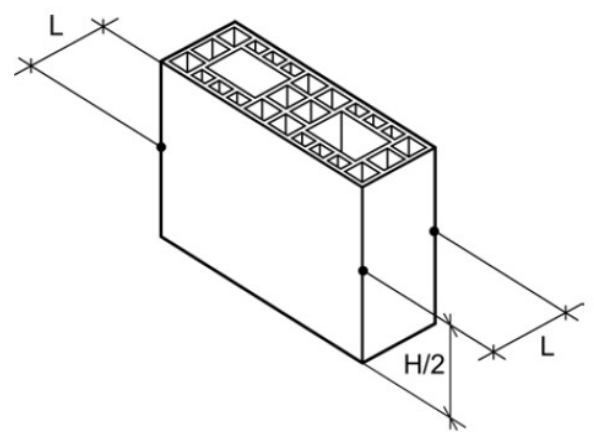

a)

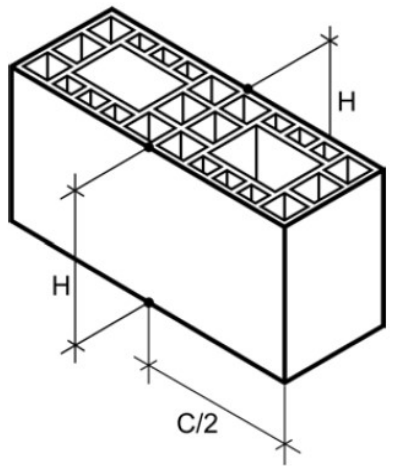

b)

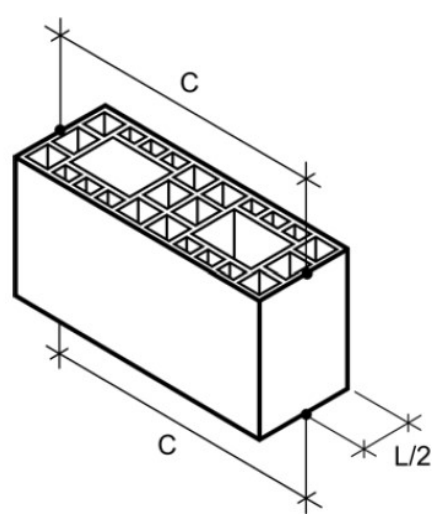

c)

Fonte: ABNT NBR15270-2:2017 
A espessura dos septos e paredes externas deve ser verificada exclusivamente com paquímetro. Para blocos de concreto, são requeridas duas determinações em cada parede longitudinal do bloco e uma determinação em cada parede transversal, extraídas na face de menor espessura de parede. No caso dos blocos cerâmicos, a espessura das paredes externas deve ser avaliada em pelo menos quatro pontos, mesmo número de medições exigido para os septos. Em todos os casos, deve-se buscar os pontos mais estreitos.

Exclusivamente para os blocos de concreto, é necessária a determinação da espessura equivalente, consistindo na razão entre a soma das espessuras de todas as paredes transversais (em milímetros) e o comprimento real do bloco (em metro), assim expressa em mm/m.

O desvio em relação ao esquadro $(D)$ e a planeza das faces (ou flecha - $F$ ) são propriedades particulares dos blocos cerâmicos. O desvio $D$ é medido entre uma das faces designadas ao assentamento e a maior face destinada ao revestimento do bloco, empregando esquadro e paquímetro metálicos. A planeza é determinada em uma das faces que serão revestidas a partir da flecha $F$ formada na diagonal, medida com um defletômetro. Tais medições são representadas na Figura 2.12. A ABNT NBR15270-1:2017 limita os valores de $D$ e $F$ em $3 \mathrm{~mm}$.

Figura 2.12 - Esquemas de medição: $a$ ) desvio em relação ao esquadro; $b$ ) planeza das faces

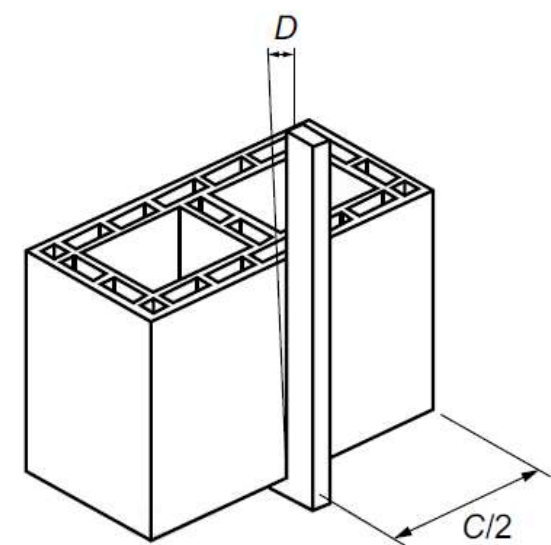

a)

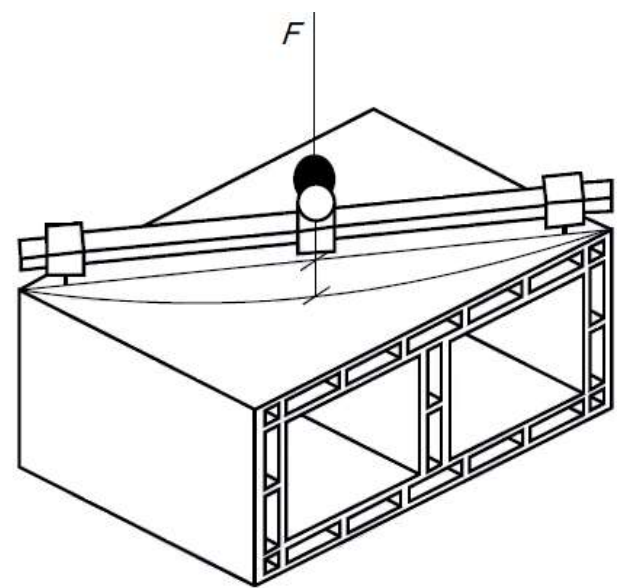

b)

Fonte: ABNT NBR15270-2:2017

Como a espessura das paredes dos blocos de concreto é variável ao longo de sua altura, seus furos possuem formato troncocônico, com diferentes dimensões em cada uma das faces (Figura 2.13). A dimensão dos furos é avaliada na face de maior espessura do bloco, sendo mensurada na direção longitudinal e transversal do mesmo (uma medida cada). De acordo com a ABNT NBR6136:2016, para blocos de classe A e B (resistência característica à compressão 
acima de $8 \mathrm{MPa}$ ou entre 4 e $8 \mathrm{MPa}$, respectivamente) a dimensão mínima dos furos é de 70 $\mathrm{mm}$ para blocos com largura de $14 \mathrm{~cm}$ e de $110 \mathrm{~mm}$ para blocos cuja largura é de $19 \mathrm{~cm}$.

Figura 2.13 - Determinação da menor dimensão do furo

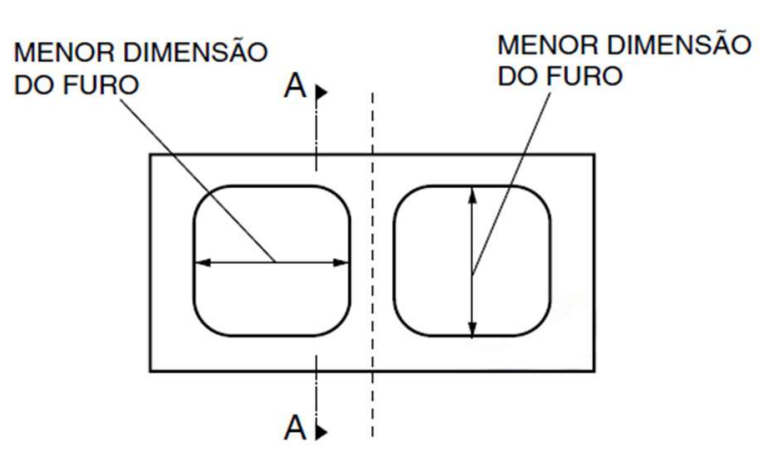

Vista superior do bloco sem escala

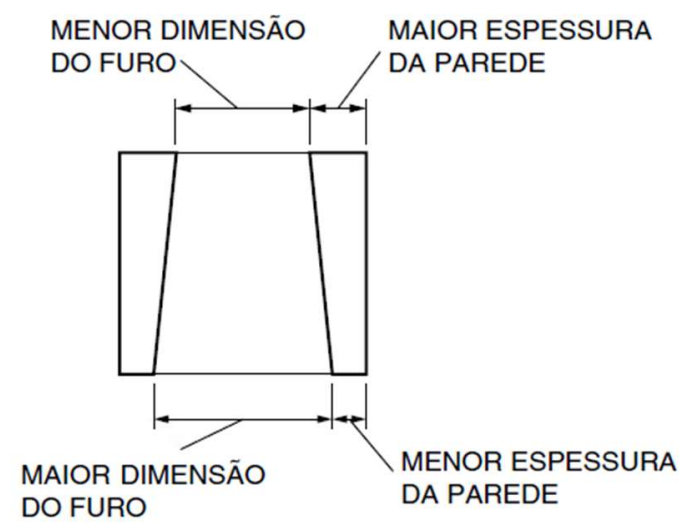

CORTE A - A sem escala

Fonte: ABNT NBR12118:2013

Blocos de concreto devem possuir mísulas de acomodação na transição entre paredes longitudinais e transversais com raio mínimo $(r)$ de acordo com sua classe: A e B requerem $r \geq$ $40 \mathrm{~mm}$, enquanto a classe $\mathrm{C}$ (resistência característica à compressão acima de $3 \mathrm{MPa}$, podendo não possuir função estrutural) exige $r \geq 20 \mathrm{~mm}$. O centro da mísula é tomado no encontro da face externa da parede longitudinal e o eixo transversal do bloco, como indicado na Figura 2.14.

Figura 2.14 - Mísula de acomodação

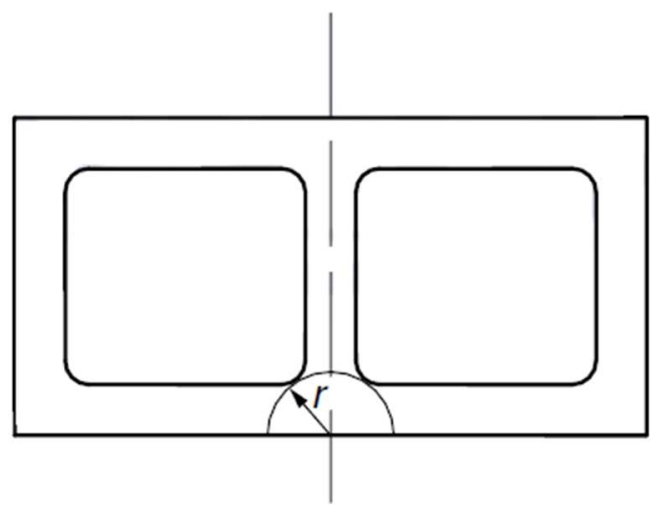

Fonte: ABNT NBR6136:2016

A área bruta $\left(A_{b}\right)$ é calculada a partir do valor médio das dimensões totais da seção de trabalho do bloco, isto é, o produto entre a largura e o comprimento efetivo. Dessa forma, não há desconto das áreas de furos e reentrâncias. 
A área líquida $\left(A_{\text {liq }}\right)$ para ambos os tipos de bloco é obtida pelo mesmo procedimento: primeiramente, imerge-se o bloco em água até sua saturação e afere-se sua massa aparente (ainda imerso) através de balança hidrostática. Em seguida, após interromper a imersão e remover o excesso de água, determina-se sua massa saturada. Calcula-se a área líquida usando o princípio de Arquimedes, ou seja, a partir do volume de água deslocado, em conformidade com a Equação 2.30 .

$$
A_{\text {líq }}=\frac{(\text { massa saturada }- \text { massa aparente })}{\gamma \cdot H} \times 1000
$$

sendo $\gamma$ a massa específica da água utilizada (normalmente tomada igual a $1 \mathrm{~g} / \mathrm{cm}^{3}$ ) e $H$ a altura média do bloco (em mm). Assim, com massas expressas em gramas, $A_{\text {liq }}$ resulta $\mathrm{em} \mathrm{mm}^{2}$.

\subsubsection{Propriedades mecânicas}

Referem-se às propriedades que definem o comportamento do material ou estrutura em resposta a solicitações externas diversas, sendo elas a resistência à compressão, a resistência à tração e o módulo de elasticidade, essencialmente determinadas através de ensaios destrutivos.

A resistência à compressão do bloco é sua propriedade fundamental pois, conforme Ramalho e Corrêa (2003), possui caráter predominante entre os fatores que influenciam no comportamento dos painéis de alvenaria sob ações compressivas. Além disso, pode ser usada para estimar a resistência à compressão do compósito alvenaria estrutural, sendo assim um importante parâmetro de projeto. É obtida a partir do ensaio de compressão axial, que consiste em comprimir o bloco até sua ruptura em uma prensa mecânica. Algumas diretrizes para o procedimento experimental são encontradas nas normas brasileiras específicas para cada tipo de bloco, concernindo a preparação dos corpos de prova, a execução do ensaio e a apresentação dos resultados.

Os blocos destinados ao ensaio de compressão devem ter suas faces de trabalho regularizadas através de capeamento (camada de material arranjada entre o bloco e os pratos da máquina de ensaio) ou retífica. De acordo com Oliveira (2014), o processo de retificação das faces de assentamento é necessário para evitar concentrações de tensão em virtude da presença de agregados nas superfícies do bloco. A ABNT NBR15270-2:2017 prescreve capeamento com pasta de cimento ou argamassa com resistência superior a 70\% da resistência esperada para os blocos na área líquida, sendo a espessura média da camada limitada a $3 \mathrm{~mm}$. A ausência de capeamento e o material escolhido para essa função possuem influência nos resultados obtidos, conclusão do estudo realizado por Abaza e Salameh (2003). 
O corpo de prova deve ser posicionado de modo que a carga aplicada pela máquina atue na mesma direção do esforço que o bloco suportará na condição de serviço, isto é, perpendicularmente ao seu comprimento e na face reservada para o assentamento. A ABNT NBR12118:2013 alerta que o bloco de concreto deve ser orientado de sorte que a face com maior espessura de parede seja a superior. Não somente, o centro de gravidade do bloco e o eixo de carga dos pratos da prensa devem estar alinhados, embora, na prática, seja difícil de se garantir tal condição. Com o bloco adequadamente disposto, o ensaio deve ser conduzido de forma que a tensão aplicada aumente gradualmente e sem choques.

Uma vez obtida a carga máxima do ensaio, registrada em newtons $(\mathrm{N})$, calcula-se a resistência à compressão do bloco $\left(f_{b}\right)$ dividindo-a pela área bruta $\left(A_{b}\right)$ do mesmo, em mm². Destarte, $f_{b}$ resulta em MPa. Com os resultados individuais dos $n$ blocos componentes da amostra, pode-se estipular sua resistência característica à compressão estimada $\left(f_{b k, e s t}\right)$.

A determinação da resistência característica da amostra $\left(f_{b k}\right)$ para blocos cerâmicos baseia-se em limites máximos e mínimos estabelecidos pela ABNT NBR15270-1:2017, podendo ser resumida como segue.

$$
f_{b k}=\left\{\begin{array}{c}
f_{b m}, \quad \text { se } f_{b k, e s t} \geq f_{b m} \\
f_{b k, e s t}, \quad \text { se } \emptyset f_{b(1)}<f_{b k, e s t}<f_{b m} \\
\emptyset f_{b(1)}, \text { se } f_{b k, e s t}<\emptyset f_{b(1)}
\end{array}\right.
$$

sendo $f_{b m}$ a média da resistência à compressão entre os blocos da amostra, $f_{b(I)}$ o menor valor de resistência à compressão entre os blocos da amostra e $\phi$ um coeficiente tabelado em função da quantidade de blocos da amostra.

Embora os principais critérios de projeto e classificação das unidades de alvenaria envolvam sua resistência à compressão, o material compósito possui limitações estruturais associadas ao surgimento de tensões de tração (MEDEIROS, 1993). Drysdale et al. (1994) comentam que a compreensão dos mecanismos de falha da alvenaria estrutural passa pelo entendimento da resistência à tração do bloco. Portanto, tal propriedade também é relevante.

A obtenção desse parâmetro pode ser praticada através de ensaios realizados no bloco ou em corpos de prova extraídos deste. O método mais difundido consiste no ensaio de tração indireta (splitting test), padronizado para unidades de alvenaria pela ASTM C1006-07. Nesse procedimento, uma carga compressiva distribuída ao longo do comprimento ou da largura do bloco, aplicada por meio de hastes, promove um estado de tensões de tração distribuídas ao longo de sua altura. A Figura 2.15 ilustra a ideia do ensaio. 
Figura 2.15 - Esquema do ensaio de tração indireta

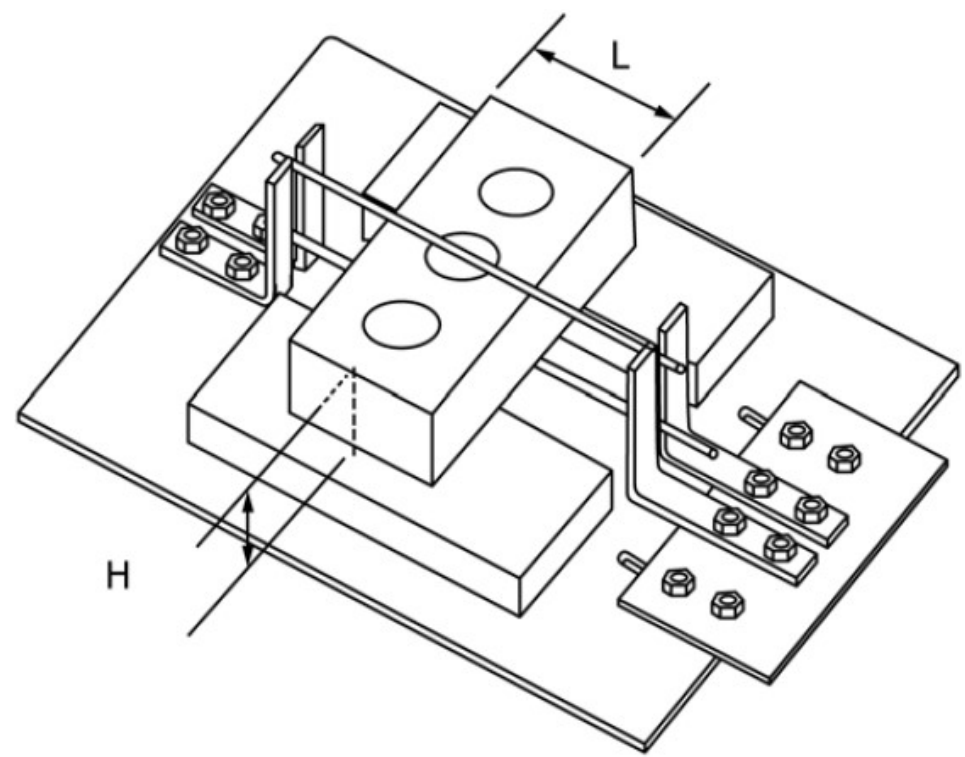

Fonte: ASTM C1006-07

A resistência à tração indireta do bloco $\left(f_{t}\right)$ é calculada a partir da Equação 2.32.

$$
f_{t}=\frac{2 P}{\pi L H}
$$

em que:

$P$ é a máxima carga aplicada, indicada pela máquina de testes $(\mathrm{em} \mathrm{kN})$;

$L$ é a dimensão da amostra sob a linha de carregamento, descontada de vazios (em mm); $H$ é a distância entre as hastes aplicadoras de carga (em mm).

A ASTM C1006-07 ressalta que os resultados obtidos por esse procedimento apresentam alto coeficiente de variação. Além disso, a dispersão de resultados torna-se ainda maior caso as hastes de carregamento estejam orientadas longitudinalmente em relação ao bloco. Conforme Parsekian, Hamid e Drysdale (2012), o ensaio de tração indireta em blocos de concreto indica uma resistência na ordem de 8 a 16\% da resistência à compressão.

Por se tratar de um material estrutural, espera-se que os blocos apresentem deformabilidade adequada antes de sua ruptura. Essa virtude está associada às suas propriedades elásticas (módulo de elasticidade e coeficiente de Poisson), que influenciam não somente na deformação da alvenaria, mas também no seu modo de falha sob compressão. A alvenaria estrutural apresenta melhor desempenho quando as propriedades dos blocos e da argamassa são semelhantes (BARBOSA, 2004), (SANTOS et al., 2014). Daí a necessidade de se estudar esse parâmetro. 
Os materiais integrantes do compósito alvenaria possuem comportamento tipicamente não linear, em virtude da natureza não homogênea do concreto, a presença de zonas de transição entre a pasta de cimento endurecida e os agregados, além da rigidez variável na interface de argamassa (FOURIE, 2017). Desse modo, quando da caracterização desses elementos, o módulo de elasticidade pode ser extraído da curva tensão-deformação de diferentes formas. A ASTM E111-04 apresenta as definições de módulo tangente (inclinação da curva para um nível de tensão ou deformação especificada) e de módulo cordal ou secante (inclinação resultante da união de dois pontos específicos do diagrama). Mehta e Monteiro (2014) comentam que, no caso do módulo secante para o concreto, é comum tomar um ponto de referência na origem da curva e outro em cerca de $40 \%$ da resistência última. A Figura 2.16 esclarece a diferença entre os dois tipos de módulo.

Figura 2.16 - Módulos de elasticidade: a) módulo tangente; b) módulo cordal

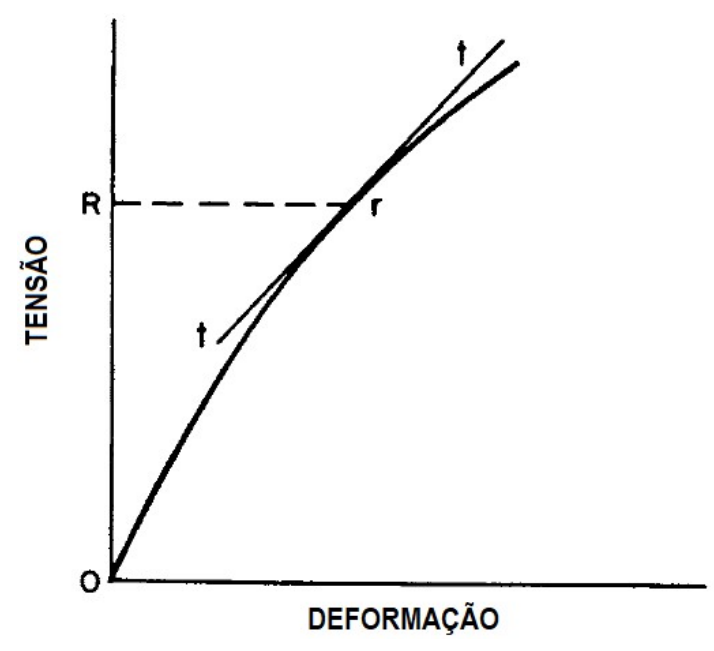

a)

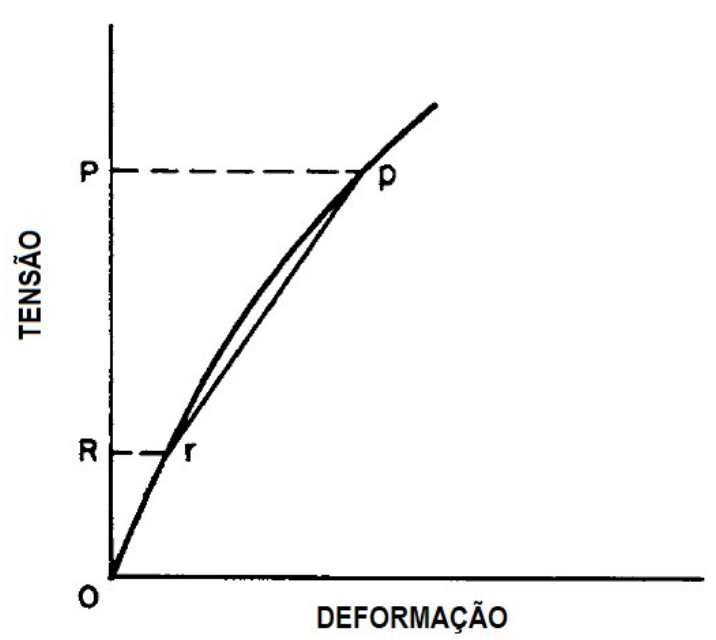

b)

Fonte: Adaptado da ASTM E111-04

No entanto, não existem ensaios normatizados para a determinação do módulo de elasticidade em blocos de alvenaria estrutural. Ademais, Oliveira (2014) comenta que não há consenso acerca da instrumentação apropriada para obter deformações no bloco com finalidade de definir o módulo de elasticidade do seu material a partir do ensaio de compressão axial. Diante desse cenário, uma alternativa a qual costuma-se recorrer, especialmente para os blocos de concreto, é estimar o módulo de elasticidade empregando expressões que relacionam essa propriedade com a resistência à compressão caraterística do material, porém utilizando a resistência medida na unidade $\left(f_{b k}\right)$ e calculada na área líquida. 


\subsection{Contextualização do estudo}

Esta seção contém um breve estado da arte relativo às duas temáticas do trabalho: a caracterização mecânica da alvenaria estrutural (com enfoque no bloco e em suas relações com o material constituinte) e o emprego dos métodos de ressonância direcionados à determinação de propriedades elásticas e modais das estruturas. Estudos desenvolvidos nos últimos anos, contemplando análises experimentais e numéricas, foram explorados com intuito de delinear a situação atual do tema e evidenciar a contribuição almejada com a presente pesquisa.

\subsubsection{Aspectos mecânicos da alvenaria estrutural}

A alvenaria estrutural é um material compósito e heterogêneo, de sorte que suas propriedades mecânicas são função das propriedades de seus componentes (bloco, argamassa, graute e armaduras, caso haja) e da interação entre eles. Apesar disso, para fins de projeto, o material costuma ser tratado como contínuo. Dessa forma, o estudo do comportamento de elementos de alvenaria (prismas de blocos e pequenas paredes) é de interesse, visto que os códigos nacionais e internacionais estabelecem que a resistência à compressão de tais elementos pode ser utilizada para avaliar a resistência característica da alvenaria à essa solicitação, bem como para fornecer uma estimativa do módulo de elasticidade.

O Quadro 2.4 expõe estudos desenvolvidos nas últimas décadas empregando elementos de alvenaria, resumindo suas contribuições para o entendimento do comportamento mecânico do material. 
Quadro 2.4 - Algumas pesquisas envolvendo elementos de alvenaria estrutural

\begin{tabular}{|c|c|c|c|}
\hline $\begin{array}{l}\text { Autoria } \\
\text { (ano) }\end{array}$ & $\begin{array}{c}\text { Caráter da } \\
\text { pesquisa }\end{array}$ & $\begin{array}{c}\text { O que foi avaliado e o } \\
\text { elemento estudado }\end{array}$ & Principal constatação ou contribuição \\
\hline $\begin{array}{l}\text { Gomes } \\
(1983)\end{array}$ & Experimental & $\begin{array}{l}\text { Resistência à compressão e } \\
\text { modos de ruptura em paredes } \\
\text { de blocos cerâmicos. }\end{array}$ & $\begin{array}{l}\text { Um aumento significativo na resistência à } \\
\text { compressão da argamassa implicou em } \\
\text { pequeno acréscimo na resistência dos painéis } \\
\text { de alvenaria, ao custo de tornar a ruptura } \\
\text { excessivamente frágil. }\end{array}$ \\
\hline $\begin{array}{l}\text { Hamid e } \\
\text { Chukwunenye } \\
\quad(1986)\end{array}$ & Numérico & $\begin{array}{l}\text { Fatores intervenientes no } \\
\text { comportamento e } \\
\text { distribuição de tensões em } \\
\text { prismas de blocos de } \\
\text { concreto. }\end{array}$ & $\begin{array}{l}\text { Os parâmetros de ensaio que mais } \\
\text { influenciaram o comportamento da alvenaria } \\
\text { foram o tipo de argamassamento (total ou } \\
\text { parcial), a razão altura/espessura do prisma e } \\
\text { a rigidez das chapas de carregamento. }\end{array}$ \\
\hline $\begin{array}{c}\text { Ganesan e } \\
\text { Ramamurthy } \\
\text { (1992) }\end{array}$ & Numérico & $\begin{array}{l}\text { Fatores intervenientes no } \\
\text { comportamento em prismas } \\
\text { de blocos de concreto. }\end{array}$ & $\begin{array}{l}\text { Prismas compostos por blocos empilhados } \\
\text { não refletiram a diferença de comportamento } \\
\text { em virtude da variação de geometria do bloco } \\
\text { e são inadequados para representar o } \\
\text { comportamento de paredes com ajuste } \\
\text { corrente, pois tendem a superestimar as } \\
\text { tensões admissíveis. }\end{array}$ \\
\hline $\begin{array}{l}\text { Mohamad } \\
\text { (1998) }\end{array}$ & Experimental & $\begin{array}{l}\text { Resistência à compressão e } \\
\text { modos de ruptura em } \\
\text { prismas de blocos de } \\
\text { concreto. }\end{array}$ & $\begin{array}{l}\text { Um modelo para prever o tipo de ruptura e a } \\
\text { tensão última dos prismas baseado nas } \\
\text { propriedades dos componentes: resistência à } \\
\text { tração do bloco, proporção entre módulos de } \\
\text { elasticidade (bloco e argamassa) e resistência } \\
\text { à compressão da argamassa. }\end{array}$ \\
\hline $\begin{array}{l}\text { Romagna } \\
(2000)\end{array}$ & Experimental & $\begin{array}{l}\text { Resistência à compressão, } \\
\text { modos de ruptura e } \\
\text { influência do graute em } \\
\text { prismas de blocos de } \\
\text { concreto. }\end{array}$ & $\begin{array}{l}\text { Em prismas não grauteados, o aumento da } \\
\text { resistência do bloco promoveu aumento da } \\
\text { resistência do prisma (a relação não é } \\
\text { proporcional). Em prismas grauteados, não } \\
\text { houve ganho de resistência na alvenaria } \\
\text { utilizando graute com resistência superior à } \\
\text { do bloco (na área líquida). }\end{array}$ \\
\hline $\begin{array}{l}\text { Freitas } \\
(2008)\end{array}$ & $\begin{array}{l}\text { Numérico e } \\
\text { experimental }\end{array}$ & $\begin{array}{l}\text { Comparativo entre análises } \\
\text { experimentais e numéricas } \\
\text { em primas e pequenas } \\
\text { paredes de blocos cerâmicos } \\
\text { e de concreto. }\end{array}$ & $\begin{array}{l}\text { As curvas força-deslocamento previstas } \\
\text { pelos modelos numéricos representaram } \\
\text { satisfatoriamente o comportamento da } \\
\text { alvenaria, principalmente no segmento } \\
\text { linear-elástico e no não linear até as forças e } \\
\text { deslocamentos últimos. }\end{array}$ \\
\hline $\begin{array}{l}\text { Rizzatti et al. } \\
\qquad(2012)\end{array}$ & Experimental & $\begin{array}{c}\text { Fatores intervenientes no } \\
\text { comportamento de prismas e } \\
\text { paredes de blocos cerâmicos. }\end{array}$ & $\begin{array}{l}\text { A ruptura dos prismas e paredes em escala } \\
\text { reduzida (1:3) ocorreu por esmagamento da } \\
\text { junta de argamassa seguido por fissuração de } \\
\text { contato entre blocos e argamassa, análogo ao } \\
\text { modo de ruptura observado para modelos em } \\
\text { escala real descritos na literatura. }\end{array}$ \\
\hline $\begin{array}{l}\text { Radovanović } \\
\text { et al. } \\
(2015)\end{array}$ & Experimental & $\begin{array}{l}\text { Resistência à compressão e } \\
\text { módulo de elasticidade em } \\
\text { paredes de blocos cerâmicos } \\
\text { e de concreto. }\end{array}$ & $\begin{array}{l}\text { Os resultados experimentais indicaram que } \\
\text { as estimativas fornecidas por diferentes } \\
\text { normas superestimam a resistência à } \\
\text { compressão. Para o módulo de elasticidade, } \\
\text { tendência contrária foi observada }\end{array}$ \\
\hline
\end{tabular}


Como nem sempre é possível realizar ensaios em paredes e prismas, em virtude das dificuldades inerentes à produção de modelos experimentais em maior escala, diversos pesquisadores utilizaram o bloco estrutural como corpo de prova. Embora em um primeiro instante isso possa conotar limitação, é possível extrair dados importantes acerca do comportamento da alvenaria estrutural a partir do bloco, posto que as propriedades mecânicas do mesmo são preponderantes em relação às dos demais constituintes do compósito. Nesse sentido, é razoável que se tenha um bom conhecimento das propriedades do material que constitui a unidade.

Uma maneira de se obter tais propriedades é extraindo do bloco corpos de prova reduzidos. De acordo com Senbu e Baba ${ }^{1}$ (1985 apud Drysdale, Hamid e Baker, 1994), a extração de pequenos prismas das paredes longitudinais de unidades vazadas fornece resultados mais condizentes para a resistência à compressão. Porém, Barbosa (2004) comenta que esse procedimento deve ser realizado com prudência para evitar danos ao corpo de prova durante sua retirada, o que pode significar gastos elevados de tempo e recursos.

Becica e Harris (1983) correlacionaram experimentalmente a resistência à compressão de blocos vazados de concreto $\left(20 \times 20 \times 39 \mathrm{~cm}^{3}\right)$ e de corpos de prova extraídos dessas unidades, sendo estes moldados de forma a reproduzir a inclinação das paredes do bloco e instrumentados na face externa (perpendicular à horizontal) e interna (com inclinação de $2 \%$ ). Os espécimes extraídos apresentaram resistências e deformações últimas superiores às dos blocos, o que os autores atribuíram ao confinamento imprimido ao bloco, influenciando negativamente em sua ductibilidade. Outra constatação foi a diferença de comportamento entre as curvas tensão-deformação obtidas para as partes externa e interna do corpo de prova.

A mesma metodologia foi adotada por Ganzerli et al. (2003). Os pesquisadores realizaram ensaios em amostras extraídas de unidades não padronizadas que possuíam, entre outras características, o prolongamento das paredes longitudinais em relação às transversais, maiores alturas e descontinuidades nos septos. A fôrma padrão consistiu em blocos de 20 x 20 x $40 \mathrm{~cm}^{3}$, sendo a extração de corpos de prova realizada no topo, na base e nas paredes longitudinais do bloco. Observou-se que a resistência à compressão dos corpos de prova extraídos superou a dos blocos (na área líquida) em cerca de 26\%, sendo justificada pela diferença de geometria entre os modelos ensaiados: os blocos possuem vazios e paredes esbeltas enquanto as amostras extraídas são sólidas e de menores dimensões. Também foi verificado

\footnotetext{
${ }^{1}$ SENBU, O.; BABA, A. Mechanical properties of masonry units. In: JOINT TECHNICAL COORDINATING, 1985, Tokyo. Proceedings. p.3.1/1-3.1/19.
} 
que o local de extração dos corpos de prova possui influência sobre à resistência à compressão, em função dos diferentes graus de compactação ao longo das camadas dos blocos.

Uma abordagem distinta foi utilizada por Frasson Junior (2000). Com objetivo de propor uma metodologia de dosagem e controle para o processo de produção de blocos estruturais de concreto, o autor comparou a resistência dos corpos de prova confeccionados em laboratório com a dos blocos produzidos em fábrica. Isso se deu através da moldagem de amostras cilíndricas $(5 \mathrm{~cm} \times 10 \mathrm{~cm})$ com o mesmo concreto empregado na fabricação dos blocos, submetendo-os inclusive à mesma cura, de modo a garantir similitude de traços e umidade. Foram avaliados blocos de 14 x 19 × $39 \mathrm{~cm}^{3}$ com geometrias que se distinguiam pela espessura das paredes, visando investigar o efeito dessa variação na relação entre resistências (CP e bloco). Baseando-se nos ensaios de compressão axial, o autor observou que a resistência à compressão alcançada pelos corpos de prova fícou em torno de $80 \%$ da esperada para um bloco vazado moldado com concreto de mesmas características do $\mathrm{CP}$, sendo tal relação válida para diferentes resistências e geometrias de bloco. Tais resultados contradizem aqueles observados nos estudos que empregaram extração de amostras do bloco.

Essa estratégia também foi empregada por Barbosa e Hanai (2005) em um estudo que lidou com correlações entre as propriedades mecânicas de blocos vazados e do concreto utilizado na sua produção. Os elementos foram moldados simultaneamente com concreto de mesma consistência plástica, de modo a garantir as mesmas características, sendo consideradas três classes de resistência. Enquanto os corpos de prova foram cilíndricos $(10 \mathrm{~cm}$ x $20 \mathrm{~cm})$, os blocos possuíam dimensões de $14 \times 19 \times 39 \mathrm{~cm}^{3}$. Ensaios de compressão axial realizados nos blocos isolados e em prismas de 2 ou 3 blocos (solidarizados por uma fina camada de resina epóxi em vez do argamassamento tradicional, objetivando simular a variação de altura do bloco isolado e também eliminar a influência da argamassa no comportamento do prisma) indicaram distribuição não uniforme de tensão e deformação na seção transversal média dos elementos, acentuada à medida que a tensão aplicada progredia, como mostra a Figura 2.17. 
Figura 2.17 - Evolução das deformações na face do bloco

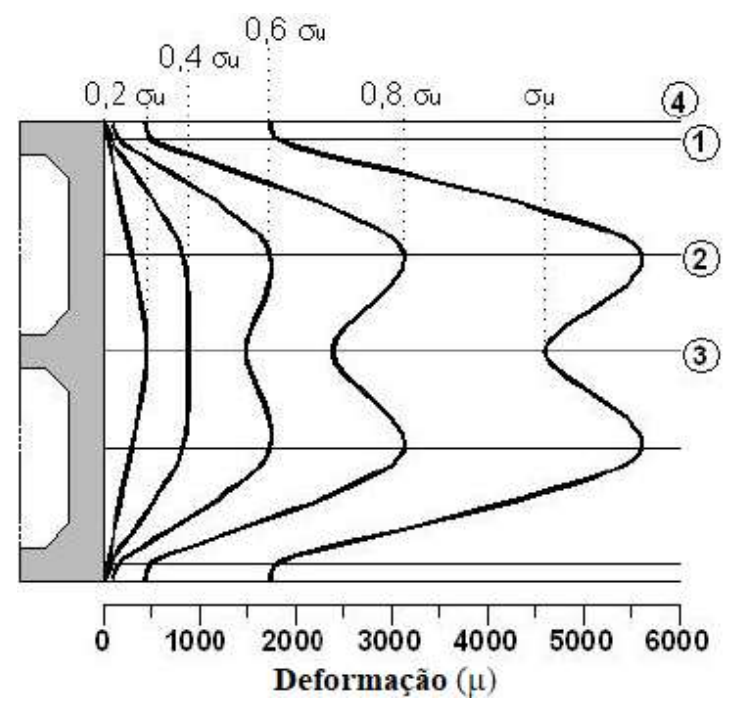

Fonte: Barbosa e Hanai (2005)

Observou-se que a esbeltez dos arranjos influenciou as correlações de resistência à compressão (em MPa) entre as amostras cilíndricas $\left(f_{c m}\right)$, blocos $\left(f_{b m}\right)$ e prismas de 2 ou 3 blocos. Para o bloco, a seguinte relação foi obtida:

$$
f_{b m}=0,60 f_{c m}+6,73
$$

Como principais conclusões do trabalho, os autores destacaram que a distribuição de tensão e deformação nos blocos está fortemente vinculada à sua geometria e ao confinamento transversal que ocorre no momento do ensaio, em função da rigidez dos pratos da máquina, induzindo um estado triaxial de tensões.

Fazendo uso das mesmas dimensões utilizadas anteriormente para os blocos vazados e corpos de prova cilíndricos, Barbosa e Hanai (2009) propuseram uma previsão da deformabilidade do bloco através do parâmetro "módulo de elasticidade fictício" $\left(E_{b, f i c}\right)$, definido como sendo a inclinação da curva tensão-deformação que liga deformações partindo de $50 \mu$ àquela associada a $40 \%$ da resistência última à compressão.

Esse parâmetro pode ser calculado para qualquer região do bloco instrumentada com transdutores de deslocamento e é dado em função do módulo de elasticidade obtido via compressão uniaxial das amostras cilíndricas $\left(E_{c}\right)$ fabricadas com o mesmo concreto do bloco. Considerando os valores médios lidos pelos transdutores situados no septo transversal central e nas paredes longitudinais à meia distância do furo (pontos 2 e 3 na Figura 2.18a), a seguinte relação foi fornecida (valores em $\mathrm{MPa}$ ).

$$
E_{b, f i c}=0,73 E_{c}-4648
$$


Com o módulo de elasticidade fictício, o comportamento do bloco pode ser aproximado pela curva tensão-deformação do corpo de prova cilíndrico e uma equação como a (2.33), que estima a resistência à compressão do bloco em função da resistência do CP. Dessa forma, segundo os autores, é possível antecipar a deformabilidade do bloco a partir das propriedades do seu material constituinte. Entretanto, essa metodologia não fornece uma aproximação adequada para altos níveis de tensão, como pode ser visto na Figura 2.18b.

Figura 2.18 - Análise tensão-deformação: a) posicionamento dos transdutores de deslocamento; $b$ ) curvas tensão-deformação experimentais e teórica

(3)

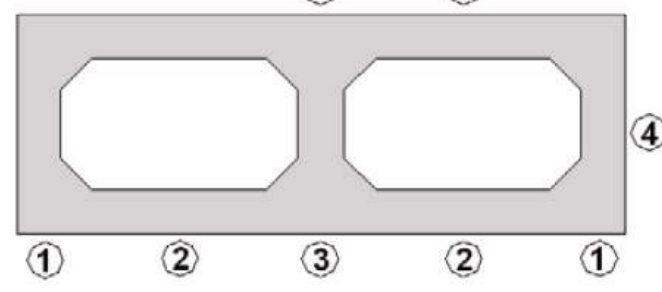

a)

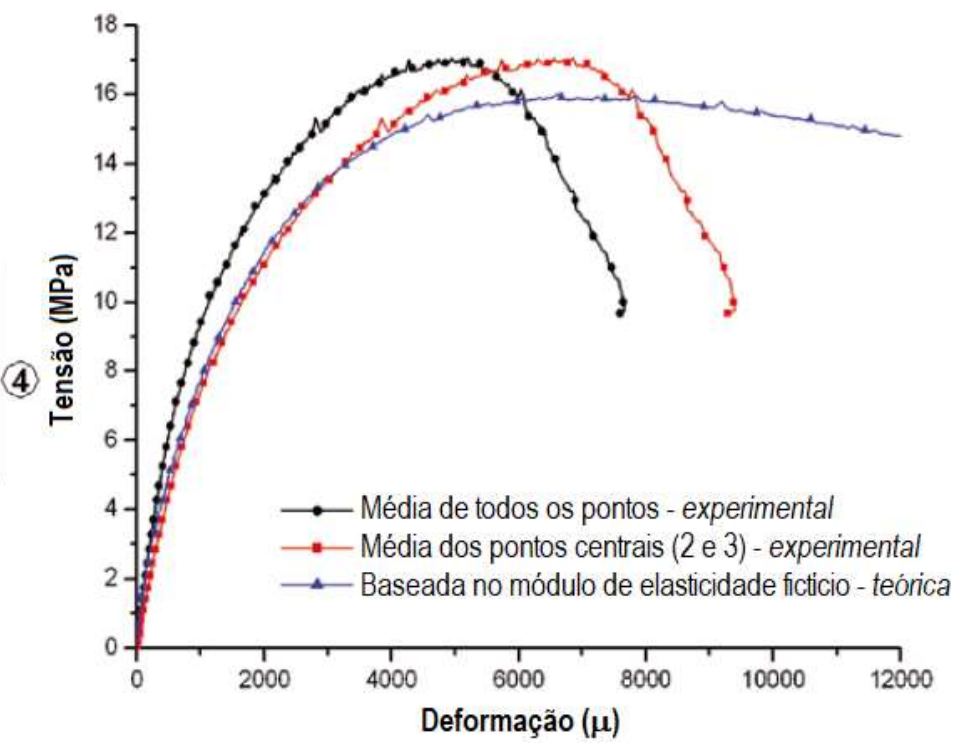

b)

Fonte: Adaptado de Barbosa e Hanai (2009)

O processo de moldagem do concreto utilizado na fabricação de um bloco estrutural difere do usualmente empregado para concretos plásticos, de modo que os procedimentos tradicionais de moldagem e adensamento adotados em laboratório para a confecção de corpos de prova não são adequados para o concreto "seco" que constitui o bloco (BARBOSA, 2004). Isso explica a escolha de alguns pesquisadores pelo uso de amostras extraídas diretamente da unidade, na tentativa de assegurar a equivalência de propriedades no bloco e no corpo de prova.

No entanto, esse tipo de estudo geralmente se limita ao comparativo entre resistências à compressão (entre bloco e amostra) ou à elaboração de correlações. Visto que uma série de fatores como geometria, velocidade e intensidade do carregamento e a rigidez dos pratos da máquina introduzem grande variabilidade nos resultados do ensaio, a comparação entre experimentos de diferentes autores torna-se inviável. 
Além disso, na determinação do módulo de elasticidade, a maneira com que os blocos e prismas submetidos ao ensaio de compressão axial costumam ser instrumentados não fornece o comportamento tensão-deformação do material: a resposta obtida é representativa apenas para o elemento que está sendo ensaiado. Assim, alternativas devem ser buscadas visando subsidiar prescrições normativas para obtenção do módulo de elasticidade dos componentes da alvenaria estrutural, em especial para o bloco.

2.4.2 Métodos de ressonância aplicados às estruturas

Como comentado anteriormente, os ENDs encontram vasta aplicabilidade na determinação de parâmetros mecânicos dos materiais. Nessa categoria, duas metodologias merecem menção: os métodos de ressonância e a VPU (ou ensaio de ultrassom). Tratando-se do módulo de elasticidade dinâmico, uma diferença fundamental entre as duas abordagens (além do fenômeno físico envolvido) é que, enquanto o ultrassom fornece uma medida local da propriedade, os métodos de ressonância avaliam a amostra por inteiro, minimizando influências de não-homogeneidades locais do material (AKKAYA et al., 2003). Embora as técnicas de ressonância sejam atualmente limitadas pela dependência de geometrias convenientes para possibilitar a determinação do módulo dinâmico, essa restrição não se aplica para a obtenção de propriedades modais (frequências, modos de vibração e fatores de amortecimento), reforçando seu caráter utilitário na avaliação das estruturas.

O desenvolvimento do método que associa frequências de ressonância às propriedades dinâmicas do material é atribuído a Powers e é datado de 1938. Tal método previa a medição de frequências fundamentais (associadas aos modos de vibrar fundamentais, vide Figura 2.1) em prismas e cilindros de concreto, compondo o arcabouço teórico que mais tarde originou a norma americana ASTM C215. Por muitos anos, a obtenção de frequências naturais foi dominada pelo método da ressonância forçada (descrito no tópico 2.1.1). Swamy e Rigby (1971) o utilizaram para investigar o módulo de elasticidade dinâmico e as propriedades de amortecimento em pastas de cimento endurecidas, argamassas e concretos a partir dos modos longitudinal, flexional e torcional de vibração. Com os resultados, os autores propuseram equações relacionando módulo de elasticidade, fatores de amortecimento e fração volumétrica do agregado. Leming, Nau e Fukuda (1998) incrementaram essa metodologia, que até então só cobria amostras prismáticas e cilíndricas, ao determinar o módulo de elasticidade do concreto a partir das frequências ressonantes de discos de concreto com pequena espessura, recortados de corpos de prova cilíndricos. 
O estudo de Ito e Uomoto (1997) suscitou uma nova abordagem para os métodos de ressonância. Os autores avaliaram a influência de defeitos internos em amostras de concreto através do impacto de uma pequena esfera de metal solta a determinada altura, com posterior captação da resposta sonora por meio de um microfone. O sinal acústico foi processado através da Transformada Rápida de Fourier (FFT), possibilitando a determinação das frequências ressonantes. Essa modalidade de ressonância induzida por impacto foi mais tarde empregada por Kolluru, Popovics e Shah (2000), porém com o uso de um acelerômetro fixado à superfície do corpo de prova. Nesse trabalho, foi proposta uma metodologia para determinar o coeficiente de Poisson dinâmico sem a necessidade de cálculo prévio do módulo de elasticidade dinâmico ao cisalhamento, que era o procedimento comum. A eficácia do método foi verificada por ensaios em cilindros de aço e alumínio, sendo posteriormente estendida para o concreto.

O uso de ressonância por impacto em conjunto com acelerometria para obter propriedades modais e mecânicas é uma metodologia eficiente e bastante explorada para diversos fins. Por exemplo, Boothby, Atamturktur e Hanagan (2006) a utilizaram para validar modelos numéricos tridimensionais de duas catedrais abobadadas em alvenaria de pedra, comparando os resultados (modos de vibrar e frequências naturais) da análise modal desenvolvida junto ao software ANSYS ${ }^{\circledR} 7.0$ com os obtidos por meio de análise modal experimental, instrumentando as abóbadas das catedrais com uma série de acelerômetros e promovendo excitação com um martelo de massa adequada, logrando as funções resposta em frequência (FRFs) através de um sistema de processamento de sinais empregando FFT. A importância da validação de tais modelos numéricos está no fato de que estruturas abobadadas são especialmente vulneráveis aos efeitos dinâmicos provenientes de sismos.

A mesma estratégia foi empregada por Atamturktur, Gilligan e Salyards (2013) na identificação da posição e gravidade de defeitos internos em elementos de concreto armado. As curvaturas relativas aos modos de vibrar foram obtidas experimentalmente para pequenas vigas de concreto armado produzidas em laboratório, sendo uma delas íntegra (referência) e outras 4 com defeitos (rock-pocket e honeycomb, associados ao adensamento deficiente do concreto fresco) com dimensão controlada, sendo então confrontadas com a resposta vibratória proveniente de simulações em elementos finitos. A análise foi conduzida utilizando martelo de impacto para excitar as estruturas em diferentes pontos enquanto 57 acelerômetros piezoelétricos uniformemente distribuídos foram responsáveis por determinar as respostas de aceleração em função do impacto, possibilitando a obtenção de FRFs que permitiram reconstruir a curvatura modal das vigas ensaiadas. 
Já Yang e Gupta (2018) fizeram uso dessa metodologia para prever a resistência à compressão de concretos com cimento geopolimérico a partir da frequência ressonante do modo longitudinal em corpos de prova cilíndricos. Após medição das frequências e cálculo do módulo de elasticidade dinâmico, as amostras foram ensaiadas à compressão aos 7 e 28 dias com intuito de aumentar a base de valores de resistência e investigar sua evolução. Com os resultados experimentais e análises de regressão, os autores forneceram correlações indicando que a resistência à compressão é diretamente proporcional ao módulo dinâmico e, consequentemente, à frequência ressonante. Ao se comparar essa relação à obtida em um estudo anterior, envolvendo velocidade de pulso ultrassônico, constatou-se que a equação que estima a resistência em função da frequência natural melhor se adequou aos valores experimentais.

Diógenes et al. (2011) se propôs a validar a solução Sonelastic ${ }^{\circledR}$ para a modalidade acústica do ensaio de ressonância comparando-a com um já consagrado sistema de aquisição empregando acelerometria. O módulo de elasticidade dinâmico do concreto foi determinado por amostras cilíndricas e prismáticas com base nas frequências naturais associadas aos modos fundamentais longitudinal e flexural. Na avaliação das frequências ressonantes utilizando acelerometria, houve suspensão dos corpos de prova por meio de fios. Na captação acústica, empregou-se o suporte próprio do Sonelastic $\AA$, repousando os corpos de prova sobre fios de aço conectados a um quadro rígido, procurando reproduzir a condição de contorno do tipo livre.

Observou-se que a geometria do corpo de prova possui certa influência nos resultados, visto que o módulo dinâmico associado ao modo fundamental longitudinal obtido em espécimes cilíndricos foi cerca de 5\% inferior ao proveniente de amostras prismáticas. Notou-se, também, que o módulo dinâmico obtido a partir da frequência flexional foi superior ao logrado a partir da frequência longitudinal em cerca de $2 \%$. Finalmente, uma vez que a diferença entre as frequências naturais medidas pelos dois sistemas de aquisição foi inferior a $1 \%$, concluiu-se que a metodologia Sonelastic ${ }^{\circledR}$ foi eficiente na caracterização do módulo dinâmico.

A partir daí, alguns estudos empregando o ensaio de ressonância acústica foram desenvolvidos, com enfoque na caracterização mecânica de argamassas e concretos. Haach et al. (2013) avaliaram experimentalmente o módulo de elasticidade de argamassas usuais produzidas conforme especificações da norma britânica de alvenaria.

Foram realizados ensaios destrutivos (compressão axial) e não destrutivos (ressonância acústica) em corpos de prova cilíndricos, possibilitando a elaboração de correlações entre módulos de elasticidade (dinâmico e estático) e entre módulos e a resistência à compressão da argamassa. Observou-se que o coeficiente de variação $(\mathrm{CV})$ das medidas do módulo de elasticidade dinâmico foi inferior ao obtido para as medidas do módulo estático, o que se deve 
à menor susceptibilidade a erros do método não destrutivo, resultando em menor dispersão de resultados. Outra conclusão do estudo foi a de que os módulos dinâmicos aferidos a partir dos modos fundamentais flexional e longitudinal de vibração indicaram melhor correlação com a resistência à compressão que o módulo estático obtido a partir de ensaio destrutivo.

Haach, Carrazedo e Oliveira (2017) expandiram as análises de Haach et al. (2013), confeccionando um maior número de amostras cilíndricas de argamassa visando avaliar a evolução das propriedades mecânicas (estáticas e dinâmicas) ao longo de diferentes idades. Também foram produzidos corpos de prova prismáticos, viabilizando a determinação do módulo de elasticidade ao cisalhamento e coeficiente de Poisson dinâmicos $(G$ e $v$, respectivamente).

A identificação dos modos de vibração e frequências naturais de interesse se deu a partir de análise modal realizada junto ao software Abaqus ${ }^{\circledR}$. As amostras foram modeladas com elementos finitos hexaédricos de 20 nós. Os resultados das simulações numéricas permitiram a determinação dos coeficientes geométricos $\alpha$ para modos de vibração além dos fundamentais. Com esses valores, obteve-se estimativas de frequência (com a Equação 1.1) que foram úteis para garantir a correta identificação das frequências naturais durante os ensaios de ressonância acústica, com exemplo mostrado na Figura 2.19.

Figura 2.19 - Espectro de frequências gerado para as amostras prismáticas

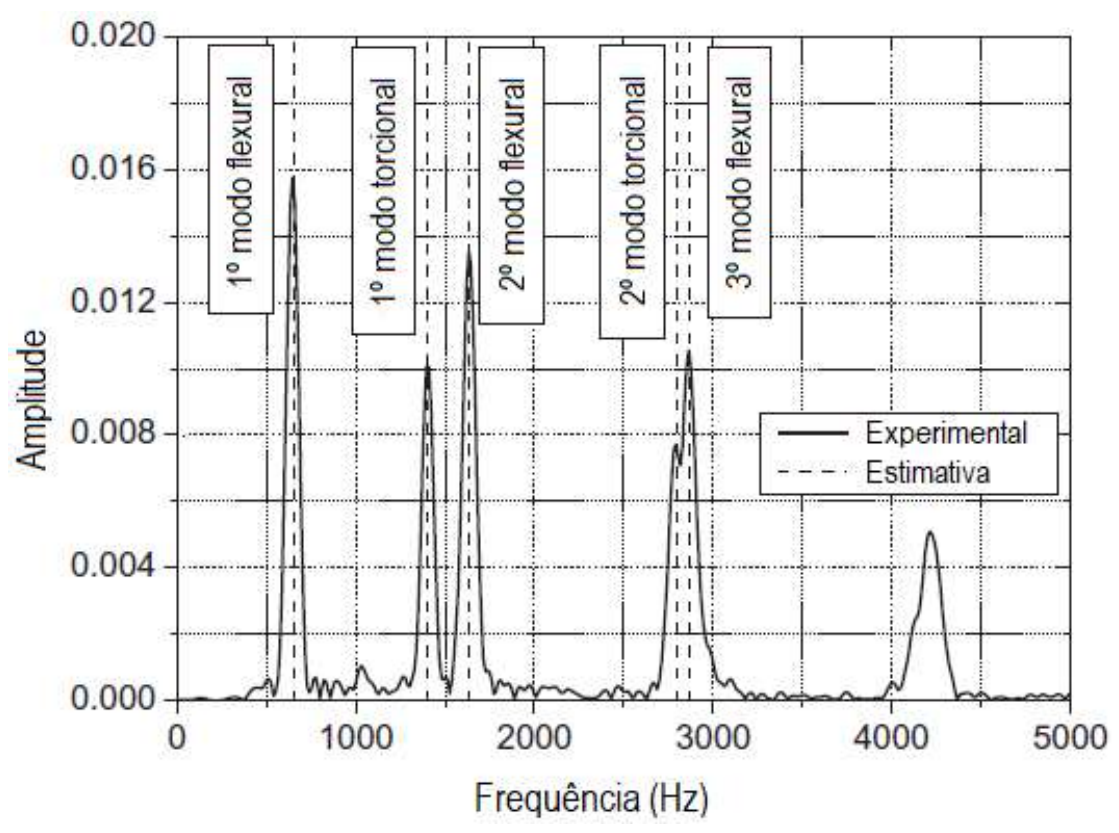

Fonte: Haach, Carrazedo e Oliveira (2017) 
Carrazedo et al. (2018) buscaram identificar vantagens e limitações do ensaio de ressonância acústica frente ao ensaio de compressão na determinação do módulo de elasticidade em diferentes idades do concreto até os 28 dias, utilizando corpos de prova cilíndricos. Observou-se que o CV dos resultados de módulo de elasticidade dinâmico foi substancialmente inferior ao equivalente estático. Além disso, verificou-se que os valores do módulo dinâmico calculados a partir dos modos fundamentais flexional e longitudinal são quase idênticos (conforme previsto por trabalhos anteriores), com o módulo dinâmico longitudinal apresentando menor dispersão.

Com base na comparação entre valores de módulo de elasticidade (estático e dinâmico), de resistência à compressão obtida para diferentes idades e das equações do fib Model Code for Concrete Structures que estimam a evolução da resistência à compressão e do módulo de elasticidade ao longo dos 28 dias, constatou-se que o módulo dinâmico foi o parâmetro melhor caracterizado por tais equações. Isso indica que, dentre as variáveis analisadas, o módulo dinâmico é o que melhor representa a maturação do concreto ao longo do tempo. A partir de uma análise de regressão múltipla, foi proposta uma equação (com $\mathrm{R}^{2}=0,90$ e $\mathrm{CV}=5,08 \%$ ) para estimar o módulo de elasticidade dinâmico a partir do estático e da resistência à compressão, fornecendo uma relação entre módulos mais precisa em relação às demais equações existentes na literatura.

Os materiais constituintes da alvenaria estrutural já foram avaliados por métodos de ressonância e outras modalidades de END. No entanto, apenas em corpos de prova com geometria conveniente e empregando acelerometria na aquisição de dados em detrimento da captação acústica. Makoond, Pelà e Molins (2019) estudaram as propriedades dinâmicas de tijolos maciços fabricados por diferentes processos e argamassas de assentamento com diferentes composições, utilizando amostras prismáticas para ambos os componentes, através da técnica de excitação por impulso e velocidade de pulso ultrassônico.

Uma vez que o teor de umidade do espécime pode ter influência nas suas frequências ressonantes e assim influir no valor das propriedades dinâmicas, os pesquisadores secaram os corpos de prova em estufa até a constância de massa antes de proceder com os experimentos. O ensaio de ressonância foi executado utilizando suportes rígidos metálicos posicionados sob as linhas nodais (marcadas nos CPs) de cada modo de interesse (flexural e torcional). A Figura 2.20 indica os pontos de excitação (X1 e X2) e captação (P1 e P2) previstos. 
Figura 2.20 - Configurações de suporte: a) modo flexional; b) modo torcional

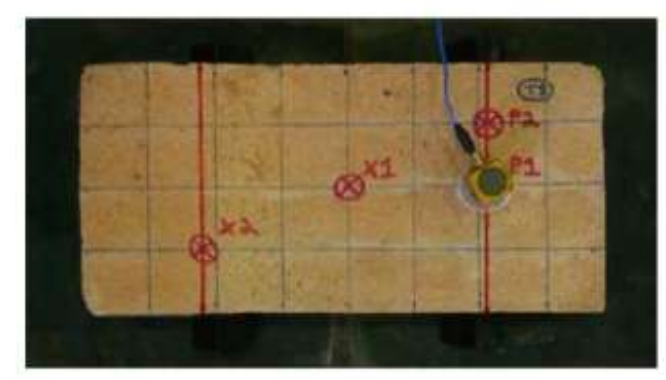

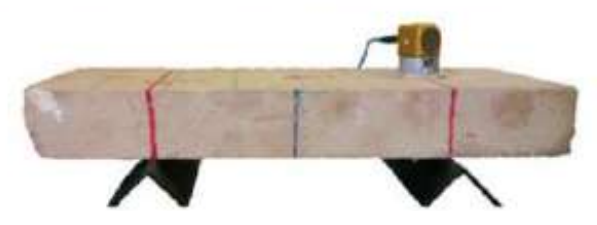

a)

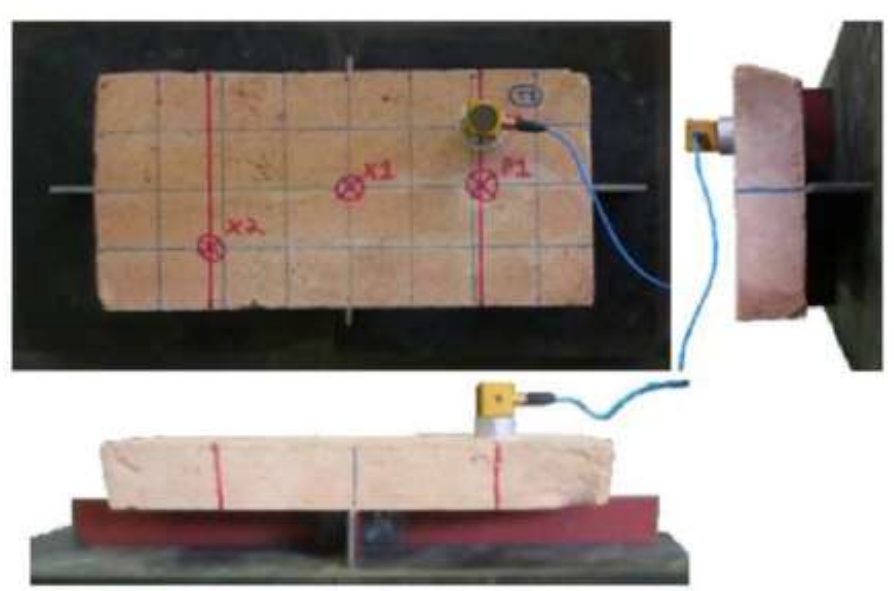

b)

Fonte: Makoond, Pelà e Molins (2019)

Com os valores de $E$ e $G$, foi possível determinar o coeficiente de Poisson dinâmico. O valor obtido serviu como primeira estimativa do parâmetro para computar o módulo de elasticidade dinâmico das amostras através do método ultrassônico (ver Equação 2.1).

É válido recordar que os códigos americanos ASTM C215-14 e E1876-15 só fornecem expressões para cálculo do módulo de elasticidade dinâmico válidas para as frequências fundamentais, isto é, relativas ao primeiro de cada um dos modos de vibrar (Figura 2.1). Assim, a análise modal se mostra útil na ampliação das possibilidades de cálculo, indicando que é possível obter o módulo dinâmico por meio de modos de vibrar alternativos aos fundamentais, uma vez que o coeficiente $\alpha$ pode ser determinado para qualquer modo através de variação dos parâmetros de um modelo numérico.

A partir do exposto, dois pontos tornam-se evidentes: o interesse pelo módulo de elasticidade dinâmico e a eficiência dos métodos de ressonância (forçada ou por impacto) em sua determinação. Pode-se inferir que o ensaio de ressonância acústica é uma opção mais prática e menos onerosa, já que dispensa equipamentos de excitação automática e os procedimentos de fixação de um acelerômetro. Contudo, a aplicação dos métodos de ressonância com a finalidade de obter o módulo de elasticidade dinâmico ainda é severamente limitada pela geometria dos corpos de prova, visto que as equações existentes só admitem cilindros, prismas e discos. 
2.4.3 Ensaio de ressonância acústica em blocos de alvenaria estrutural

A interseção entre os temas discutidos anteriormente compõe o objeto de interesse do estudo, tratando-se, até o presente momento, de um assunto pouco explorado e bastante escasso em publicações.

Santos et al. (2014) avaliaram o módulo de elasticidade de blocos vazados de concreto através de ensaios convencionais (destrutivos) e não destrutivos (ressonância acústica e ultrassom). Com intuito de visualizar os modos de vibração do bloco, foi conduzida análise modal junto ao software DIANA ${ }^{\circledR}$ em um modelo numérico calibrado com os resultados dos ensaios de caracterização e compressão uniaxial. Por fim, os autores propuseram um modelo simplificado para relacionar frequência de vibração e módulo de elasticidade dinâmico.

O modelo em elementos finitos teve sua malha composta por elementos sólidos de 8 nós e como condição de contorno foram aplicadas restrições de deslocamento vertical na base do bloco, procurando representar o bloco apoiado sobre o chão em toda sua face inferior (condição em que o ensaio de ressonância acústica foi realizado). Elegendo o primeiro modo de vibrar, foi desenvolvida análise paramétrica variando densidade (e consequentemente a massa) e o módulo de elasticidade do bloco, sendo então elaborados dois gráficos: um representando a influência da variação dos parâmetros do material na frequência natural do modo estudado e outro indicando o que ocorre com o produto da massa do bloco pelo quadrado da frequência para diferentes valores do módulo de elasticidade. A dita análise é ilustrada na Figura 2.21.

Figura 2.21 - Análise paramétrica: a) modo de vibrar selecionado; b) gráficos elaborados

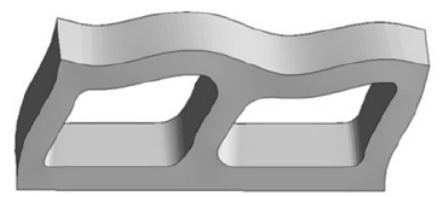

a)
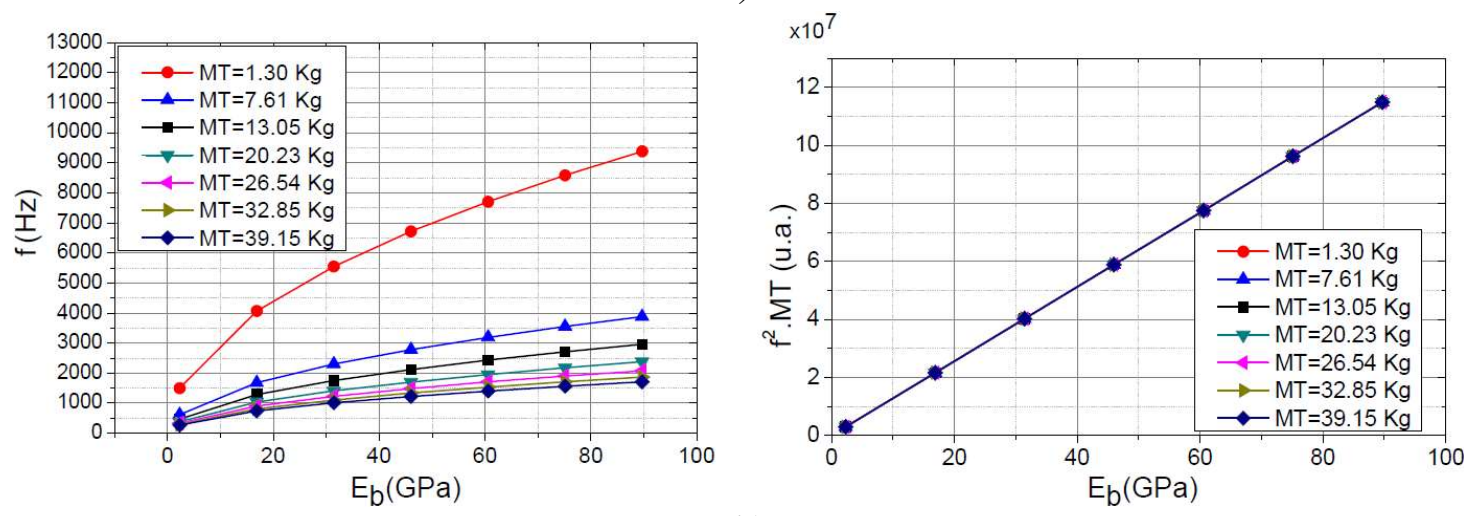

b)

Fonte: Adaptado de Santos et al. (2014) 
O gráfico à direita atesta que o produto $M \times f^{2}$ varia linearmente $\operatorname{com} E$, tendência válida para qualquer valor da massa e do módulo de elasticidade. Os autores constataram que a inclinação dessa reta (coeficiente angular) é numericamente proporcional à constante geométrica $\alpha$. Por conseguinte, foi possível determinar o módulo de elasticidade dinâmico do bloco a partir da Equação 1.1, uma vez que a frequência real associada ao modo de vibrar foi encontrada através do ensaio acústico e a massa do bloco já era conhecida.

Por fim, comparou-se o módulo dinâmico logrado a partir da estratégia descrita com o proveniente de testes ultrassônicos. Verificou-se que as medidas com ultrassonografia resultaram em módulos dinâmicos mais elevados (na ordem de 10\%). Entre as razões para essa discrepância, foi mencionada a condição de contorno empregada no ensaio e reproduzida no modelo numérico, além do fato de que o ensaio ultrassônico fornece medidas locais do módulo de elasticidade, ao passo que a ressonância acústica prevê o comportamento global da estrutura.

Esta foi uma das poucas tentativas (talvez a única que se tem registro de publicação) de determinar o coeficiente geométrico $\alpha$ e, consequentemente, o módulo de elasticidade dinâmico de um bloco vazado de alvenaria estrutural a partir do ensaio de ressonância acústica. $O$ cenário para o bloco cerâmico é ainda mais ignorado. Diante disso, a presente pesquisa espera colaborar na especulação das condições de contorno mais adequadas para a realização do ensaio e na escolha dos modos de vibrar mais apropriados de se trabalhar. 


\subsection{Síntese do capítulo}

Esse capítulo buscou fornecer subsídios teóricos e informativos para o leitor, possibilitando melhor compreensão das decisões a serem tomadas ao longo das etapas experimental e numérica do trabalho, bem como situá-lo no contexto do estudo.

Em um primeiro momento, um panorama sobre ENDs foi apresentado, tratando do princípio geral de funcionamento e as características que os diferem dos métodos destrutivos, além de elencar exemplos de ensaios e suas aplicações. As técnicas que serão utilizadas no presente trabalho (velocidade de pulso ultrassônico e excitação por impulso) foram tratadas com maiores detalhes. As relações entre as propriedades mecânicas do material e o fenômeno físico associado a cada uma dessas técnicas ficaram bem definidas, assim como as vantagens e desvantagens inerentes a cada método de ensaio.

Visto que o emprego do ensaio de ressonância acústica ainda é limitado e pouco difundido a nível nacional, julgou-se necessário incluir nesse capítulo alguns conceitos da Dinâmica (modelo modal teórico e função resposta em frequência) e abordar métodos de aquisição e processamento de sinais, procurando antecipar e elucidar dúvidas sobre a metodologia experimental a ser aplicada. Outras utilidades da análise modal experimental também foram mencionadas.

Os aspectos normativos referentes à caracterização geométrica e mecânica dos blocos estruturais foram apresentados de forma sucinta e organizada, com foco nos procedimentos experimentais. Procurou-se evidenciar as diferentes propriedades geométricas avaliadas na análise dimensional dos blocos cerâmicos e de concreto. No âmbito das propriedades mecânicas, fez-se algumas ressalvas referentes à determinação do módulo de elasticidade a partir do ensaio de compressão axial.

Finalmente, um conciso estado da arte das duas grandes áreas da pesquisa (caracterização mecânica da alvenaria estrutural e aplicação de métodos de ressonância às estruturas), mesmo que limitado aos tópicos mais pertinentes, permitiu entrever a contribuição da presente pesquisa em duas frentes: uma forma alternativa de determinar uma importante propriedade mecânica do bloco de alvenaria estrutural e a possibilidade de expandir a quantidade de geometrias para as quais a relação entre frequência ressonante e módulo de elasticidade dinâmico é conhecida, a partir da determinação do coeficiente geométrico $\alpha$ de forma experimental. 


\section{PROGRAMA EXPERIMENTAL}

A parcela experimental da pesquisa foi conduzida no Laboratório de Estruturas situado na Escola de Engenharia de São Carlos (EESC-USP). O programa é constituído por três etapas: ensaios de caracterização das unidades de alvenaria, ensaio de ultrassom (VPU) e ensaio de ressonância acústica via excitação por impulso. Concomitantemente à última, foi realizada simulação numérica para subsidiar os procedimentos experimentais.

A amostra é composta por unidades cerâmicas ${ }^{2}$ e de concreto $^{3}$ com diferentes geometrias e resistências nominais à compressão. As quantidades consideradas para os ensaios de caracterização obedeceram às especificações da ABNT NBR15270-1:2017 - Componentes cerâmicos - Blocos e tijolos para alvenaria Parte 1 - Requisitos e ABNT NBR6136:2016 Blocos vazados de concreto simples para alvenaria - Requisitos. Em virtude da inexistência de prescrições normativas relativas ao número de blocos a ser utilizado nos ensaios não destrutivos que compõem o programa, este foi arbitrado. O Quadro 3.1 detalha as geometrias (exibidas na Figura 3.1), as resistências nominais e a quantidade de unidades reservada para cada finalidade.

Quadro 3.1 - Amostra experimental

\begin{tabular}{|c|c|c|c|c|c|}
\hline \multicolumn{2}{|c|}{ UNIDADES DE CONCRETO } & \multicolumn{2}{c|}{ UNIDADES CERÂMICAS } \\
\hline Tipo / Resistência & Caracterização & ENDs & Tipo / Resistência & Caracterização & ENDs \\
\hline $\begin{array}{c}\text { Bloco inteiro } / 10 \mathrm{MPa} \\
\left(14 \times 19 \times 39 \mathrm{~cm}^{3}\right)\end{array}$ & 6 & 3 & $\begin{array}{c}\text { Bloco inteiro } / 6 \mathrm{MPa} \\
\left(14 \times 19 \times 29 \mathrm{~cm}^{3}\right)\end{array}$ & 13 & 3 \\
\hline $\begin{array}{c}\text { Meio-bloco } / 10 \mathrm{MPa} \\
\left(19 \times 19 \times 19 \mathrm{~cm}^{3}\right)\end{array}$ & 6 & 3 & $\begin{array}{c}\text { Meio-bloco } / 14 \mathrm{MPa} \\
\left(14 \times 19 \times 14 \mathrm{~cm}^{3}\right)\end{array}$ & 13 & 3 \\
\hline
\end{tabular}

Fonte: Autor (2020)

Figura 3.1 - Unidades componentes da amostra experimental

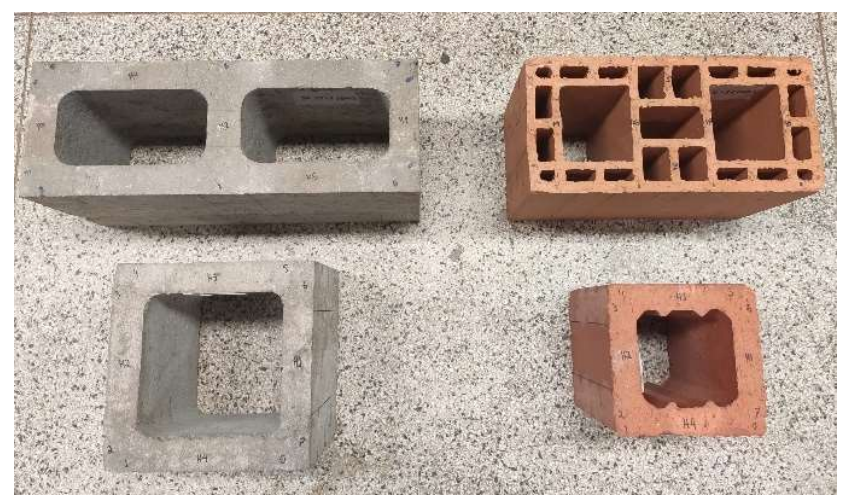

Fonte: Autor (2020)

\footnotetext{
${ }^{2}$ Doados pelas empresas Cerâmica City (blocos inteiros) e Cerâmica Palma de Ouro (meio-blocos).

${ }^{3}$ Doados pela empresa TATU Pré-moldados.
} 


\subsection{Caracterização geométrica e mecânica das unidades de alvenaria}

A caracterização dos blocos e meio-blocos utilizados inclui os seguintes procedimentos: análise dimensional, determinação da área líquida e ensaio de compressão axial. Estes são suficientes para determinar todas as propriedades geométricas elencadas no Quadro 2.3, além de possibilitar a obtenção da resistência à compressão e uma estimativa do módulo de elasticidade estático, propriedades mecânicas de interesse.

A execução dos procedimentos supracitados foi balizada pelas normas ABNT NBR15270-2:2017 - Componentes cerâmicos - Blocos e tijolos para alvenaria Parte 2 Métodos de ensaio e ABNT NBR12118:2013 - Blocos vazados de concreto simples para alvenaria - Métodos de ensaio, conforme exposto na seção 2.3 deste trabalho. O corpo do texto traz apenas valores médios das propriedades estudadas. Resultados mais detalhados podem ser verificados no Apêndice A - "Resultados individuais da caracterização das unidades".

Inicialmente, havia-se pensado em utilizar blocos e meio-blocos de mesmo padrão (paredes vazadas ou maciças), família (larguras nominais iguais) e resistência à compressão especificada pelo fabricante. No entanto, em função dos lotes que estavam disponíveis em laboratório, fez-se a seleção da amostra de modo a proporcionar geometrias bem variadas. Isso explica a diferença de resistência e padrão entre as unidades cerâmicas e de família entre as unidades de concreto. Uma breve inspeção visual foi realizada para identificar defeitos que poderiam dificultar ou inviabilizar a realização dos ensaios.

\subsubsection{Propriedades geométricas: bloco e meio-bloco cerâmico}

As propriedades geométricas das unidades cerâmicas foram obtidas fazendo uso de régua metálica (utilizada na aferição das dimensões efetivas), paquímetro digital com resolução de 0,01 mm (na medição da espessura dos septos), esquadro metálico (para medir o desvio em relação ao esquadro e auxiliar a determinação da planeza das faces) e balança digital com resolução de $0,1 \mathrm{~g}$ até $5 \mathrm{~kg}$.

Quanto a determinação das dimensões efetivas dos blocos e meio-blocos cerâmicos, foi observado que a discrepância entre as medidas reais e nominais foi inferior a tolerância estabelecida em norma. A Tabela 3.1 apresenta os valores médios obtidos e tolerâncias estabelecidas por norma. 
Tabela 3.1 - Dimensões efetivas para blocos e meio-blocos cerâmicos

\begin{tabular}{ccccccc}
\hline & \multicolumn{3}{c}{ BLOCO INTEIRO } & \multicolumn{3}{c}{ MEIO-BLOCO } \\
\cline { 2 - 7 } & $\begin{array}{c}\text { Largura } \\
(\mathbf{m m})\end{array}$ & $\begin{array}{c}\text { Altura } \\
(\mathbf{m m})\end{array}$ & $\begin{array}{c}\text { Comprimento } \\
\mathbf{( m m})\end{array}$ & $\begin{array}{c}\text { Largura } \\
(\mathbf{m m})\end{array}$ & $\begin{array}{c}\text { Altura } \\
(\mathbf{m m})\end{array}$ & $\begin{array}{c}\text { Comprimento } \\
(\mathbf{m m})\end{array}$ \\
\hline Média & 139,1 & 189,2 & 288,0 & 137,8 & 188,1 & 140,4 \\
DP & 0,77 & 1,47 & 1,40 & 0,40 & 0,36 & 0,37 \\
CV (\%) & 0,55 & 0,77 & 0,49 & 0,29 & 0,19 & 0,26 \\
\hline \multicolumn{7}{c}{ Tolerâncias: } \\
\hline \multicolumn{7}{c}{ Largura, altura e comprimento: $\pm 3,0 \mathrm{~mm}$} \\
\hline
\end{tabular}

As demais propriedades obtidas na análise dimensional (espessura das paredes externas e dos septos internos, desvio em relação ao esquadro e planeza das faces) dizem respeito apenas aos blocos inteiros e são expostas na Tabela 3.2. A coluna ID refere-se ao título identificador de cada unidade da amostra.

Tabela 3.2 - Espessura das paredes e septos, desvio em relação ao esquadro (D) e planeza das faces (F) para blocos inteiros cerâmicos

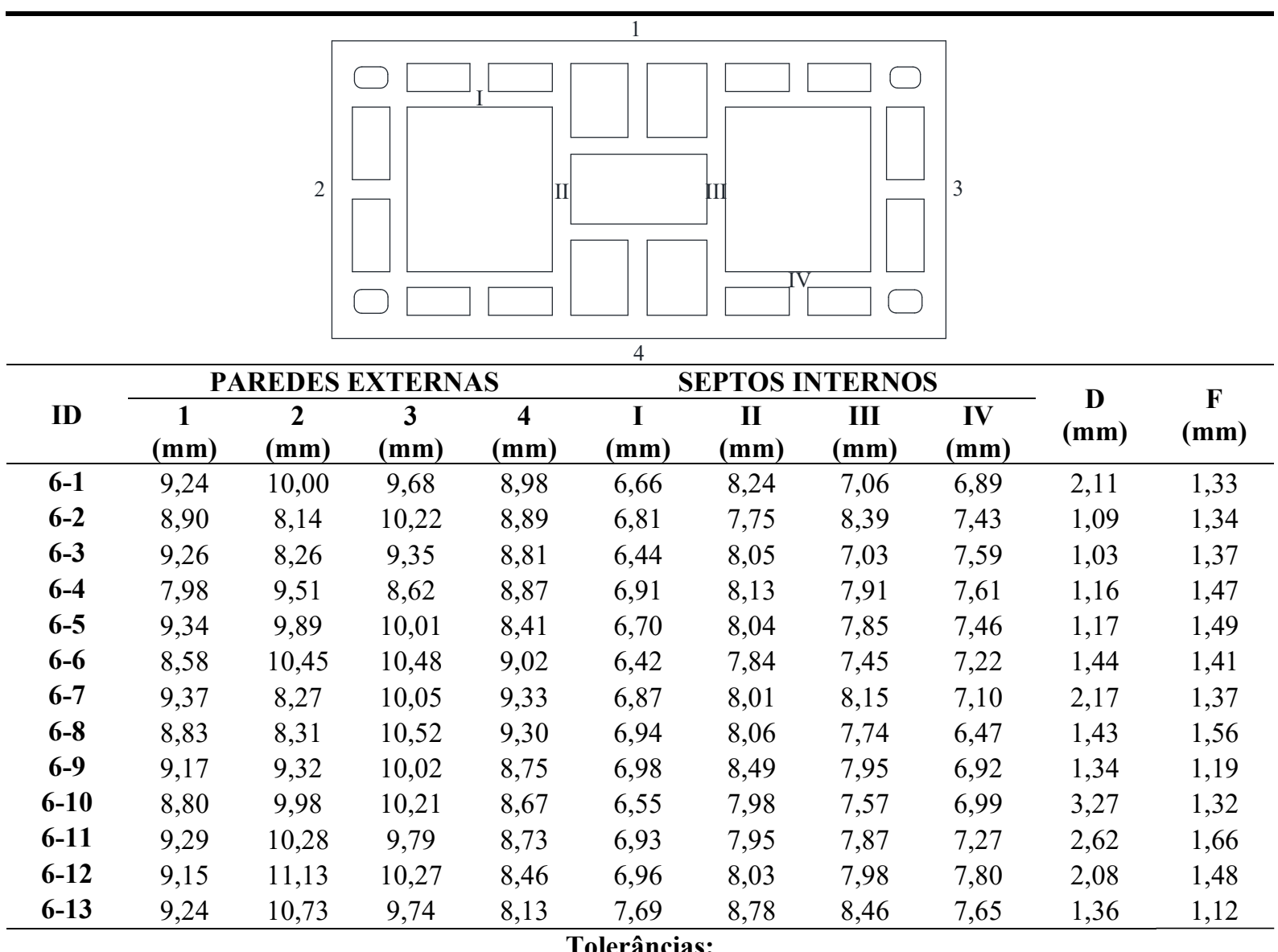

Espessura mínima das paredes externas: $8 \mathrm{~mm}$, com tolerância de $-0,3 \mathrm{~mm}$ (para cada valor individual)

Espessura mínima dos septos internos: $7 \mathrm{~mm}$, com tolerância de $-0,3 \mathrm{~mm}$ (para cada valor individual) Desvio em relação ao esquadro (D) máximo: $3 \mathrm{~mm}$ 
Finalmente, foram calculadas a área bruta (a partir das dimensões efetivas mensuradas) e a área líquida (através da pesagem hidrostática e da massa do bloco saturado). Um dispositivo auxiliar foi empregado para manter as unidades em submersão durante o procedimento, como mostra a Figura 3.2a. A Tabela 3.3 resume tais resultados, trazendo também a razão entre as duas grandezas para blocos inteiros e meio-blocos.

Figura 3.3 - Determinação da área líquida: a) massa aparente; b) massa saturada

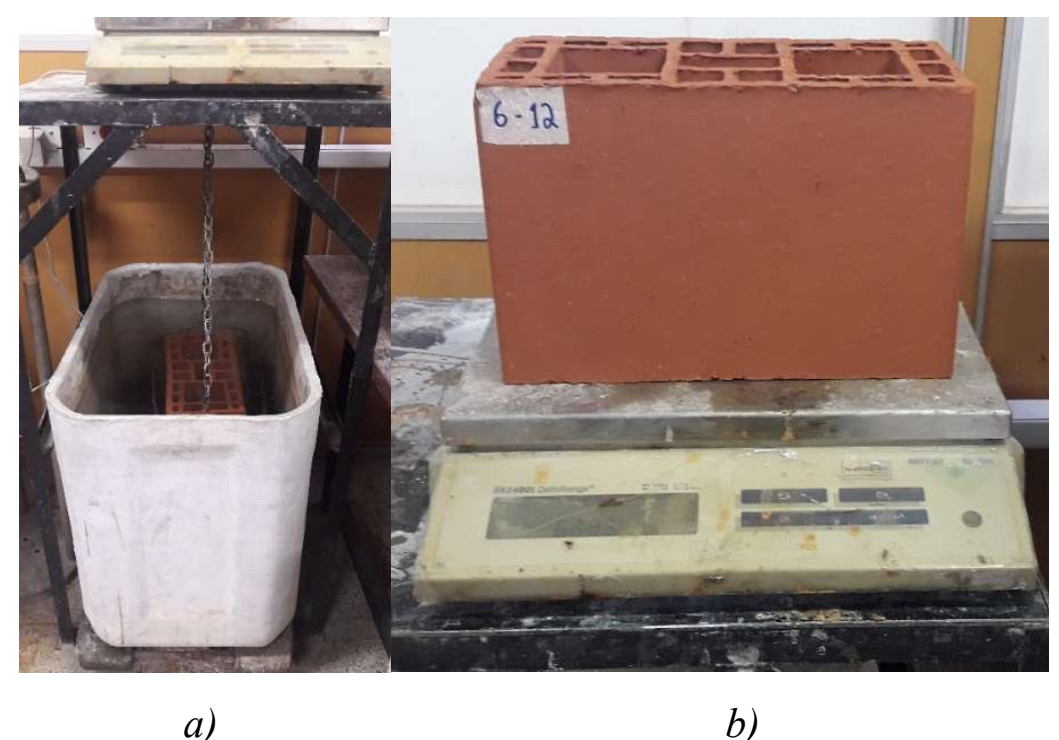

Fonte: Autor (2020)

Tabela 3.3 - Área bruta e área líquida para blocos e meio-blocos cerâmicos

\begin{tabular}{|c|c|c|c|c|c|c|}
\hline & \multicolumn{3}{|c|}{ BLOCO INTEIRO } & \multicolumn{3}{|c|}{ MEIO-BLOCO } \\
\hline & $\begin{array}{l}\text { Área bruta } \\
\left(\mathrm{mm}^{2}\right)\end{array}$ & $\begin{array}{l}\text { Área líquida } \\
\qquad\left(\mathrm{mm}^{2}\right)\end{array}$ & $\begin{array}{c}\mathbf{A}_{\text {líq }} / \mathbf{A}_{\mathbf{b}} \\
(\%)\end{array}$ & $\begin{array}{l}\text { Área bruta } \\
\left(\mathrm{mm}^{2}\right)\end{array}$ & $\begin{array}{l}\text { Área líquida } \\
\left(\mathbf{m m}^{2}\right)\end{array}$ & $\begin{array}{c}\mathbf{A}_{\text {líq }} / \mathbf{A}_{\mathbf{b}} \\
(\mathbf{( \% )})\end{array}$ \\
\hline Média & 40066,0 & 16361,6 & 40,84 & 19359,4 & 11343,1 & 58,59 \\
\hline DP & 395,2 & 68,2 & 0,30 & 78,9 & 48,8 & 0,28 \\
\hline CV $(\%)$ & 0,99 & 0,42 & 0,74 & 0,41 & 0,43 & 0,48 \\
\hline
\end{tabular}

Para os blocos inteiros, a relação entre áreas líquida e bruta inferior a 75\% reafirma que tais unidades podem ser classificadas como vazadas.

\subsubsection{Propriedades geométricas: bloco e meio-bloco de concreto}

As ferramentas utilizadas para obter as propriedades geométricas das unidades de concreto são análogas às mencionadas no tópico anterior. Como os elementos de concreto possuem espessura variável ao longo da altura, diferentemente dos cerâmicos, é importante atentar ao que a norma especifica no instante da tomada de medidas. 
As dimensões efetivas foram determinadas na face com maior espessura de parede. A Tabela 3.4 apresenta os valores desta propriedade para blocos inteiros e meio-blocos, bem como as tolerâncias. Os resultados obtidos demonstram que há conformidade com os limites normativos. Aqui deve-se recordar que os blocos inteiros possuem largura nominal de $14 \mathrm{~cm}$ conquanto os meio-blocos têm largura nominal de $19 \mathrm{~cm}$.

Tabela 3.4 - Dimensões efetivas para blocos e meio-blocos de concreto

\begin{tabular}{|c|c|c|c|c|c|c|}
\hline & \multicolumn{3}{|c|}{ BLOCO INTEIRO } & \multicolumn{3}{|c|}{ MEIO-BLOCO } \\
\hline & $\begin{array}{c}\text { Largura } \\
(\mathrm{mm})\end{array}$ & $\begin{array}{c}\text { Altura } \\
(\mathbf{m m})\end{array}$ & $\begin{array}{c}\text { Comprimento } \\
(\mathrm{mm})\end{array}$ & $\begin{array}{c}\text { Largura } \\
(\mathrm{mm})\end{array}$ & $\begin{array}{c}\text { Altura } \\
(\mathbf{m m})\end{array}$ & $\begin{array}{c}\text { Comprimento } \\
(\mathrm{mm})\end{array}$ \\
\hline Média & 138,9 & 189,3 & 390,5 & 189,6 & 188,7 & 189,2 \\
\hline DP & 0,31 & 1,28 & 0,51 & 0,57 & 0,89 & 0,53 \\
\hline CV $(\%)$ & 0,22 & 0,68 & 0,13 & 0,30 & 0,47 & 0,28 \\
\hline \multicolumn{7}{|c|}{$\begin{array}{l}\text { Tolerâncias: } \\
\text { argura: } \pm 2,0 \mathrm{~mm} \\
\text { comprimento: } \pm 3,0 \mathrm{~mm} \\
\text { dia das determinações executadas) }\end{array}$} \\
\hline
\end{tabular}

As demais propriedades (espessura das paredes longitudinais e transversais, dimensão dos furos e raio de mísula) concernem apenas aos blocos inteiros. Assim como as dimensões efetivas, as dimensões dos furos e da mísula são aferidas na face de maior espessura do bloco. Em contrapartida, a espessura das paredes é medida na de menor espessura. Tais resultados, juntamente com os valores mínimos requeridos e suas tolerâncias, são exibidos na Tabela 3.5.

Tabela 3.5 - Espessura das paredes, dimensões dos furos e raio das mísulas para blocos inteiros de concreto

\begin{tabular}{|c|c|c|c|c|c|c|}
\hline \multirow[b]{2}{*}{ ID } & \multicolumn{3}{|c|}{ ESPESSURA } & \multicolumn{2}{|c|}{ DIMENSÕES DOS FUROS } & \multirow[b]{2}{*}{$\begin{array}{l}\text { RAIO DAS } \\
\text { MÍSULAS } \\
\quad(\mathbf{m m})\end{array}$} \\
\hline & $\begin{array}{c}\text { Paredes } \\
\text { longitudinais } \\
(\mathbf{m m})\end{array}$ & $\begin{array}{c}\text { Paredes } \\
\text { transversais } \\
(\mathbf{m m})\end{array}$ & $\begin{array}{c}\text { Transversal } \\
\text { equivalente } \\
(\mathbf{m m} / \mathbf{m})\end{array}$ & $\begin{array}{l}\text { Longitudinal } \\
\quad(\mathbf{m m})\end{array}$ & $\begin{array}{c}\text { Transversal } \\
(\mathbf{m m})\end{array}$ & \\
\hline $14.10-1$ & 26,0 & 25,3 & 194,4 & 147,5 & 76,5 & 43,0 \\
\hline $14.10-2$ & 26,0 & 24,3 & 187,3 & 148,5 & 78,0 & 43,5 \\
\hline $14.10-3$ & 25,8 & 25,0 & 191,8 & 146,5 & 76,0 & 42,8 \\
\hline $14.10-4$ & 26,0 & 25,3 & 194,5 & 148,0 & 77,5 & 43,3 \\
\hline $14.10-5$ & 25,6 & 25,2 & 193,4 & 148,0 & 77,5 & 43,5 \\
\hline $14.10-6$ & 25,8 & 24,7 & 189,6 & 149,0 & 77,0 & 43,0 \\
\hline Média & 25,9 & 25,0 & 191,8 & 147,9 & 77,1 & 43,2 \\
\hline DP & $\mathbf{0 , 1 7}$ & $\mathbf{0 , 4 0}$ & 2,9 & $\mathbf{0 , 8 6}$ & 0,74 & $\mathbf{0 , 3 0}$ \\
\hline CV (\%) & 0,64 & 1,60 & 1,51 & $\mathbf{0 , 5 8}$ & 0,95 & $\mathbf{0 , 7 0}$ \\
\hline
\end{tabular}

Espessura mínima das paredes longitudinais e transversais: $25 \mathrm{~mm}$, com tolerância de $-1,0 \mathrm{~mm}$ (para cada valor individual)

Espessura equivalente mínima das paredes transversais: $188 \mathrm{~mm} / \mathrm{m}$ Dimensão mínima do furo: $70 \mathrm{~mm}$

Raio mínimo das mísulas de acomodação: $40 \mathrm{~mm}$ (blocos classe A), expresso individualmente. 
A espessura transversal equivalente foi calculada somando as espessuras das três paredes transversais ao comprimento do bloco e dividindo este valor pelo seu comprimento efetivo. Apenas o bloco “14.10-2” não atendeu o respectivo valor mínimo de norma. As demais medidas obtidas indicam que os blocos inteiros atendem a todas as preconizações normativas no tocante à geometria.

Por fim, foram determinadas as áreas bruta e líquida das unidades com procedimento idêntico ao conduzido para as unidades cerâmicas. A Tabela 3.6 traz o resultado destas e a razão entre elas.

Tabela 3.6 - Área bruta e área líquida para blocos e meio-blocos de concreto

\begin{tabular}{|c|c|c|c|c|c|c|}
\hline & \multicolumn{3}{|c|}{ BLOCO INTEIRO } & \multicolumn{3}{|c|}{ MEIO-BLOCO } \\
\hline & $\begin{array}{c}\text { Área bruta } \\
\left(\mathbf{m m}^{2}\right)\end{array}$ & $\begin{array}{l}\text { Área líquida } \\
\left(\mathbf{m m}^{2}\right)\end{array}$ & $\begin{array}{c}\text { Aliq }_{\text {liq }} / \mathbf{A}_{\mathbf{b}} \\
(\%)\end{array}$ & $\begin{array}{c}\text { Área bruta } \\
\left(\mathbf{m m}^{2}\right)\end{array}$ & $\begin{array}{l}\text { Área líquida } \\
\left(\mathrm{mm}^{2}\right)\end{array}$ & $\begin{array}{c}A_{\text {liq }} / A_{t} \\
(\%)\end{array}$ \\
\hline Média & 54222,1 & 29156,0 & 53,77 & 35847,1 & 17933,7 & 50,03 \\
\hline DP & 170,6 & 344,0 & 0,62 & 175,5 & 37,5 & 0,34 \\
\hline CV (\%) & 0,31 & 1,18 & 1,14 & 0,49 & 0,21 & 0,68 \\
\hline
\end{tabular}

Assim como para o bloco inteiro cerâmico, a razão entre áreas líquida e bruta do bloco de concreto indica que o mesmo pode ser classificado como vazado.

\subsubsection{Propriedades mecânicas: bloco e meio-bloco cerâmico}

Os ensaios de compressão axial foram realizados em uma máquina servo-hidráulica Instron ${ }^{\circledR}$ com capacidade nominal de carga igual a $1500 \mathrm{kN}$, juntamente com o sistema de aquisição de dados System 5000 da Vishay Instruments ${ }^{\circledR}$. Na tentativa de mitigar a concentração de tensão nas faces das unidades (em virtude da presença de agregados superficiais), foi utilizado um capeamento com placas de forro mineral.

O carregamento foi aplicado através de controle de deslocamento a uma velocidade de $0,02 \mathrm{~mm} / \mathrm{s}$. De modo a obter deformações, fez-se uso de dois extensômetros do tipo clip-on com gauge length de $100 \mathrm{~mm}$, colados na parte externa e no centro dos vazios (em faces opostas) das unidades, de forma antissimétrica nos blocos inteiros e simétrica nos meio-blocos. A Figura 3.3 ajuda a compreender disposição dos clip-gauges. 
Figura 3.3 - Arranjo de extensômetros para ensaio de compressão (unidades cerâmicas)

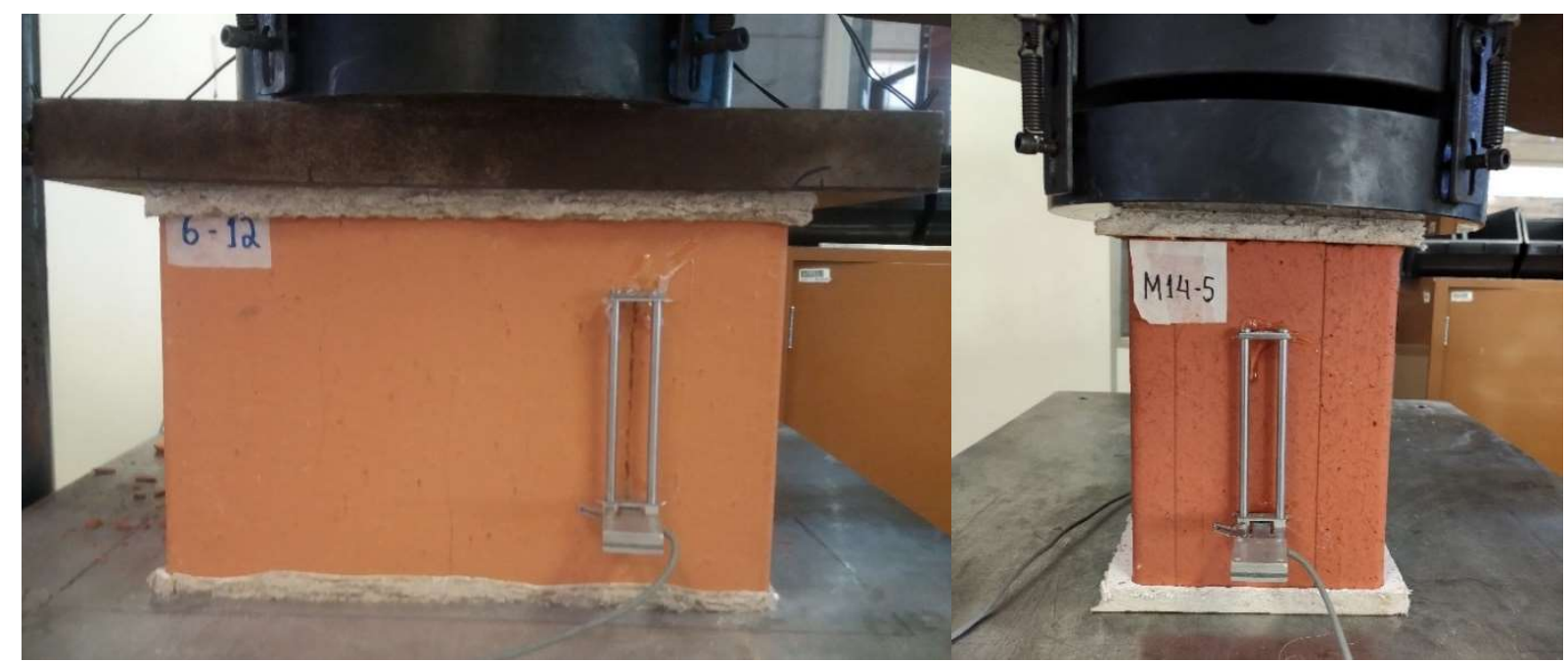

Fonte: Autor (2020)

Apesar de se ter empregado controle de deslocamento, não foi possível obter o ramo descendente da curva tensão versus deformação, uma vez que a ruptura das unidades se mostrou explosiva em grande parte dos casos. Assim, para preservar a integridade dos extensômetros, o ensaio era interrompido assim que a carga aplicada passava a se reduzir, o que acontecia à medida que surgiam as primeiras fissuras indicadoras da ruptura. Entretanto, esse fator não afeta negativamente os resultados, uma vez que os níveis de tensão e deformação recomendados por diferentes normas para o cálculo do módulo de elasticidade estático foram atendidos.

Para cada unidade ensaiada, foram obtidas duas relações entre tensão e deformação, uma para cada clip-gauge empregado. A Figura 3.4 apresenta as curvas obtidas através da média entre as duas relações para todos os blocos e meio-blocos da amostra. Um tratamento estatístico (Teste de Grubbs) foi realizado para identificar eventuais valores espúrios a serem descartados. No entanto, não foram encontrados indícios de tais valores nas amostras. 
Figura 3.4 - Curvas tensão-deformação das unidades cerâmicas: a) blocos; $b$ ) meio-blocos

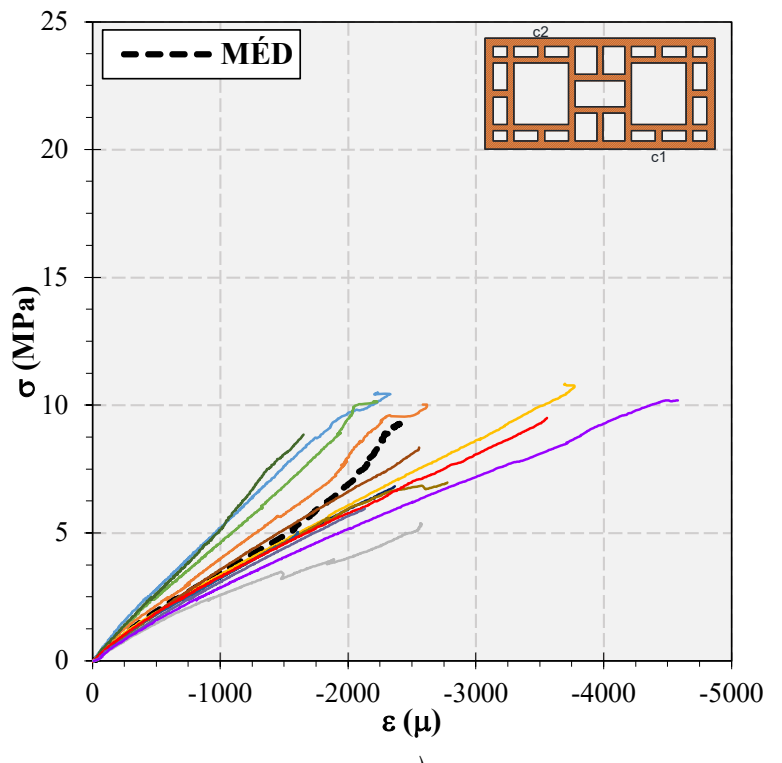

a)

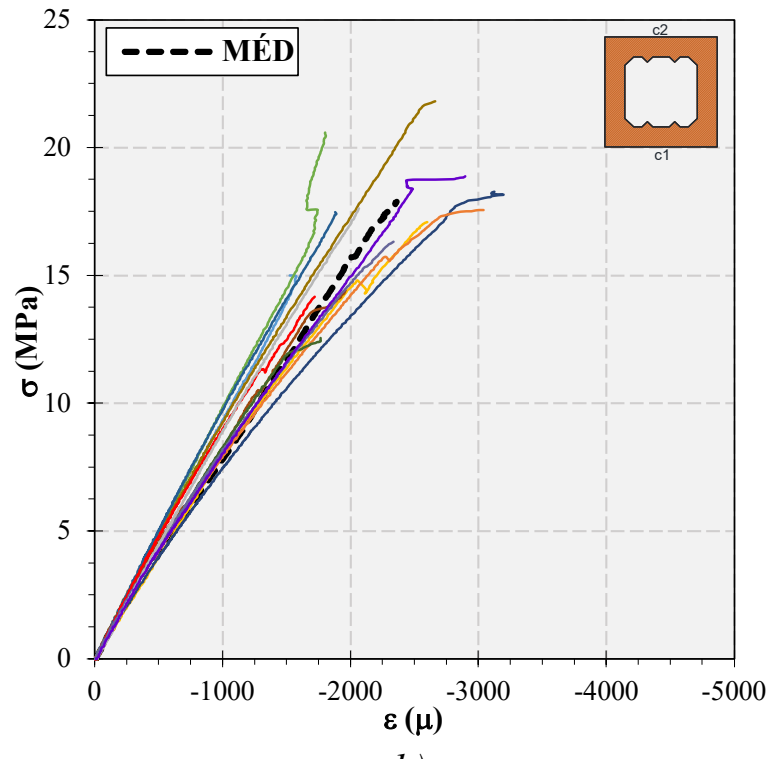

b)

Fonte: Autor (2020)

As Tabelas 3.7 e 3.8 exibem os valores médios de carga última, tensão na área bruta e módulo de elasticidade estático (calculado na área bruta) conforme especificação do código ACI 530-05, que estipula um módulo secante correspondente aos níveis de 5\% e 33\% da resistência à compressão. Também foi realizado o cálculo da resistência à compressão característica $\left(f_{b k}\right)$ destas unidades a partir dos valores de resistência individuais, resultando 5,33 MPa para o bloco inteiro e 14,39 MPa para o meio-bloco.

Tabela 3.7 - Resistência à compressão e módulo de elasticidade para blocos cerâmicos

\begin{tabular}{ccccc}
\hline & $\begin{array}{c}\text { Carga } \\
(\mathbf{k N})\end{array}$ & $\begin{array}{c}\text { Área bruta } \\
\left.\mathbf{( m m}^{2}\right)\end{array}$ & $\begin{array}{c}\text { Tensão na } \\
\text { área bruta } \\
(\mathbf{M P a})\end{array}$ & $\begin{array}{c}\text { Módulo de } \\
\text { elasticidade } \\
\text { estático } \\
\mathbf{( G P a )}\end{array}$ \\
\hline Média & 371,05 & 40066,0 & 9,27 & 3,64 \\
DP & 69,77 & 395,2 & 1,79 & 0,85 \\
CV (\%) & 18,80 & 0,99 & 19,32 & 23,33 \\
\hline
\end{tabular}

Tabela 3.8 - Resistência à compressão e módulo de elasticidade para meio-blocos cerâmicos

\begin{tabular}{ccccc}
\hline Cn & $\begin{array}{c}\text { Carga } \\
\mathbf{( k N )}\end{array}$ & $\begin{array}{c}\text { Área bruta } \\
\left(\mathbf{m m}^{2}\right)\end{array}$ & $\begin{array}{c}\text { Tensão na } \\
\text { área bruta } \\
(\mathbf{M P a})\end{array}$ & $\begin{array}{c}\text { Módulo de } \\
\text { elasticidade } \\
\text { estático } \\
\mathbf{( G P a )}\end{array}$ \\
\hline Média & 346,50 & 19359,4 & 17,90 & 8,80 \\
DP & 39,68 & 78,9 & 2,07 & 0,79 \\
$\mathbf{C V} \mathbf{( \% )}$ & 11,45 & 0,41 & 11,54 & 8,95 \\
\hline
\end{tabular}


3.1.4 Propriedades mecânicas: bloco e meio-bloco de concreto

Os equipamentos e procedimentos adotados para o ensaio de compressão axial das unidades de concreto foram idênticos aos descritos para as unidades cerâmicas: máquina de testes, sistema de aquisição, capeamento com forro de gesso, tipo e posicionamento dos extensômetros, tipo de controle do pistão e velocidade de carregamento. A Figura 3.5 retrata o arranjo experimental.

Figura 3.5 - Arranjo de extensômetros para ensaio de compressão (unidades de concreto)

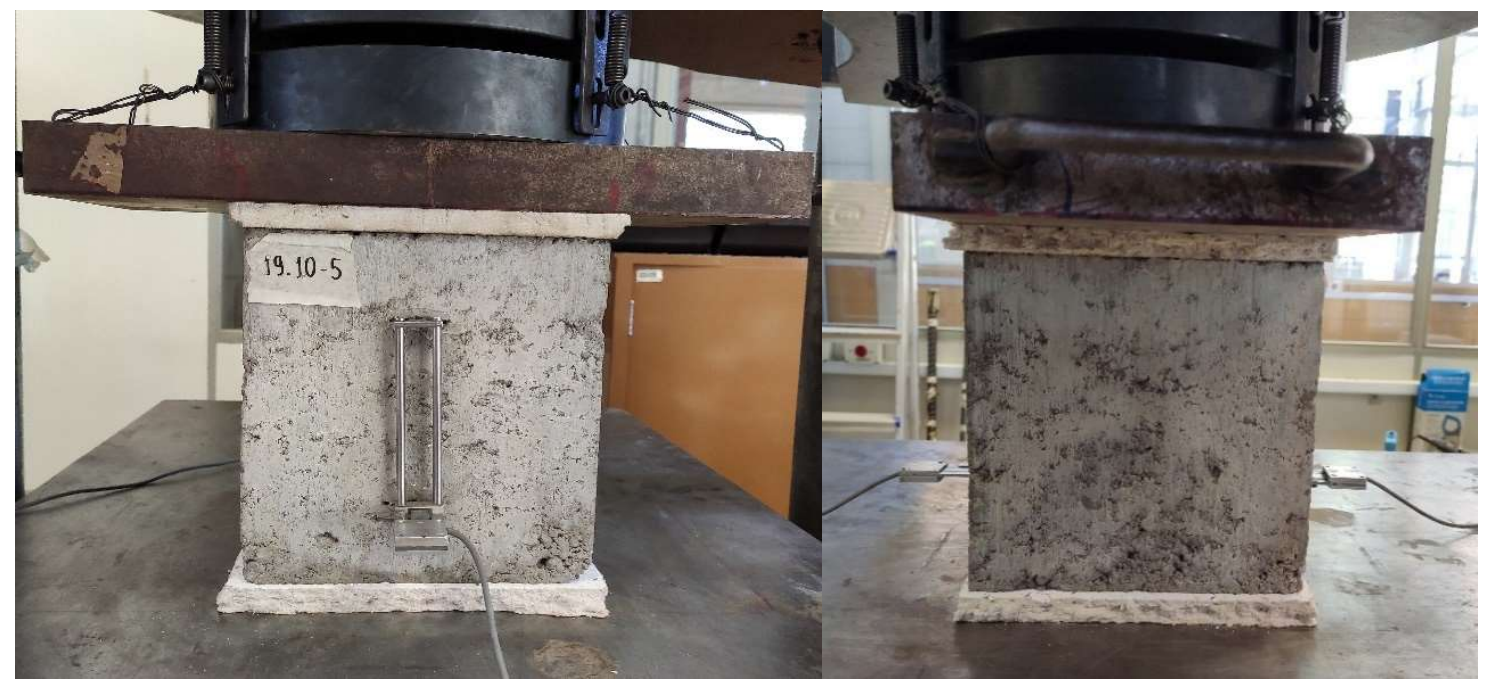

Fonte: Autor (2020)

Assim como nas unidades cerâmicas, a ruptura dos blocos e meio-blocos de concreto aconteceu de forma súbita e violenta. Assim, para evitar danos aos clip-ganges, tomou-se o mesmo cuidado mencionado anteriormente. Os históricos tensão versus deformação médios entre os dois extensômetros de cada unidade são relatados na Figura 3.6. Assim como nas unidades de material cerâmico, foi conduzido o teste de Grubbs para valores extremos, por meio do qual não foram identificados valores espúrios. 
Figura 3.6 - Curvas tensão-deformação das unidades de concreto: $a$ ) blocos; b) meio-blocos
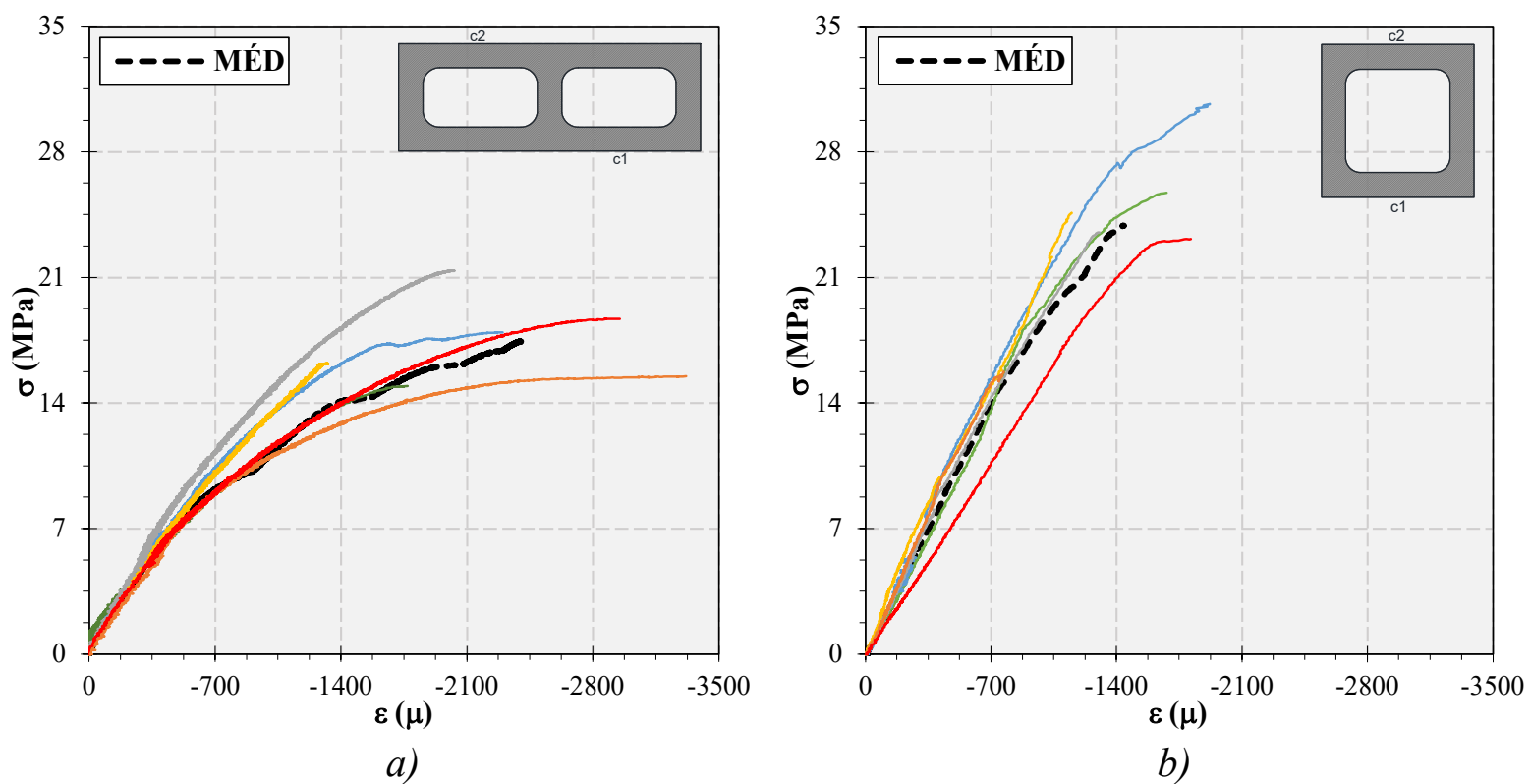

Fonte: Autor (2020)

Resultados médios de força última, tensão compressiva e módulo de elasticidade na área bruta (de acordo com o ACI 530-05) estão dispostos nas Tabelas 3.9 e 3.10. A resistência característica à compressão calculada para cada amostra indicou $f_{b k}=14,22 \mathrm{MPa}$ pra o bloco inteiro e $f_{b k}=15,39 \mathrm{MPa}$ para o meio-bloco.

Tabela 3.9 - Resistência à compressão e módulo de elasticidade para blocos de concreto

\begin{tabular}{ccccc}
\hline & $\begin{array}{c}\text { Carga } \\
\mathbf{( k N )}\end{array}$ & $\begin{array}{c}\text { Área bruta } \\
\left(\mathbf{m m}^{\mathbf{2}}\right)\end{array}$ & $\begin{array}{c}\text { Tensão na } \\
\text { área bruta } \\
\mathbf{( M P a )}\end{array}$ & $\begin{array}{c}\text { Módulo de } \\
\text { elasticidade } \\
\text { estático } \\
\mathbf{( G P a )}\end{array}$ \\
\hline Média & 946,29 & 54257,8 & 17,44 & 15,35 \\
DP & 131,43 & 121,8 & 2,40 & 1,13 \\
$\mathbf{C V}(\mathbf{\%})$ & 13,89 & 0,22 & 13,79 & 7,37 \\
\hline
\end{tabular}

Tabela 3.10 - Resistência à compressão e módulo de elasticidade para meio-blocos de concreto

\begin{tabular}{ccccc}
\hline$\square$ & $\begin{array}{c}\text { Carga } \\
(\mathbf{k N})\end{array}$ & $\begin{array}{c}\text { Área bruta } \\
\left.\mathbf{( m m}^{2}\right)\end{array}$ & $\begin{array}{c}\text { Tensão na } \\
\text { área bruta } \\
\mathbf{( M P a )}\end{array}$ & $\begin{array}{c}\text { Módulo de } \\
\text { elasticidade } \\
\text { estático } \\
\mathbf{( G P a )}\end{array}$ \\
\hline Média & 858,43 & 35910,3 & 23,90 & 21,26 \\
DP & 175,22 & 190,9 & 3,44 & 3,73 \\
$\mathbf{C V}(\%)$ & 20,41 & 0,53 & 20,24 & 17,55 \\
\hline
\end{tabular}




\subsection{Ensaio de ultrassom (VPU)}

Uma nova amostragem constituída por 3 unidades de cada tipo foi separada para aplicação dos métodos não destrutivos, sendo o primeiro deles o ensaio de ultrassom. A rotina experimental concebe a medição de pulsos ultrassônicos em diversos pontos do espécime através de transmissão direta (vide Figura 2.7a) avaliando a propagação de ondas longitudinais (primárias) e transversais (secundárias). Seguiu-se as instruções da ABNT NBR8802:2013 e ASTM C597-16 no que concerne à preparação das amostras e execução do ensaio.

Foram utilizados o equipamento Pundit $\mathrm{Lab}^{+}$e o software Pundit Link, que permite a visualização e armazenamento do pulso de onda, ambos da empresa Proceq ${ }^{\circledR}$. O equipamento apresenta resolução de $0,1 \mu$ s na determinação do tempo de percurso da onda e possui transdutores específicos para análise de ondas primárias e secundárias. Estes possuem frequências nominais de 54 e $250 \mathrm{kHz}$, respectivamente, e diâmetro de $4 \mathrm{~cm}$, aproximadamente. A aparelhagem Pundit $\mathrm{Lab}^{+}$é ilustrada na Figura 3.7.

Figura 3.7 - Equipamento para ensaios ultrassônicos Pundit Lab+

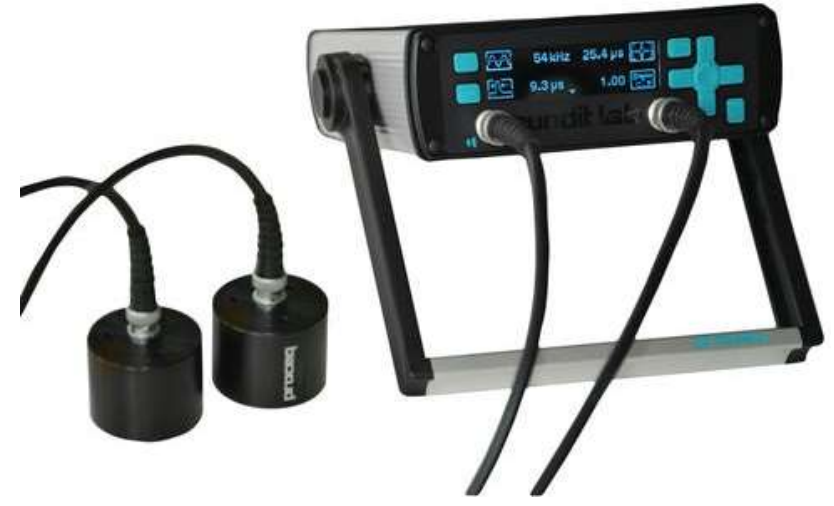

Fonte: http://www.directindustry.it/prod/proceq/product-7242-589132.html

O agente acoplante foi escolhido em função do tipo de onda: utilizou-se um gel à base d'água (similar ao aplicado medicinalmente) quando ondas longitudinais foram estudadas, enquanto a glucose de milho foi escolhida (em função de sua alta viscosidade e disponibilidade) para medições com objetivo de averiguar ondas transversais.

O aparelho registra o tempo que a primeira onda leva para completar o percurso em questão. Assim, por ser a mais veloz, a onda longitudinal tem seu tempo de chegada indicado automaticamente, podendo este ser adotado sem maiores ressalvas caso a medição seja realizada com transdutores próprios para esse tipo de onda. 
$\mathrm{Na}$ determinação do tempo de propagação da onda transversal, além do uso de transdutores e material acoplante adequados, é necessária uma análise da forma de onda observada no software do equipamento. Para tanto, lançou-se mão da ferramenta computacional desenvolvida por Schiavon (2015), que se baseia nos valores de amplitude da onda e suas derivadas em relação ao tempo para identificar possíveis tempos de chegada das ondas primárias e secundárias. A interface do programa é exibida na Figura 3.8, contendo dados de um pulso emitido com transdutor apropriado para ondas de cisalhamento.

Figura 3.8 - Interface utilizada na identificação do tempo de percurso da onda transversal

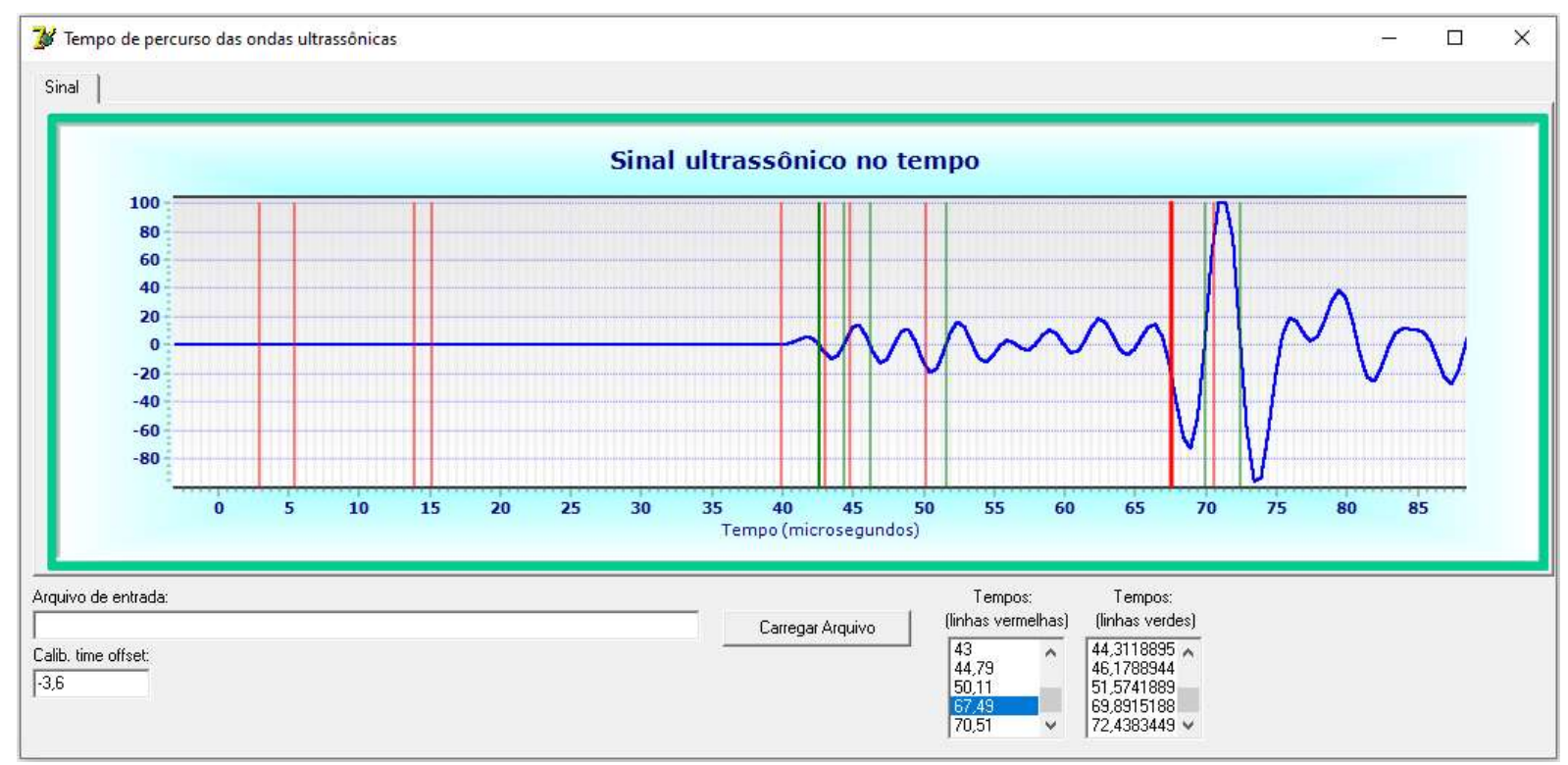

Fonte: Autor (2020)

Nota-se a presença de linhas verticais vermelhas e verdes. As primeiras são traçadas no instante de tempo no qual ocorre a primeira derivada ("amplitude em módulo"/tempo) não nula de um conjunto formado por pelo menos duas derivadas não nulas consecutivas. As demais representam instantes em que a amplitude do pulso cruza o eixo horizontal (ou seja, torna-se nula) pela primeira vez após uma reta vermelha. Selecionando um dos valores de tempo na parte inferior da interface, a linha correspondente (verde ou vermelha) é destacada.

As amplitudes mais baixas, que começam a surgir por volta de $40 \mu \mathrm{s}$, provém da onda longitudinal. A presença de onda transversal no sinal fica caracterizada por um aumento súbito de amplitude, resultando em um pico como o que ocorre em aproximadamente $71 \mu$ s na figura acima. Uma vez que o pico de amplitude já indica a existência da onda cisalhante, é necessário um critério para demarcar o instante de chegada (eco) da onda transversal com maior precisão. 
Ficou padronizada a escolha da linha vermelha anterior à linha verde contígua ao primeiro pico significativo de amplitude (próximo aos 100\%). No exemplo da Figura 3.8, a linha vermelha no instante $67,49 \mu$ s (destacada) seria tomada como provável tempo de chegada da primeira onda cisalhante.

Para obter uma forma de onda como a representada na figura anterior, com trechos de amplitude das ondas longitudinal e transversal bem definidos e sem picos fora de escala, as configurações dos transdutores (voltagem do emissor e ganho do receptor) devem ser ajustadas conforme o comprimento da medida e o material da unidade. Procurou-se seguir as instruções de operação do aparelho (PROCEQ $\left.{ }^{\circledR}, 2017\right)$ e as considerações feitas por Schiavon (2015) e Resende (2018) durante seus experimentos com ondas ultrassônicas. Especial atenção foi dada à orientação dos conectores dos cabos coaxiais, pois esta interfere no plano de polarização da onda transversal.

De modo a facilitar a tomada de medidas em diferentes posições, uma malha quadrada com aproximadamente $5 \mathrm{~cm}$ de lado (para comportar devidamente os transdutores) foi desenhada nas faces laterais externas da unidade em quatro camadas ao longo da altura, nas regiões onde há um trecho contínuo de material, isto é, septos transversais e longitudinais.. Além da malha auxiliar, foi adotado um sistema de pontos em faces opostas das unidades de modo a possibilitar uma notação para diferenciar as medidas realizadas: quando ao longo das dimensões da seção transversal (comprimento $-C$ e largura $-L$ ), uma notação do tipo "X-Y" é utilizada; para as medidas no sentido da altura $(H)$, a notação é do tipo "HX". A Figura 3.9 exemplifica a malha prevista para os blocos inteiros e alguns dos pontos considerados.

Figura 3.9 - Exemplos de malha auxiliar para o ensaio de ultrassom

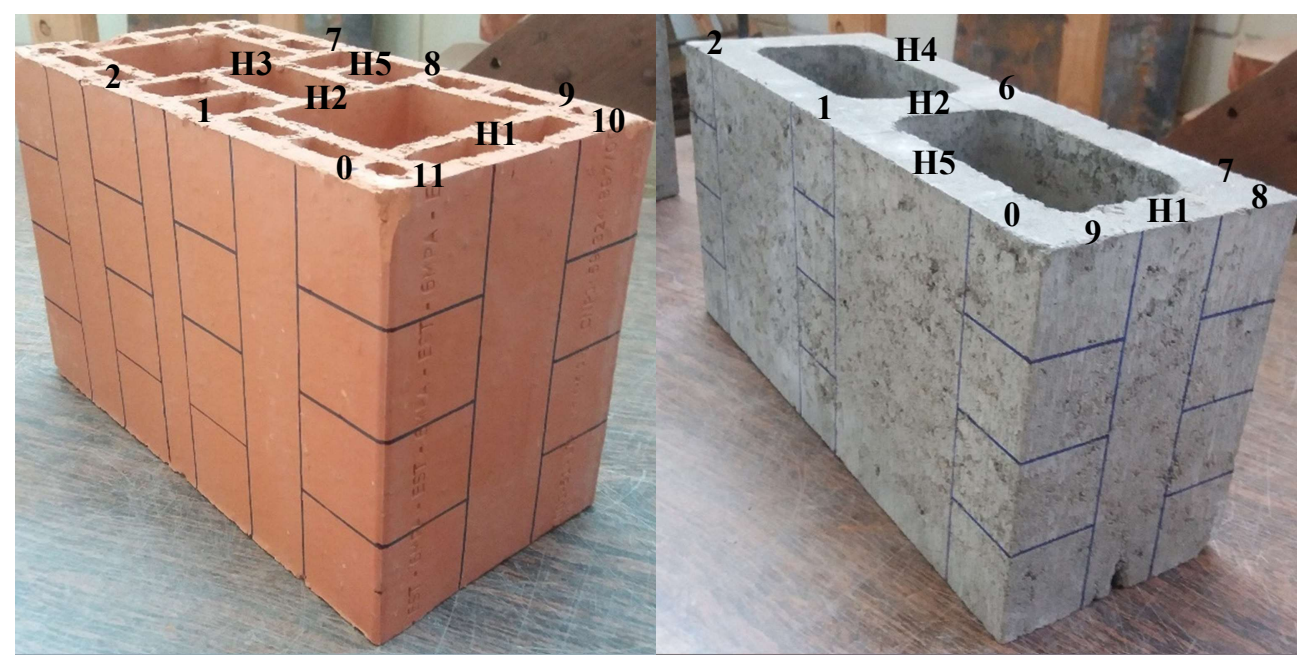

Fonte: Autor (2020) 
A seguir estão relatadas as dimensões efetivas, massa no instante do ensaio $(M)$, volume $(V)$ e densidade $(\rho)$ das unidades que compuseram a nova amostra experimental, além do sistema de pontos próprio de cada geometria. Valores médios obtidos para as velocidades de propagação das ondas longitudinais e transversais pelas três dimensões do espécime são apresentados no Capítulo 5 "Resultados e discussão". Tais velocidades foram consideradas para estimar propriedades elásticas dinâmicas do material de cada unidade (via Equações 2.1 a 2.3), sendo úteis para a modelagem desenvolvida no Capítulo 4 "Análise numérica".

\subsubsection{Bloco inteiro cerâmico}

Foram avaliados 4 trechos contínuos de material ao longo da largura e 2 trechos na direção da maior dimensão (comprimento). Considerou-se 6 medidas através da altura, em pontos que se situam entre as demais medidas na seção transversal. Assim, considerando as 4 camadas ao longo da altura (vide Figura 3.9), perfaz-se 30 posições de aferição. Como as faces superior e inferior do espécime são idênticas, a face lateral contendo inscrições do fabricante foi utilizada como referência, de modo a tornar consistente a comparação entre as camadas de diferentes unidades. A Tabela 3.11 aponta dados relativos às unidades ensaiadas e a Figura 3.10 ilustra o sistema de pontos adotado.

Tabela 3.11 - Dados da amostra de blocos inteiros cerâmicos para ensaios não destrutivos

\begin{tabular}{ccccccc}
\hline ID & $\begin{array}{c}\boldsymbol{C} \\
(\mathbf{m m})\end{array}$ & $\begin{array}{c}\boldsymbol{H} \\
\mathbf{( m m})\end{array}$ & $\begin{array}{c}\boldsymbol{H} \\
(\mathbf{m m})\end{array}$ & $\begin{array}{c}\boldsymbol{M} \\
\mathbf{( g )}\end{array}$ & $\begin{array}{c}\boldsymbol{V} \\
\left(\mathbf{c m}^{\mathbf{3}}\right)\end{array}$ & $\begin{array}{c}\boldsymbol{\rho} \\
\left(\mathbf{k g} / \mathbf{m}^{\mathbf{3}}\right)\end{array}$ \\
\hline 6-1(END) & 290,3 & 140,5 & 189,9 & 5855 & 3155,3 & 1855,6 \\
6-2(END) & 289,3 & 140,6 & 190,5 & 5895 & 3166,5 & 1861,7 \\
6-3(END) & 289,6 & 140,5 & 189,4 & 5878 & 3137,2 & 1873,6 \\
\hline
\end{tabular}

Figura 3.10 - Sistema de pontos: bloco inteiro cerâmico

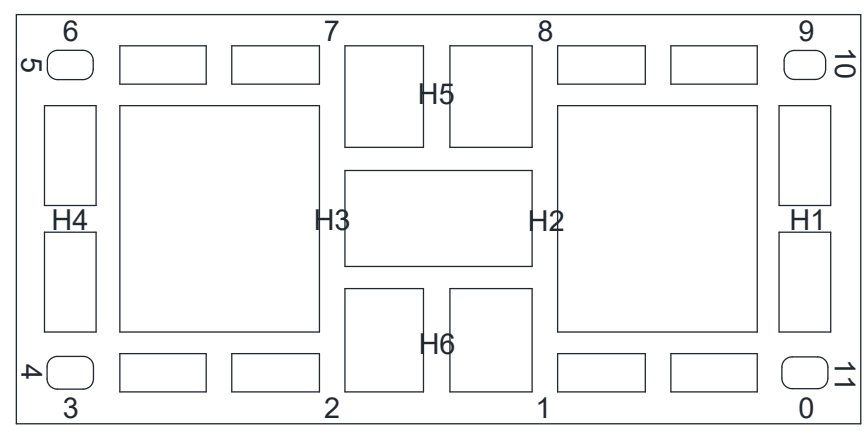

Fonte: Autor (2020) 


\subsubsection{Bloco inteiro de concreto}

O esquema de medições para o bloco de concreto foi baseado na disposição de seus septos transversais e longitudinais, resultando em 3 medições em sua largura e duas ao longo de seu comprimento. $\mathrm{Na}$ altura, 5 pontos ao redor dos vazios foram avaliados. Uma vez que esse tipo de unidade possui faces superior e inferior com espessuras distintas, é fundamental diferenciá-las: a camada 1 (inferior) corresponde à face de menor espessura, enquanto a camada 4 é adjacente à face de maior espessura. Desse modo, são totalizadas 25 posições de medida. As características das unidades submetidas ao ensaio são descritas na Tabela 3.12 e o sistema de pontos é exibido na Figura 3.11.

Tabela 3.12 - Dados da amostra de blocos inteiros de concreto para ensaios não destrutivos

\begin{tabular}{ccccccc}
\hline ID & $\begin{array}{c}\boldsymbol{L} \\
(\mathbf{m m})\end{array}$ & $\begin{array}{c}\boldsymbol{H} \\
\mathbf{( m m )}\end{array}$ & $\begin{array}{c}\boldsymbol{H} \\
(\mathbf{m m})\end{array}$ & $\begin{array}{c}\boldsymbol{V} \\
(\mathbf{g})\end{array}$ & $\begin{array}{c}\boldsymbol{\rho} \\
\left(\mathbf{c m}^{\mathbf{3}}\right)\end{array}$ & $\begin{array}{c}\boldsymbol{\rho} \\
\left(\mathbf{k g} / \mathbf{m}^{\mathbf{3}}\right)\end{array}$ \\
\hline $\mathbf{1 4 . 1 0 - 1 ( E N D )}$ & 390,3 & 138,9 & 190,6 & 12961 & 5524 & 2346,3 \\
$\mathbf{1 4 . 1 0 - 2 ( E N D )}$ & 389,9 & 138,8 & 189,9 & 12726 & 5527 & 2302,5 \\
$\mathbf{1 4 . 1 0 - 3 ( E N D )}$ & 389,9 & 138,9 & 191,0 & 12854 & 5570 & 2307,7 \\
\hline
\end{tabular}

Figura 3.11 - Sistema de pontos: bloco inteiro de concreto

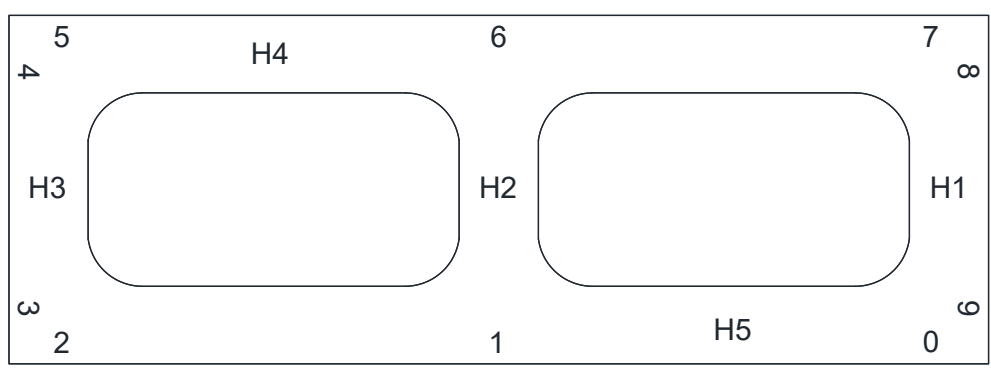

Fonte: Autor (2020)

\subsubsection{Meio-bloco cerâmico}

Para essa geometria, duas medições na largura e no comprimento são suficientes para examinar as quatro paredes da unidade nas dimensões de sua seção transversal. Por consequência, 4 medidas foram tomadas considerando a altura do meio-bloco como percurso, uma em cada parede. Como a malha auxiliar dos meio-blocos também possui 4 camadas dispostas ao longo da altura, um total de 20 pontos de mensuração compõe a rotina de ensaio deste espécime, como sugere a Figura 3.12. Os dados de geometria e propriedades físicas angariados para a amostra são expostos na Tabela 3.13 . 
Tabela 3.13 - Dados da amostra de meio-blocos cerâmicos para ensaios não destrutivos

\begin{tabular}{ccccccc}
\hline ID & $\begin{array}{c}\boldsymbol{C} \\
(\mathbf{m m})\end{array}$ & $\begin{array}{c}\boldsymbol{L} \\
\mathbf{( m m})\end{array}$ & $\begin{array}{c}\boldsymbol{H} \\
\mathbf{( m m})\end{array}$ & $\begin{array}{c}\boldsymbol{M} \\
\mathbf{( g )}\end{array}$ & $\begin{array}{c}\boldsymbol{V} \\
\left(\mathbf{c m}^{3}\right)\end{array}$ & $\begin{array}{c}\boldsymbol{\rho} \\
\left(\mathbf{k g} / \mathbf{m}^{3}\right)\end{array}$ \\
\hline M14-1(END) & 140,3 & 137,3 & 188,0 & 4111,8 & 2128,5 & 1931,8 \\
M14-2(END) & 140,8 & 138,3 & 189,8 & 4242,4 & 2174,8 & 1950,7 \\
M14-3(END) & 140,5 & 137,3 & 188,3 & 4155,8 & 2134,0 & 1947,4 \\
\hline
\end{tabular}

Figura 3.12 - Sistema de pontos: meio-bloco cerâmico

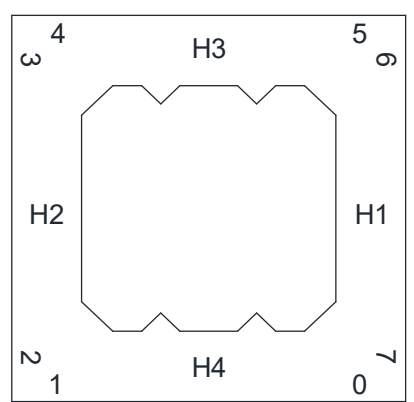

Fonte: Autor (2020)

3.2.4 Meio-bloco de concreto

A quantidade (20) e a disposição dos pontos de medição para o meio-bloco de concreto são idênticas às descritas para o meio-bloco cerâmico. Dados colhidos para a amostra constam na Tabela 3.14 e o esquema de pontos inerente da geometria é mostrado na Figura 3.13.

Tabela 3.14 - Dados da amostra de meio-blocos cerâmicos para ensaios não destrutivos

\begin{tabular}{ccccccc}
\hline ID & $\begin{array}{c}\boldsymbol{C} \\
(\mathbf{m m})\end{array}$ & $\begin{array}{c}\boldsymbol{L} \\
(\mathbf{m m})\end{array}$ & $\begin{array}{c}\boldsymbol{H} \\
(\mathbf{m m})\end{array}$ & $\begin{array}{c}\boldsymbol{M} \\
\mathbf{( g )}\end{array}$ & $\begin{array}{c}\boldsymbol{V} \\
\left(\mathbf{c m}^{\mathbf{3}}\right)\end{array}$ & $\begin{array}{c}\boldsymbol{\rho} \\
\left(\mathbf{k g} / \mathbf{m}^{\mathbf{3}}\right)\end{array}$ \\
\hline $\mathbf{1 9 . 1 0 - 1 ( E N D )}$ & 188,5 & 190,0 & 188,0 & 8220 & 3377,0 & 2434,1 \\
$\mathbf{1 9 . 1 0 - 2 ( E N D )}$ & 190,2 & 191,0 & 189,5 & 8357 & 3436,0 & 2432,2 \\
$\mathbf{1 9 . 1 0 - 3 ( E N D )}$ & 189,7 & 190,3 & 188,0 & 8166 & 3380,0 & 2416,0 \\
\hline
\end{tabular}

Figura 3.13 - Sistema de pontos: meio-bloco de concreto

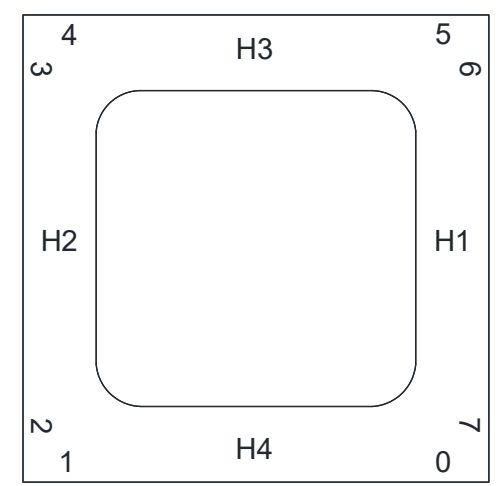

Fonte: Autor (2020) 


\subsection{Ensaio de ressonância acústica}

A obtenção das frequências naturais das unidades (as mesmas previamente submetidas ao ensaio de VPU) se deu por meio da técnica de excitação por impulso em conjunto com a

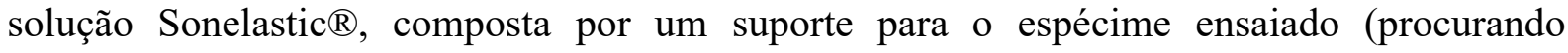
reproduzir a condição de vibração livre), acessórios (excitador, microfone e pulsador eletromagnético) e um programa computacional responsável pelo processamento de dados. $\mathrm{O}$ conjunto descrito é mostrado na Figura 3.14.

Figura 3.14 - Solução Sonelastic $\AA$ para ensaio de ressonância acústica

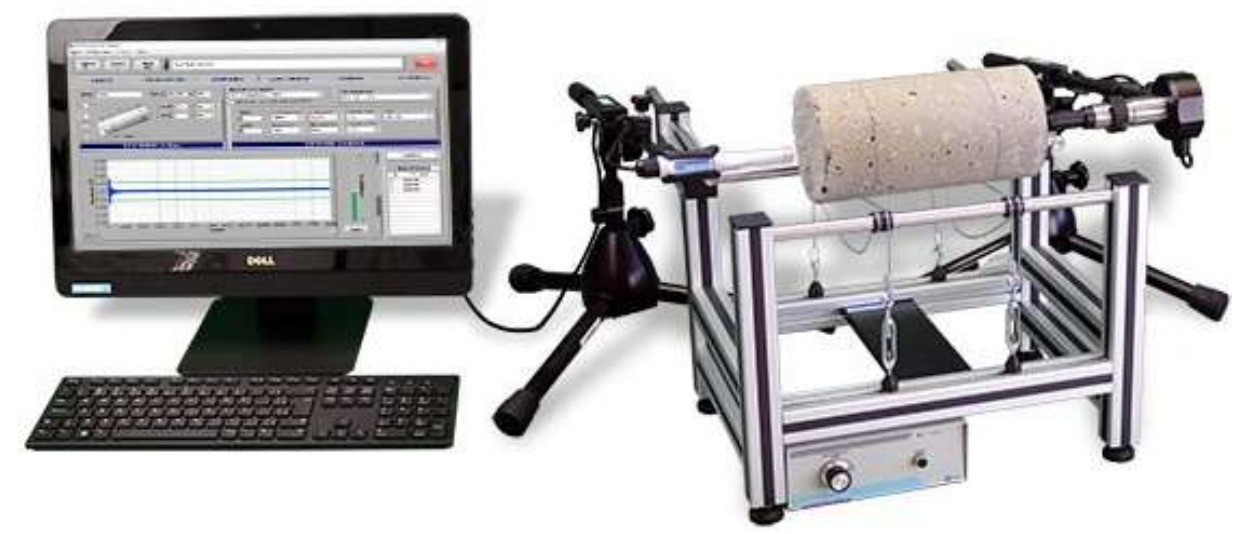

Fonte: https://www.sonelastic.com/pt/productos/sistemas/sonelastic-medio-porte.html\#

A excitação das amostras se deu pelo dispositivo usual, que consiste em uma esfera de aço (diâmetro de aproximadamente $1 \mathrm{~cm}$ ) presa a uma haste de material polimérico. Em virtude da massa e dimensão das unidades de alvenaria, passíveis de danificar o suporte e dificultar sua operação, um aparato alternativo foi montado para suspender os blocos e meio-blocos, sendo composto por um perfil metálico (apoiado nas extremidades) e linhas de poliamida com espessura de 0,45 mm e capacidade de 9,8 kg na tração. Esse arranjo (exibido na Figura 3.15) também reproduz a condição de apoio do tipo livre, uma vez que a rigidez da linha é inferior à dos cabos de apoio que compõem o suporte padrão. 
Figura 3.15 - Aparato para execução do ensaio de ressonância acústica

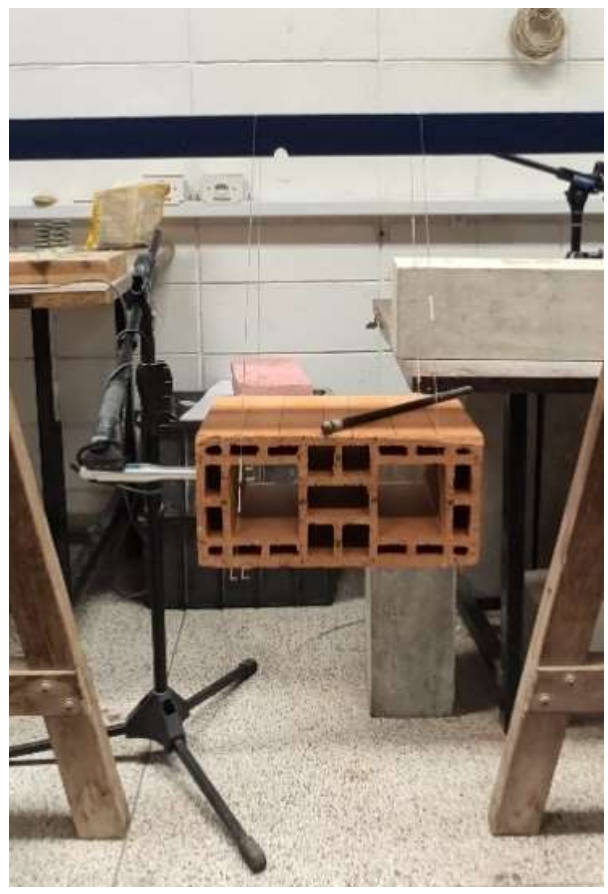

Fonte: Autor (2020)

Diferentes pontos de excitação e captação do som, além de repetições para confirmar os espectros amplitude versus frequência obtidos para cada caso testado, compõem a rotina de ensaio. Um total de seis combinações de impacto/captação foram definidas baseando-se nos arranjos prescritos pela ASTM E1876-15 para obtenção dos três modos fundamentais (flexional, torcional e longitudinal, vide Figura 2.4) e na observação das amplitudes de deslocamento nos dez primeiros modos de vibração obtidos via análise modal numérica (conforme será tratado no Capítulo 4 "Análise numérica") para cada tipo de unidade presente na amostra experimental. Essa constatação é explicada na forma de um exemplo pela Figura 3.16, que também introduz a legenda para diferenciar pontos de impacto e de captação. 
Figura 3.16 - Exemplo de configuração de ensaio baseada em análise modal numérica
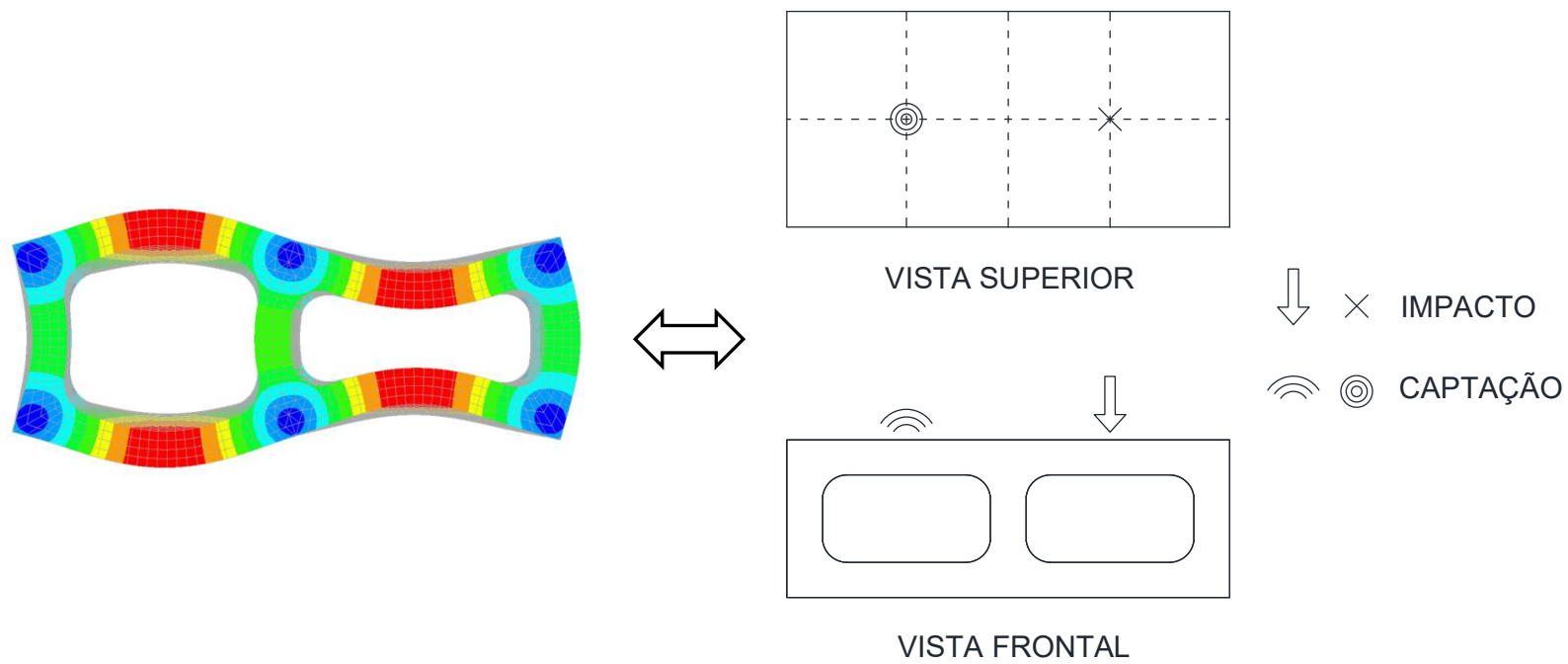

Fonte: Autor (2020)

No modelo numérico, a cor vermelha indica regiões com amplitudes máximas de deslocamento, ao passo que trechos com amplitudes nulas são designados em azul escuro. Desse modo, para facilitar a obtenção experimental da frequência ressonante do modo representado, deve-se promover o impacto e a captação nas regiões em vermelho. Caso a excitação do espécime fosse feita em um dos pontos em azul, tal modo não seria induzido.

As combinações escolhidas foram padronizadas, adequando-se para cada geometria em função da posição dos septos e vazios, sendo cada uma delas executada três vezes por amostra. Um caso de mesma configuração para bloco e meio-bloco é mostrado na Figura 3.17.

Figura 3.17 - Exemplo de uma mesma configuração de ensaio para bloco e meio-bloco
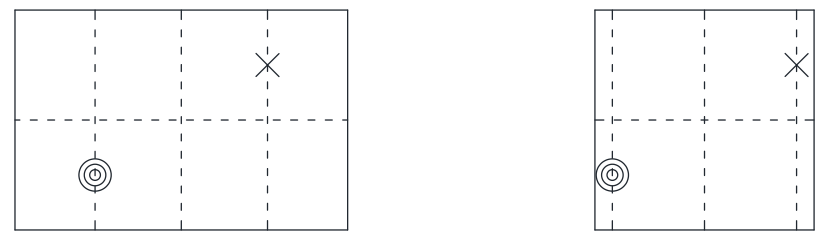

VISTA SUPERIOR

$\sqrt{3} \times$ IMPACTO
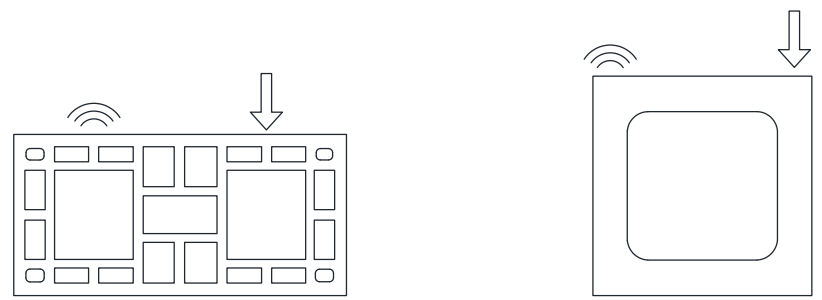

乞 (0) CAPTAÇÃO

VISTA FRONTAL

Fonte: Autor (2020) 
O mapeamento dos locais de excitação e captação sonora é elucidado na Figura 3.18 para bloco inteiro e meio-bloco cerâmicos, sendo análogo para as unidades de concreto.

Figura 3.18 - Combinações impacto/captação: a) bloco inteiro; b) meio-bloco

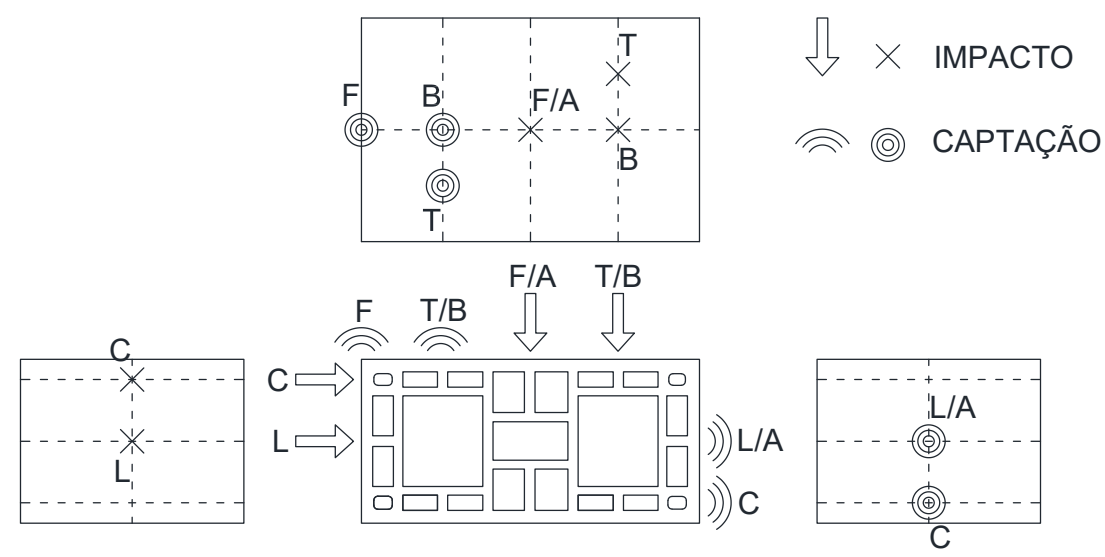

a)

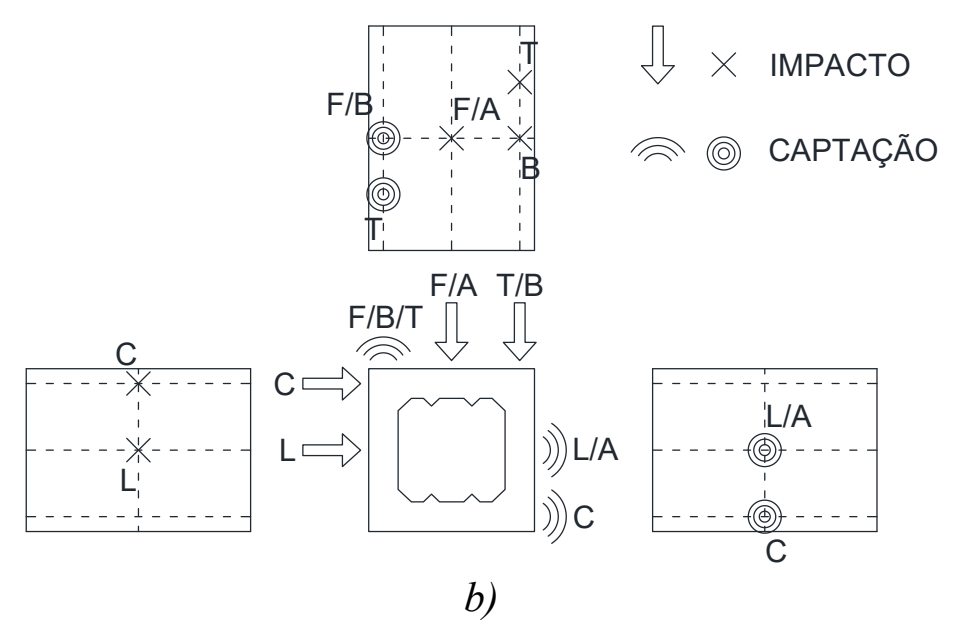

Fonte: Autor (2020)

Definiu-se a nomenclatura de cada configuração da seguinte maneira:

F: associa-se à incitação do modo fundamental de flexão (no plano da seção transversal);

T: objetiva induzir o modo fundamental de torção do espécime;

L: busca excitar o $1^{\circ}$ modo longitudinal (vibração ao longo da maior dimensão);

A: configuração alternativa mista - impacto de "F" com captação de "L";

B: configuração alternativa baseada em simulação numérica e semelhante à " $T$ ";

C: configuração alternativa baseada em simulação numérica e semelhante à " $L$ ". 
Para garantir a coleta acurada das frequências ressonantes, foi dedicada atenção aos parâmetros do programa (a sensibilidade do microfone, o filtro da detecção de frequências e os tempos de aquisição e de processamento do sinal), pois estes detêm influência expressiva na quantidade e no valor das frequências identificadas.

Foram seguidas as recomendações para materiais cerâmicos e de baixo amortecimento (caso do concreto), que dizem respeito aos tempos de aquisição e de processamento do sinal adequados para evitar o "alargamento" dos picos de ressonância e a consequente perda de resolução na determinação das frequências (ATCP ENGENHARIA FÍSICA, 2015).

Os demais parâmetros (sensibilidade e filtro da detecção) foram ajustados a partir de testes prévios realizados no ambiente de ensaio e das faixas de frequência estimadas pela análise numérica (abordada no Capítulo 4). O Quadro 3.2 resume a configuração adotada.

Quadro 3.2 - Parâmetros do software Sonelastic ${ }^{\circledR}$ utilizados no ensaio

\begin{tabular}{|c|c|c|c|}
\hline Tempo de aquisição & Tempo de processamento & Sensibilidade & Filtro da detecção \\
\hline $0,683 \mathrm{~s}$ & Posição 5 & 0,025 & Padrão $[0,5 \mathrm{kHz}-20 \mathrm{kHz}]$ \\
\hline
\end{tabular}

Fonte: Autor (2020)

O tempo de aquisição controla a extensão do espectro, enquanto o tempo de processamento governa a quantidade de pontos em que a FFT é calculada. As configurações adotadas correspondem a um espectro de frequências até $48 \mathrm{kHz}$ dispostas em 4096 pares ordenados (frequência/amplitude). O programa permite exportar tais dados em formato .txt. 


\subsection{Síntese do capítulo}

O capítulo teve como enfoque os materiais utilizados e métodos propostos para execução da campanha experimental da pesquisa.

$\mathrm{Na}$ seção de caracterização das unidades, valores médios de aspectos geométricos (dimensões efetivas, área bruta e líquida) e propriedades mecânicas (resistência à compressão e módulo de elasticidade) foram relatados, permitindo julgar a conformidade dos blocos e meioblocos quanto aos limites e tolerâncias normativas.

Quanto ao ensaio de ultrassom, procurou-se esclarecer o mapeamento das medições realizadas nas diferentes geometrias e detalhar o procedimento para obtenção do tempo de propagação das ondas transversais, considerada tarefa não intuitiva. Através das velocidades calculadas, advieram estimativas das propriedades elásticas dinâmicas do material de cada espécime, aproveitadas na análise numérica.

No que se refere ao ensaio de ressonância acústica, foram tratados detalhes do arranjo experimental preparado, da idealização das combinações impacto/captação para induzir diferentes modos de vibrar e das configurações do software Sonelastic $₫$ adotadas em busca de uma aferição precisa das frequências ressonantes. 


\section{ANÁLISE NUMÉRICA}

O procedimento de modelagem numérica pode ser dividido em três etapas: préprocessamento, processamento e pós-processamento. A primeira compreende a definição do modelo (descrição da geometria, atribuição de propriedades dos materiais e a especificação de condições de contorno e carregamento). A segunda refere-se ao tipo de análise a ser executada (linear, não linear física e/ou geométrica, térmica, dinâmica, entre outras) e às técnicas utilizadas para solução matemática do problema físico em questão. A última consiste na visualização e interpretação de resultados (gradiente de deslocamentos, distribuição de tensões e deformações, panorama de fissuração etc.) a depender da análise desenvolvida.

Para a pesquisa, tem-se intuito de conduzir análise modal admitindo vibração livre dos blocos inteiros e meio-blocos da amostra experimental. Portanto, os modelos numéricos não contemplam a incidência de ações externas e restrições de deslocamento. Trata-se de um problema de autovetores e autovalores resolvido admitindo comportamento linear-elástico do material, fornecendo os modos de vibrar e as frequências naturais vinculadas.

Dadas as condições de resolução e o pequeno porte das estruturas exploradas, a análise modal computacional torna-se relativamente pouco onerosa em termos de processamento, permitindo a modelagem com fidelidade à geometria sem acarretar dispêndio excessivo de tempo. Assim, as unidades de alvenaria podem ser representadas tridimensionalmente e com especial atenção aos aspectos de sua conformação, como a espessura variável das paredes ao longo da altura e a presença de mísulas de acomodação, no caso dos blocos de concreto, e os septos individuais, no caso dos blocos inteiros cerâmicos.

A simulação numérica proposta foi desenvolvida com auxílio do software DIANA ${ }^{\circledR}$ (acrônimo para DIsplacement ANAlyzer) versão 9.6, um robusto pacote de elementos finitos dedicado especialmente à solução de problemas de engenharia civil. O programa dispõe de uma vasta quantidade de modelos constitutivos para materiais e diferentes categorias de elementos finitos, bem como variados procedimentos de análise e metodologias de solução (solvers). $\mathrm{O}$ DIANA ${ }^{\circledR}$ contém pré e pós processadores próprios, mas pode ser vinculado a outros programas de modelagem em ambiente CAD (Computer Aided Design). 


\subsection{Definição dos modelos}

4.1.1 Geometria e propriedades do material

Apenas um modelo numérico foi elaborado para representar a amostra de cada bloco e meio-bloco. Suas dimensões ficaram definidas a partir da análise dimensional conduzida durante a etapa de caracterização geométrica. Além das dimensões efetivas médias coletadas, foram realizadas medições extras para representar com maior precisão as características específicas de cada geometria: espessuras dos septos individuais em blocos inteiros cerâmicos; os "dentes" anexos às paredes e os chanfros no furo dos meio-blocos cerâmicos; e a curvatura no canto dos furos e a distinção de espessura das faces nas unidades de concreto. As Figuras 4.1 a 4.4 apresentam as dimensões consideradas para cada exemplar.

Figura 4.1 - Dimensões do modelo de bloco inteiro cerâmico (milímetros)
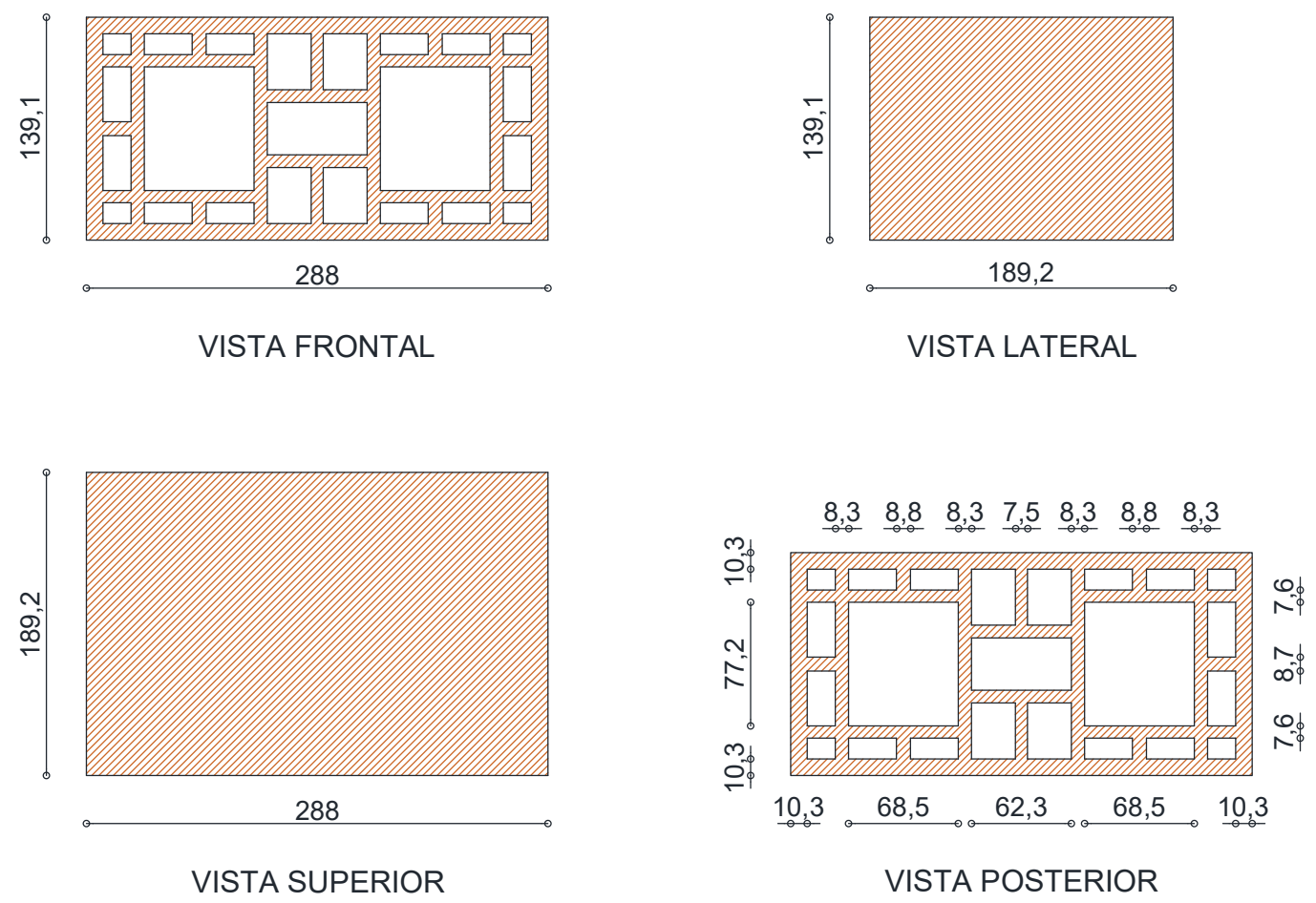

Fonte: Autor (2020) 
Figura 4.2 - Dimensões do modelo de meio-bloco cerâmico (milímetros)
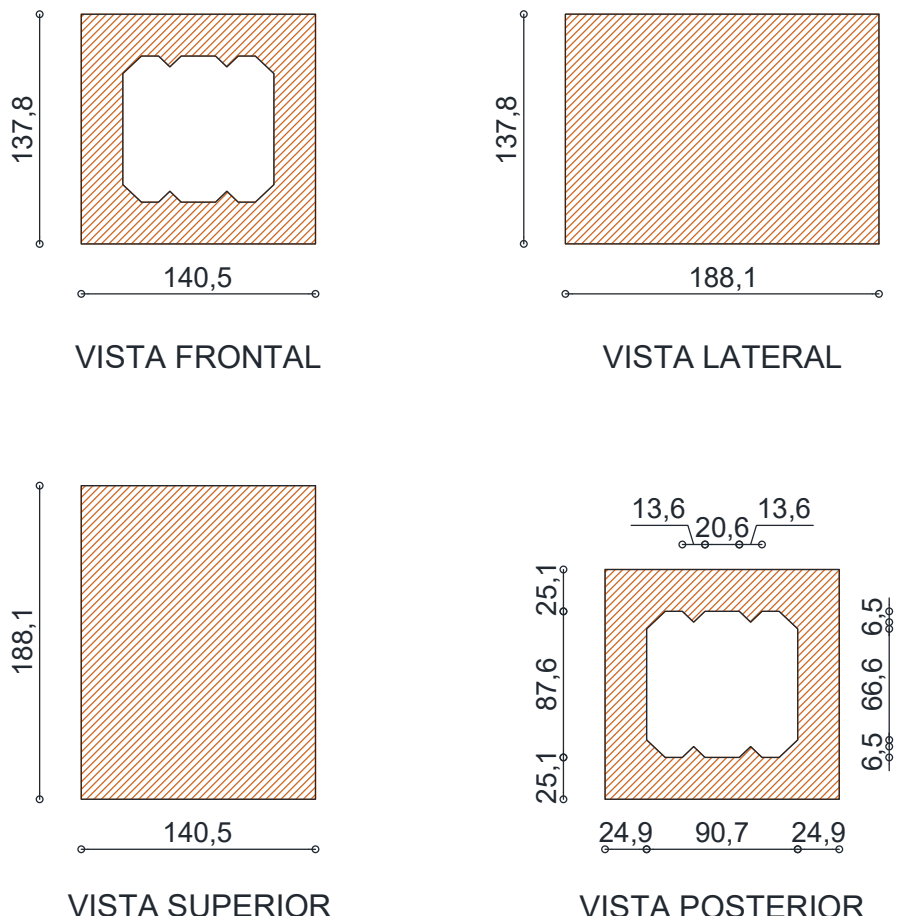

Fonte: Autor (2020)

Figura 4.3 - Dimensões do modelo de bloco inteiro de concreto (milímetros)
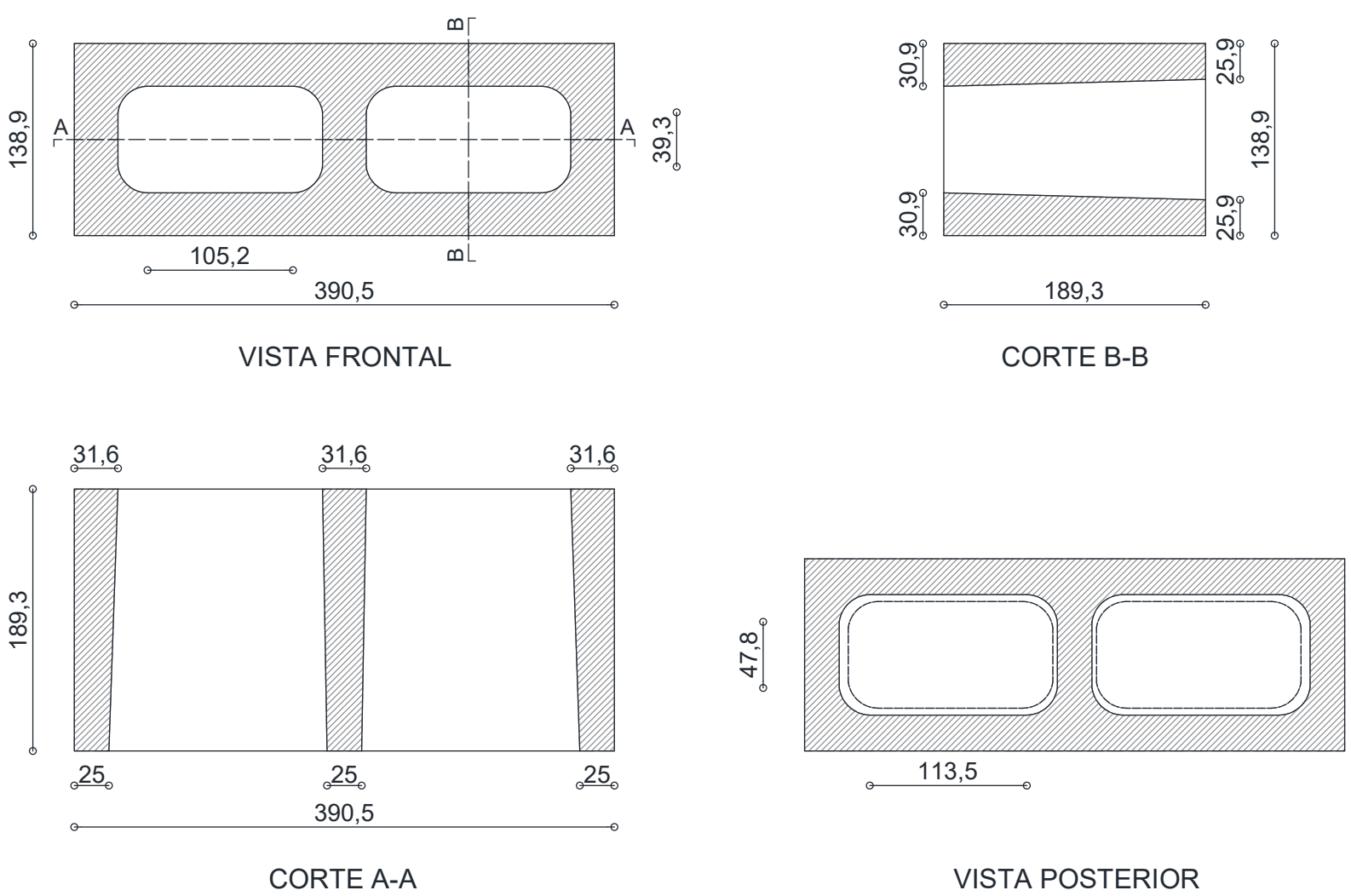

Fonte: Autor (2020)

\section{VISTA POSTERIOR}


Figura 4.4 - Dimensões do modelo de meio-bloco de concreto (milímetros)
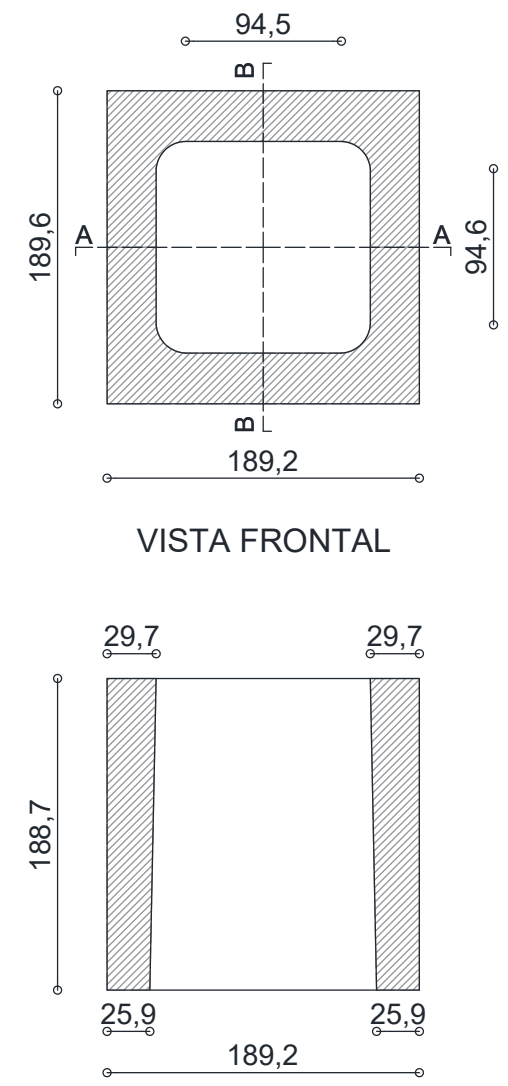

CORTE A-A

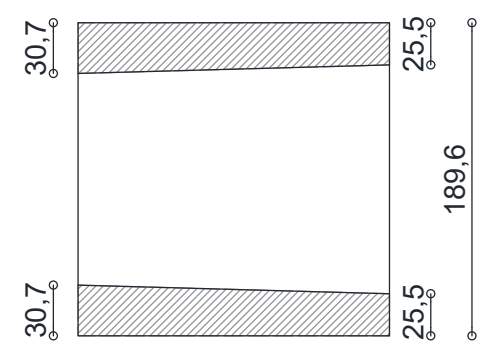

188,7

CORTE B-B

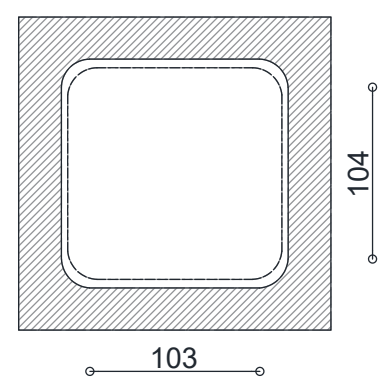

VISTA POSTERIOR

Fonte: Autor (2020)

Entende-se que o erro instaurado pela adoção de uma geometria típica para todo o lote é tolerável, uma vez que a variação dimensional observada nas unidades caracterizadas foi inferior a $1 \%$. Tais geometrias foram lançadas junto ao iDIANA, pré-processador nativo do software utilizado. O programa é apto a ler scripts de extensão ".txt” contendo os comandos necessários para gerar as formas pretendidas, desde pontos e linhas a superfícies e corpos.

Para a análise em questão, é necessário fornecer o módulo de elasticidade (assumindo isotropia), o coeficiente de Poisson e a densidade do material. Por conseguinte, propriedades elásticas dinâmicas providas pelas velocidades de propagação de ondas no ensaio de ultrassom ( $E$ e $v$, expostos no Capítulo 5 "Resultados e discussão") e as densidades das unidades ensaiadas foram utilizadas para alimentar os modelos numéricos, visando obter estimativas já ajustadas para as frequências ressonantes.

Como há somente um modelo representativo para cada espécie de bloco, considerou-se os valores médios de cada amostra (três unidades). A Tabela 4.1 resume os parâmetros selecionados para a simulação, além de apresentar a nomenclatura doravante utilizada para se referir a cada modelo numérico. 
Tabela 4.1 - Modelagem numérica: propriedades dos materiais constituintes

\begin{tabular}{cccc}
\hline $\begin{array}{c}\text { UNIDADE } \\
\text { (nomenclatura do modelo) }\end{array}$ & $\begin{array}{c}\boldsymbol{E} \\
\mathbf{( G P a )}\end{array}$ & $\boldsymbol{v}$ & $\begin{array}{c}\boldsymbol{\rho} \\
\left.\mathbf{( k g} / \mathbf{m}^{3}\right)\end{array}$ \\
\hline $\begin{array}{c}\text { Bloco inteiro cerâmico } \\
\text { (BICE) }\end{array}$ & 8,51 & 0,17 & 1863,6 \\
$\begin{array}{c}\text { Meio-bloco cerâmico } \\
\text { (MBCE) }\end{array}$ & 15,00 & 0,17 & 1943,3 \\
$\begin{array}{c}\text { Bloco inteiro de concreto } \\
\text { (BICO) }\end{array}$ & 38,24 & 0,23 & 2318,8 \\
$\begin{array}{c}\text { Meio-bloco de concreto } \\
\text { (MBCO) }\end{array}$ & 47,05 & 0,24 & 2427,4 \\
\hline
\end{tabular}

4.1.2 Malha de elementos finitos e análise de convergência

A concepção da malha de elementos finitos dos protótipos numéricos ficou condicionada ao seu desempenho nos testes de qualidade do DIANA ${ }^{\circledR}$, verificando a eventual existência de elementos desconformes quanto a alongamento (razão menor dimensão/maior dimensão), distorção (ângulos máximo e mínimo entre arestas), empenamento (grau de coplanaridade dos nós), entre outros critérios. A função dos testes é avaliar se os elementos variam significativamente do idealizado pelas formulações teóricas, podendo introduzir erros expressivos no resultado esperado.

Destarte, cada modelo teve sua geometria particionada (sempre que possível) em regiões retangulares, possibilitando a geração de malhas com o máximo de elementos quadrados regulares. Nas etapas de refinamento, buscou-se equalizar a densidade da malha nas três dimensões do modelo, com exceção do modelo "BICE", onde a quantidade de divisões ao longo da altura foi fixada em 20 .

Foram utilizados elementos sólidos isoparamétricos com três graus de liberdade (translação nas três direções ortogonais) por nó. Antecipando a necessidade de estudo de convergência para determinar as malhas definitivas, admitiu-se aproximação linear e quadrática para os deslocamentos. Foi dada preferência aos elementos hexaédricos HX24L (oito nós, interpolação linear) e CHX60 (20 nós, interpolação quadrática) de faces retangulares (brick). A Figura 4.5 retrata os elementos finitos aludidos, ao passo que a Figura 4.6 ilustra os modelos discretizados em sua totalidade por estes. 
Figura 4.5 - Elementos finitos hexaédricos: a) HX24L; b) CHX60

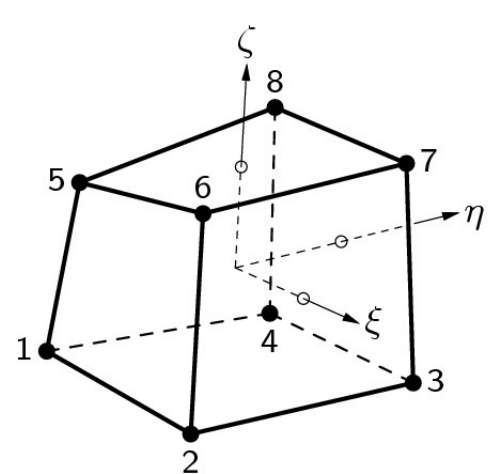

a)

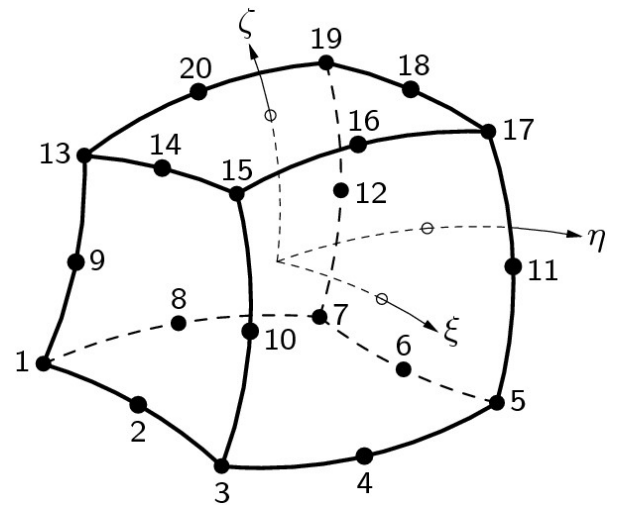

b)

Fonte: DIANA (2016)

Figura 4.6 - Discretizações: a) modelo "BICE"; b) modelo "MBCO"

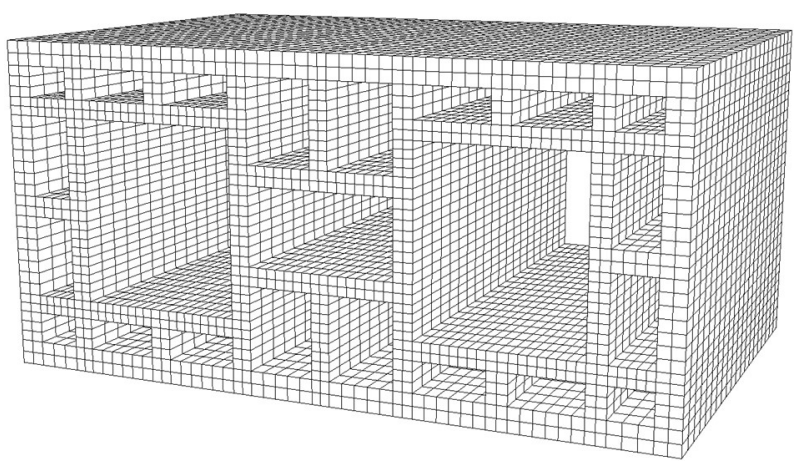

a)

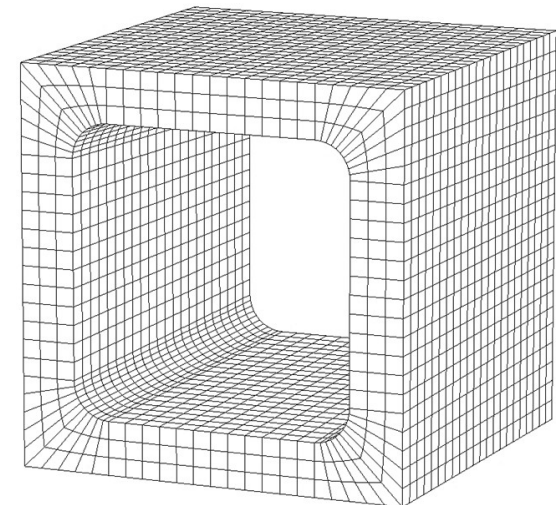

b)

Fonte: Autor (2020)

No caso do modelo "BICO", em regiões nas quais os elementos hexaédricos apresentaram distorções excessivas, foram empregados elementos pentaédricos TP18L (6 nós, primeira ordem) e CTP45 (15 nós, segunda ordem) com duas faces triangulares (wedge). Também se recorreu a estes elementos para compor partes do modelo "MBCE", nos cantos chanfrados do furo e nos "dentes" incorporados às paredes. A representação gráfica dos elementos pentaédricos é exibida na Figura 4.7, enquanto a Figura 4.8 demonstra a discretização dos modelos referidos, com destaque nas porções díspares onde tais elementos foram utilizados. 
Figura 4.7 - Elementos finitos pentaédricos: a) TP18L; b) CTP45

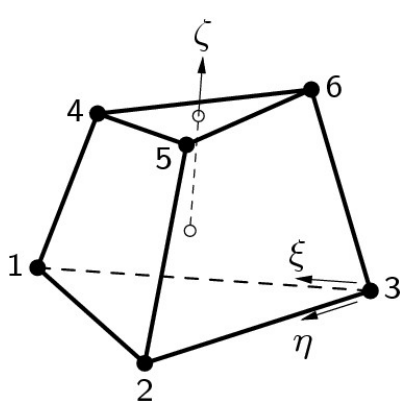

a)

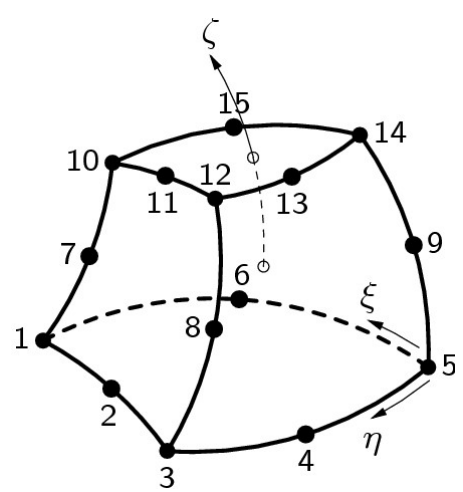

b)

Fonte: DIANA (2016)

Figura 4.8 - Discretizações: a) modelo "BICO"; b) modelo "MBCE"

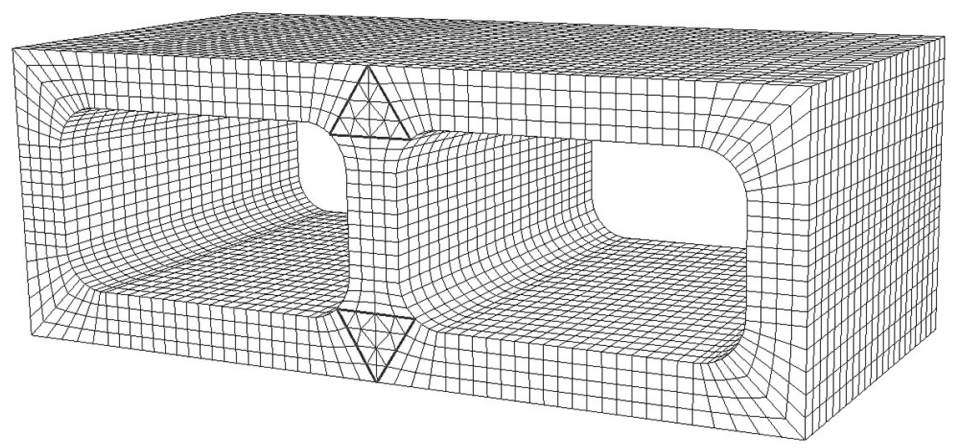

a)

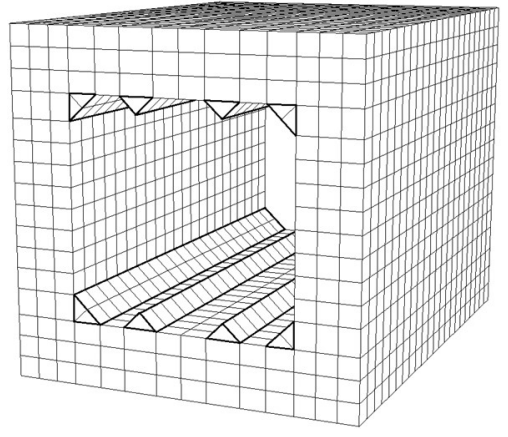

b)

Fonte: Autor (2020)

Como o tempo de processamento é função da quantidade de autovetores/autovalores solicitada na análise, um total de 16 modos de vibrar e suas frequências ressonantes foram requisitados, buscando possibilitar o uso de malhas bem refinadas. Por padrão, o programa elenca os modos naturais em ordem crescente do valor da frequência natural associada, sendo os 6 primeiros espúrios (rotações e translações de corpo rígido com frequência nula). Logo, somente os demais (10) foram apreciados.

Três níveis de refinamento da malha foram testados, cada um processado com elementos de aproximação linear e quadrática, perfazendo 6 malhas por espécime. Como não se dispõe de previsões analíticas para as frequências naturais das geometrias estudadas, a convergência numérica foi avaliada a partir de dois fatores:

$\Delta_{1}$ - variação relativa ao enriquecimento da malha, calculada como

$$
\Delta_{1}=\left|\frac{f_{1}-f_{2}}{f_{2}}\right|
$$


sendo $f_{1}$ e $f_{2}$ frequências de determinado modo de vibrar obtidas em malhas sucessivas constituídas por elementos de mesma ordem, sendo $f_{2}$ a resposta da mais refinada.

$\Delta_{2}$ - variação relativa ao grau de aproximação do elemento finito, dada por

$$
\Delta_{2}=\left|\frac{f_{a}-f_{b}}{f_{b}}\right|
$$

em que $f_{a}$ e $f_{b}$ são frequências de um mesmo modo de vibrar observadas em malhas igualmente densas, sendo $f_{b}$ a resposta daquela com elementos de ordem superior.

O estudo de convergência considerou, para cada modelo, o modo de vibração entre os 10 investigados com a pior tendência de estabilização da frequência calculada. A Tabela 4.2 mostra o resultado desta análise, juntamente com as discretizações adotadas e o tempo de processamento $(t)$ demandado por cada uma delas.

Tabela 4.2 - Análise de convergência numérica

\begin{tabular}{|c|c|c|c|c|c|c|c|}
\hline \multirow{3}{*}{$x^{2}$} & & \multicolumn{6}{|c|}{ MODELO "BICE" } \\
\hline & & \multicolumn{2}{|c|}{18000 elementos } & \multicolumn{2}{|c|}{40080 elementos } & \multicolumn{2}{|c|}{70720 elementos } \\
\hline & & LINEAR & QUAD & LINEAR & QUAD & LINEAR & QUAD \\
\hline \multirow{4}{*}{$3^{\circ}$ modo } & $f(\mathrm{~Hz})$ & 833,54 & 802,06 & 811,74 & 792,70 & 801,91 & - \\
\hline & $\Delta_{1}(\%)$ & - & - & 2,69 & 1,18 & 1,23 & - \\
\hline & $\Delta_{2}(\%)$ & \multicolumn{2}{|c|}{3,92} & \multicolumn{2}{|c|}{2,40} & \multicolumn{2}{|c|}{-} \\
\hline & $t(\mathbf{s})$ & 19 & 126 & 46 & 612 & 87 & - \\
\hline \multirow{3}{*}{ 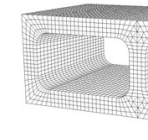 } & & \multicolumn{6}{|c|}{ MODELO "BICO" } \\
\hline & & \multicolumn{4}{|c|}{44826 elementos } & \multicolumn{2}{|c|}{121072 elementos } \\
\hline & & LINEAR & QUAD & LINEAR & QUAD & LINEAR & QUAD \\
\hline \multirow{4}{*}{$3^{\circ}$ modo } & $f(\mathbf{H z})$ & 1762,8 & 1733,3 & 1747,0 & 1732,5 & 1740,6 & - \\
\hline & $\Delta_{1}(\%)$ & - & - & 0,90 & 0,05 & 0,37 & - \\
\hline & $\Delta_{2}(\%)$ & \multicolumn{2}{|c|}{1,70} & \multicolumn{2}{|c|}{0,84} & \multicolumn{2}{|c|}{ - } \\
\hline & \multirow[t]{4}{*}{$t(s)$} & 14 & 84 & 48 & 1682 & 182 & - \\
\hline \multirow{7}{*}{$1^{\circ}$ modo } & & \multicolumn{6}{|c|}{ MODELO "MBCE" } \\
\hline & & \multicolumn{2}{|c|}{3432 elementos } & \multicolumn{2}{|c|}{10080 elementos } & \multicolumn{2}{|c|}{18648 elementos } \\
\hline & & LINEAR & QUAD & LINEAR & QUAD & LINEAR & QUAD \\
\hline & $f(\mathbf{H z})$ & 1834,6 & 1754,9 & 1784,6 & 1749,4 & 1775,7 & 1747,5 \\
\hline & $\Delta_{1}(\%)$ & - & - & 2,80 & 0,31 & 0,50 & 0,11 \\
\hline & $\Delta_{2}(\%)$ & \multicolumn{2}{|c|}{4,54} & \multicolumn{2}{|c|}{2,01} & \multicolumn{2}{|c|}{1,61} \\
\hline & \multirow[t]{4}{*}{$t(\mathbf{s})$} & 4 & 17 & 10 & 60 & 19 & 145 \\
\hline & & \multicolumn{6}{|c|}{ MODELO "MBCO" } \\
\hline & & \multicolumn{2}{|c|}{5808 elementos } & \multicolumn{2}{|c|}{13440 elementos } & \multicolumn{2}{|c|}{25920 elementos } \\
\hline & & LINEAR & QUAD & LINEAR & QUAD & LINEAR & QUAD \\
\hline & $f(\mathbf{H z})$ & 4339,4 & 4299,8 & 4326,7 & 4297,6 & 4316,6 & 4296,8 \\
\hline 60 modo & $\Delta_{1}(\%)$ & - & - & 0,29 & 0,05 & 0,23 & 0,02 \\
\hline$\sigma^{\circ}$ modo & $\Delta_{2}(\%)$ & & & & & & \\
\hline & $t(\mathbf{s})$ & 6 & 28 & 13 & 84 & 28 & 245 \\
\hline
\end{tabular}


Nos modelos "BICE" e "BICO", o uso de elementos com aproximação quadrática em sua malha mais densa acarretou tempos de processamento não razoáveis para uma análise modal. Isso explica esses modelos possuírem apenas 5 resultados de frequência, em contraste com os 6 valores apresentados pelos demais.

A redução de $\Delta_{1}$ em modelos consecutivos empregando elementos afins (LINEAR ou QUAD) indica a melhora da resposta em função do progressivo refinamento da malha, tendendo a um patamar à medida que $\Delta_{1}$ se aproxima de zero. Já $\Delta_{2}$ julga a qualidade da discretização, posto que uma densidade de malha adequada deve fornecer resultados semelhantes independentemente do grau de aproximação do elemento finito. Esses dois parâmetros ainda precisam ser ponderados pelo tempo de processamento requerido por cada modelo, pois a adoção de refinamentos suplementares e/ou elementos de ordem superior em busca de melhores resultados pode configurar estratégia inviável computacionalmente ou que não se justifica diante das respostas logradas com malhas mais pobres.

Conforme esperado, malhas com elementos de aproximação quadrática demonstraram convergência mais acelerada devido sua capacidade de melhor representar arestas curvas (caso das unidades de concreto) e o maior rigor dos polinômios interpoladores. Além disso, foi constatado que as geometrias com material cerâmico exigiram altas densidades de malha para manifestar variações aceitáveis, o que pode estar ligado à maior complexidade de seus contornos. Com base nos tempos de processamento e nas variações observadas, malhas definitivas para análises posteriores foram selecionadas como resume o Quadro 4.1.

Quadro 4.1 - Malhas de elementos finitos adotadas

\begin{tabular}{|c|c|c|}
\hline Modelo & $\mathbf{N}^{\text {o de elementos }}$ & Aproximação \\
\hline "BICE" & 40080 & Quadrática \\
\hline "BICO" & 44826 & Quadrática \\
\hline "MBCE" & 18648 & Quadrática \\
\hline "MBCO" & 25920 & Quadrática \\
\hline
\end{tabular}

Fonte: Autor (2020)

\subsection{Modos de vibrar e frequências naturais}

Concluída a elaboração dos modelos, estes foram pós-processados no ambiente iDIANA, permitindo visualizar a animação dos modos de vibrar. Nas Figuras 4.9 a 4.12 estão ilustrados os 10 primeiros modos ressonantes (desprezando os espúrios) de cada modelo concebido, acrescidos dos valores de frequência natural acessados no arquivo de saída gerado. 
Figura 4.9 - Bloco inteiro cerâmico: modos e frequências naturais

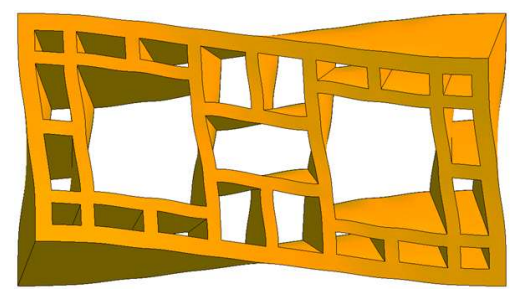

$1^{\circ}$ modo: $f_{1}=605,40 \mathrm{~Hz}$

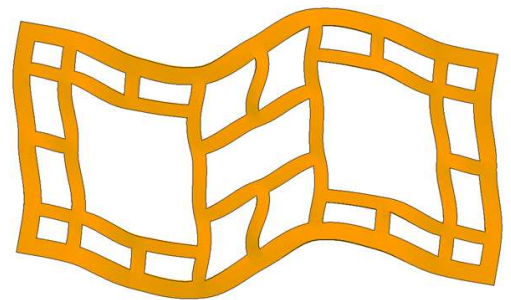

$4^{\circ} \operatorname{modo}: f_{4}=1415,2 \mathrm{~Hz}$

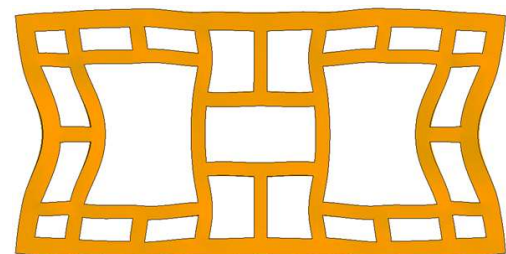

$7^{0} \operatorname{modo}: f_{7}=1708,1 \mathrm{~Hz}$

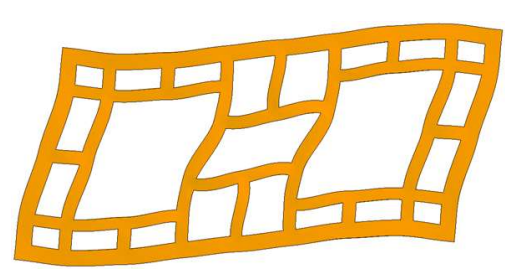

$2^{\circ} \operatorname{modo}: f_{2}=690,43 \mathrm{~Hz}$

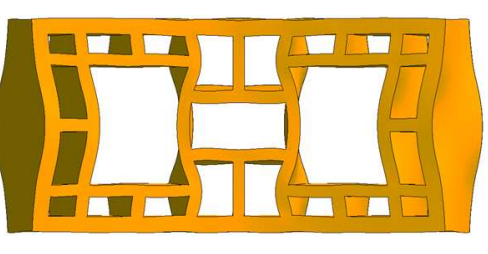

$5^{\circ} \operatorname{modo}: f_{5}=1601,1 \mathrm{~Hz}$

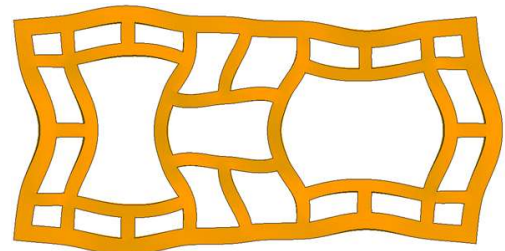

$8^{\circ} \operatorname{modo}: f_{8}=1957,1 \mathrm{~Hz}$

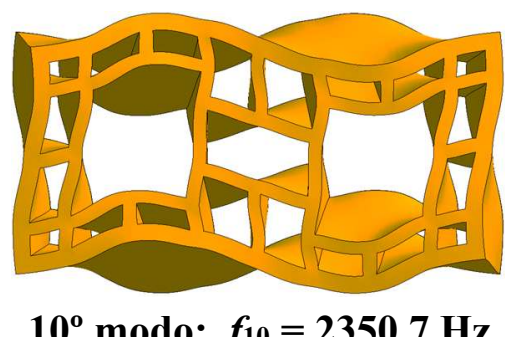

Fonte: Autor (2020)

10 ${ }^{\circ} \operatorname{modo}: f_{10}=2350,7 \mathrm{~Hz}$

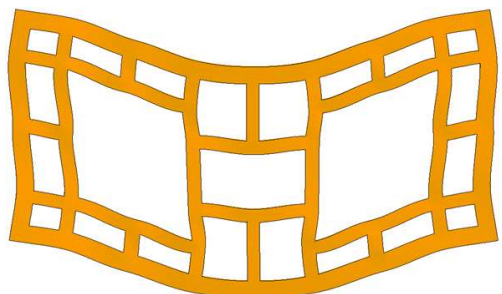

$3^{\circ}$ modo: $f_{3}=792,70 \mathrm{~Hz}$

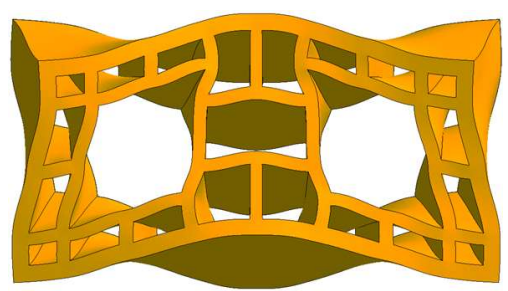

$6^{\circ} \operatorname{modo}: f_{6}=1691,6 \mathrm{~Hz}$

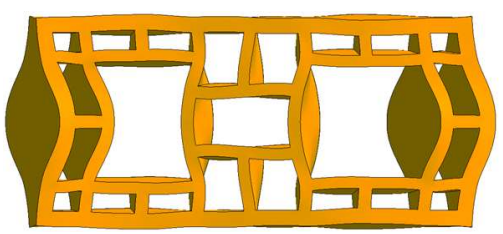

$9^{\circ} \operatorname{modo}: f_{9}=2216,1 \mathrm{~Hz}$

No bloco inteiro cerâmico, o primeiro modo indica torção, o terceiro atesta flexão no plano da seção transversal e o sétimo representa alongamento/encolhimento total na direção do comprimento do bloco. Observa-se que há uma correspondência entre modos à medida que as faces frontal e posterior vibram de forma distinta ou consonante, sendo elas: $1^{\mathrm{o}} / 2^{\circ}, 3^{\circ} / 6^{\circ}, 4^{\circ} / 10^{\circ}$, $5^{\circ} / 7^{\circ}$ e $8^{\circ} / 9^{\circ}$. 
Figura 4.10 - Bloco inteiro de concreto: modos e frequências naturais

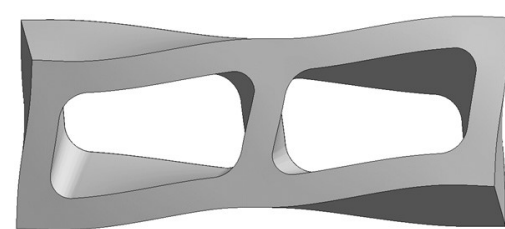

$1^{\circ}$ modo: $f_{1}=1185,3 \mathrm{~Hz}$

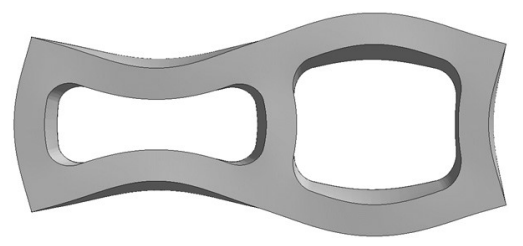

$4^{\circ}$ modo: $f_{4}=2110,5 \mathrm{~Hz}$

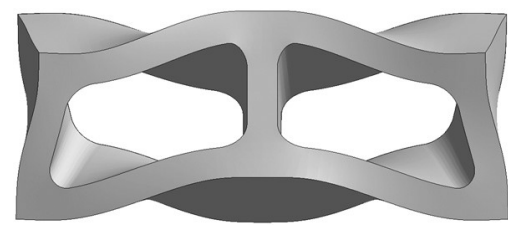

$7^{\circ} \operatorname{modo}: f_{7}=2805,0 \mathrm{~Hz}$

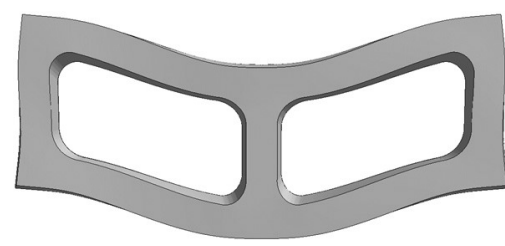

$2^{\circ}$ modo: $f_{2}=1230,5 \mathrm{~Hz}$

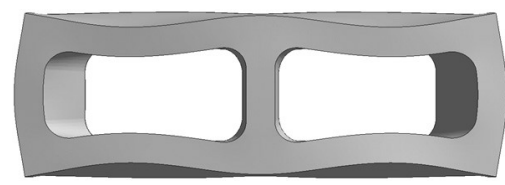

$5^{\circ}$ modo: $f_{5}=2596,0 \mathrm{~Hz}$

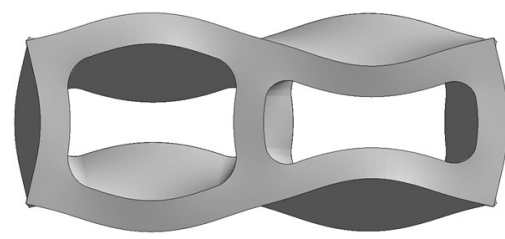

$8^{\circ}$ modo: $f_{8}=3110,4 \mathrm{~Hz}$

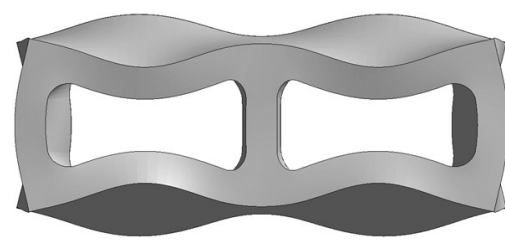

$10^{\circ}$ modo: $f_{10}=3665,8 \mathrm{~Hz}$

Fonte: Autor (2020)

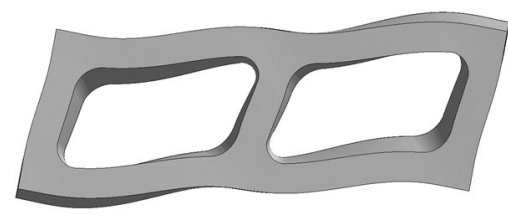

$3^{\circ}$ modo: $f_{3}=1732,5 \mathrm{~Hz}$

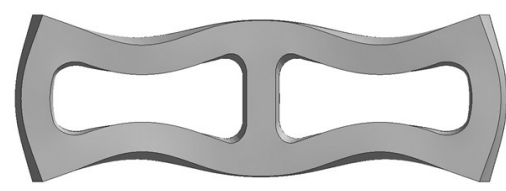

$6^{0} \operatorname{modo}: f_{6}=2784,3 \mathrm{~Hz}$

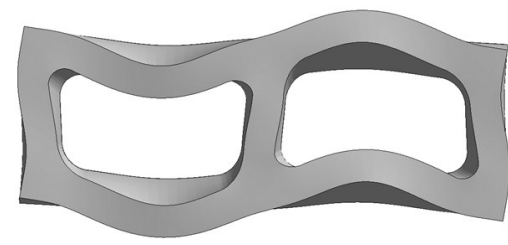

$9^{\circ} \operatorname{modo}: f_{9}=3599,0 \mathrm{~Hz}$

Assim como no bloco cerâmico, no bloco inteiro de concreto é possível identificar modos associados à torção $\left(1^{\circ}\right)$, flexão da seção em seu plano $\left(2^{\circ}\right)$ e extensão/contração ao longo do comprimento $\left(6^{\circ}\right)$. Também é possível estabelecer relações entre modos nos quais faces opostas da seção vibram de forma invertida ou idêntica, sendo elas: $1^{\circ} / 3^{\circ}, 2^{\circ} / 7^{\circ}, 4^{\circ} / 8^{\circ}$ e $6^{\circ} / 10^{\circ}$. 
Figura 4.11 - Meio-bloco cerâmico: modos e frequências naturais

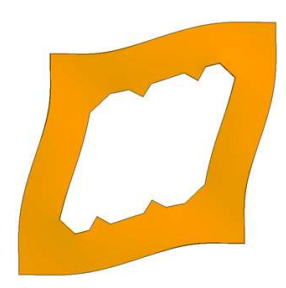

$1^{\circ} \operatorname{modo}: f_{1}=1747,5 \mathrm{~Hz}$

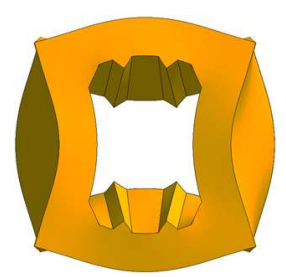

$4^{0} \operatorname{modo}: f_{4}=2932,3 \mathrm{~Hz}$

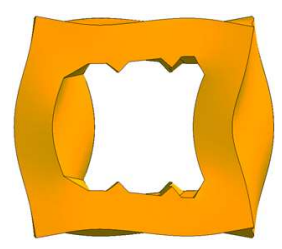

$7^{\circ} \operatorname{modo}: f_{7}=4501,4 \mathrm{~Hz}$

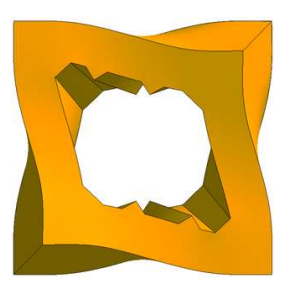

$2^{\circ}$ modo: $f_{2}=1850,5 \mathrm{~Hz}$

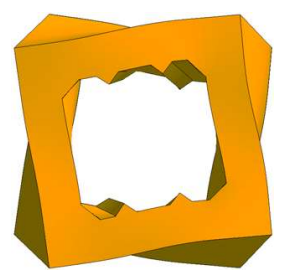

$5^{\circ} \operatorname{modo}: f_{5}=4316,3 \mathrm{~Hz}$

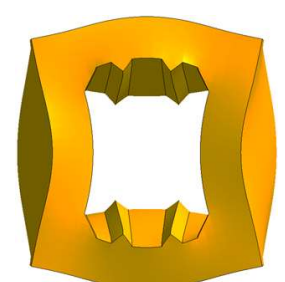

$8^{\circ} \operatorname{modo}: f_{8}=4685,0 \mathrm{~Hz}$

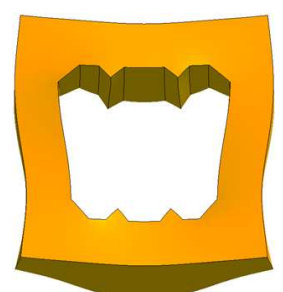

$10^{\circ} \operatorname{modo}: f_{10}=4907,9 \mathrm{~Hz}$

Fonte: Autor (2020)

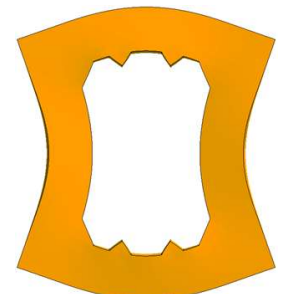

$3^{\circ}$ modo: $f_{3}=2261,3 \mathrm{~Hz}$

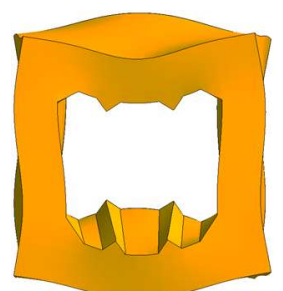

$6^{\circ} \operatorname{modo}: f_{6}=4318,7 \mathrm{~Hz}$

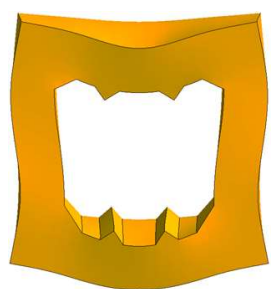

$9^{\circ} \operatorname{modo}: f_{9}=4791,4 \mathrm{~Hz}$

No meio-bloco cerâmico, foi constatada a ausência de um modo de flexão bem definido entre os 10 primeiros. Provavelmente, isso se justifica pela geometria da unidade não favorecer a excitação desse modo, de tal forma que sua ocorrência está concatenada a um maior valor de frequência (associada à rigidez mobilizada). No mais, percebe-se a existência de dois modos de torção $\left(2^{\circ}\right.$ e $\left.5^{\circ}\right)$, bem como de outros muito símiles entre si $\left(4^{\circ}\right.$ e $8^{\circ}, 6^{\circ}$ e $\left.9^{\circ}\right)$. 
Figura 4.12 - Meio-bloco de concreto: modos e frequências naturais

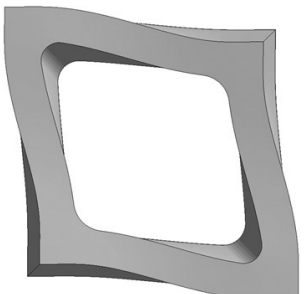

$1^{\circ}$ modo: $f_{1}=1469,3 \mathrm{~Hz}$

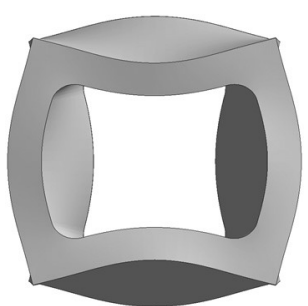

$4^{\circ} \operatorname{modo}: f_{4}=3106,4 \mathrm{~Hz}$

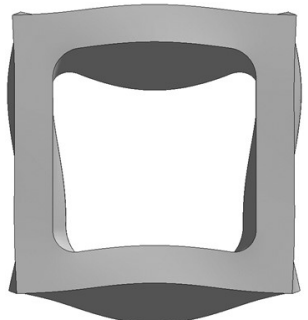

$7^{\circ} \operatorname{modo}: f_{7}=4642,3 \mathrm{~Hz}$

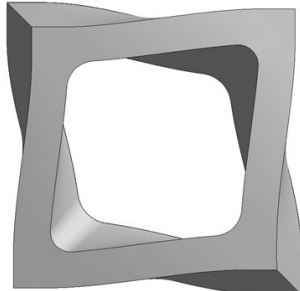

$2^{\circ}$ modo: $f_{2}=1681,6 \mathrm{~Hz}$

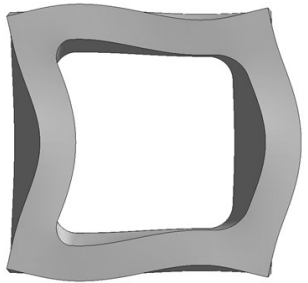

$5^{\circ} \operatorname{modo}: f_{5}=4278,8 \mathrm{~Hz}$

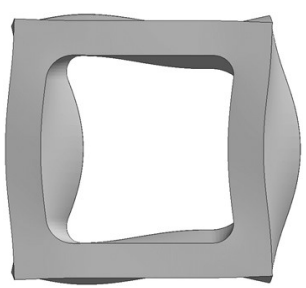

$8^{\circ} \operatorname{modo}: f_{8}=4676,9 \mathrm{~Hz}$

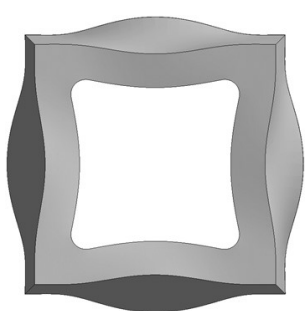

$10^{\circ} \operatorname{modo}: f_{10}=5669,1 \mathrm{~Hz}$

Fonte: Autor (2020)

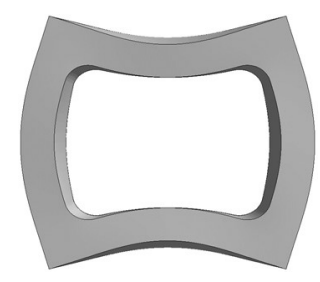

$3^{\circ}$ modo: $f_{3}=2053,9 \mathrm{~Hz}$

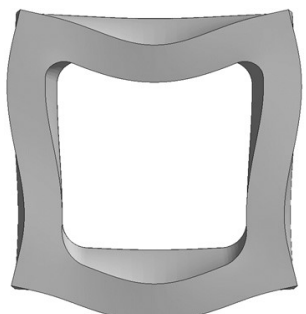

$6^{0} \operatorname{modo}: f_{6}=4296,8 \mathrm{~Hz}$

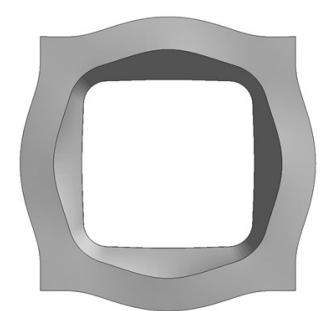

$9^{\circ}$ modo: $f_{9}=5199,1 \mathrm{~Hz}$

É evidente a semelhança entre os modos ressonantes do meio-bloco cerâmico e de concreto (especialmente os quatro primeiros, inclusive ocorrendo na mesma sequência) em função de ambos possuírem seção transversal quadrada e mesma altura. Além disso, fica claro que determinados modos são similares entre si, alternando forma de vibrar das faces de maior e menor espessura $\left(5^{\circ} / 8^{\circ}, 6^{\circ} / 7^{\circ}\right.$ e $\left.9^{\circ} / 10^{\circ}\right)$. 


\subsection{Determinação dos coeficientes geométricos}

Como dito, a frequência natural de certo modo de vibrar está relacionada com o módulo de elasticidade dinâmico e a massa da estrutura através de uma constante puramente geométrica. Isso pode ser verificado analisando dimensionalmente a Equação 1.1 já exposta:

$$
\begin{gathered}
f=\alpha \sqrt{\frac{E}{M}} \rightarrow \alpha=f \sqrt{\frac{M}{E}} \\
{[\alpha]=[T]^{-1} \cdot\left(\frac{[M]}{\frac{[M]}{[L] \cdot[T]^{2}}}\right)^{1 / 2} \quad \therefore \quad[\alpha]=[L]^{1 / 2}}
\end{gathered}
$$

Logo, se consideradas unidades do S.I., o coeficiente $\alpha$ é dado em $\mathrm{m}^{1 / 2}$.

Partindo da Equação 1.1, pode-se chegar à expressão

$$
E=\beta M f^{2}
$$

$\operatorname{com} \beta=1 / \alpha^{2}$.

Observa-se que $\beta$ também é um parâmetro geométrico, com unidade $\mathrm{m}^{-1}$. Dessa forma, a Equação 4.1 é conveniente para determinar experimentalmente o módulo de elasticidade dinâmico do material de um corpo de prova, pois é possível obter suas frequências naturais através dos métodos de ressonância e medir sua massa facilmente. Resta conhecer o coeficiente geométrico de algum modo de vibrar.

Dispondo das geometrias em questão (Figuras 4.1 a 4.4), é possível determinar coeficientes geométricos com auxílio de análise paramétrica, variando a densidade (consequentemente a massa do bloco) e o módulo de elasticidade do modelo numérico. Para exemplificar o procedimento, arbitrou-se para cada modelo um modo de vibração e 5 valores de densidade e módulo dinâmico, perfazendo 25 combinações entre parâmetros do material.

Em seguida, procedeu-se assim como Santos et al. (2014), confeccionando curvas relativas à variação da frequência do modo selecionado com a alteração das propriedades do material e, a partir destas, um novo gráfico representando a relação entre o módulo de elasticidade e o produto "massa do bloco $\times$ quadrado da frequência natural do modo" para os valores de $E$ e $M$ considerados (vide Figura 2.21). Para as unidades da pesquisa, o procedimento descrito é exemplificado pelas Figuras 4.13 a 4.16. 
Figura 4.13 - Determinação de $\alpha$ e $\beta$ via análise paramétrica: bloco cerâmico, $6^{\circ}$ modo
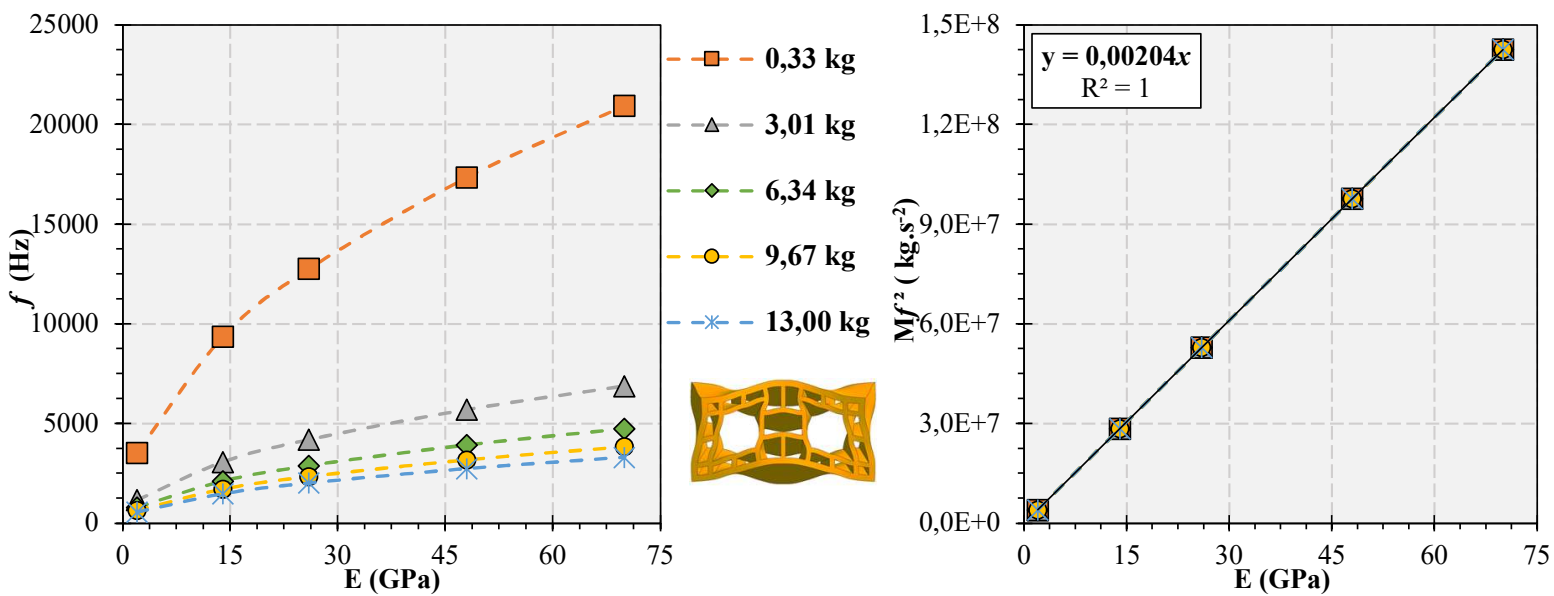

Fonte: Autor (2020)

Figura 4.14 - Determinação de $\alpha$ e $\beta$ via análise paramétrica: meio-bloco cerâmico, $3^{\circ}$ modo
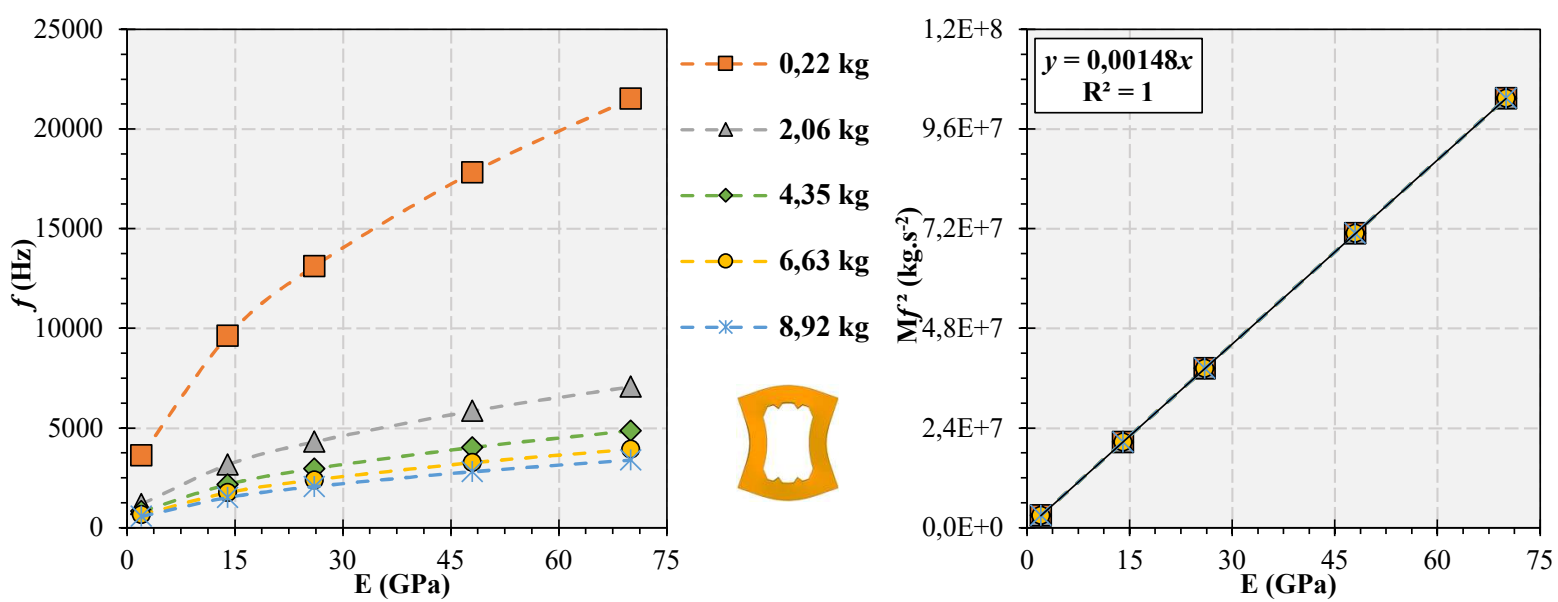

Fonte: Autor (2020)

Figura 4.15 - Determinação de $\alpha$ e $\beta$ via análise paramétrica: bloco de concreto, $2^{\circ}$ modo
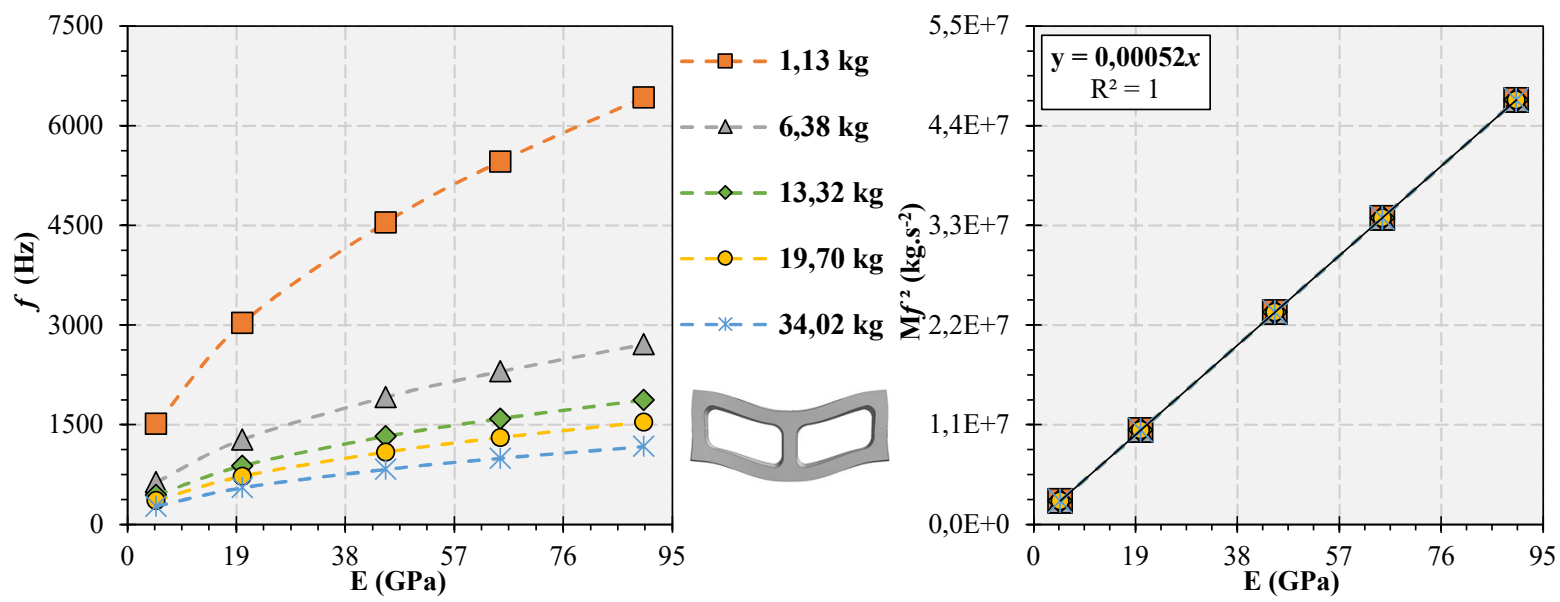

Fonte: Autor (2020) 
Figura 4.16 - Determinação de $\alpha$ e $\beta$ via análise paramétrica: meio-bloco de concreto, $9^{\circ}$ modo
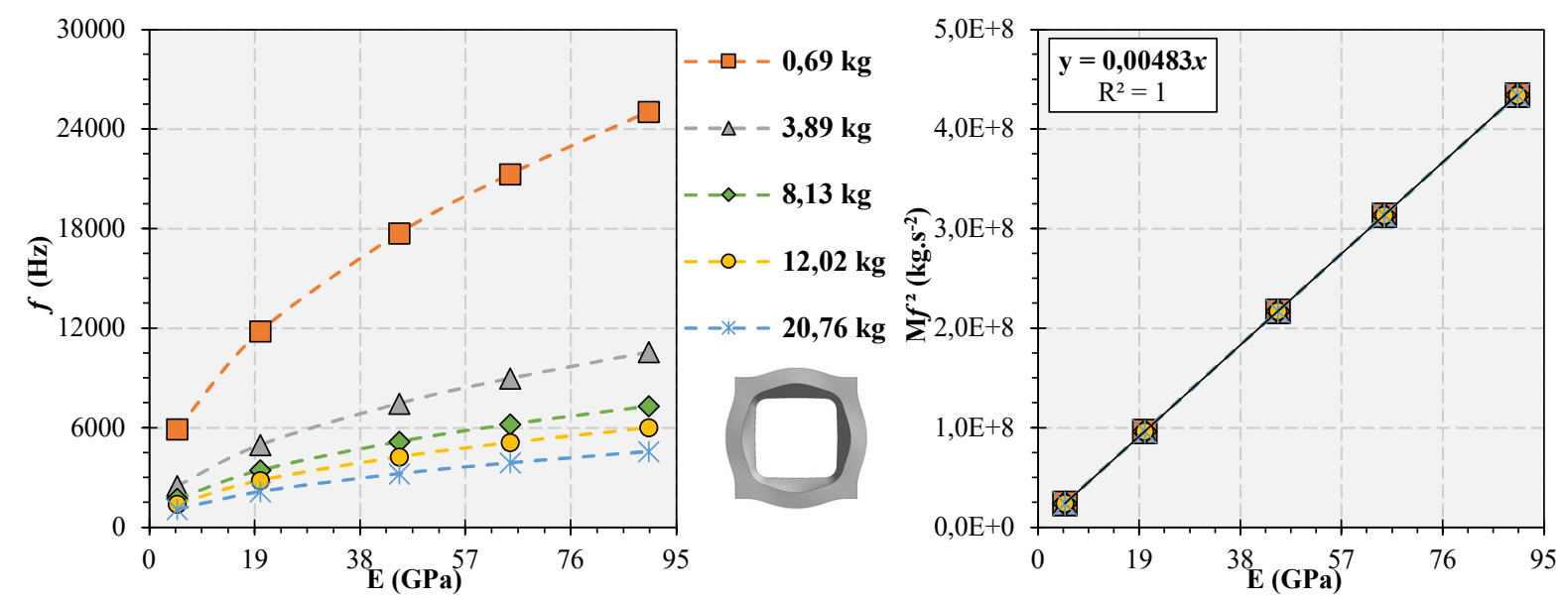

Fonte: Autor (2020)

Percebe-se, pelos gráficos à direita, que há uma relação perfeitamente linear entre $E$ e o produto $M \times f^{2}$ independentemente dos valores da massa e do módulo de elasticidade, posto que regressões lineares resultaram em coeficiente de determinação $\mathrm{R}^{2}$ igual a 1 . Para extrair o valor de $\alpha$ ou $\beta$ do gráfico, deve-se atentar ao fato de que as retas sobrepostas são todas descritas pela equação $M f^{2}=a E$, de modo que o coeficiente angular " $a$ " é numericamente igual ao quadrado do parâmetro $\alpha$ ou ao inverso de $\beta$ (como sugere a Equação 4.1).

Uma alternativa a tal processo (e que fornece resultados equivalentes) parte de dada combinação de parâmetros do material $(E, \rho$ e $v)$ e das frequências naturais resultantes. Caso seja estipulada uma "massa fictícia" para o espécime simulado, a obtenção dos coeficientes torna-se possível através das Equações 1.1 e 4.1. Em posse do valor da densidade, resta calcular o volume da geometria modelada. Assim foram computadas as constantes geométricas para os 10 modos de vibrar coletados em cada um dos quatro modelos estudados, com base nas frequências ressonantes obtidas pela malha final oriunda da análise de convergência.

Contudo, ao se adotar tal estratégia, o valor das constantes passa a ser função da frequência indicada pelo modelo numérico, por sua vez influenciada pela qualidade da malha de elementos finitos. Portanto, a magnitude dessa ingerência em $\beta$ (coeficiente necessário para estimar o módulo de elasticidade através de um método de ressonância) foi investigada, considerando a variação $(\Delta)$ deste parâmetro entre a malha mais pobre (inicial) e aquela utilizada no modelo definitivo de cada unidade (final). 


\subsubsection{Bloco inteiro cerâmico}

Os coeficientes geométricos do bloco inteiro cerâmico são reunidos na Tabela 4.3, que também contempla a variação de $\beta$ com a malha de elementos finitos para cada modo.

Tabela 4.3 - Constantes geométricas para os 10 primeiros modos: bloco cerâmico

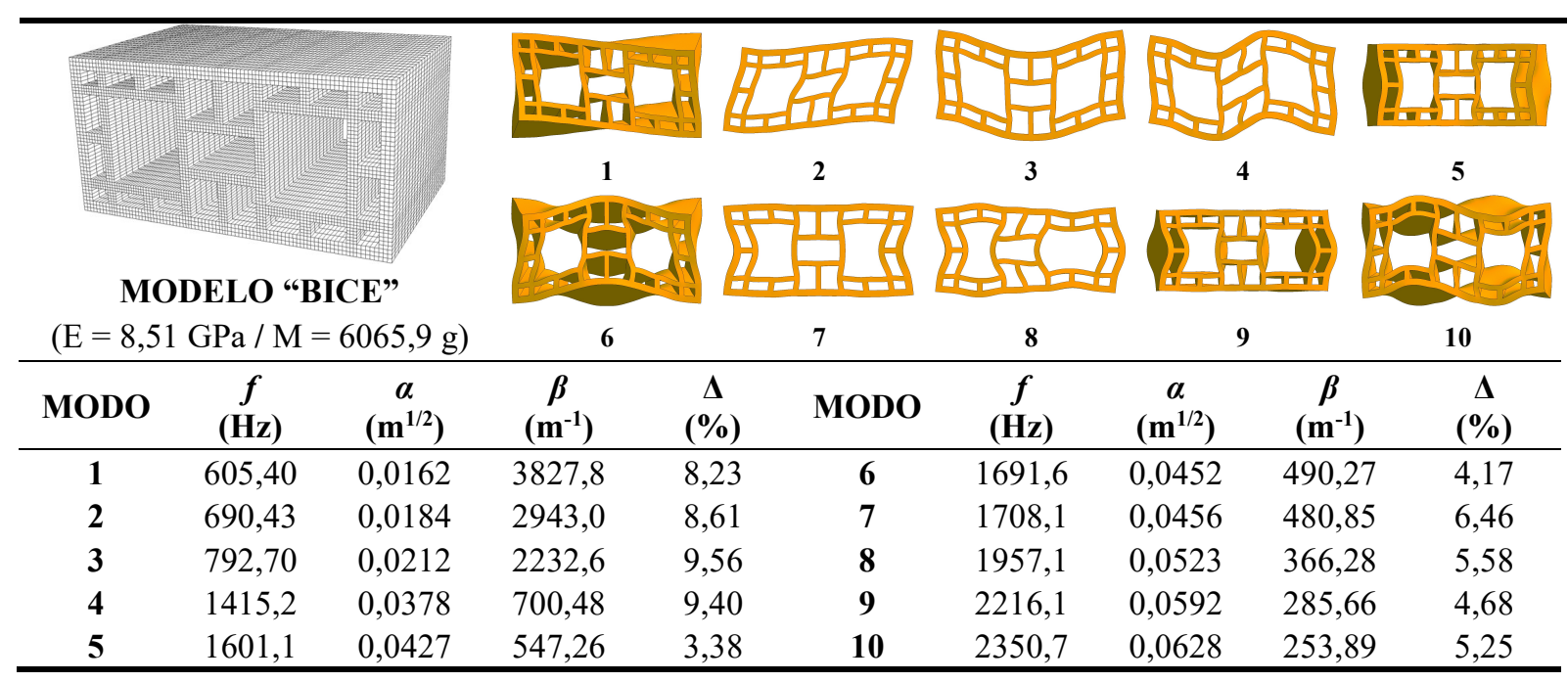

Diante do exposto, infere-se que a geometria do bloco inteiro cerâmico exige certo rigor no tocante ao refinamento e uso de elementos de ordem superior na malha de elementos finitos. Alguns modos de vibrar apresentaram variação próxima a 10\% no sentido de subestimar o valor de $\beta$, o que corresponderia a um erro de mesma magnitude na determinação do módulo de elasticidade a partir de um deles.

Ademais, entende-se que a influência da malha não se manifestou igualmente em todas as frequências ressonantes (na média em torno de 6,5\%), tendo em vista a alta dispersão (próxima a $35 \%$ ) de $\Delta$ entre os 10 modos.

\subsubsection{Bloco inteiro de concreto}

A Tabela 4.4 resume as constantes geométricas para o bloco inteiro de concreto e a flutuação do valor de $\beta$ conforme a qualidade da malha utilizada e o modo ressonante. 
Tabela 4.4 - Constantes geométricas para os 10 primeiros modos: bloco de concreto

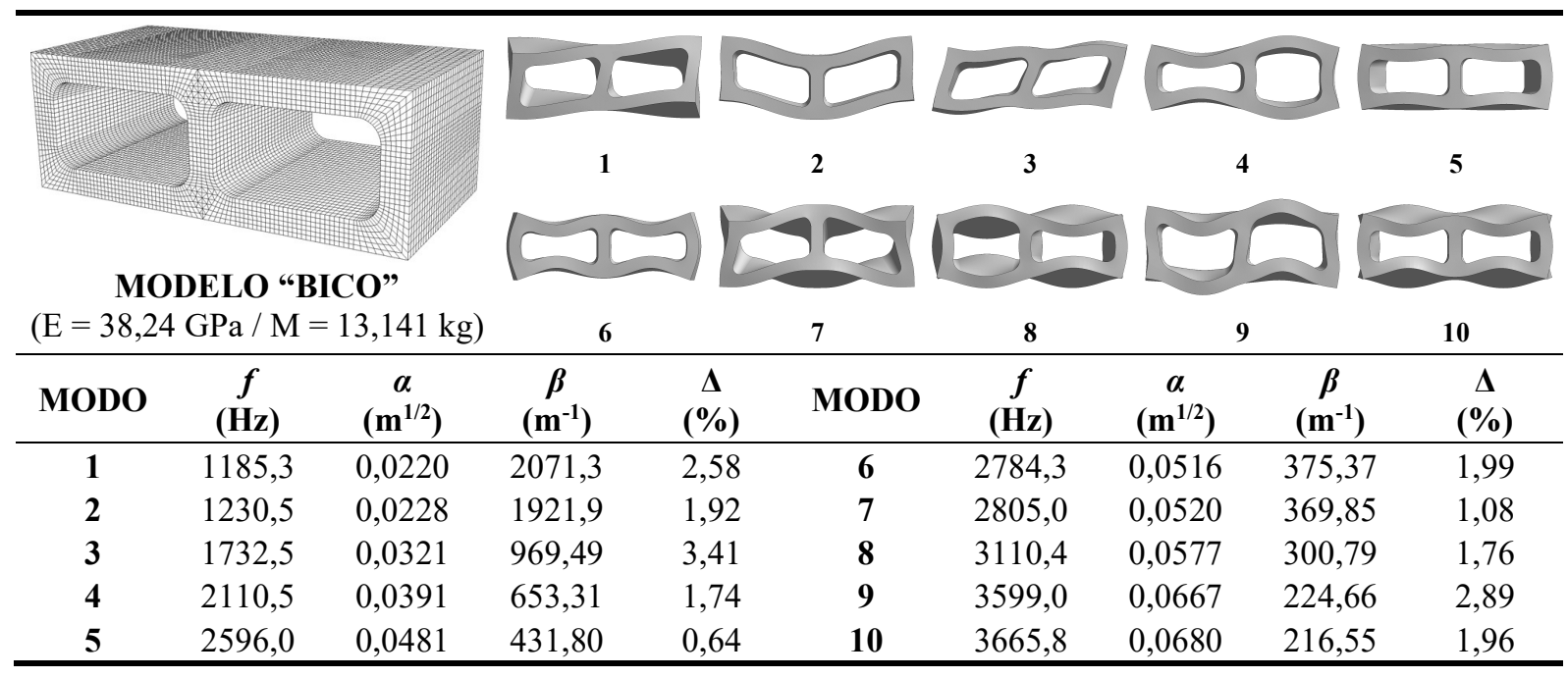

As variações observadas sugerem que a discretização inicial do bloco de concreto já possuía uma densidade de malha adequada e, a depender do modo de vibrar selecionado, poderia ser utilizada para fins de obtenção das constantes geométricas sem grandes prejuízos à precisão. Ainda assim, é difícil prever o erro oriundo de uma simplificação da malha (em média igual a $2 \%$ ), pois o coeficiente de variação relativo é elevado (da ordem de $40 \%$ ).

\subsubsection{Meio-bloco cerâmico}

Para o meio-bloco cerâmico, coeficientes geométricos dos diferentes modos de vibrar e a influência da malha de elementos finitos nos valores correspondentes de $\beta$ são dispostos na Tabela 4.5.

Tabela 4.5 - Constantes geométricas para os 10 primeiros modos: meio-bloco cerâmico

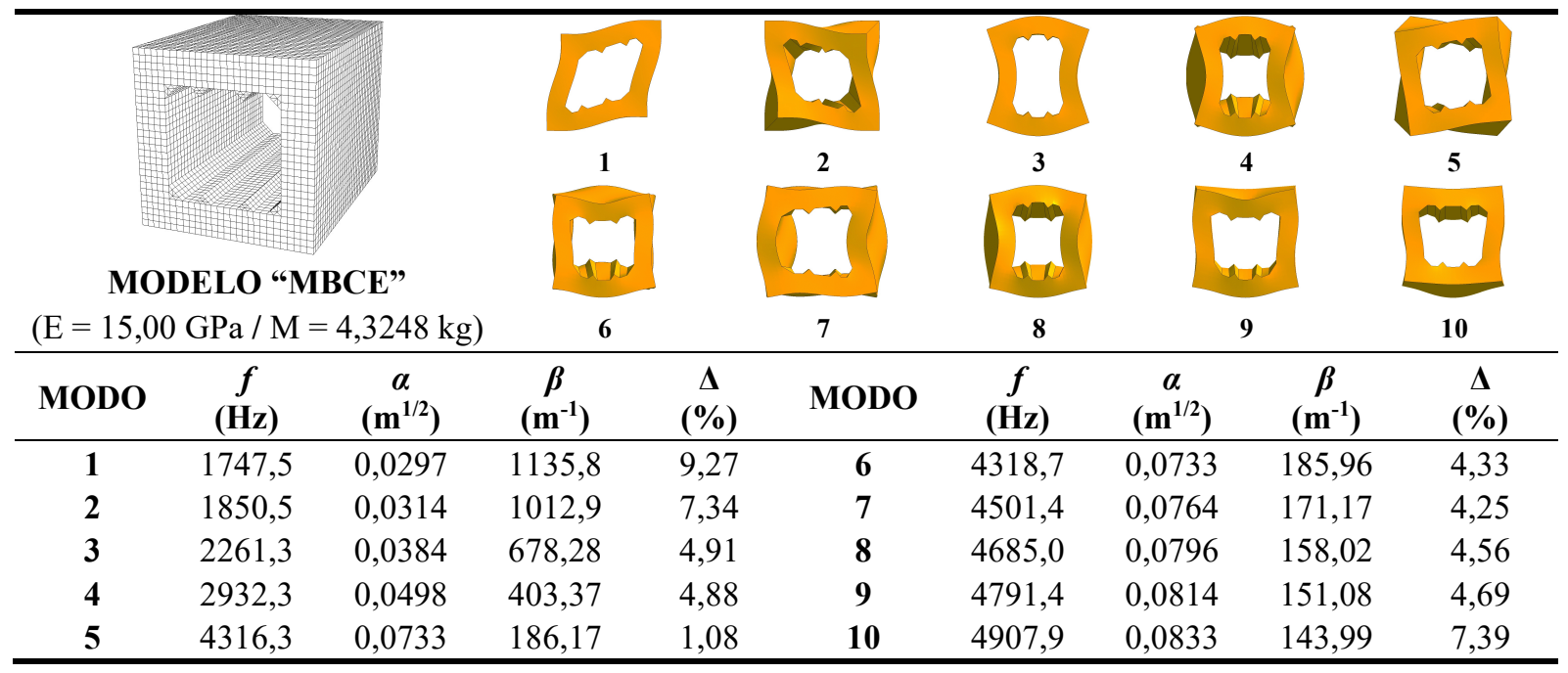


Assim como no bloco inteiro cerâmico, o influxo da malha nos parâmetros $\beta$ do meiobloco foi considerável, o que provavelmente se deve ao fato dessas unidades possuírem geometrias mais complexas que as de suas equivalentes em concreto.

No entanto, em pelo menos um modo de vibrar $\left(5^{\circ}\right)$ é possível constatar pouca interferência da malha, o que acaba por aumentar a dispersão dos valores de $\Delta$ (cerca de $43 \%$ ). Ao simplificar a malha, um erro médio de 5,3\% no cálculo do módulo seria admitido.

\subsubsection{Meio-bloco de concreto}

As constantes geométricas para o meio-bloco de concreto são retratadas na Tabela 4.6, que também reporta a variação de $\beta$ segundo a qualidade da malha utilizada.

Tabela 4.6 - Constantes geométricas para os 10 primeiros modos: meio-bloco de concreto

\begin{tabular}{cccccccccccccc}
\hline & & & & & \\
\end{tabular}

A ingerência da malha (refinamento e grau de aproximação dos elementos) não foi substancial no modelo "MBCO", o que leva a crer que a malha concebida inicialmente já possuía qualidade suficiente para emprego na determinação dos coeficientes geométricos, assumindo erro médio de $1,6 \%$.

Pode-se observar maior uniformidade nas variações de $\beta$ entre modos, resultando no menor CV entre os quatro modelos avaliados (inferior a 20\%). Presume-se que isso ocorre por essa unidade possuir geometria com contornos mais simples e três dimensões (nominais) iguais. 


\subsection{Síntese do capítulo}

Neste capítulo foram descritos os procedimentos efetuados na obtenção do modelo numérico de cada unidade: definição da geometria, especificação das propriedades do material (baseada em resultados experimentais), discretização em elementos finitos e escolha da malha definitiva a partir do estudo de convergência.

Em posse dos modelos consolidados e processadas as análises modais, os 10 primeiros modos ressonantes passaram a ser conhecidos, sendo brevemente comentadas as peculiaridades observadas em cada unidade. As frequências naturais e configurações deformadas fornecidas pela análise numérica balizaram a execução do ensaio de ressonância acústica.

Por fim, foram determinados coeficientes geométricos $(\alpha \mathrm{e} \beta)$ para os 10 primeiros modos de vibrar de cada unidade. Em um primeiro momento, foi demonstrado o procedimento para encontrar tais coeficientes a partir de análise paramétrica, especialmente útil quando não se possui estimativas das propriedades do material que compõe o elemento examinado.

Quando calculado através da Equação 4.1 com base nos dados de um modelo numérico, o valor de $\beta$ fica vinculado à discretização em elementos finitos utilizada. Uma malha de baixa qualidade pode influenciar consideravelmente o valor desse parâmetro a depender da geometria do espécime e do modo de vibrar, como pôde ser verificado em casos das unidades cerâmicas. 


\section{RESULTADOS E DISCUSSÃO}

\subsection{Estimativa de propriedades elásticas dinâmicas via VPU}

As propriedades elásticas dinâmicas (módulo de elasticidade longitudinal, módulo de elasticidade transversal ou ao cisalhamento e coeficiente de Poisson) do material constituinte das unidades foram estimadas mediante Equações 2.1 a 2.3, considerando velocidades de onda longitudinal $\left(V_{P}\right)$ e transversal $\left(V_{S}\right)$ obtidas por média aritmética simples de todas as medições oriundas do ensaio de ultrassom. Os valores médios amostrais fornecidos para $E$ e $v$ abasteceram os respectivos modelos numéricos (Tabela 4.1), possibilitando uma previsão ajustada das frequências naturais.

Para avaliar a homogeneidade das unidades e assim complementar a discussão de tais estimativas, alguns testes de hipóteses foram propostos. Os dados de velocidade de propagação foram submetidos a tratamento estatístico envolvendo os testes F e t de Student em ambiente Excel®. Os resultados mais expressivos (eventos observados nas três unidades componentes da amostra, considerados tendência) são sintetizados nessa seção, enquanto detalhes da elaboração dos testes e seus resultados individuais podem ser consultados no Apêndice B - "Testes de hipóteses: homogeneidade das unidades de alvenaria".

\subsubsection{Bloco inteiro cerâmico}

A Tabela 5.1 traz valores médios e medidas de dispersão da velocidade de propagação das ondas longitudinais e transversais ao longo da largura, comprimento e altura do espécime, bem como a média total de cada unidade. O sistema de pontos indicado equivale ao já apresentado pela Figura 3.10. Os valores calculados para as propriedades dinâmicas a partir de tais velocidades são expostos na Tabela 5.2. 
Tabela 5.1 - Velocidade de propagação de ondas em blocos cerâmicos

\begin{tabular}{|c|c|c|c|c|c|c|c|c|}
\hline \multirow{2}{*}{ 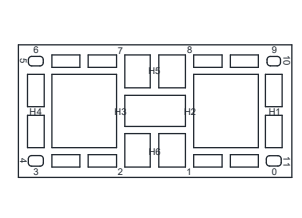 } & \multicolumn{2}{|c|}{$\begin{array}{c}\text { Largura (L) } \\
0-9,1-8, \\
2-7 \text { e 3-6 }\end{array}$} & \multicolumn{2}{|c|}{$\begin{array}{c}\text { Comprimento (C) } \\
4-11 \text { e } 5-10\end{array}$} & \multicolumn{2}{|c|}{$\begin{array}{l}\text { Altura (H) } \\
\text { H1, H2, H3, } \\
\text { H4, H5 e H6 }\end{array}$} & \multicolumn{2}{|c|}{ Total } \\
\hline & $\begin{array}{c}V_{P} \\
(\mathrm{~m} / \mathbf{s})\end{array}$ & $\begin{array}{c}V_{S} \\
(\mathbf{m} / \mathbf{s})\end{array}$ & $\begin{array}{c}V_{P} \\
(\mathbf{m} / \mathbf{s})\end{array}$ & $\begin{array}{c}V_{S} \\
(\mathbf{m} / \mathbf{s})\end{array}$ & $\begin{array}{c}V_{P} \\
(\mathrm{~m} / \mathrm{s})\end{array}$ & $\begin{array}{c}V_{S} \\
(\mathrm{~m} / \mathrm{s})\end{array}$ & $\begin{array}{c}V_{P} \\
(\mathrm{~m} / \mathbf{s})\end{array}$ & $\begin{array}{c}V_{S} \\
(\mathrm{~m} / \mathrm{s})\end{array}$ \\
\hline & \multicolumn{8}{|c|}{ 6-1(END) } \\
\hline MÉD & 2057,6 & 1475,8 & 2148,9 & 1550,2 & 2423,1 & 1496,8 & 2155,0 & 1499,9 \\
\hline DP & 130,1 & 63,1 & 11,4 & 14,3 & 78,3 & 31,5 & 173,1 & 57,4 \\
\hline \multirow[t]{2}{*}{ CV (\%) } & 6,32 & 4,27 & 0,53 & 0,92 & 3,23 & 2,11 & 8,03 & 3,83 \\
\hline & \multicolumn{8}{|c|}{ 6-2(END) } \\
\hline MÉD & 2073,1 & 1488,1 & 2171,8 & 1556,7 & 2422,2 & 1502,5 & 2169,3 & 1509,2 \\
\hline DP & 104,8 & 54,7 & 20,9 & 10,7 & 54,8 & 29,0 & 157,0 & 51,0 \\
\hline \multirow[t]{2}{*}{ CV (\%) } & 5,06 & 3,68 & 0,96 & 0,69 & 2,26 & 1,93 & 7,24 & 3,38 \\
\hline & \multicolumn{8}{|c|}{ 6-3(END) } \\
\hline MÉD & 2253,7 & 1567,4 & 2271,8 & 1635,0 & 2556,4 & 1581,7 & 2319,1 & 1588,3 \\
\hline DP & 151,8 & 58,4 & 40,8 & 41,4 & 104,3 & 43,0 & 169,8 & 57,9 \\
\hline CV $(\%)$ & 6,74 & 3,73 & 1,80 & 2,53 & 4,08 & 2,72 & 7,32 & 3,64 \\
\hline
\end{tabular}

Tabela 5.2 - Estimativa das propriedades elásticas dinâmicas: blocos cerâmicos

\begin{tabular}{cccc}
\hline ID & $\boldsymbol{E}$ & $\boldsymbol{G}$ & $\boldsymbol{v}$ \\
& (GPa) & (GPa) & 0,17 \\
6-1(END) & 8,02 & 4,17 & 0,17 \\
6-2(END) & 8,15 & 4,24 & 0,17 \\
6-3(END) & 9,37 & 4,73 & \\
\hline
\end{tabular}

Foi constatada uma flutuação das velocidades de onda longitudinal (até $8 \%$ ) muito superior à observada para a onda transversal (inferior a 4\%). Essa variabilidade sobrepuja os índices típicos de dispersão em métodos não destrutivos, suscitando questionamentos acerca da homogeneidade do material constituinte dessas unidades.

O resultado dos ensaios de ultrassom havia indicado, em todas as unidades, um valor errôneo para o coeficiente de Poisson (em torno de 0,05). Acredita-se que isso se deu em função da pequena espessura dos septos individuais dessas unidades (inferior a $10 \mathrm{~mm}$ ) e sua influência na propagação de ondas, no sentido de que o tempo de chegada indicado pelo aparelho de medição pode não ser referente ao tipo de onda esperado.

Então, para o cálculo de $E$ e utilização na simulação numérica, tomou-se $v=0,17$, valor que foi encontrado experimentalmente no meio-bloco cerâmico (mostrado adiante) e também balizado pelo estipulado nas normas de projeto em alvenaria estrutural para o caráter estático dessa propriedade $(0,15)$, com o equivalente dinâmico tendendo a ser mais elevado. 
As velocidades (tanto de ondas longitudinais quanto transversais) não diferiram significativamente entre as 4 camadas definidas ao longo da altura do bloco. No entanto, para ambos os tipos de onda, houve diferença significativa entre medidas simétricas ao longo da largura (0-9/3-6). Por fim, verificou-se que as velocidades na direção da altura (com ondas primárias) e do comprimento (com ondas secundárias) divergiram significativamente daquelas nas demais dimensões do espécime.

Após observação detalhada dos demais resultados estatísticos, uma nova hipótese em moldes semelhantes aos dos testes iniciais (Apêndice B) foi proposta, intentando averiguar se a velocidade de propagação ao longo da altura é superior àquelas nas demais dimensões, em função de uma suposta maior homogeneidade nessa dimensão por equivaler à direção de extrusão do material cerâmico no instante da fabricação da unidade. O novo teste apontou que a velocidade das ondas longitudinais é de fato superior quando medida ao longo da altura do bloco, se comparada com as observadas nas dimensões de sua seção transversal (largura e comprimento). Tal fenômeno não foi comprovado para as ondas transversais.

Esse resultado sugere que o processo de produção pode gerar não homogeneidades no espécime. A influência dessa constatação na determinação do módulo de elasticidade dinâmico foi estudada na forma de cenários: em um deles, apenas as velocidades ao longo da altura foram contabilizadas para o cálculo do módulo de elasticidade longitudinal $(E)$; no outro, as velocidades ao longo da altura foram descartadas da média aritmética para a determinação dessa propriedade. Na Tabela 5.3 é feito o comparativo entre os cenários descritos e o utilizado.

Tabela 5.3 - Influência da não homogeneidade do material no módulo de elasticidade longitudinal dinâmico: blocos inteiros cerâmicos

\begin{tabular}{|c|c|c|c|c|c|c|}
\hline \multirow[b]{2}{*}{ ID } & \multicolumn{2}{|c|}{ UTILIZADO (três dimensões) } & \multicolumn{2}{|c|}{ CENÁRIO 1 (apenas H) } & \multicolumn{2}{|c|}{ CENÁRIO 2 (apenas L e C) } \\
\hline & $\begin{array}{c}V P \\
(\mathrm{~m} / \mathrm{s})\end{array}$ & $\begin{array}{c}E \\
(\mathbf{G P a})\end{array}$ & $\begin{array}{c}V_{P} \\
(\mathrm{~m} / \mathrm{s})\end{array}$ & $\begin{array}{c}E \\
(\mathbf{G P a})\end{array}$ & $\begin{array}{c}V P \\
(\mathrm{~m} / \mathrm{s})\end{array}$ & $\begin{array}{c}E \\
(\mathrm{GPa})\end{array}$ \\
\hline 6-1(END) & $2155,0 \pm 173,1$ & 8,02 & $2423,1 \pm 78,3$ & 10,14 & $2088,0 \pm 114,0$ & 7,53 \\
\hline 6-2(END) & $2169,3 \pm 157,0$ & 8,15 & $2422,2 \pm 54,8$ & 10,16 & $2106,0 \pm 97,8$ & 7,68 \\
\hline 6-3(END) & $2319,1 \pm 169,8$ & 9,37 & $2556,4 \pm 104,3$ & 11,39 & $2259,7 \pm 124,9$ & 8,90 \\
\hline
\end{tabular}

No Cenário 1, a dispersão das medidas de velocidade foi severamente mitigada quando comparada à situação originalmente utilizada (coeficiente de variação ficando, em média, em cerca de 3\%). Ao se considerar apenas medidas nas dimensões da seção transversal (largura e comprimento), a flutuação da velocidade, embora reduzida, não ocorre em taxa tão notável (na faixa de $5 \%$, em média). 
Para o cálculo de $E$, foi fixado o valor de $v$ em 0,17 . Contudo, mantendo a velocidade média das ondas transversais inalteradas e com as novas velocidades médias para onda longitudinal no Cenário 1 , o coeficiente de Poisson passaria a apresentar valores coerentes $(0,18$ a 0,19$)$. Já no Cenário 2, a redução das velocidades médias $\left(V_{P}\right)$ fez com que os valores dessa propriedade ficassem mais afetados que na situação original, resultando em coeficientes negativos. Isso leva a crer que o procedimento nesses espécimes superestimou as velocidades de onda transversal e/ou subestimou as velocidades de onda longitudinal.

Finalmente, o impacto das diferentes formas de se calcular o módulo de elasticidade dinâmico é caracterizado por um aumento de cerca de $24 \%$ no Cenário 1 e uma redução em torno de 5,5\% no Cenário 2, ambos em relação a situação inicialmente considerada (média simples das medidas ao longo das três dimensões). Essas diferenças corresponderiam, respectivamente, a variações da ordem de $11 \%$ (para cima) e 2,8\% (para baixo) nas frequências naturais estimadas numericamente.

\subsubsection{Bloco inteiro de concreto}

As velocidades médias de propagação e suas dispersões estão denotadas na Tabela 5.4, que faz referência ao sistema de pontos já apresentado na Figura 3.11. As propriedades elásticas obtidas através destas velocidades são informadas na Tabela 5.5.

Tabela 5.4 - Velocidade de propagação de ondas em blocos de concreto

\begin{tabular}{|c|c|c|c|c|c|c|c|c|}
\hline & \multicolumn{2}{|c|}{$\begin{array}{l}\text { Largura (L) } \\
0-7,1-6 \text { e 2-5 }\end{array}$} & \multicolumn{2}{|c|}{$\begin{array}{c}\text { Comprimento }(\mathrm{C}) \\
3-9 \text { e } 4-8\end{array}$} & \multicolumn{2}{|c|}{$\begin{array}{c}\text { Altura (H) } \\
H 1, H 2, H 3, \\
H 4 \text { e H5 }\end{array}$} & \multicolumn{2}{|c|}{ Total } \\
\hline & $\begin{array}{c}V_{P} \\
(\mathrm{~m} / \mathbf{s})\end{array}$ & $\begin{array}{c}V S \\
(\mathrm{~m} / \mathrm{s})\end{array}$ & $\begin{array}{c}V_{P} \\
(\mathrm{~m} / \mathbf{s})\end{array}$ & $\begin{array}{c}V_{S} \\
(\mathrm{~m} / \mathrm{s})\end{array}$ & $\begin{array}{c}V_{P} \\
(\mathrm{~m} / \mathrm{s})\end{array}$ & $\begin{array}{c}V_{S} \\
(\mathbf{m} / \mathbf{s})\end{array}$ & $\begin{array}{c}V_{P} \\
(\mathrm{~m} / \mathrm{s})\end{array}$ & 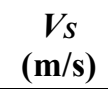 \\
\hline & \multicolumn{8}{|c|}{ 14.10-1(END) } \\
\hline MÉD & 4447,4 & 2625,2 & 4358,5 & 2581,5 & 4393,1 & 2634,8 & 4408,2 & 2613,1 \\
\hline DP & 104,8 & 41,9 & 70,4 & 65,1 & 60,8 & 62,6 & $\mathbf{9 3 , 5}$ & 56,6 \\
\hline \multirow[t]{2}{*}{ CV $(\%)$} & 2,36 & 1,60 & 1,62 & 2,52 & 1,38 & 2,38 & 2,12 & 2,16 \\
\hline & \multicolumn{8}{|c|}{ 14.10-2(END) } \\
\hline MÉD & 4390,8 & 2598,7 & 4288,8 & 2552,6 & 4370,1 & 2616,6 & 4354,0 & 2587,5 \\
\hline DP & 145,3 & 71,4 & 80,6 & 60,2 & 64,6 & 75,7 & 120,1 & 70,6 \\
\hline \multirow[t]{2}{*}{ CV (\%) } & 3,31 & 2,75 & 1,88 & 2,36 & 1,48 & 2,89 & 2,76 & 2,73 \\
\hline & \multicolumn{8}{|c|}{ 14.10-3(END) } \\
\hline MÉD & 4452,8 & 2594,4 & 4273,5 & 2521,9 & 4306,5 & 2551,9 & 4366,1 & 2562,7 \\
\hline DP & 79,1 & 59,8 & 97,1 & 48,6 & 55,4 & 24,9 & 116,1 & 59,3 \\
\hline CV $(\%)$ & 1,78 & 2,31 & 2,27 & 1,93 & 1,29 & 0,98 & 2,66 & 2,31 \\
\hline
\end{tabular}


Tabela 5.5 - Estimativa das propriedades elásticas dinâmicas: blocos de concreto

\begin{tabular}{cccc}
\hline ID & $\boldsymbol{E}$ & $\boldsymbol{G}$ & \multirow{2}{*}{} \\
& $(\mathbf{G P a})$ & $(\mathbf{G P a})$ & 0,23 \\
$\mathbf{1 4 . 1 0 - 1 ( E N D )}$ & 39,39 & 16,02 & 0,23 \\
$\mathbf{1 4 . 1 0 - 2 ( E N D )}$ & 37,83 & 15,42 & 0,24 \\
\hline $\mathbf{1 4 . 1 0 - 3 ( E N D )}$ & 37,50 & 15,16 & \\
\hline
\end{tabular}

A dispersão das velocidades em relação à média pode ser considerada baixa (por volta de $2 \%$ para ambos os tipos de onda), o que pode estar associada à maior uniformidade do material que constitui essas unidades.

As estimativas logradas para o coeficiente de Poisson (empregando as velocidades médias de ondas primárias e secundárias) foram satisfatórias, pois sobrepujam o valor do equivalente estático, usualmente tomado como 0,20 para concretos de diferentes classes. Esse comportamento é previsto por Mehta e Monteiro (2014).

Caso $v$ fosse determinado de forma local, isto é, com valores de $V_{P}$ e $V_{S}$ calculados em cada ponto da malha prevista para o ensaio, coeficientes de variação próximos a $10 \%$ seriam verificados. Essa flutuação, apesar de alta para um ensaio não destrutivo, é bastante razoável diante das variações típicas dos métodos destrutivos, especialmente na aferição de uma propriedade como o coeficiente de Poisson.

Entretanto, os resultados da análise estatística não foram tão conclusivos quanto aqueles dos blocos inteiros cerâmicos, no sentido de que nenhum evento estatisticamente significante foi observado nas três unidades da amostra. Apenas no limite do nível de significância adotado (5\%) seria possível afirmar que a velocidade das ondas longitudinais na camada 1 (face de menor espessura do bloco) é diferente daquela em pelo menos uma outra camada qualquer ao longo da altura, sem padrão definido. Caso fosse constatada com maior incidência, essa tendência poderia incutir uma não homogeneidade supostamente relacionada ao processo de compactação do material quando da produção de tais espécimes.

\subsubsection{Meio-bloco cerâmico}

Os valores médios e taxas de dispersão da propagação de ondas pelas três direções da unidade são especificados na Tabela 5.6, contemplando o sistema de pontos adotado para o meio-bloco cerâmico (vide Figura 3.12). Os parâmetros mecânicos estimados em função das velocidades médias são indicados na Tabela 5.7. 
Tabela 5.6 - Velocidade de propagação de ondas em meio-blocos cerâmicos

\begin{tabular}{|c|c|c|c|c|c|c|c|c|}
\hline \multirow[b]{2}{*}{ H2 } & \multicolumn{2}{|c|}{$\begin{array}{l}\text { Largura (L) } \\
\quad 0-5 \text { e } 1-4\end{array}$} & \multicolumn{2}{|c|}{$\begin{array}{c}\text { Comprimento (C) } \\
2-7 \text { e 3-6 }\end{array}$} & \multicolumn{2}{|c|}{$\begin{array}{c}\text { Altura (H) } \\
\mathrm{H1}, \mathrm{H} 2, \mathrm{H} 3 \text { e H4}\end{array}$} & \multicolumn{2}{|c|}{ Total } \\
\hline & $\begin{array}{c}V_{P} \\
(\mathrm{~m} / \mathbf{s})\end{array}$ & $\begin{array}{c}V S \\
(\mathbf{m} / \mathbf{s})\end{array}$ & $\begin{array}{c}V_{P} \\
(\mathrm{~m} / \mathrm{s})\end{array}$ & $\begin{array}{c}V S \\
(\mathbf{m} / \mathbf{s})\end{array}$ & $\begin{array}{c}V_{P} \\
(\mathrm{~m} / \mathbf{s})\end{array}$ & $\begin{array}{c}V S \\
(\mathbf{m} / \mathbf{s})\end{array}$ & $\begin{array}{c}V_{P} \\
(\mathbf{m} / \mathbf{s})\end{array}$ & $\begin{array}{c}V S \\
(\mathrm{~m} / \mathrm{s})\end{array}$ \\
\hline & \multicolumn{8}{|c|}{ M14-1(END) } \\
\hline MÉD & 2540,8 & 1673,5 & 2856,5 & 1821,1 & 3098,0 & 1812,1 & 2778,5 & 1760,3 \\
\hline DP & 200,6 & 76,2 & 40,5 & 27,1 & 93,5 & 72,7 & 254,3 & 92,4 \\
\hline \multirow[t]{2}{*}{ CV (\%) } & 7,89 & 4,55 & 1,42 & 1,49 & 3,02 & 4,01 & 9,15 & 5,25 \\
\hline & \multicolumn{8}{|c|}{ M14-2(END) } \\
\hline MÉD & 2646,6 & 1761,0 & 3087,2 & 1908,7 & 3244,7 & 1917,3 & 2942,5 & 1851,4 \\
\hline DP & 192,5 & 86,0 & 97,7 & 45,0 & 124,4 & 91,3 & 290,7 & 102,6 \\
\hline \multirow[t]{2}{*}{ CV (\%) } & 7,27 & 4,89 & 3,16 & 2,36 & 3,83 & 4,76 & $\mathbf{9 , 8 8}$ & 5,54 \\
\hline & \multicolumn{8}{|c|}{ M14-3(END) } \\
\hline MÉD & 2647,2 & 1738,8 & 2979,1 & 1873,2 & 3301,6 & 1975,5 & 2910,8 & 1839,9 \\
\hline DP & 211,4 & 77,2 & 88,5 & 99,7 & 121,8 & 72,0 & 291,7 & 123,8 \\
\hline CV (\%) & 7,98 & 4,44 & 2,97 & 5,32 & 3,69 & 3,65 & 10,02 & 6,73 \\
\hline
\end{tabular}

Tabela 5.7 - Estimativa das propriedades elásticas dinâmicas: meio-blocos cerâmicos

\begin{tabular}{cccc}
\hline ID & $\boldsymbol{E}$ & $\boldsymbol{G}$ & $\boldsymbol{v}$ \\
\hline M14-1(END) & 13,94 & $(\mathbf{G P a})$ & 0,16 \\
M14-2(END) & 15,68 & 5,99 & 0,17 \\
M14-3(END) & 15,39 & 6,69 & 0,17 \\
\hline
\end{tabular}

Os meio-blocos cerâmicos manifestaram as maiores taxas de variação relativa das velocidades de propagação, aproximando-se de $10 \%$ para as ondas longitudinais e em torno de $6 \%$ para as ondas transversais. A magnitude dessas flutuações é um indicativo de possíveis não homogeneidades no material constituinte dessas unidades.

Diferentemente dos blocos inteiros cerâmicos, foi possível obter estimativas dentro do que se considera um valor consistente para o coeficiente de Poisson dinâmico, utilizando velocidades médias das ondas primárias e secundárias. Todavia, caso essa propriedade fosse calculada localmente, a partir das velocidades de onda longitudinal e transversal medidas em cada ponto da malha estabelecida, altas dispersões (acima de 40\%) seriam reveladas em virtude de valores espúrios apresentados em algumas regiões dos espécimes.

A partir dos testes de hipóteses, constataram-se as seguintes tendências: as velocidades das ondas longitudinais e transversais não diferiram significativamente entre as 4 camadas previstas. Além disso, as velocidades nas medidas simétricas ao longo da largura (0-5/1-4) foram significativamente diferentes para ambos os tipos de onda. Por fim, as velocidades de ondas longitudinais ao longo das três dimensões do espécime mostraram-se significativamente 
diferentes entre si, enquanto nas ondas transversais apenas a velocidade ao longo da largura divergiu significativamente daquela nas demais dimensões.

A variação de velocidade constatada nas medidas ao longo da largura pode ser imputada ao fato de que essas unidades são produzidas na forma de dois meio-blocos unidos por um pequeno trecho intermediário de material, devendo ser separados manualmente (com auxílio de colher de pedreiro, por exemplo). Esse procedimento acaba danificando uma das laterais da unidade, ao passo que a outra permanece íntegra.

É curioso notar que, apesar das altas dispersões de velocidade verificadas nas unidades de material cerâmico, as velocidades médias mantêm-se semelhantes ao longo das quatro camadas dispostas pela altura do espécime. Tal tendência não ocorreu nos blocos inteiros de concreto, que apresentaram baixa variabilidade.

Assim como feito para o bloco inteiro cerâmico, o teste de hipótese adicional relativo à comparação entre velocidades na altura e nas demais dimensões do espécime foi reproduzido. O resultado foi análogo, atestando que a velocidade das ondas longitudinais é superior quando a propagação se dá na direção de extrusão do material, o que não ocorre com as ondas transversais. A magnitude dessa influência na estimativa do módulo de elasticidade do material foi examinada confrontando diferentes cenários de seleção das velocidades para o cálculo da propriedade, conforme exposto na Tabela 5.8.

Tabela 5.8 - Influência da não homogeneidade do material no módulo de elasticidade longitudinal dinâmico: meio-blocos cerâmicos

\begin{tabular}{ccccccc}
\hline \multirow{2}{*}{ ID } & \multicolumn{2}{c}{ UTILIZADO (três dimensões) } & \multicolumn{2}{c}{ CENÁRIO 1 (apenas H) } & \multicolumn{2}{c}{ CENÁRIO 2 (apenas L e C) } \\
\cline { 2 - 7 } & $\begin{array}{c}\boldsymbol{V} \boldsymbol{P} \\
(\mathbf{m} / \mathbf{s})\end{array}$ & $\begin{array}{c}\boldsymbol{E} \\
(\mathbf{G P a})\end{array}$ & $\begin{array}{c}\boldsymbol{V} \boldsymbol{P} \\
(\mathbf{m} / \mathbf{s})\end{array}$ & $\begin{array}{c}\boldsymbol{E} \\
(\mathbf{G P a})\end{array}$ & $\begin{array}{c}\boldsymbol{V} \boldsymbol{P} \\
(\mathbf{m} / \mathbf{s})\end{array}$ & $\begin{array}{c}\boldsymbol{E} \\
(\mathbf{G P a})\end{array}$ \\
\hline M14-1(END) & $2778,5 \pm 254,3$ & 13,94 & $3098,0 \pm 93,5$ & 17,41 & $2698,6 \pm 214,8$ & 13,21 \\
M14-2(END) $2942,5 \pm 290,7$ & 15,68 & $3244,7 \pm 124,4$ & 19,11 & $2866,9 \pm 271,1$ & 15,06 \\
M14-3(END) $2910,8 \pm 291,7$ & 15,39 & $3301,6 \pm 121,8$ & 19,75 & $2813,1 \pm 232,1$ & 14,47 \\
\hline
\end{tabular}

A dispersão das medidas de velocidade continua alta (em torno de 8,5\%) ao se admitir o Cenário 2. Já quando apenas medidas ao longo da altura são consideradas, a flutuação é drasticamente reduzida, mostrando-se inferior a $4 \%$ nas três unidades.

Preservando as velocidades médias obtidas para as ondas secundárias e calculando $v$ com as novas velocidades de onda primária em cada cenário, observou-se coeficientes nas faixas de 0,25 no Cenário 1 e 0,15 no Cenário 2 . No entanto, assim como para os blocos inteiros cerâmicos, o contraponto entre possíveis valores de $E$ foi realizado mantendo o valor do coeficiente de Poisson encontrado inicialmente para cada unidade da amostra (Tabela 5.7). 
O primeiro cenário representaria um aumento da ordem de $25 \%$ no módulo de elasticidade longitudinal originalmente estimado, o que corresponderia a uma alteração de quase $12 \%$ no sentido de amplificar as frequências ressonantes previstas pela modelagem numérica. Para o Cenário 2, ocorreria minoração média de 5,1\% no valor do parâmetro mecânico, implicando em frequências naturais cerca de 2,8\% mais baixas. Repara-se que tais valores são muito semelhantes aos verificados no bloco inteiro, apesar das unidades possuírem resistências nominais diferentes.

\subsubsection{Meio-bloco de concreto}

A Tabela 5.9 reúne as médias e dispersões das velocidades de propagação ao longo das três dimensões do corpo de prova. O sistema de pontos remetido é aquele da Figura 3.13. As propriedades elásticas determinadas são relatadas pela Tabela 5.10.

Tabela 5.9 - Velocidade de propagação de ondas em meio-blocos de concreto

\begin{tabular}{|c|c|c|c|c|c|c|c|c|c|}
\hline \multirow{2}{*}{$\mathrm{H} 2$} & \multirow[t]{2}{*}{ низ } & \multicolumn{2}{|c|}{$\begin{array}{c}\text { Largura (L) } \\
0-5 \text { e } 1-4\end{array}$} & \multicolumn{2}{|c|}{$\begin{array}{c}\text { Comprimento (C) } \\
2-7 \text { e 3-6 }\end{array}$} & \multicolumn{2}{|c|}{$\begin{array}{c}\text { Altura (H) } \\
H 1, H 2, H 3 \text { e H4 }\end{array}$} & \multicolumn{2}{|c|}{ Total } \\
\hline & & $\begin{array}{c}V_{P} \\
(\mathbf{m} / \mathbf{s})\end{array}$ & $\begin{array}{c}V_{S} \\
(\mathrm{~m} / \mathrm{s})\end{array}$ & $\begin{array}{c}V_{P} \\
(\mathbf{m} / \mathbf{s})\end{array}$ & $\begin{array}{c}V_{S} \\
(\mathrm{~m} / \mathrm{s})\end{array}$ & $\begin{array}{c}V_{P} \\
(\mathrm{~m} / \mathbf{s})\end{array}$ & $\begin{array}{c}V_{S} \\
(\mathrm{~m} / \mathrm{s})\end{array}$ & $\begin{array}{c}V_{P} \\
(\mathbf{m} / \mathbf{s})\end{array}$ & $\begin{array}{c}V_{S} \\
(\mathrm{~m} / \mathrm{s})\end{array}$ \\
\hline & & \multicolumn{8}{|c|}{ 19.10-1(END) } \\
\hline & MÉD & 4859,3 & 2811,4 & 4815,0 & 2788,5 & 4709,0 & 2767,4 & 4811,6 & 2793,4 \\
\hline & DP & 50,9 & 29,0 & 50,3 & 23,4 & 32,4 & 23,3 & 72,3 & 29,8 \\
\hline \multirow{2}{*}{\multicolumn{2}{|c|}{ CV $(\%)$}} & 1,05 & 1,03 & 1,04 & 0,84 & 0,69 & 0,84 & 1,50 & $\mathbf{1 , 0 7}$ \\
\hline & & \multicolumn{8}{|c|}{ 19.10-2(END) } \\
\hline & MÉD & 4836,7 & 2805,2 & 4825,7 & 2817,9 & 4724,5 & 2784,5 & 4809,9 & 2806,1 \\
\hline & DP & 84,3 & 64,3 & 63,8 & 42,9 & 60,8 & 52,1 & 81,5 & 52,8 \\
\hline \multirow{2}{*}{\multicolumn{2}{|c|}{ CV (\%) }} & 1,74 & 2,29 & 1,32 & 1,52 & 1,29 & 1,87 & 1,69 & 1,88 \\
\hline & & \multicolumn{8}{|c|}{ 19.10-3(END) } \\
\hline & MÉD & 4794,0 & 2760,3 & 4778,9 & 2774,4 & 4694,1 & 2797,9 & 4768,0 & 2773,4 \\
\hline & DP & 80,2 & 65,8 & 73,7 & 45,2 & 5,9 & 31,1 & 76,5 & 51,9 \\
\hline & CV (\%) & 1,67 & 2,38 & 1,54 & 1,63 & 0,13 & 1,11 & 1,60 & 1,87 \\
\hline
\end{tabular}

Tabela 5.10 - Estimativa das propriedades elásticas dinâmicas: meio-blocos de concreto

\begin{tabular}{cccc}
\hline ID & $\begin{array}{c}\boldsymbol{E} \\
\text { (GPa) }\end{array}$ & $\begin{array}{c}\boldsymbol{G} \\
(\mathbf{G P a})\end{array}$ & $\boldsymbol{v}$ \\
\hline $\mathbf{1 9 . 1 0 - 1 ( E N D )}$ & 47,32 & 18,99 & 0,25 \\
$\mathbf{1 9 . 1 0 - 2 ( E N D )}$ & 47,57 & 19,15 & 0,24 \\
$\mathbf{1 9 . 1 0 - 3 ( E N D )}$ & 46,25 & 18,58 & 0,24 \\
\hline
\end{tabular}


Aqui é válido recordar que, embora os blocos e meio-blocos de concreto utilizados possuam a mesma resistência nominal, foram identificados módulos de elasticidade estáticos com certa diferença entre si. Os valores de módulo de elasticidade dinâmico aferidos nas unidades de concreto asseveram esse comportamento. As estimativas para $v$ condizem com aquelas observadas no bloco inteiro, evidenciando menor dispersão (em torno de 5\%) quando essa propriedade é analisada de modo localizado, ponto a ponto na malha concebida em detrimento do uso de velocidades médias.

Entre as diferentes unidades utilizadas na pesquisa, os meio-blocos de concreto apresentaram a menor variabilidade da velocidade de propagação de ondas (inferior a $2 \%$ para primárias e secundárias), o que intercede favoravelmente acerca da uniformidade de seu material constituinte. Essa percepção é reforçada ao constatar que, apenas nestes espécimes, as velocidades (tanto de ondas longitudinais quanto transversais) não diferiram significativamente entre as medidas simétricas na largura (0-5/1-4) e no comprimento (2-7/3-6).

Contudo, houve diferença significativa de velocidade entre pelo menos duas camadas ao longo da altura (tratando-se de ondas longitudinais) em toda a amostra, sem um padrão definido. Além disso, a velocidade das ondas longitudinais ao longo da altura do espécime divergiu significativamente daquela nas demais dimensões. Desse modo, semelhante ao observado no bloco inteiro, há sugestão de uma não homogeneidade possivelmente correlacionada ao processo de compactação na fabricação dessas unidades. 


\subsection{Ressonância acústica: resultados experimentais versus previsões numéricas}

A partir dos gráficos amplitude versus frequência logrados experimentalmente e das previsões obtidas através de análise modal numérica, foi feita a associação entre modos de vibrar e frequências ressonantes, indicadas pelos picos de amplitude.

Para tanto, lançou-se mão de um recurso gráfico confeccionado em duas fases: a primeira trata de validar a Função Resposta em Frequência (FRF) de cada uma das 6 configurações de ensaio, através da sobreposição de FRFs referentes às três repetições, proporcionando um espectro médio representativo. A segunda consiste em sobrepor os 6 espectros médios (cada um associado a uma configuração) de uma mesma unidade e então adicionar os valores de frequência previstos pela análise modal na forma de linhas tracejadas. Essa metodologia é elucidada pela Figura 5.1, ilustrando cada uma das fases separadamente.

Figura 5.1 - Elaboração dos gráficos amplitude versus frequência analisados
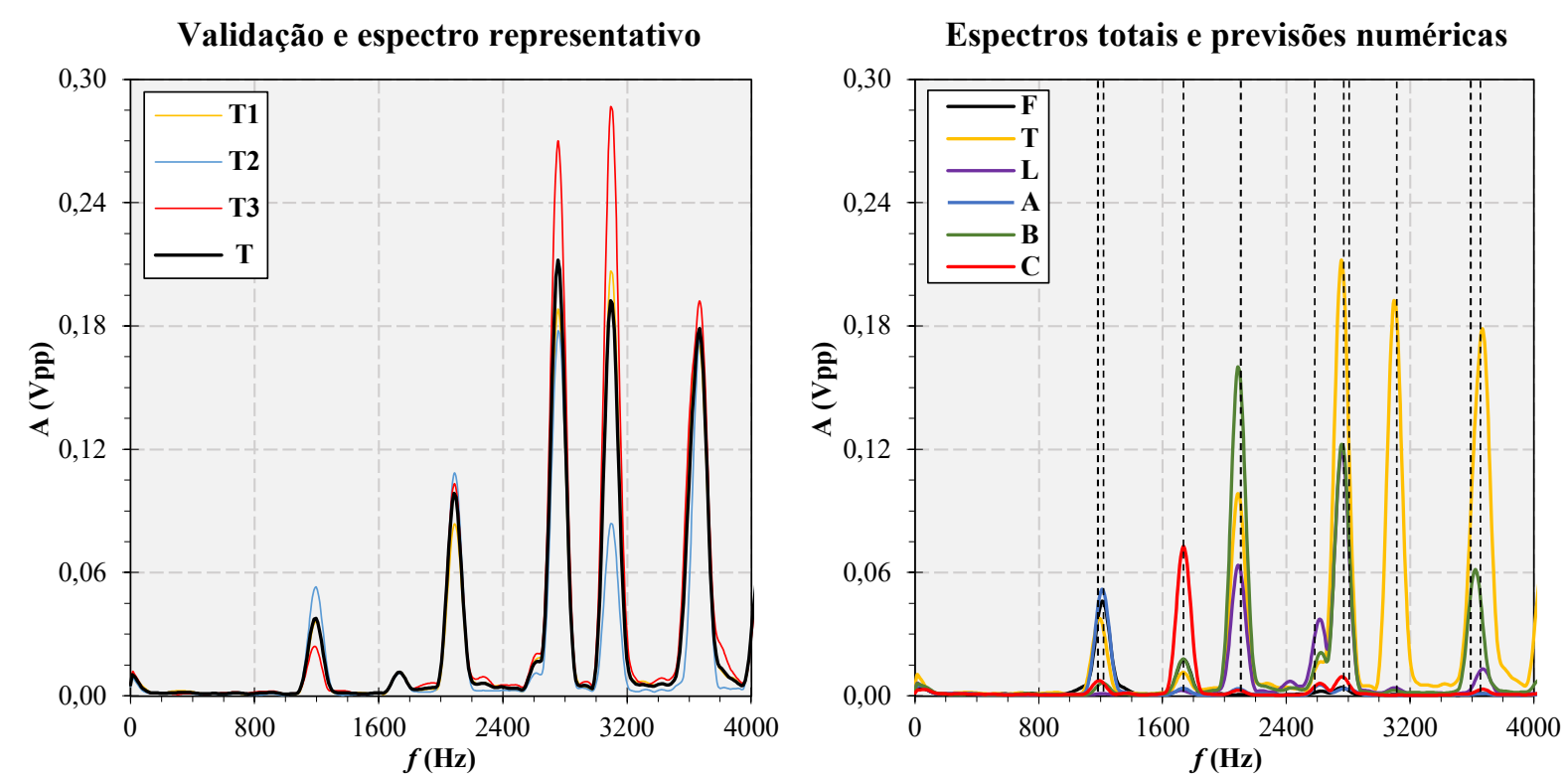

Fonte: Autor (2020)

Nesses gráficos, a resolução do eixo referente à frequência varia conforme a faixa estimada numericamente para cada unidade, contemplando as respectivas previsões dos 10 primeiros modos de vibrar. As amplitudes são dadas em nível de pressão sonora (SPL - Sound Pressure Level) com unidade de tensão de pico a pico (Vpp - Peak-to-peak voltage). Uma visão geral dos resultados obtidos para as frequências ressonantes é apresentada na Figura 5.2. 
Figura 5.2 - Frequências ressonantes: experimental versus numérico
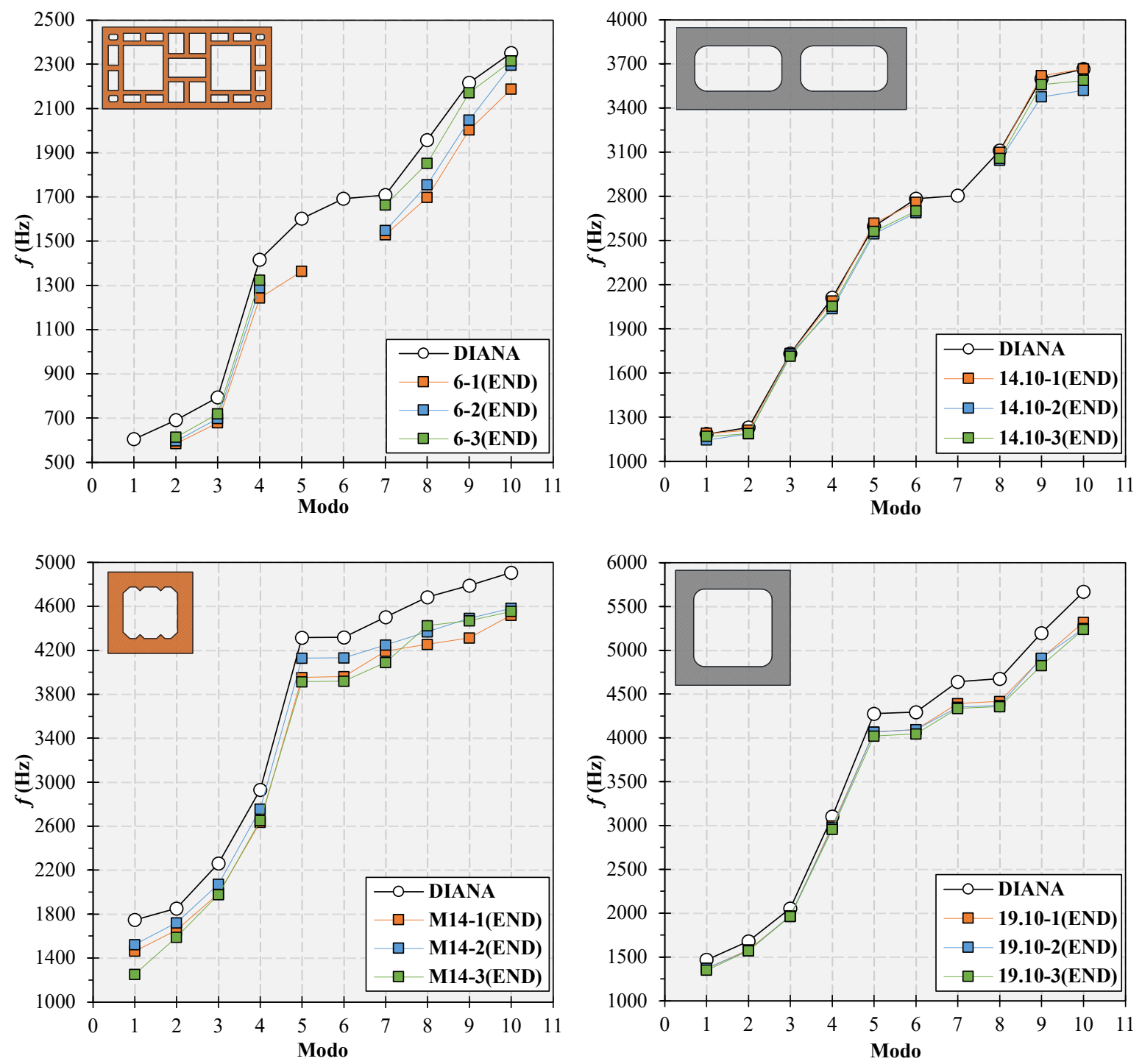

Fonte: Autor (2020)

A apuração das frequências naturais dos diferentes modos de vibrar é tratada a seguir, considerando a média dos valores de frequência nos casos em que determinado modo incidiu em mais de uma das configurações de ensaio. Além disso, foram calculados módulos de elasticidade com base na Equação 4.1, utilizando a massa medida para as unidades de cada amostra, as frequências naturais identificadas experimentalmente e os coeficientes geométricos $\beta$ determinados na análise numérica.

Por fim, baseando-se na quantidade de frequências claramente identificáveis quando a unidade é excitada isoladamente por cada combinação impacto/captação, foi possível julgar quais delas são mais "eficazes" para cada geometria/material, bem como identificar os modos ressonantes mais facilmente induzidos. 


\subsubsection{Bloco inteiro cerâmico}

Na Figura 5.3 são exibidos os espectros acumulados para as unidades da amostra de blocos inteiros cerâmicos, além das estimativas numéricas de suas frequências naturais.

Figura 5.3 - Espectros totais e previsões numéricas: blocos cerâmicos
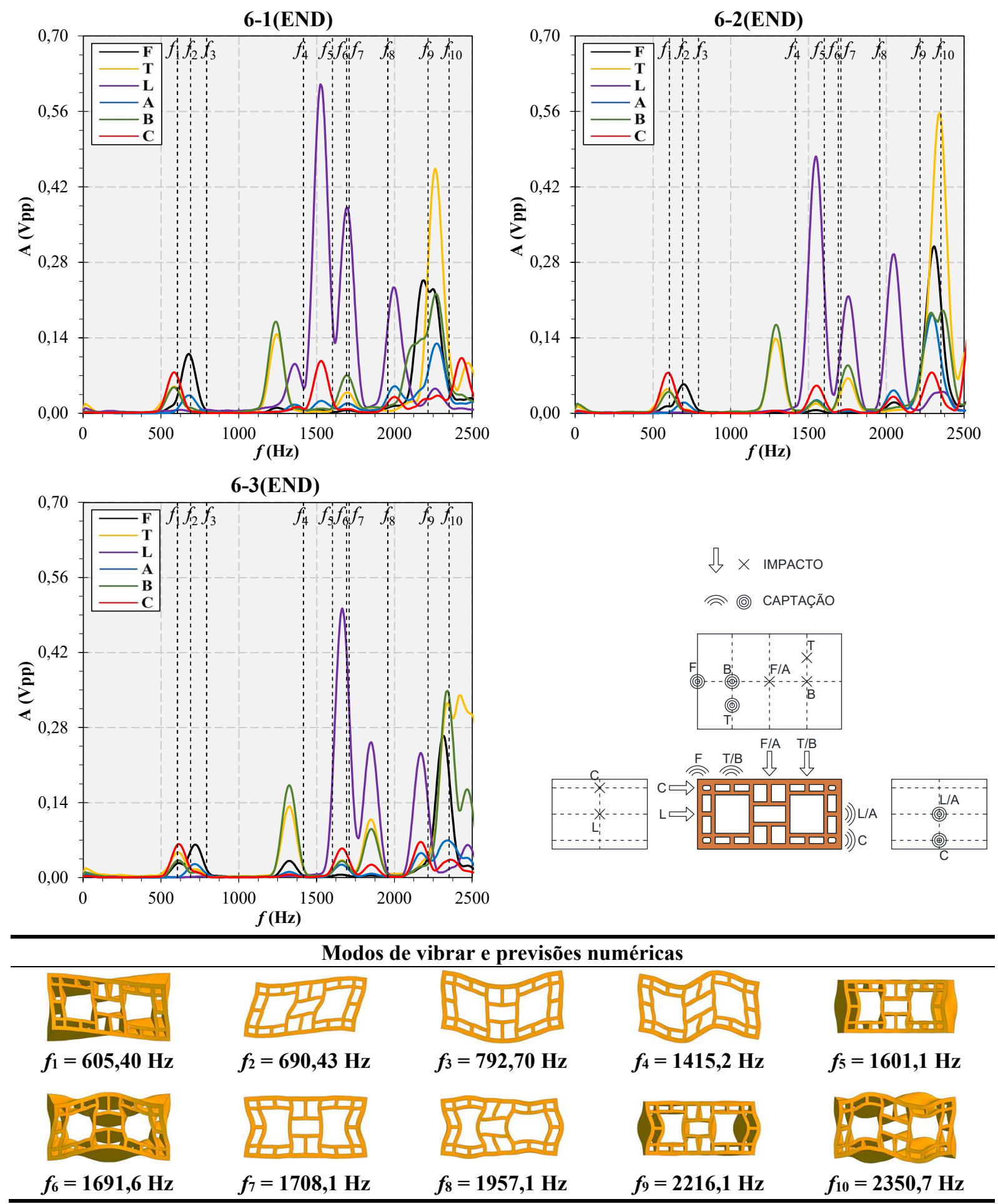

Fonte: Autor (2020) 
A comparação entre valores experimentais e numéricos de frequências naturais, assim como os módulos de elasticidade obtidos em consequência, são expostos na Tabela 5.11.

Tabela 5.11 - Frequências experimentais e módulo de elasticidade: blocos cerâmicos

\begin{tabular}{|c|c|c|c|c|c|c|c|c|c|}
\hline \multirow{2}{*}{ MODO } & \multicolumn{3}{|c|}{$\begin{array}{c}\text { 6-1(END) } \\
\mathrm{M}=5,855 \mathrm{~kg}\end{array}$} & \multicolumn{3}{|c|}{$\begin{array}{c}\text { 6-2(END) } \\
\mathrm{M}=5,895 \mathrm{~kg}\end{array}$} & \multicolumn{3}{|c|}{$\begin{array}{c}\text { 6-3(END) } \\
\mathrm{M}=5,878 \mathrm{~kg}\end{array}$} \\
\hline & $\begin{array}{l}f_{\exp } \\
(\mathbf{H z})\end{array}$ & $f_{\exp } / f_{\text {DIANA }}$ & $\begin{array}{c}E \\
\text { (GPa) }\end{array}$ & $\begin{array}{l}f_{\exp } \\
(\mathbf{H z})\end{array}$ & $f_{\text {exp }} / f_{\text {DIANA }}$ & $\begin{array}{c}E \\
(\mathbf{G P a}) \\
\end{array}$ & $\begin{array}{l}f_{\exp } \\
(\mathbf{H z})\end{array}$ & $f_{\text {exp }} / f_{\text {DIANA }}$ & $\begin{array}{c}E \\
\text { (GPa) }\end{array}$ \\
\hline 1 & $*$ & - & - & $*$ & - & - & $*$ & - & - \\
\hline 2 & 584,04 & 0,85 & 5,88 & 596,00 & 0,86 & 6,16 & 613,37 & 0,89 & 6,51 \\
\hline 3 & 678,54 & 0,86 & 6,02 & 697,67 & 0,88 & 6,41 & 718,40 & 0,91 & 6,77 \\
\hline 4 & 1242,5 & 0,88 & 6,33 & 1289,0 & 0,91 & 6,86 & 1323,6 & 0,94 & 7,21 \\
\hline 5 & 1363,6 & 0,85 & 5,96 & $*$ & - & - & $*$ & - & - \\
\hline 6 & $*$ & - & - & $*$ & - & - & $*$ & - & - \\
\hline 7 & 1528,8 & 0,90 & 6,58 & 1547,8 & 0,91 & 6,79 & 1662,9 & 0,97 & 7,82 \\
\hline 8 & 1697,4 & 0,87 & 6,18 & 1754,3 & 0,90 & 6,65 & 1850,9 & 0,95 & 7,38 \\
\hline 9 & 2002,2 & 0,90 & 6,70 & 2046,3 & 0,92 & 7,05 & 2170,0 & 0,98 & 7,91 \\
\hline 10 & 2187,2 & 0,93 & 7,11 & 2294,3 & 0,98 & 7,88 & 2313,9 & 0,98 & 7,99 \\
\hline MÉD & - & $\mathbf{0 , 8 8}$ & 6,35 & - & 0,91 & 6,83 & - & 0,94 & 7,37 \\
\hline DP & - & $\mathbf{0 , 0 3}$ & 0,43 & - & $\mathbf{0 , 0 4}$ & 0,55 & - & 0,04 & $\mathbf{0 , 5 8}$ \\
\hline CV (\%) & - & 3,34 & 6,72 & - & 3,97 & 8,04 & - & 3,94 & 7,83 \\
\hline
\end{tabular}

* Frequência ressonante não identificada experimentalmente.

A partir das Figuras 5.3 ou 5.2, já se poderia antecipar que as previsões numéricas para as frequências naturais do bloco inteiro cerâmico estão nitidamente superestimadas, impressão confirmada pelos valores logrados. O quinto modo foi excitado em apenas uma das unidades e o sexto modo não foi excitado em nenhuma delas.

Atenta-se para a não identificação do primeiro modo: a princípio, tem-se a impressão de que o modo não excitado é o terceiro, a julgar pela disposição das linhas tracejadas. Contudo, visto que a estimativa da análise modal para o primeiro modo é de $605 \mathrm{~Hz}$ e está superestimada, é possível que ele tenha sido excitado, mas com frequência inferior à do filtro de detecção padrão do Sonelastic $(500 \mathrm{~Hz})$, utilizado durante os ensaios. Além disso, em uma inspeção mais cuidadosa, vê-se que o segundo pico de amplitude destaca o espectro da configuração "F" (cor preta), concebida justamente para a excitação do $3^{\circ}$ modo (flexão no plano da seção).

Para esse espécime, as combinações impacto/excitação "T", "L", "B" e "C" possuem eficácia semelhante, incitando de 3 a 4 frequências ressonantes cada. Os modos de vibrar que figuraram com maior constância foram o segundo, o oitavo e o nono. 
5.2.2 Bloco inteiro de concreto

A sobreposição de espectros experimentais e previsões numéricas das frequências naturais para a amostra de blocos inteiros de concreto é retratada na Figura 5.4.

Figura 5.4 - Espectros totais e previsões numéricas: blocos de concreto
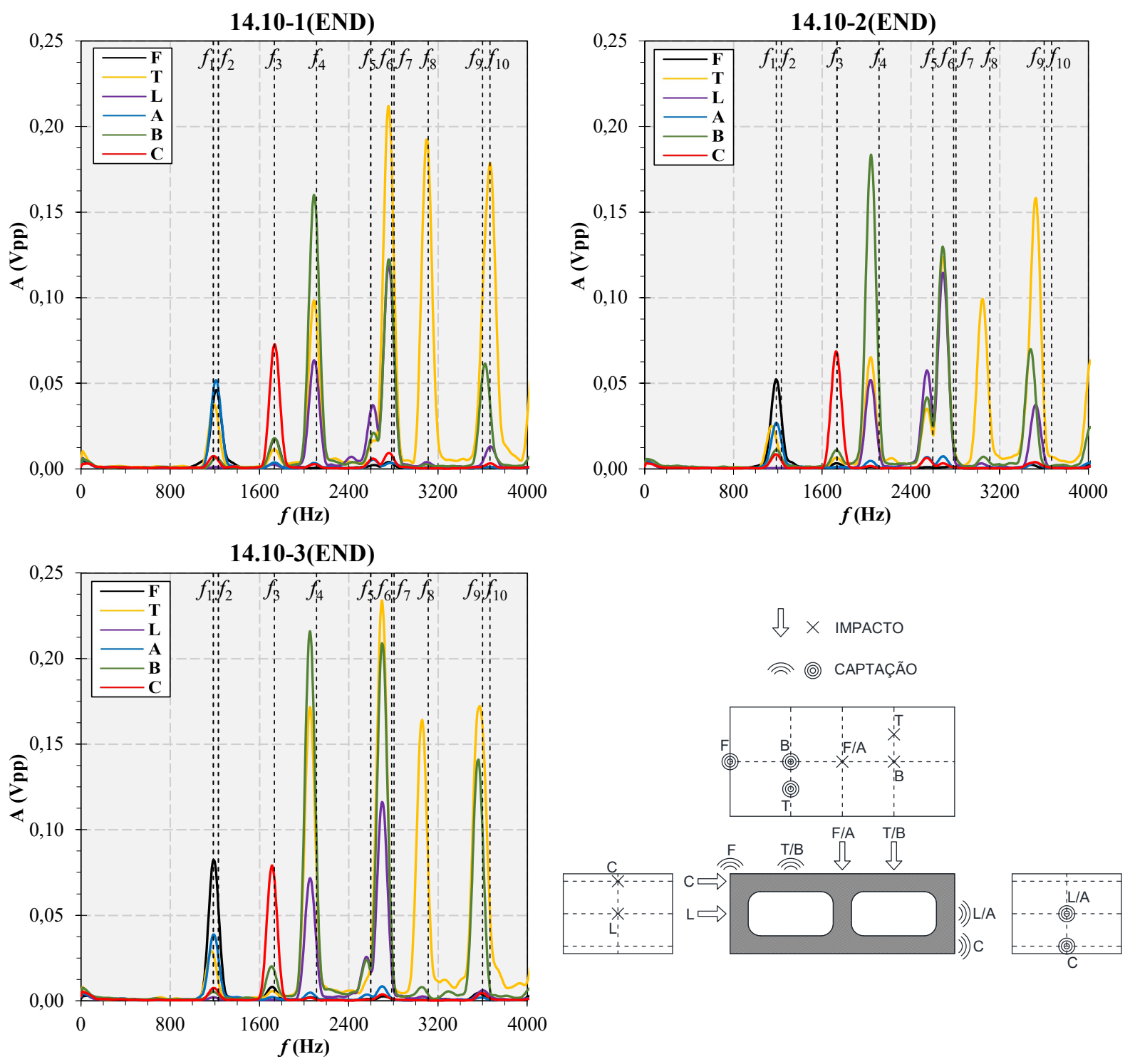

Modos de vibrar e previsões numéricas
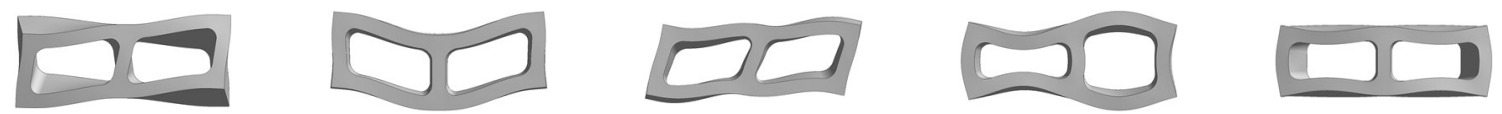

$f_{1}=1185,3 \mathrm{~Hz}$

$f_{2}=1230,5 \mathrm{~Hz}$

$f_{3}=1732,5 \mathrm{~Hz}$

$f_{4}=2110,5 \mathrm{~Hz}$

$f_{5}=2596,0 \mathrm{~Hz}$
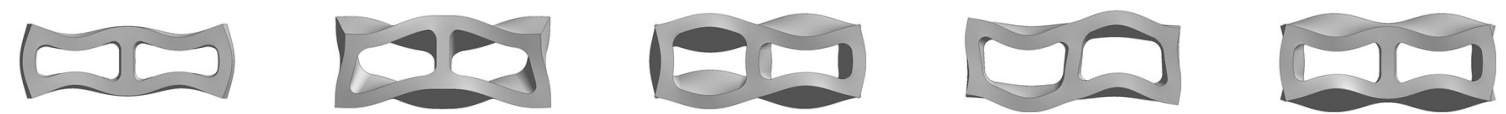

$f_{6}=2784,3 \mathrm{~Hz}$

$f_{7}=2805,0 \mathrm{~Hz}$

$f_{8}=3110,4 \mathrm{~Hz}$

$f_{9}=3599,0 \mathrm{~Hz}$

$f_{10}=3665,8 \mathrm{~Hz}$

Fonte: Autor (2020) 
$\mathrm{Na}$ Tabela 5.12, além do confronto entre resultados experimentais e numéricos de frequência, são relacionadas as estimativas para o módulo de elasticidade das unidades.

Tabela 5.12 - Frequências experimentais e módulo de elasticidade: blocos de concreto

\begin{tabular}{|c|c|c|c|c|c|c|c|c|c|}
\hline \multirow{2}{*}{ MODO } & \multicolumn{3}{|c|}{$\begin{array}{l}\text { 14.10-1(END) } \\
\mathrm{M}=12,961 \mathrm{~kg}\end{array}$} & \multicolumn{3}{|c|}{$\begin{array}{l}\text { 14.10-2(END) } \\
\mathrm{M}=12,726 \mathrm{~kg}\end{array}$} & \multicolumn{3}{|c|}{$\begin{array}{l}\text { 14.10-3(END) } \\
\mathrm{M}=12,854 \mathrm{~kg}\end{array}$} \\
\hline & $\begin{array}{l}f_{\text {exp }} \\
(\mathbf{H z})\end{array}$ & $f_{\text {exp }} / f_{\text {DIANA }}$ & $\begin{array}{c}E \\
\text { (GPa) }\end{array}$ & $\begin{array}{l}f_{\text {exp }} \\
(\mathbf{H z})\end{array}$ & $f_{\text {exp }} / f_{\text {DIANA }}$ & $\begin{array}{c}E \\
(\mathbf{G P a})\end{array}$ & $\begin{array}{l}f_{\text {exp }} \\
(\mathrm{Hz})\end{array}$ & $f_{\exp } / f_{\text {DIANA }}$ & $\begin{array}{c}E \\
(\mathbf{G P a})\end{array}$ \\
\hline 1 & 1189,5 & 1,00 & 37,98 & 1144,9 & 0,97 & 34,55 & 1168,7 & 0,99 & 36,36 \\
\hline 2 & 1211,0 & 0,98 & 36,53 & 1185,5 & 0,96 & 34,37 & 1188,1 & 0,97 & 34,87 \\
\hline 3 & 1731,7 & 1,00 & 37,68 & 1728,1 & 1,00 & 36,84 & 1712,2 & 0,99 & 36,53 \\
\hline 4 & 2088,5 & 0,99 & 36,93 & 2036,3 & 0,96 & 34,47 & 2052,3 & 0,97 & 35,39 \\
\hline 5 & 2617,9 & 1,01 & 38,36 & 2543,6 & 0,98 & 35,55 & 2560,7 & 0,99 & 36,30 \\
\hline 6 & 2757,9 & 0,99 & 37,00 & 2688,2 & 0,97 & 34,52 & 2699,7 & 0,97 & 35,17 \\
\hline 7 & $*$ & - & - & $*$ & - & - & $*$ & - & - \\
\hline 8 & 3098,2 & 1,00 & 37,42 & 3044,8 & 0,98 & 35,49 & 3055,9 & 0,98 & 36,11 \\
\hline 9 & 3620,0 & 1,01 & 38,16 & 3474,8 & 0,97 & 34,52 & 3559,7 & 0,99 & 36,59 \\
\hline 10 & 3665,6 & 1,00 & 37,71 & 3519,5 & 0,96 & 34,14 & 3587,7 & 0,98 & 35,83 \\
\hline MÉD & - & 1,00 & 37,53 & - & 0,97 & 34,94 & - & 0,98 & 35,91 \\
\hline DP & - & 0,01 & 0,61 & - & 0,01 & $\mathbf{0 , 8 7}$ & - & 0,01 & 0,64 \\
\hline CV (\%) & - & $\mathbf{0 , 8 1}$ & 1,63 & - & 1,23 & 2,48 & - & $\mathbf{0 , 8 9}$ & 1,78 \\
\hline
\end{tabular}

Apesar da excelente concordância entre valores experimentais e previsão numérica, nota-se que o sétimo modo de vibrar não foi excitado em nenhuma das três unidades, o que provavelmente indica as combinações impacto/captação concebidas são inadequadas para a indução de tal modo. Essa percepção é corroborada pelo fato do modo análogo no bloco inteiro cerâmico (sexto modo) também não ter sido excitado em nenhuma unidade daquela amostra.

Em duas das três unidades foi constatado um valor de frequência situado entre as dos $6^{\circ}$ e $8^{\circ}$ modos (e bem próximo ao sexto, como ocorreu na previsão do DIANA®). Porém, ocorria em apenas um dos casos de impacto/excitação e com amplitude muito baixa (sequer visível na escala utilizada). Logo, tal valor não foi atribuído ao $7^{\circ}$ modo.

Para o bloco inteiro de concreto, as configurações de ensaio "T" e "B" são as que induzem maior quantidade de picos de amplitude (entre 4 e 6). Em geral, o quarto e sexto modos de vibrar são os excitados com maior regularidade nesse tipo de unidade. 


\subsubsection{Meio-bloco cerâmico}

A Figura 5.5 revela os espectros reunidos para a amostra de meio-blocos cerâmicos, além da estimativa da análise modal para as 10 primeiras frequências ressonantes.

Figura 5.5 - Espectros totais e previsões numéricas: meio-blocos cerâmicos
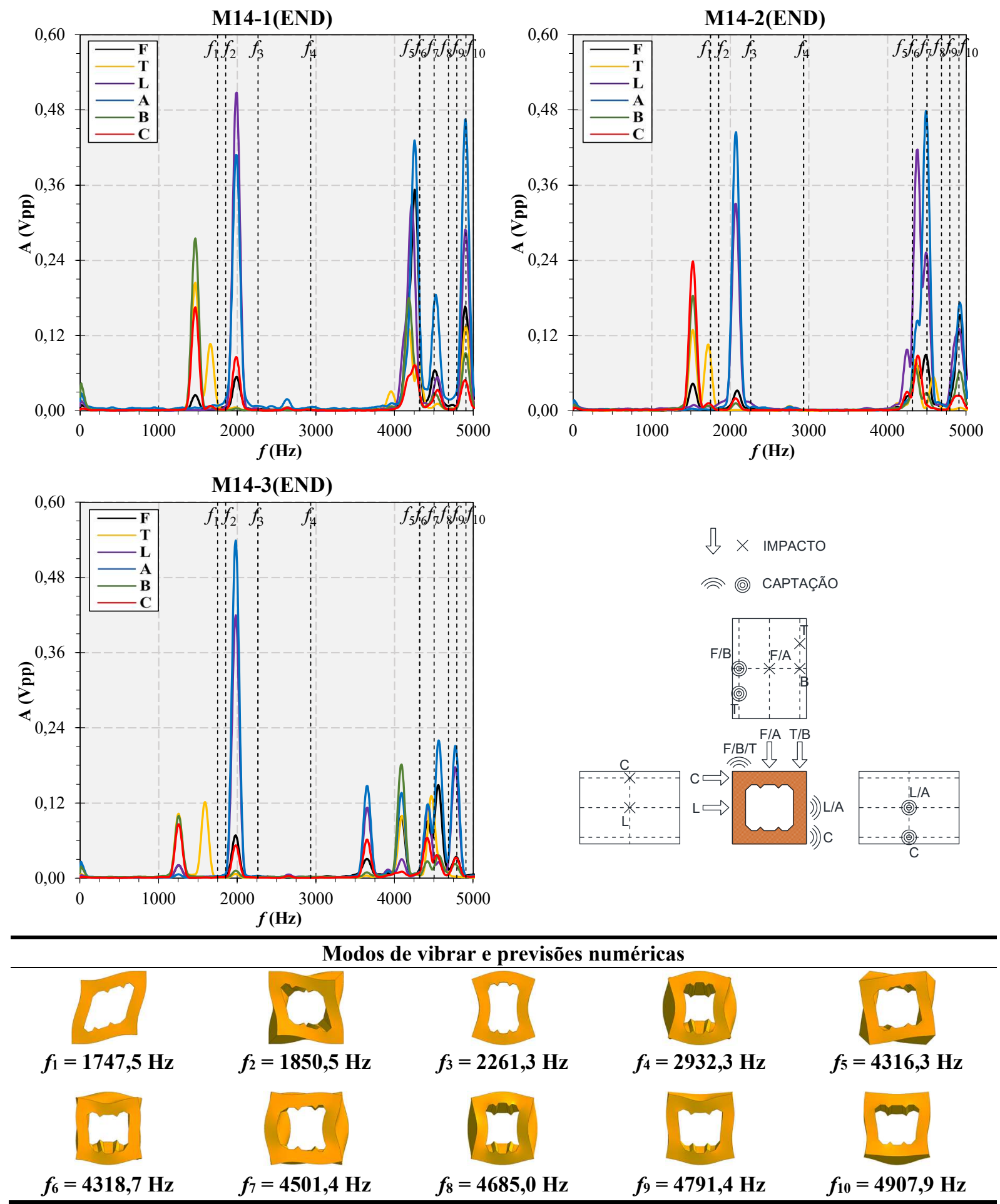

Fonte: Autor (2020) 
O comparativo entre frequências obtidas experimentalmente e previsão numérica para os meio-blocos cerâmicos é realizado na Tabela 5.13, que também exibe os valores calculados para o módulo de elasticidade.

Tabela 5.13 - Frequências experimentais e módulo de elasticidade: meio-blocos cerâmicos

\begin{tabular}{|c|c|c|c|c|c|c|c|c|c|}
\hline \multirow{2}{*}{ MODO } & \multicolumn{3}{|c|}{$\begin{array}{l}\text { M14-1(END) } \\
\mathrm{M}=4,112 \mathrm{~kg}\end{array}$} & \multicolumn{3}{|c|}{$\begin{array}{l}\text { M14-2(END) } \\
\text { M = 4,242 kg }\end{array}$} & \multicolumn{3}{|c|}{$\begin{array}{l}\text { M14-3(END) } \\
M=4,156 \mathrm{~kg}\end{array}$} \\
\hline & $\begin{array}{l}f_{\exp } \\
(\mathbf{H z})\end{array}$ & $f_{\text {exp }} / f_{\text {DIANA }}$ & $\begin{array}{c}E \\
(\mathbf{G P a})\end{array}$ & $\begin{array}{l}f_{\text {exp }} \\
(\mathbf{H z})\end{array}$ & $f_{\text {exp }} / f_{\text {DIANA }}$ & $\begin{array}{c}E \\
(\mathbf{G P a})\end{array}$ & $\begin{array}{l}f_{\text {exp }} \\
(\mathrm{Hz})\end{array}$ & $f_{\text {exp }} / f_{\text {DIANA }}$ & $\begin{array}{c}E \\
\text { (GPa) }\end{array}$ \\
\hline 1 & 1463,4 & 0,84 & 10,00 & 1523,7 & 0,87 & 11,19 & 1252,9 & $0,72^{*}$ & $7,41^{*}$ \\
\hline 2 & 1654,6 & 0,89 & 11,40 & 1720,4 & 0,93 & 12,72 & 1588,1 & 0,86 & 10,62 \\
\hline 3 & 1987,0 & 0,88 & 11,01 & 2073,0 & 0,92 & 12,37 & 1978,3 & 0,87 & 11,03 \\
\hline 4 & 2634,7 & 0,90 & 11,51 & 2755,5 & 0,94 & 12,99 & 2652,8 & 0,90 & 11,80 \\
\hline 5 & 3954,4 & 0,92 & 11,97 & 4127,5 & 0,96 & 13,46 & 3914,1 & 0,91 & 11,85 \\
\hline 6 & 3961,6 & 0,92 & 12,00 & 4132,9 & 0,96 & 13,48 & 3920,1 & 0,91 & 11,88 \\
\hline 7 & 4192,4 & 0,93 & 12,37 & 4248,7 & 0,94 & 13,11 & 4089,0 & 0,91 & 11,89 \\
\hline 8 & 4254,7 & 0,91 & 11,76 & 4368,2 & 0,93 & 12,79 & 4423,3 & 0,94 & 12,85 \\
\hline 9 & 4312,5 & 0,90 & 11,55 & 4491,1 & 0,94 & 12,93 & 4468,8 & 0,93 & 12,54 \\
\hline 10 & 4519,5 & 0,92 & 12,09 & 4583,2 & 0,93 & 12,83 & 4555,7 & 0,93 & 12,42 \\
\hline MÉD & - & 0,90 & 11,57 & - & 0,93 & 12,79 & - & 0,91 & 11,87 \\
\hline DP & - & 0,03 & 0,68 & - & 0,02 & 0,65 & - & 0,03 & 0,71 \\
\hline CV (\%) & - & 2,97 & 5,84 & - & 2,60 & 5,10 & - & $\mathbf{3 , 0 0}$ & 5,95 \\
\hline
\end{tabular}

As frequências ressonantes registradas experimentalmente são consistentemente inferiores às estimadas pela análise modal numérica, repetindo a tendência constatada no bloco inteiro cerâmico. Em uma das unidades, o $1^{\circ}$ modo ocorreu com frequência bem mais baixa que a observada nas demais, o que pode ser atribuído a um possível defeito interno ou trinca mais pronunciada e orientada de forma a afetar apenas a vibração em determinado sentido.

Pode-se notar, pela Figura 5.5, que os espectros das três unidades se diferenciam excepcionalmente a partir das frequências acima de $4000 \mathrm{~Hz}$, e que em cada um dos casos observam-se picos de amplitude levemente defasados e sobrepostos, fatores que dificultaram a identificação e associação de frequências e modos naturais.

Combinações de impacto/captação do tipo " $\mathrm{T}$ " e "F" foram as mais profícuas para a geometria do meio-bloco cerâmico, produzindo de 4 a 5 picos de ressonância bem caracterizados. Os modos de vibrar com maior incidência são o primeiro, o terceiro e o oitavo. 
5.2.4 Meio-bloco de concreto

A totalidade dos espectros amplitude versus frequência e as previsões numéricas para a amostra de três meio-blocos de concreto são apresentadas na Figura 5.6.

Figura 5.6 - Espectros totais e previsões numéricas: meio-blocos de concreto
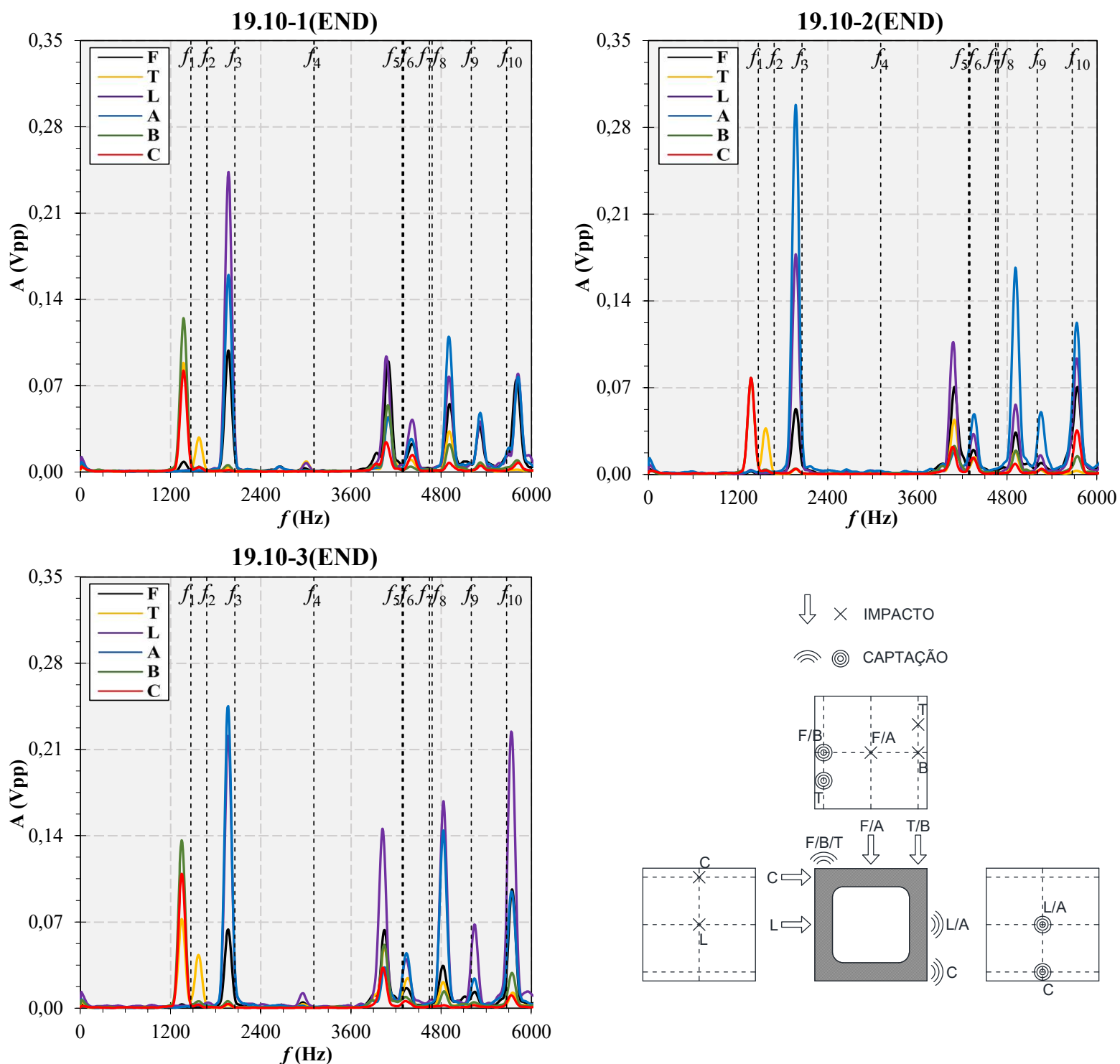

Modos de vibrar e previsões numéricas

$f_{1}=1469,3 \mathrm{~Hz} \quad f_{2}=1681,6 \mathrm{~Hz} \quad f_{3}=2053,9 \mathrm{~Hz} \quad f_{4}=3106,4 \mathrm{~Hz} \quad f_{5}=4278,8 \mathrm{~Hz}$
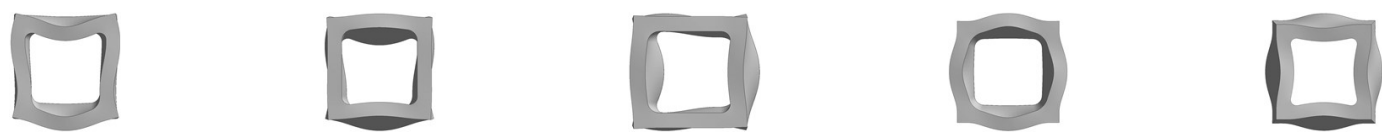

$f_{6}=4296,8 \mathrm{~Hz}$

$f_{7}=4642,3 \mathrm{~Hz}$

$f_{8}=4676,9 \mathrm{~Hz}$

$f_{9}=5199,1 \mathrm{~Hz}$

$f_{10}=5669,1 \mathrm{~Hz}$ 
$\mathrm{Na}$ Tabela 5.14 é feita a confrontação entre frequências naturais numéricas e experimentais, com as quais se obteve estimativas do módulo de elasticidade das unidades.

Tabela 5.14 - Frequências experimentais e módulo de elasticidade: meio-blocos de concreto

\begin{tabular}{|c|c|c|c|c|c|c|c|c|c|}
\hline \multirow{2}{*}{ MODO } & \multicolumn{3}{|c|}{$\begin{array}{l}\text { 19.10-1(END) } \\
\mathrm{M}=8,220 \mathrm{~kg}\end{array}$} & \multicolumn{3}{|c|}{$\begin{array}{c}\text { 19.10-2(END) } \\
\mathrm{M}=8,357 \mathrm{~kg}\end{array}$} & \multicolumn{3}{|c|}{$\begin{array}{c}\text { 19.10-3(END) } \\
\mathrm{M}=8,166 \mathrm{~kg}\end{array}$} \\
\hline & $\begin{array}{l}f_{\exp } \\
(\mathbf{H z})\end{array}$ & $f_{\exp } / f_{\text {DIANA }}$ & $\begin{array}{c}E \\
(\mathbf{G P a})\end{array}$ & $\begin{array}{l}f_{\exp } \\
(\mathbf{H z})\end{array}$ & $f_{\text {exp }} / f_{\text {DIANA }}$ & $\begin{array}{c}E \\
(\mathrm{GPa})\end{array}$ & $\begin{array}{l}f_{\exp } \\
(\mathbf{H z})\end{array}$ & $f_{\text {exp }} / f_{\text {DIANA }}$ & $\begin{array}{c}E \\
\text { (GPa) }\end{array}$ \\
\hline 1 & 1371,7 & 0,93 & 40,18 & 1372,7 & 0,93 & 40,91 & 1350,0 & 0,92 & 38,66 \\
\hline 2 & 1582,0 & 0,94 & 40,80 & 1570,3 & 0,93 & 40,87 & 1572,3 & 0,94 & 40,04 \\
\hline 3 & 1965,0 & 0,96 & 42,20 & 1970,3 & 0,96 & 43,13 & 1963,5 & 0,96 & 41,86 \\
\hline 4 & 2995,8 & 0,96 & 42,88 & 2977,5 & 0,96 & 43,06 & 2958,3 & 0,95 & 41,54 \\
\hline 5 & 4069,2 & 0,95 & 41,70 & 4067,8 & 0,95 & 42,36 & 4022,9 & 0,94 & 40,48 \\
\hline 6 & 4094,7 & 0,95 & 41,87 & 4094,2 & 0,95 & 42,55 & 4046,6 & 0,94 & 40,62 \\
\hline 7 & 4394,5 & 0,95 & 41,31 & 4350,4 & 0,94 & 41,16 & 4337,1 & 0,93 & 39,97 \\
\hline 8 & 4417,9 & 0,94 & 41,14 & 4371,1 & 0,93 & 40,94 & 4359,4 & 0,93 & 39,79 \\
\hline 9 & 4907,4 & 0,94 & 41,07 & 4909,5 & 0,94 & 41,79 & 4828,9 & 0,93 & 39,51 \\
\hline 10 & 5320,7 & 0,94 & 40,61 & 5249,3 & 0,93 & 40,19 & 5240,8 & 0,92 & 39,14 \\
\hline MÉD & - & 0,95 & 41,38 & - & 0,94 & 41,70 & - & 0,94 & 40,16 \\
\hline DP & - & 0,01 & $\mathbf{0 , 8 0}$ & - & $\mathbf{0 , 0 1}$ & 1,03 & - & $\mathbf{0 , 0 1}$ & 1,00 \\
\hline CV (\%) & - & $\mathbf{0 , 9 7}$ & 1,94 & - & 1,23 & 2,47 & - & 1,24 & 2,49 \\
\hline
\end{tabular}

Assim como no bloco inteiro de concreto, os valores experimentais se aproximaram substancialmente da previsão numérica para o meio-bloco de concreto, tornando a identificação dos modos relativamente simples. Há ressalva apenas para os modos 5/6 e 7/8, que representam vibrações similares entre si e com frequências semelhantes na estimativa da análise modal.

Através da Figura 5.6, foi detectado que o último pico de amplitude (próximo aos 6000 $\mathrm{Hz}$ ) é de algum modo fora dos 10 analisados. Picos de amplitude além dos 10 previstos também figuraram nos gráficos das demais amostras (com exceção da de blocos inteiros de concreto), pois as faixas previstas para as frequências ressonantes se mostraram superestimadas. Assim, por vezes houve até dois picos experimentais excedentes dentro do intervalo de frequências inicialmente estipulado pela estimativa numérica.

Nesse tipo de unidade, as configurações de ensaio "F", "T", "L" e "A" mostraram-se igualmente eficientes, incitando de 4 a 5 frequências ressonantes cada. Observou-se que os modos de vibrar induzidos com maior periodicidade foram o terceiro e o nono modo. 


\subsection{Módulo de elasticidade: comparativo entre metodologias de determinação}

Em posse dos módulos de elasticidade obtidos a partir das duas metodologias empregadas (VPU e ressonância acústica), foi feito um comparativo entre resultados visando avaliar valores médios e medidas de dispersão (individual e amostral) relativas a cada método, de modo a entender como essas técnicas performam em diferentes materiais e geometrias.

Aqui deve ser lembrado que os módulos dinâmicos considerados para essa comparação foram aferidos de maneira peculiar a cada método: no caso do ultrassom, utilizou-se a velocidade média referente às $n$ medições realizadas na unidade para o cálculo dessa propriedade; no ensaio de ressonância acústica, foi computado um módulo de elasticidade para cada frequência ressonante reconhecida experimentalmente, sendo então calculado um valor médio representativo para todos os modos de vibrar.

Esses valores foram confrontados com aqueles provenientes do ensaio de compressão axial, representados pelos módulos "aparentes" ou de deformabilidade calculados na área bruta e líquida das unidades. Para prover o último, recorreu-se aos valores médios de $A_{l i q}$ oriundos da caracterização geométrica de cada amostra. Os resultados pertinentes a essa discussão constam nas Tabelas 5.15 a 5.18 adiante.

Tabela 5.15 - Módulos de elasticidade: blocos inteiros cerâmicos

\begin{tabular}{|c|c|c|c|c|}
\hline \multirow{3}{*}{ ID } & \multicolumn{4}{|c|}{$E$ (GPa) } \\
\hline & \multicolumn{2}{|c|}{ DINÂMICO } & \multicolumn{2}{|c|}{ ESTÁTICO } \\
\hline & Ultrassom & Ressonância & Área bruta & Área líquida \\
\hline 6-1(END) & $8,02 \pm 1,29$ & $6,35 \pm 0,43$ & & \\
\hline 6-2(END) & $8,15 \pm 1,18$ & $6,83 \pm 0,55$ & $3,64^{*}$ & $8,91^{*}$ \\
\hline 6-3(END) & $9,37 \pm 1,38$ & $7,37 \pm 0,58$ & & \\
\hline MÉD & 8,51 & 6,85 & - & - \\
\hline DP & 0,74 & $\mathbf{0 , 5 1}$ & 0,85 & 2,08 \\
\hline CV (\%) & 8,70 & 7,45 & & \\
\hline
\end{tabular}

*Valor médio referente à amostra utilizada na caracterização mecânica e geométrica (13 unidades)

Tabela 5.16 - Módulos de elasticidade: meio-blocos cerâmicos

\begin{tabular}{|c|c|c|c|c|}
\hline \multirow{3}{*}{ ID } & \multicolumn{4}{|c|}{$E$ (GPa) } \\
\hline & \multicolumn{2}{|c|}{ DINÂMICO } & \multicolumn{2}{|c|}{ ESTÁTICO } \\
\hline & Ultrassom & Ressonância & Área bruta & Área líquida \\
\hline M14-1(END) & $13,94 \pm 2,55$ & $11,57 \pm 0,68$ & & \\
\hline M14-2(END) & $15,68 \pm 3,10$ & $12,79 \pm 0,65$ & $8,80^{*}$ & $15,02^{*}$ \\
\hline M14-3(END) & $15,39 \pm 3,09$ & $11,87 \pm 0,71$ & & \\
\hline MÉD & 15,00 & 12,08 & - & - \\
\hline DP & $\mathbf{0 , 9 3}$ & 0,63 & 0,79 & 1,35 \\
\hline CV (\%) & 6,20 & 5,23 & & \\
\hline
\end{tabular}


Tabela 5.17 - Módulos de elasticidade: blocos inteiros de concreto

\begin{tabular}{|c|c|c|c|c|}
\hline \multirow{3}{*}{ ID } & \multicolumn{4}{|c|}{$E($ GPa $)$} \\
\hline & \multicolumn{2}{|c|}{ DINÂMICO } & \multicolumn{2}{|c|}{ ESTÁTICO } \\
\hline & Ultrassom & Ressonância & Área bruta & Área líquida \\
\hline 14.10-1(END) & $39,39 \pm 1,67$ & $37,53 \pm 0,61$ & & \\
\hline 14.10-2(END) & $37,83 \pm 2,09$ & $34,94 \pm 0,87$ & $15,35^{*}$ & $28,55^{*}$ \\
\hline 14.10-3(END) & $37,50 \pm 2,00$ & $35,91 \pm 0,64$ & & \\
\hline MÉD & 38,24 & 36,13 & - & - \\
\hline DP & 1,01 & 1,31 & 1,13 & 2,10 \\
\hline CV (\%) & 2,64 & 3,62 & & \\
\hline
\end{tabular}

*Valor médio referente à amostra utilizada na caracterização mecânica (6 unidades) e geométrica (3 unidades)

Tabela 5.18 - Módulos de elasticidade: meio-blocos de concreto

\begin{tabular}{ccccc}
\hline \multirow{2}{*}{ ID } & \multicolumn{5}{c}{$\boldsymbol{c}$ (GPa) } \\
\cline { 2 - 5 } & \multicolumn{2}{c}{ DINÂMICO } & \multicolumn{2}{c}{ ESTÁTICO } \\
\cline { 2 - 5 } & Ultrassom & Ressonância & Área bruta & Área líquida \\
\hline $\mathbf{1 9 . 1 0 - 1 ( E N D ) ~}$ & $47,32 \pm 1,43$ & $41,38 \pm 0,80$ & & \\
$\mathbf{1 9 . 1 0 - 2 ( E N D ) ~}$ & $47,57 \pm 1,61$ & $41,70 \pm 1,03$ & $21,26^{*}$ & $42,49^{*}$ \\
$\mathbf{1 9 . 1 0 - 3 ( E N D ) ~}$ & $46,25 \pm 1,48$ & $40,16 \pm 1,00$ & & - \\
MÉD & $\mathbf{4 7 , 0 5}$ & $\mathbf{4 1 , 0 8}$ & - & $\mathbf{7 , 4 5}$ \\
DP & $\mathbf{0 , 7 0}$ & $\mathbf{0 , 8 1}$ & $\mathbf{3 , 7 3}$ & $\mathbf{1 7 , 5 4}$ \\
CV (\%) & $\mathbf{1 , 4 9}$ & $\mathbf{1 , 9 7}$ & & $\mathbf{1 7 9}$ \\
\hline *Valor médio referente à amostra utilizada na caracterizacão mecânica (6 unidades) e geométrica (3 unidades)
\end{tabular}

Observa-se, em todas as amostras, que os valores de $E$ providos pelo ensaio de ultrassom são superiores aos logrados através do método de ressonância. Nas unidades cerâmicas, essa diferença chegou a $25 \%$ (em termos da média amostral), enquanto as unidades de concreto mostraram comportamentos distintos: nos blocos inteiros, a diferença média entre módulos dinâmicos foi de cerca de $6 \%$, ao passo que nos meio-blocos foi de $15 \%$.

Ainda que moderadamente próximos em valores médios, os módulos dinâmicos aferidos via ultrassom e Sonelastic ${ }^{\circledR}$ são estatisticamente diferentes em todas as unidades, conforme atestado por novos testes $\mathrm{F}$ e $\mathrm{t}$ (significância de 5\%) realizados com duas amostras de valores de $E$, uma para cada metodologia de ensaio. Nos meio-blocos de concreto, as variâncias entre os dois grupos não foram significativamente diferentes. Nos blocos inteiros cerâmicos, essa mesma tendência foi constatada ao suprimir da amostra referente ao ultrassom os valores de módulo de elasticidade medidos ao longo da altura do espécime (os mais elevados).

No caso das unidades cerâmicas, as divergências observadas estão em consonância com as defasagens verificadas entre frequências experimentais e numéricas desses espécimes, uma vez que o módulo de elasticidade médio relacionado às medidas com ultrassom foi utilizado para prever tais frequências. Essa diferença fica ampliada em termos de $E$, pois é um parâmetro diretamente proporcional ao quadrado de $f$ (vide Equação 4.1). 
Para as unidades de concreto, é possível realizar um paralelo com os resultados obtidos por Santos (2014), embora concernam a amostras com diferente resistência nominal (4 MPa) e geometria (bloco inteiro com outro formato de furo e meio-bloco da família de $15 \mathrm{~cm}$ ). Com três medições ao longo do comprimento do espécime (VPU) e considerando apenas um modo de vibrar no ensaio de ressonância (realizado com unidades apoiadas em vez de suspensas), foram averiguadas diferenças entre módulos dinâmicos de $21 \%$ no bloco inteiro e de $9 \%$ no meio-bloco, sendo o $E$ associado ao ultrassom também superior em ambos os casos.

É importante considerar que, quando se calcula o módulo de elasticidade dinâmico utilizando a VPU, é necessário conhecimento do coeficiente de Poisson. A maneira pela qual v foi estimado para as diferentes unidades é passível a duas fontes de erro, que são a obtenção das velocidades médias de ondas longitudinais e transversais. Em contrapartida, ao empregar a ressonância acústica, o coeficiente de Poisson incidiu implicitamente sobre o módulo calculado, já que possui influência (apesar de exígua) sobre as frequências numéricas utilizadas para determinar as constantes geométricas. Isso pode ajudar a compreender a distinção entre os valores de $E$ angariados através de cada método não destrutivo.

Nos blocos inteiros cerâmicos, a variabilidade do módulo de elasticidade em uma mesma unidade está na faixa de $15 \%$ para o método ultrassônico e de 7,5\% no ensaio de ressonância. Para os meio-blocos cerâmicos, a diferença entre flutuações foi ainda mais expressiva (respectivamente, 19,4\% e 5,6\%). Esses resultados poderiam ser antecipados em função da alta dispersão na velocidade de propagação das ondas longitudinais apresentada por essas unidades, já que $E$ é diretamente proporcional ao quadrado de $V_{P}$ (conforme infere-se pela Equação 2.1), amplificando as medidas de dispersão. O mesmo raciocínio explica a baixa variabilidade do módulo dinâmico relativo ao ultrassom nas unidades de concreto, sendo de aproximadamente 5\% nos blocos inteiros e 3\% nos meio-blocos. A dispersão unitária no método de ressonância foi da ordem de $2 \%$ em ambas as amostras, denotando pouca influência da metodologia de determinação nos resultados, diferentemente das unidades cerâmicas.

Por se tratar de uma medida pontual, a velocidade de pulso ultrassônico é mais sensível à porosidade e não homogeneidade do material que o método de ressonância, caracterizado por promover uma resposta global do corpo de prova. Contudo, também foram atestadas variações no módulo de elasticidade encontrado a partir de diferentes frequências naturais do mesmo espécime, o que indica certo grau de anisotropia nas unidades de alvenaria. Efetuar medidas ao longo das três dimensões da unidade com o ultrassom e avaliar diferentes modos de vibrar durante o ensaio acústico podem ser alternativas para obter um valor médio representativo dessa propriedade mecânica, minimizando efeitos dispersivos localizados. 
Comparar módulos de elasticidade obtidos de forma dinâmica com os módulos de deformabilidade decorrentes do ensaio de compressão axial constitui uma tarefa delicada. Da maneira que costuma ser aferido em unidades de alvenaria, o módulo estático "aparente" é severamente afetado pela geometria, pelo tipo de capeamento ou sua ausência, pela forma da instrumentação para aquisição de deformações (sem padronização), entre outros fatores que podem tornar o resultado não representativo para o material. Tais condições também promovem maior dispersão do método destrutivo em relação às técnicas não destrutivas, como pôde ser constatado sobretudo nas amostras de bloco inteiro cerâmico e meio-bloco de concreto.

Não obstante, optou-se por realizar um comparativo com tais valores, visto que estes são o que se tem disponível atualmente para utilização em projeto, através de correlações bem consagradas. Além do mais, há quase nenhuma literatura disponível para balizar resultados em termos do módulo dinâmico. Deve-se, no entanto, priorizar a comparação deste com o módulo de deformabilidade obtido na área líquida da unidade, por representar com um pouco mais de rigor (se comparado àquele calculado na área bruta) a propriedade mecânica associada.

Por ser correlato a níveis diminutos de deformação aplicada instantaneamente, em contraponto a uma grande deformação imposta de forma quase-estática, o módulo dinâmico tende a ser mais elevado que o estático de fato. No caso do concreto, Mehta e Monteiro (2014) preveem um incremento de até $40 \%$ a depender da classe de resistência. Essa tendência foi constatada no bloco inteiro de concreto, no qual os módulos dinâmicos apresentaram valores de 26\% (ressonância) a 34\% (VPU) mais altos que o "módulo estático" relativo à área líquida.

No bloco inteiro cerâmico, o valor do módulo "aparente" calculado na $A_{\text {líq }}$ chega a sobrepujar ligeiramente o indicado pelo método ultrassônico. É possível que a conformação da seção transversal da unidade (paredes vazadas e septos individuais) promova uma distribuição de tensão menos irregular durante o ensaio de compressão (diferente daquela em blocos inteiros de concreto com paredes maciças, vide Figura 2.17), justificando a proximidade entre valores.

Nos meio-blocos (cerâmico e de concreto), que possuem seção transversal quadrada e paredes maciças como fatores em comum, os módulos previstos pela ressonância acústica se mostraram inferiores aos módulos "aparentes" considerados em suas áreas líquidas.

Nas unidades de concreto utilizadas em seu estudo, Santos (2014) obteve módulos dinâmicos significativamente mais elevados que os "estáticos" em área líquida. A disparidade entre módulos chegou a $52 \%$ no bloco inteiro e $25 \%$ no meio-bloco, quando considerados os resultados advindos da VPU. Em termos do ensaio acústico, a discrepância foi mais branda (25\% e 14\%, respectivamente). Todavia, há de se ponderar que as formas de obtenção dos valores dinâmicos de $E$ foram totalmente diferentes das adotadas no presente trabalho. 


\subsection{Proposta experimental para determinação da constante geométrica}

A principal motivação deste estudo parte de que, apesar de ser possível obter as constantes geométricas de um elemento qualquer com auxílio de análise modal assistida por um software de elementos finitos, tal processo é válido apenas para o caso específico simulado. Devido a existência de diferentes famílias de bloco (associadas ao processo de modulação, típico das construções em alvenaria estrutural), somada às diversas conformações de geometria que uma unidade do mesmo padrão dimensional pode vir a possuir (paredes maciças ou vazadas, formatos de furo etc.), o ideal, no sentido prático, seria dispor de um procedimento para determinar $\alpha$ ou $\beta$ experimentalmente, independentemente da unidade em questão.

Já é um pressuposto bem estabelecido que o coeficiente geométrico é uma entidade variável segundo o modo de vibrar e a geometria do espécime, e não com seu material constituinte. Portanto, uma maneira de prevê-lo para um elemento cujo módulo de elasticidade é desconhecido seria replicar a geometria de interesse com um material eletivo, no qual essa propriedade elástica dinâmica seja prontamente acessível. Em posse desse módulo de elasticidade, restaria obter a massa da réplica e conhecer alguma de suas frequências naturais para poder calcular um valor de $\beta$ partindo diretamente da Equação 4.1.

Assim, a proposta consiste em estimar a constante geométrica de blocos e meio-blocos por meio da aplicação do ensaio de ressonância acústica via excitação por impulso em réplicas de material alternativo com $E$ predeterminado. Com a massa da réplica e a frequência ressonante correspondente a um de seus modos de vibrar, o $\beta$ da unidade passa a ser determinável, posto que é igual ao da réplica. Além disso, bastaria repetir o ensaio na unidade original e identificar a frequência relativa àquele modo para definir o seu módulo dinâmico.

Uma maneira relativamente simples de replicar as unidades de parede maciça (bloco inteiro de concreto e meio-blocos cerâmico e de concreto) seria confeccionar uma fôrma apenas com suas dimensões efetivas (altura, comprimento e largura) e constituir os respectivos vazios com isopor adequadamente cortado e disposto, preenchendo o restante do molde com o material escolhido. No caso do bloco inteiro cerâmico (e meio-bloco cerâmico de parede vazada), onde a incidência de vazios é bem maior e complexa, a composição do molde deve ainda ser pensada.

Em um primeiro instante, imagina-se os compostos cimentícios (calda de cimento, argamassa etc.) como candidatos naturais a material alternativo para uso nesse procedimento. Através da moldagem de um corpo de prova cilíndrico ou prismático, o módulo de elasticidade desse material pode ser facilmente aferido com auxílio do Sonelastic ${ }^{\circ}$, que incorpora as relações já existentes entre frequências ressonantes e módulo dinâmico para tais geometrias. 
Para melhor entendimento da proposta, o procedimento descrito é roteirizado a seguir.

1. Colher as dimensões efetivas da unidade de interesse (caracterização geométrica do lote). Recomenda-se executar medições extras na seção transversal para melhor representar as particularidades de cada unidade (septos individuais, raio de mísula, entre outras);

2. Confeccionar uma fôrma para fabricar uma réplica da unidade com material alternativo;

3. Com esse material, produzir dois corpos de prova: um cilindro e a réplica da unidade. Pesálos e registrar suas massas ( $m$ e $M_{r}$, respectivamente);

4. Com o Sonelastic $₫$, determinar o módulo de elasticidade dinâmico do material alternativo a partir da amostra cilíndrica e as equações da ASTM E1876-15 ou C215-14:

$$
\begin{aligned}
& E_{\text {flex }}=1,6067\left(\frac{L^{3} T}{D^{4}}\right) m f^{2} \\
& E_{\text {long }}=5,093\left(\frac{L}{K D^{2}}\right) m f^{2}
\end{aligned}
$$

Recorda-se que $\mathrm{T}$ e $\mathrm{K}$ são fatores de correção que incorporam a geometria do corpo de prova e o coeficiente de Poisson ( $v$ ) do material. Além disso, é necessário admitir que o módulo de elasticidade obtido para o cilindro seja representativo para a réplica da unidade, ou seja, $E_{r}$.

5. Refazer o ensaio de ressonância acústica na réplica da unidade, preferencialmente simulando a vibração livre, empregando uma das combinações impacto/captação propostas neste trabalho. Ao registrar as frequências ressonantes, identificar a do modo desejado $\left(f_{r}\right)$;

6. Estimar o coeficiente geométrico da unidade de interesse $(\beta)$ a partir dos dados obtidos para sua réplica, através da relação:

$$
\beta=\frac{E_{r}}{M_{r} \times f_{r}{ }^{2}}
$$

Utilizando $E_{r}$ em $\mathrm{Pa}, M_{r}$ em $\mathrm{kg}$ e $f_{r}$ em $\mathrm{Hz}, \beta$ resulta $\mathrm{em} \mathrm{m}^{-1}$. Essa constante é válida apenas para o modo de vibrar selecionado na etapa anterior.

7. Determinar a massa da unidade $(M)$ e repetir nela o ensaio acústico, fazendo uso da mesma condição de apoio e configuração impacto/captação utilizada na réplica. Identificar a frequência ressonante $(f)$ correspondente ao modo de vibrar definido na Etapa 5.

8. $\operatorname{Com} \beta, M$ e $f$, calcular o módulo de elasticidade da unidade $(E)$ utilizando a Equação 4.1.

$$
E=\beta M f^{2}
$$


No intuito de vislumbrar resultados da aplicação desse procedimento, foram elaborados exemplos hipotéticos com as unidades já conhecidas desse estudo. O material alternativo escolhido foi uma argamassa (cimento e areia 1:3) com densidade e módulo de elasticidade dinâmico aferidos experimentalmente com base em uma amostra de 10 cilindros $(5 \mathrm{~cm} \times 10$ $\mathrm{cm})$. Réplicas de cada modelo numérico original foram modeladas no DIANA ${ }^{\circledR}$ considerando as propriedades mecânicas dessa argamassa $\left(E=18,24 \mathrm{GPa}, \rho=2003,1 \mathrm{~kg} / \mathrm{m}^{3}\right.$ e $v$ estimado em $0,20)$. Após o processamento da análise modal, foram calculados os coeficientes $\beta$ das réplicas (via Equação 5.3), sendo posteriormente comparados com os já apresentados na seção 4.3 “Determinação dos coeficientes geométricos". A previsão de tais resultados e o erro relativo às constantes originalmente determinadas são relatados na Tabela 5.19.

Tabela 5.19 - Estimativa dos resultados esperados para o procedimento experimental

\begin{tabular}{|c|c|c|c|c|c|c|c|c|c|c|}
\hline \multicolumn{11}{|c|}{ BLOCO INTEIRO CERÂMICO } \\
\hline MODO & 1 & 2 & 3 & 4 & 5 & 6 & 7 & 8 & 9 & 10 \\
\hline $\begin{array}{c}\beta_{\text {original }} \\
\left(\mathrm{m}^{-1}\right)\end{array}$ & 3827,8 & 2943,0 & 2232,6 & 700,48 & 547,26 & 490,27 & 480,85 & 366,28 & 285,66 & 253,89 \\
\hline $\begin{array}{c}\beta_{\text {réplica }} \\
\left(\mathbf{m}^{-1}\right)\end{array}$ & 3836,8 & 2913,9 & 2212,0 & 693,78 & 547,93 & 494,31 & 477,51 & 363,46 & 287,30 & 256,79 \\
\hline $\begin{array}{c}\text { Erro } \beta \\
(\%)\end{array}$ & 0,23 & $-0,99$ & $-0,92$ & $-0,96$ & 0,12 & 0,82 & $-0,69$ & $-0,77$ & 0,57 & 1,14 \\
\hline \multicolumn{11}{|c|}{ BLOCO INTEIRO DE CONCRETO } \\
\hline MODO & 1 & 2 & 3 & 4 & 5 & 6 & 7 & 8 & 9 & 10 \\
\hline $\begin{array}{c}\boldsymbol{\beta}_{\text {original }} \\
\left(\mathrm{m}^{-1}\right)\end{array}$ & 2071,3 & 1921,9 & 969,49 & 653,31 & 431,80 & 375,37 & 369,85 & 300,79 & 224,66 & 216,55 \\
\hline $\begin{array}{c}\beta_{\text {réplica }} \\
\left(\mathrm{m}^{-1}\right)\end{array}$ & 2056,0 & 1935,4 & 976,96 & 656,76 & 429,92 & 377,05 & 366,29 & 298,01 & 225,26 & 215,75 \\
\hline $\begin{array}{c}\operatorname{Erro} \beta \\
(\%)\end{array}$ & $-0,74$ & 0,70 & 0,77 & 0,53 & $-0,43$ & 0,45 & $-0,96$ & $-0,92$ & 0,27 & $-0,37$ \\
\hline \multicolumn{11}{|c|}{ MEIO-BLOCO CERÂMICO } \\
\hline MODO & 1 & 2 & 3 & 4 & 5 & 6 & 7 & 8 & 9 & 10 \\
\hline $\begin{array}{c}\beta_{\text {original }} \\
\left(\mathrm{m}^{-1}\right)\end{array}$ & 1135,8 & 1012,9 & 678,28 & 403,37 & 186,17 & 185,96 & 171,17 & 158,02 & 151,08 & 143,99 \\
\hline $\begin{array}{c}\beta \text { réplica } \\
\left(\mathbf{m}^{-1}\right)\end{array}$ & 1127,9 & 1017,4 & 674,91 & 406,09 & 190,83 & 188,39 & 173,44 & 159,53 & 151,95 & 143,32 \\
\hline $\begin{array}{c}\text { Erro } \beta \\
(\%) \\
\end{array}$ & $-0,69$ & 0,45 & $-0,50$ & 0,67 & 2,50 & 1,31 & 1,33 & 0,96 & 0,58 & $-0,47$ \\
\hline \multicolumn{11}{|c|}{ MEIO-BLOCO DE CONCRETO } \\
\hline MODO & 1 & 2 & 3 & 4 & 5 & 6 & 7 & 8 & 9 & 10 \\
\hline $\begin{array}{c}\boldsymbol{\beta}_{\text {original }} \\
\left(\mathbf{m}^{-1}\right)\end{array}$ & 2597,9 & 1983,3 & 1329,5 & 581,21 & 306,34 & 303,78 & 260,24 & 256,41 & 207,49 & 174,51 \\
\hline $\begin{array}{c}\beta_{\text {réplica }} \\
\left(\mathbf{m}^{-1}\right)\end{array}$ & 2618,6 & 1968,3 & 1337,8 & 573,63 & 306,18 & 303,76 & 259,02 & 255,39 & 208,37 & 175,03 \\
\hline $\begin{array}{c}\text { Erro } \beta \\
(\%)\end{array}$ & 0,80 & $-0,76$ & 0,63 & $-1,30$ & $-0,05$ & $-0,01$ & $-0,47$ & $-0,40$ & 0,43 & 0,30 \\
\hline
\end{tabular}


Os resultados logrados, ainda que fictícios, sinalizam que a proposta está bem fundamentada do ponto de vista teórico. Em termos dos modelos numéricos, as módicas diferenças entre as constantes geométricas das unidades originais e as observadas em suas réplicas provavelmente se devem ao fato do coeficiente de Poisson nos protótipos modelados com argamassa ser diferente daqueles estimados para o concreto e o material cerâmico. Como dito anteriormente, esse parâmetro elástico possui uma pequena influência nas frequências naturais, consequentemente afetando o valor de $\beta$. Além disso, é importante destacar que, mesmo alterando as propriedades mecânicas das unidades, não houve inversão de modos entre os 10 avaliados, o que é bastante favorável para o cumprimento do roteiro experimental.

Porém, é evidente que o procedimento real estará sujeito a diversas fontes de erro, desde as dimensões da fôrma construída (uma geometria única para representar todo o lote) até a determinação de frequências naturais através da ressonância acústica (possibilidade de realizar associações incorretas entre picos de amplitude e modos de vibrar). No entanto, sabe-se que a variação dimensional em um lote é ínfima, como mostrou a caracterização geométrica das unidades utilizadas na pesquisa. Além do mais, com auxílio de análise modal prévia, mesmo que sem propriedades ajustadas para os materiais (isto é, apenas para conhecer a ordem dos modos de vibrar), pode-se facilitar a execução do ensaio e a interpretação dos resultados.

Outra importante fonte de erro reside em não ser possível assegurar que o módulo de elasticidade do material alternativo seja exatamente o mesmo na amostra cilíndrica e na réplica da unidade, diante das formas de moldagem e compactação desses espécimes. Pensando em mitigar essa disparidade, seria prudente utilizar calda de cimento em detrimento da argamassa, visto que esta apresenta maior variabilidade em seu comportamento mecânico devido a presença de agregado. Ainda nesse sentido, seria preferível confeccionar cilindros de $10 \mathrm{~cm} \mathrm{x}$ $20 \mathrm{~cm}$ quando o procedimento for conduzido em meio-blocos e $15 \mathrm{~cm}$ x $30 \mathrm{~cm}$ quando em blocos inteiros, visando reduzir a atuação do efeito de escala no módulo de elasticidade.

Finalmente, para garantir o sucesso dessa proposta, é vital que frequências ressonantes inerentes a um mesmo modo de vibração sejam identificadas na unidade original e em sua réplica. Além da análise modal preliminar, outras providências a serem tomadas para dirimir a incidência de erro nessa etapa são adotar configurações de ensaio que propiciem com regularidade picos de ressonância bem distintos (com altas amplitudes e/ou relativamente isolados dos demais) e selecionar modos que são mais facilmente induzidos. Com base nos espectros $A$ x $f$ obtidos para as amostras desse trabalho, a Figura 5.7 adiante ilustra combinações impacto/captação e modos de vibrar sugeridos para uso no procedimento, com pretensão de servir como guia para outras unidades com resistência nominal ou geometria semelhantes. 
Figura 5.7 - Configurações de ensaio e modos de vibrar recomendados para cada unidade

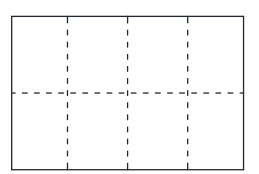

\& $\times$ IMPACTO

๙ (Q) CAPTAÇÃO
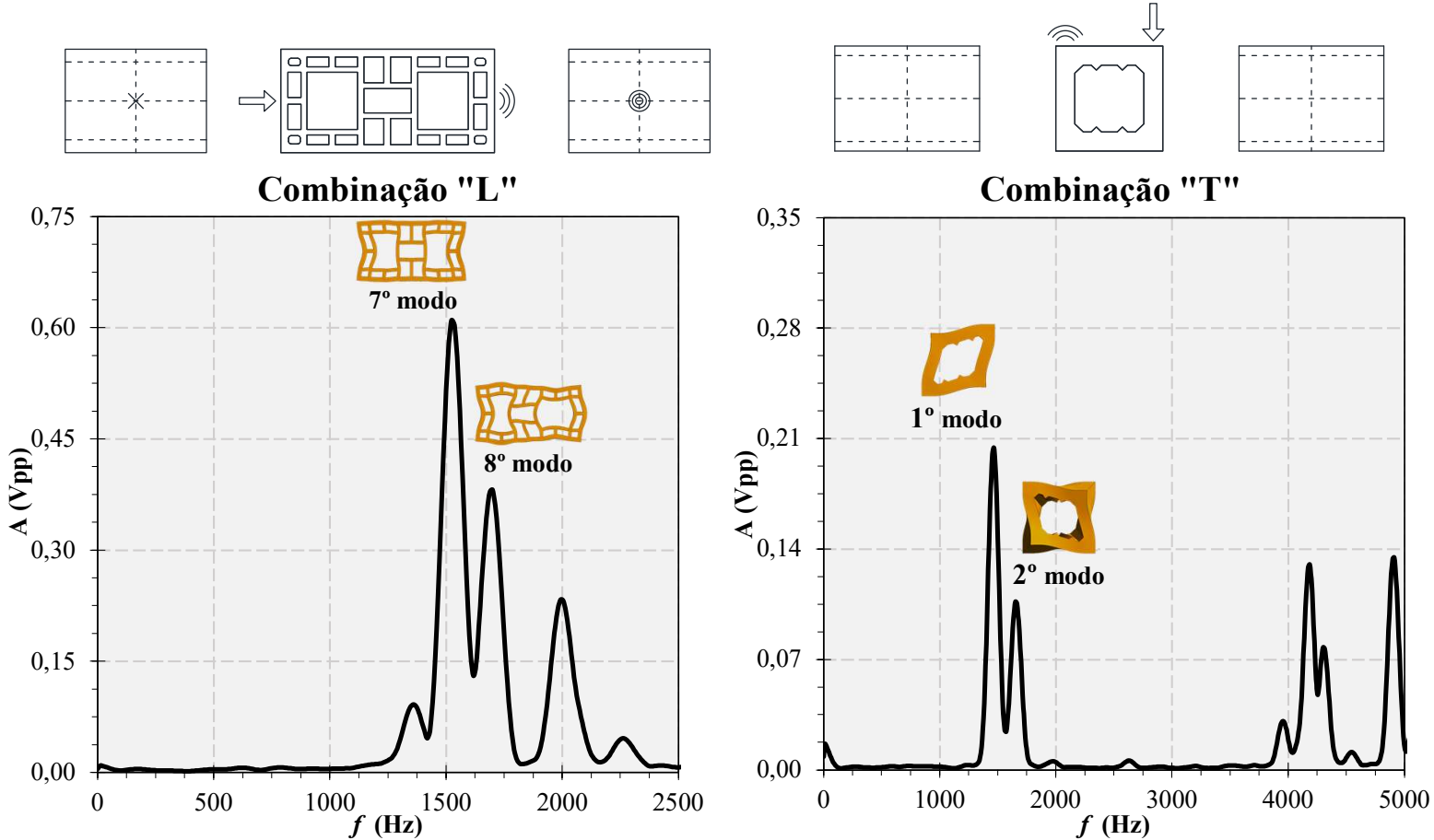

\ $\times$ IMPACTO

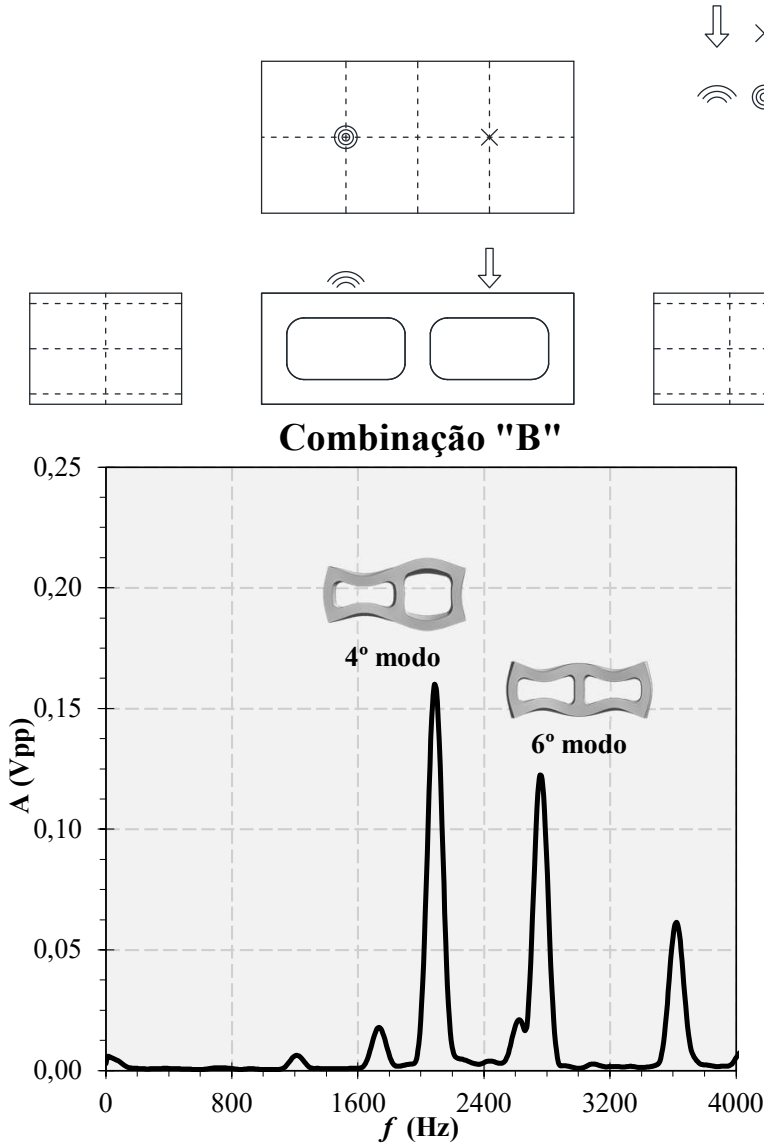

乞 (O) CAPTAÇÃO
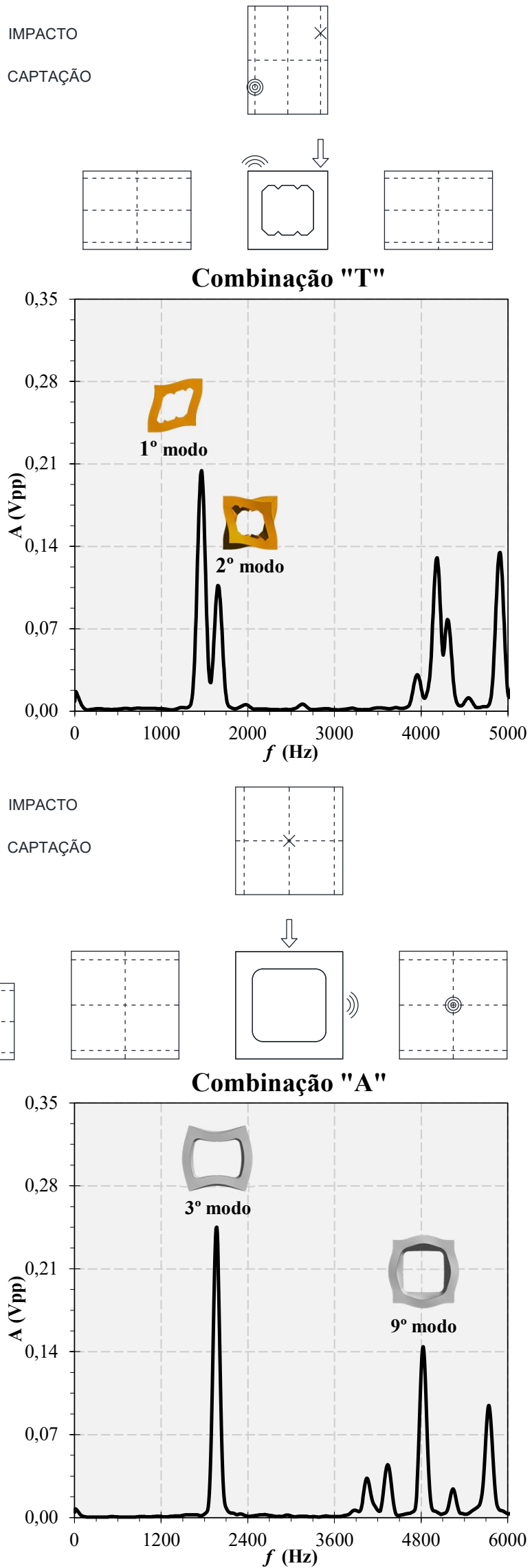

Fonte: Autor (2020) 


\subsection{Síntese do capítulo}

Com as velocidades de ondas longitudinal e transversal obtidas através do ensaio de ultrassom, estimativas das propriedades dinâmicas elásticas $(E, G$ e $v)$ do material de cada unidade foram calculadas. Foi constatado que as unidades cerâmicas apresentam expressiva dispersão entre velocidades medidas em diferentes posições, diferentemente daquelas de concreto. A aplicação de testes estatísticos permitiu delinear diferentes cenários para o cálculo do módulo de elasticidade longitudinal em função de possíveis não homogeneidades.

Baseando-se nos espectros amplitude versus frequência (provenientes do ensaio de ressonância acústica) e nas previsões da análise modal numérica, se deu a identificação e associação de modos e frequências naturais experimentais. Notou-se que as estimativas numéricas estavam majoradas em relação às frequências reais, especialmente nas unidades cerâmicas. Através dos espectros isolados para cada combinação impacto/captação utilizada, foram detectados os modos de vibrar com maior incidência e as configurações de ensaio que induzem mais picos de amplitude nas diferentes amostras.

O comparativo entre módulos de elasticidade oriundos das duas metodologias dinâmicas indicou que a VPU tende a fornecer valores mais elevados para essa propriedade que o ensaio de ressonância, além de estar suscetível a maior dispersão em uma mesma unidade. Tais técnicas geraram módulos de elasticidade com diferentes comportamentos em relação ao módulo de deformabilidade obtido na área líquida de forma estática. Os ENDs também apresentaram menor variabilidade que o método destrutivo convencional. Essas constatações estão respaldadas pela literatura e resultados observados em um estudo similar.

Finalmente, foram estabelecidas diretrizes de um procedimento para determinação da constante geométrica de forma experimental. Uma breve aplicação numérica foi conduzida na expectativa de prever o desempenho da proposta, cujas limitações e eventuais fontes de erro foram ponderadas. Também foram preconizadas algumas diligências para aumentar as chances de sucesso do procedimento. 


\section{CONCLUSÃO}

Diante do exposto, pode-se alegar que o objetivo do estudo foi cumprido, posto que a caracterização do módulo de elasticidade dinâmico em unidades de alvenaria através do ensaio de ressonância acústica foi exitosa. $\mathrm{O}$ sucesso dessa tarefa permitiu propor um procedimento experimental para obtenção dessa propriedade mecânica prescindindo de simulações numéricas na determinação do coeficiente geométrico. Apesar de não ter sido validada, julga-se que a proposta é teoricamente consistente e de simples aplicação, em virtude da maior praticidade do ensaio acústico quando comparado à metodologia mais usual, baseada em acelerometria.

Esse trabalho salienta o caráter utilitário da análise modal numérica na aplicação dos métodos de ressonância, especialmente quando se lança mão da técnica de excitação por impulso em conjunto com um captador acústico, cenário em que normalmente não se tem acesso à configuração deformada da estrutura durante o experimento. Sendo feita uma análise modal prévia para entrever amplitudes de deslocamento relativas aos diferentes modos de vibrar, a definição dos pontos de impacto e captação para o tratamento de casos específicos torna-se bem mais intuitiva. Atesta-se, ainda, que a reprodução do comportamento "vibração livre", através de apoios com baixa rigidez ou suspensão por fios, deve sempre que possível ser priorizada para a execução desse tipo de ensaio.

Nesse sentido, a modelagem numérica se reafirma como ferramenta auxiliar no desenvolvimento de atividades relacionadas à engenharia de estruturas. Simulações computacionais com o Método dos Elementos Finitos constituem poderoso recurso para balizar tomadas de decisão, desde que se conceba o estudo de convergência da malha e a análise de sensibilidade para apurar a influência de parâmetros pertinentes. Tais cuidados são essenciais para garantir que o modelo numérico represente satisfatoriamente o físico.

No que concerne a avaliação de propriedades dinâmicas, requer menção o polivalente ensaio de ultrassom, que forneceu estimativas coerentes das três constantes elásticas do material das unidades, com algumas ressalvas. Diante da considerável variabilidade constatada e da dificuldade em se obter uma previsão assertiva para o coeficiente de Poisson naquelas de material cerâmico (sobretudo o bloco inteiro), fica evidente a necessidade de maior rigor na execução do ensaio nesses espécimes, podendo fomentar a aplicação da VPU em unidades cerâmicas, relativamente deficiente de publicações. 
A análise da velocidade de propagação de ondas baseada em testes de hipóteses propiciou a associação entre eventuais não homogeneidades do material constituinte e o processo de fabricação das unidades. Isso demonstra a importância do tratamento estatístico de dados experimentais, viabilizando interpretações enriquecidas e mais rigorosas.

Em conclusão, por se tratar de técnicas não destrutivas, valendo-se de atributos como reprodutibilidade e agilidade, os métodos ultrassônico e de ressonância se alinham plenamente aos preceitos de racionalização de insumos e rapidez executiva da tecnologia construtiva em alvenaria estrutural. Espera-se que com maior disseminação, promovida principalmente por trabalhos acadêmicos como este, tais ensaios possam figurar com constância no controle tecnológico dos blocos e demais componentes (argamassa de assentamento, graute etc.) integrantes da alvenaria estrutural.

\subsection{Sugestões para trabalhos futuros}

Caso esse estudo estimule o interesse acadêmico por novas investidas na aplicação do ensaio de ressonância acústica na caracterização mecânica das unidades de alvenaria, uma primeira moção conveniente seria a de verificar se a replicação destas com um material alternativo é de fato exequível, para então se proceder a validação experimental da proposta para determinação do parâmetro geométrico.

Outra perspectiva interessante seria o desenvolvimento de modelos simplificados para o cálculo analítico da constante geométrica. Uma abordagem inicial consiste em tratar modos de vibrar da unidade como esquemas estáticos de estruturas reticuladas, facilitando o uso do artifício da equivalência de energia cinética. Como dentre os modos de vibrar há ocorrência de configurações deformadas com um ou mais eixos de simetria, pode-se valer dessa propriedade para definir as condições de contorno de cada situação.

Por fim, deve-se ter em conta que as comparações entre valores dinâmicos e estáticos do módulo de elasticidade aqui realizadas se configuram indiretas, pois incorporaram unidades que, embora pertencessem aos mesmos lotes, foram de amostras distintas. No intuito de estabelecer correlações condizentes entre diferentes propriedades mecânicas, como resistência característica do bloco versus módulo de elasticidade dinâmico ou módulo estático versus módulo dinâmico, seria razoável efetuar comparações diretas, submetendo ao ensaio de compressão as mesmas unidades avaliadas pelos métodos não destrutivos. 


\section{REFERÊNCIAS BIBLIOGRÁFICAS}

ABAZA, O. A.; SALAMEH, A. A. The Effect of Capping Condition on the Compressive Strength of Concrete Hollow Blocks. An-Najah Univ. J. Res. (N. Sc), Vol. 17(1), 2003.

AKKAYA, Y.; VOIGT, T.; SUBRAMANIAM, K. V.; SHAH, S. P. Nondestructive measurement of concrete strength gain by an ultrasonic wave reflection method. Materials and Structures, [s.1.], v. 36, n. 8, p.507-514, out. 2003. Springer Nature. http://dx.doi.org/10.1007/bf02480827.

AMERICAN CONCRETE INSTITUTE. ACI 228.1R-95: In-Place Methods to Estimate Concrete Strength. Farmington Hills, 1995.

ACI 228.2R-98: Nondestructive Test Methods for Evaluation of Concrete in Structures. Farmington Hills, 1998.

Structures. Detroit, 2005.

ACI 530-05: Building Code Requirements for Masonry

AMERICAN SOCIETY FOR TESTING AND MATERIALS. C215-14: Standard Test Method for Fundamental Transverse, Longitudinal, and Torsional Resonant Frequencies of Concrete Specimens. Pennsylvania, 2014.

Concrete. West Conshohocken, 2016.

C597-16: Standard Test Method for Pulse Velocity Through C1006-07: Standard Test Method for Splitting Tensile Strength of Masonry Units. Pennsylvania, 2013.

. E111-04: Standard Test Method for Young's Modulus, Tangent Modulus, and Chord Modulus. West Conshohocken, 2004.

E1876-15: Standard Test Method for Dynamic Young's Modulus,

Shear Modulus and Poisson's Ratio by Impulse Excitation of Vibration. Pennsylvania, 2015.

ASSOCIAÇÃO BRASILEIRA DE NORMAS TÉCNICAS. NBR 6136: Blocos vazados de concreto simples para alvenaria - Requisitos. Rio de Janeiro, 2016.

. NBR 8802: Concreto Endurecido - Determinação da velocidade de propagação de onda ultrassônica. Rio de Janeiro, 2013.

Métodos de ensaio. Rio de Janeiro, 2013.

NBR 12118: Blocos vazados de concreto simples para alvenaria - 
NBR 15270-1: Componentes cerâmicos - Blocos e tijolos para alvenaria Parte 1 - Requisitos. Rio de Janeiro, 2017.

. NBR 15270-2: Componentes cerâmicos - Blocos e tijolos para alvenaria Parte 2 - Métodos de ensaio. Rio de Janeiro, 2017.

ATAMTURKTUR, H. S.; GILLIGAN, C. R.; SALYARDS, K. A. Detection of Internal Defects in Concrete Members Using Global Vibration Characteristics. ACI Materials Journal, [s.1], v. 110, n. 5, p.529-538, ago. 2013.

ATCP ENGENHARIA FÍSICA. Sonelastic ${ }^{\circledR}$ : A solução prática, precisa e não-destrutiva para medir os módulos elásticos e o amortecimento de materiais. [201-]. Disponível em: $<$ https://www.sonelastic.com/images/downloads/Folder-Sonelastic-PT.pdf $>$. Acesso em: 24 mar. 2019.

- Manual de instalação e operação Software Sonelastic ${ }^{\circledR}$ 3.0

(Versão 3.1). Disponível em: <https://www.sonelastic.com/pt/productos/software.html>. Acesso em: 06 dez. 2019. Ribeirão Preto, 2015.

BARBOSA, C. S. B. Resistência e deformabilidade de blocos vazados de concreto e suas correlações com as propriedades mecânicas do material constituinte. 2004. 153p. Dissertação (Mestrado) - Escola de Engenharia de São Carlos, Universidade de São Paulo. São Carlos, 2004.

BARBOSA, C. S. B.; HANAI, J. B. Strength and deformability of hollow concrete blocks and their correlations with mechanical properties of constituent material. 10th Canadian Masonry Symposium. Banff, Alberta, June 8 - 12, 2005.

BARBOSA, C. S. B.; HANAI, J. B. Strength and deformability of hollow concrete blocks: correlation of block and cylindrical sample test results. IBRACON Structures and Materials Journal. v. 2, n. 1, p.85-99. March, 2009.

BECICA, I. J.; HARRIS, H. G. Behavior of hollow concrete masonry prisms under axial load and bending. The Masonry Society Journal, Boulder, v.2, n.2, p.T1-T26, jan-jun. 1983.

BOOTHBY, T. E.; ATAMTURKTUR, H. S.; HANAGAN, L. M. Modal analysis methods for validation of vaulted stone masonry models. In AEI 2006: Building Integration Solutions Proceedings of the 2006 Architectural Engineering National Conference (Vol. 2006). https://doi.org/10.1061/40798(190)66.

CARRAZEDO, R.; HAACH, V. G.; MONFRINATO; E. F.; PERISSIN, D. A. M. Mechanical Characterization of Concrete by Impact Acoustics Tests. Journal of Materials in Civil Engineering, [s.1.], v. 30, n. 4, p.1-10, abr. 2018. American Society of Civil Engineers (ASCE). http://dx.doi.org/10.1061/(asce)mt.1943-5533.0002231. 
COLEMAN, R. E. Experimental Structural Dynamics: An Introduction to Experimental Methods of Characterizing Vibrating Structures. Bloomington: AutorHouse, 2004.

COSSOlinO, L. C.; PEREIRA, A. H. A. Módulos elásticos: visão geral e métodos de caracterização. São Carlos, 2010. Disponível em: <www.atcp.com.br>.

CRAIG JR., R. R.; KURDILA, A. J. Fundamentals of structural dynamics. New Jersey: John Wiley \& Sons, 2006.

CUNHA, Á.; CAETANO, E. Experimental modal analysis of civil engineering structures. Sound and Vibration, p. 12-20, 2006.

DIÓGENES, H. J. F.; COSSOLINO, L. C.; PEREIRA, A. H. A.; EL DEBS, M. K.; EL DEBS, A. L. H. C. Determinação do módulo de elasticidade do concreto a partir da resposta acústica. Revista Ibracon de Estruturas e Materiais, [s.1.], v. 4, n. 5, p.803-813, dez. 2011. FapUNIFESP (SciELO). http://dx.doi.org/10.1590/s1983-41952011000500007.

DRYSDALE, R. G.; HAMID, A. A.; BAKER, L. R. Masonry structures: behavior and design. Englewood Cliffs, New Jersey: Prentice Hall, 1994.

EWINS, D. J. Modal Testing: Theory, Practice and Application. 2 ed. Hertfordshire: Research Studies Press, 2000.

FOURIE, J. Characterisation and evaluation of the mechanical properties of alternative masonry units. 2017. 136 f. Dissertação (Mestrado) - Curso de Engenharia Estrutural, Departamento de Engenharia Estrutural, Universidade de Stellenbosch. Stellenbosch, 2017.

FRASSON JUNIOR, A. F. Metodologia de dosagem e controle do processo produtivo de blocos de concreto para a alvenaria estrutural. 146p. Dissertação (Mestrado) - Universidade Federal de Santa Catarina, Florianópolis. 2000.

FREITAS, A. A. Análise numérica e experimental do comportamento de prismas e miniparedes submetidos à compressão. 289p. Tese (Doutorado) - Escola de Engenharia de São Carlos, Universidade de São Paulo. São Carlos. 2008.

GANESAN, T. P.; RAMAMURTHY, K. Behavior of Concrete Hollow-Block Masonry Prisms under Axial Compression. Journal of Structural Engineering, [s.1.], v. 118, n. 7, p.17511769, jul. 1992. American Society of Civil Engineers (ASCE). http://dx.doi.org/10.1061/(asce)0733-9445(1992)118:7(1751).

GANZERLI, S.; ROSSLOW, J.; YOUNG, T.; KREBS, K; MUJUMDAR, V. Compression strength testing for nonstandard concrete masonry units. In: Proceedings of North American Masonry Conference, 9., p.60-71. Clemson, South Carolina. 2003. 
GIDRÃO, G. M. S. Propriedades dinâmicas do concreto e relações com sua microestrutura. 2015. 131p. Dissertação (Mestrado) - Escola de Engenharia de São Carlos, Universidade de São Paulo. São Carlos, 2015.

GOMES, N. G. A resistência das paredes de alvenaria. 191p. Dissertação (Mestrado) - Escola Politécnica, Universidade de São Paulo. São Paulo, 1983.

HAACH, V. G.; CARRRAZEDO, R.; OLIVEIRA, L. M. F.; CORRÊA, M. R. S. Application of acoustic tests to mechanical characterization of masonry mortars. NDT\&E International, [s.1.], v. 59, p.18-24, out. 2013. Elsevier BV. http://dx.doi.org/10.1016/j.ndteint.2013.04.013

HAACH, V. G.; CARRAZEDO, R.; OLIVEIRA, L. M. F. Resonant acoustic evaluation of mechanical properties of masonry mortars. Construction and Building Materials, [s.1.], v. 152, p.494-505, out. 2017. Elsevier BV. http://dx.doi.org/10.1016/j.conbuildmat.2017.07.032

HAMID, A. A.; CHUKWUNENYE, A. O. Compression behavior of concrete masonry prisms. Journal of Structural Engineering, v. 112, n. 3, p. 605-613, 1986.

HE, J.; FU, Z. Modal Analysis. Oxford: Butterworth-Heinemann, 2001.

HELLIER, C. J. Handbook of Nondestructive Evaluation. [s.1]: McGraw-Hill Professional, 2003. Disponível em: <https://biblioteca.cio.mx/ebooks/e0211.pdf>. Acesso em: 10 fev. 2019.

ITO, Y.; UOMOTO, T. Nondestructive testing method of concrete using impact acoustics. NDT\&E International, [s.1.], v. 30, n. 4, p.217-222, ago. 1997. Elsevier BV. http://dx.doi.org/10.1016/s0963-8695(96)00059-x.

JULIANI, L. M. Avaliação das propriedades mecânicas do concreto de lajes alveolares pré-fabricadas utilizando ensaios não destrutivos. 2014. 193 f. Dissertação (Mestrado) Curso de Engenharia de Estruturas, Escola de Engenharia de São Carlos. São Carlos, 2014.

KOLLURU, S. V.; POPOVICS, J. S.; SHAH, S. P. Determining Elastic Properties of Concrete Using Vibrational Resonance Frequencies of Standard Test Cylinders. Cement, Concrete and Aggregates, [s.1.], v. 22, n. 2, p.81-89, 2000. ASTM International.

LEMING, M. L.; NAU, J. M.; FUKUDA, J. Non-Destructive Determination of the Dynamic Modulus of Concrete Disks. ACI Materials Journal, v. 95, n. 1, p.50-57, 1998.

LIMA, S. S.; SANTOS, S. H. Análise dinâmica das estruturas. Rio de Janeiro: Ciência Moderna LTDA, 2008

MAKOOND, N.; PELÀ, L.; MOLINS, C. Dynamic elastic properties of brick masonry constituents. Construction and Building Materials, [s.1.], v. 199, p.756-770, fev. 2019. Elsevier BV. http://dx.doi.org/10.1016/j.conbuildmat.2018.12.071. 
MALHOTRA, V. M.; CARINO, N. J. Handbook on Nondestructive Testing of Concrete. 2 ed. Boca Raton: CRC Press, 2004.

MALHOTRA, V. M.; SIVASUNDARAM, V. Resonant Frequency Methods. In: MALHOTRA, V. M.; CARINO, N. J. Handbook on Nondestructive Testing of Concrete. 2 ed. Boca Raton: CRC Press, 2004.

MEDEIROS, J. S. Alvenaria estrutural não armada de blocos de concreto: produção de componentes e parâmetros de projeto. 1993. 449p. Dissertação (Mestrado) - Escola Politécnica, Universidade de São Paulo. São Paulo, 1993.

MEHTA, P. K.; MONTEIRO, P. J. M. Concreto: microestrutura, propriedades e materiais. 2 ed. São Paulo: IBRACON, 2014.

MOHAMAD, G. Comportamento mecânico na ruptura de prismas de blocos de concreto. 117p. Dissertação (Mestrado) - Universidade Federal de Santa Catarina, Florianópolis, 1998.

NAIK, T. R.; MALHOTRA, V. M.; POPOVICS, J. S. The ultrasonic pulse velocity method. In: MALHOTRA, V. M.; CARINO, N. J. Handbook on Nondestructive Testing of Concrete. 2 ed. Boca Raton: CRC Press, 2004.

NÓBREGA, P. G. B. Análise dinâmica de estruturas de concreto: estudo experimental e numérico das condições de contorno de estruturas pré-moldadas. 2004. 265 f. Tese (Doutorado), Escola de Engenharia de São Carlos. São Carlos, 2004.

OLIVEIRA, L. M. F. Estudo teórico e experimental do comportamento das interfaces verticais de paredes interconectadas de alvenaria estrutural. 2014. 272p. Tese (Doutorado) - Escola de Engenharia de São Carlos, Universidade de São Paulo. São Carlos, 2014.

PAIVA, M. A. C. Análise das propriedades mecânicas nas primeiras idades do concreto de lajes alveolares utilizando o ensaio de ultrassom. 2017. 160p. Dissertação (Mestrado em Estruturas) - Escola de Engenharia de São Carlos, Universidade de São Paulo, São Carlos, 2017.

PARSEKIAN, G. A.; HAMID, A. A.; DRYSDALE R, R. G., Comportamento e dimensionamento de alvenaria estrutural. São Carlos: EdUFSCar, 2012.

PRADO, D. M. Avaliação experimental de vigas de concreto armado reforçadas ao cisalhamento com laminados de CFRP por meio de análise estática e modal. 2016. $212 \mathrm{f}$. Dissertação (Mestrado) - Escola de Engenharia de São Carlos. São Carlos, 2016.

PROCEQ ${ }^{\circledR}$. Operating Instructions: Pundit Lab / Pundit $\mathrm{Lab}^{+}$Ultrasonic Instrument. Schwerzenbach: PROCEQ ${ }^{\circledR}$ SA, 2017. 
RADOVANOVIĆ, Ž.; GREBROVIĆ, R. S.; DIMOVSKA, S.; SERDAR, N.; VATIN, N.; MURGUL, V. The Mechanical Properties of Masonry Walls - Analysis of the Test Results. Procedia Engineering, [s.1.], v. 117, p.865-873, 2015. Elsevier BV. http://dx.doi.org/10.1016/j.proeng.2015.08.155.

RAMALhO, M. A.; CORRÊA, M. R. S. Projeto de edifícios de alvenaria estrutural. 1 ed. São Paulo: PINI, 2003.

RESENDE, R. M. L. G. Avaliação dos efeitos da danificação e da acustoelasticidade sobre a velocidade de pulso ultrassônico em corpos de prova de concreto submetidos a compressão uniaxial. 2018. 133p. Dissertação (Mestrado) - Escola de Engenharia de São Carlos, Universidade de São Paulo. São Carlos, 2018.

RIZZATTI, E.; ROMAN, H. R.; MOHAMAD, G.; NAKANISHI, E. Y. Mechanical behavior analysis of small-scale modeling of ceramic block masonry structures - Geometries effect. Revista Ibracon de Estruturas e Materiais, [s.1], v. 5, n. 5, p.702-718, out. 2012.

ROMAGNA, R. H. Resistência à compressão de prismas de blocos de concreto grauteados e não grauteados. 195p. Dissertação (Mestrado) - Universidade Federal de Santa Catarina. Florianópolis, 2000.

SANTOS, E. A. F. Estudo da influência das propriedades elásticas da interface blocoargamassa na rigidez de paredes de alvenaria. 2014. 277p. Dissertação (Mestrado) - Escola de Engenharia de São Carlos, Universidade de São Paulo. São Carlos, 2014.

SANTOS, E. A. F.; OLIVEIRA, L. M. F.; HAACH, V. G.; CORREAA, M. R. S. Evaluation of elastic modulus of concrete blocks using acoustic tests. 9th International Masonry Conference. Guimarães, 2014.

SCHIAVON, K. F. B. Estudo da aplicação de ultrassom na medição de tensões em estruturas de concreto. 2015. 130p. Dissertação (Mestrado) - Escola de Engenharia de São Carlos, Universidade de São Paulo. São Carlos, 2015.

SORIANO, H. L. Introdução à dinâmica das estruturas. 1 ed. Rio de Janeiro: Elsevier, 2014.

SWAMY, N.; RIGBY, G. Dynamic properties of hardened paste, mortar and concrete. Matériaux Et Constructions, [s.1.], v. 4, n. 1, p.13-40, jan. 1971. Springer Nature. http://dx.doi.org/10.1007/bf02473927.

YANG, C.; GUPTA, R. Prediction of the Compressive Strength from Resonant Frequency for Low-Calcium Fly Ash-Based Geopolymer Concrete. Journal of Materials in Civil Engineering, [s.1.], v. 30, n. 4, p.1-6, abr. 2018. American Society of Civil Engineers (ASCE). http://dx.doi.org/10.1061/(asce)mt.1943-5533.0002228. 
APÊNDICE A

RESULTADOS INDIVIDUAIS DA CARACTERIZAÇÃO DAS UNIDADES

Bloco inteiro cerâmico - 6 MPa e largura nominal de $14 \mathrm{~cm}(M-15)$

Tabela A.1 - Dimensões efetivas para blocos inteiros cerâmicos (individuais)

\begin{tabular}{cccc}
\hline ID & $\begin{array}{c}\text { Largura } \\
(\mathbf{m m})\end{array}$ & $\begin{array}{c}\text { Altura } \\
(\mathbf{m m})\end{array}$ & $\begin{array}{c}\text { Comprimento } \\
(\mathbf{m m})\end{array}$ \\
\hline $\mathbf{6 - 1}$ & 138,0 & 188,5 & 287,5 \\
$\mathbf{6 - 2}$ & 138,5 & 189,0 & 287,5 \\
$\mathbf{6 - 3}$ & 138,5 & 189,0 & 287,0 \\
$\mathbf{6 - 4}$ & 138,5 & 189,0 & 288,0 \\
$\mathbf{6 - 5}$ & 138,5 & 187,0 & 287,0 \\
$\mathbf{6 - 6}$ & 139,0 & 188,5 & 286,5 \\
$\mathbf{6 - 7}$ & 140,5 & 192,0 & 291,0 \\
$\mathbf{6 - 8}$ & 139,5 & 187,5 & 287,0 \\
$\mathbf{6 - 9}$ & 139,0 & 188,5 & 287,0 \\
$\mathbf{6 - 1 0}$ & 139,5 & 189,5 & 288,5 \\
$\mathbf{6 - 1 1}$ & 139,0 & 189,5 & 287,5 \\
$\mathbf{6 - 1 2}$ & 140,5 & 192,0 & 290,5 \\
$\mathbf{6 - 1 3}$ & 139,5 & 190,0 & 289,0 \\
Média & $\mathbf{1 3 9 , 1}$ & $\mathbf{1 8 9 , 2}$ & $\mathbf{2 8 8 , 0}$ \\
DP & $\mathbf{0 , 7 7}$ & $\mathbf{1 , 4 0}$ \\
$\mathbf{C V}(\mathbf{1})$ & $\mathbf{0 , 5 5}$ & $\mathbf{0 , 4 7}$ \\
\multicolumn{4}{c}{ Tolerâncias: } \\
\hline \multicolumn{4}{c}{} \\
\hline
\end{tabular}

Tabela A.2 - Espessura das paredes e septos, desvio em relação ao esquadro (D) e planeza das faces $(\mathrm{F})$ para blocos inteiros cerâmicos

\begin{tabular}{|c|c|c|c|c|c|c|c|c|c|c|}
\hline \multirow[b]{2}{*}{ ID } & \multicolumn{4}{|c|}{ Paredes externas } & \multicolumn{4}{|c|}{ Septos internos } & \multirow[b]{2}{*}{$\underset{(\mathbf{m m})}{\mathrm{D}}$} & \multirow[b]{2}{*}{$\underset{(\mathbf{m m})}{\mathbf{F}}$} \\
\hline & $\begin{array}{c}1 \\
(\mathbf{m m})\end{array}$ & $\begin{array}{c}2 \\
(\mathbf{m m})\end{array}$ & $\begin{array}{c}3 \\
(\mathbf{m m})\end{array}$ & $\begin{array}{c}4 \\
(\mathrm{~mm})\end{array}$ & $\begin{array}{c}\mathrm{I} \\
(\mathbf{m m})\end{array}$ & $\begin{array}{c}\text { II } \\
(\mathbf{m m})\end{array}$ & $\begin{array}{c}\text { III } \\
(\mathbf{m m})\end{array}$ & $\begin{array}{c}\text { IV } \\
(\mathbf{m m})\end{array}$ & & \\
\hline 6-1 & 9,24 & 10,00 & 9,68 & 8,98 & 6,66 & 8,24 & 7,06 & 6,89 & 2,11 & 1,33 \\
\hline 6-2 & 8,90 & 8,14 & 10,22 & 8,89 & 6,81 & 7,75 & 8,39 & 7,43 & 1,09 & 1,34 \\
\hline $6-3$ & 9,26 & 8,26 & 9,35 & 8,81 & 6,44 & 8,05 & 7,03 & 7,59 & 1,03 & 1,37 \\
\hline $6-4$ & 7,98 & 9,51 & 8,62 & 8,87 & 6,91 & 8,13 & 7,91 & 7,61 & 1,16 & 1,47 \\
\hline $6-5$ & 9,34 & 9,89 & 10,01 & 8,41 & 6,70 & 8,04 & 7,85 & 7,46 & 1,17 & 1,49 \\
\hline $6-6$ & 8,58 & 10,45 & 10,48 & 9,02 & 6,42 & 7,84 & 7,45 & 7,22 & 1,44 & 1,41 \\
\hline $6-7$ & 9,37 & 8,27 & 10,05 & 9,33 & 6,87 & 8,01 & 8,15 & 7,10 & 2,17 & 1,37 \\
\hline $6-8$ & 8,83 & 8,31 & 10,52 & 9,30 & 6,94 & 8,06 & 7,74 & 6,47 & 1,43 & 1,56 \\
\hline $6-9$ & 9,17 & 9,32 & 10,02 & 8,75 & 6,98 & 8,49 & 7,95 & 6,92 & 1,34 & 1,19 \\
\hline $6-10$ & 8,80 & 9,98 & 10,21 & 8,67 & 6,55 & 7,98 & 7,57 & 6,99 & 3,27 & 1,32 \\
\hline 6-11 & 9,29 & 10,28 & 9,79 & 8,73 & 6,93 & 7,95 & 7,87 & 7,27 & 2,62 & 1,66 \\
\hline $6-12$ & 9,15 & 11,13 & 10,27 & 8,46 & 6,96 & 8,03 & 7,98 & 7,80 & 2,08 & 1,48 \\
\hline $6-13$ & 9,24 & 10,73 & 9,74 & 8,13 & 7,69 & 8,78 & 8,46 & 7,65 & 1,36 & 1,12 \\
\hline
\end{tabular}

Espessura mínima das paredes externas: $8 \mathrm{~mm}$, com tolerância de $-0,3 \mathrm{~mm}$ (para cada valor individual) Espessura mínima dos septos internos: $7 \mathrm{~mm}$, com tolerância de $-0,3 \mathrm{~mm}$ (para cada valor individual) Desvio em relação ao esquadro (D) máximo: $3 \mathrm{~mm}$ 
Tabela A.3 - Área bruta e área líquida para blocos inteiros cerâmicos (individuais)

\begin{tabular}{cccccc}
\hline ID & $\begin{array}{c}\text { Massa } \\
\text { saturada } \\
(\mathbf{g})\end{array}$ & $\begin{array}{c}\text { Massa } \\
\text { aparente } \\
\mathbf{( g )}\end{array}$ & $\begin{array}{c}\text { Área } \\
\text { bruta } \\
\left.\mathbf{( m m}^{2}\right)\end{array}$ & $\begin{array}{c}\text { Área } \\
\text { líquida } \\
\left(\mathbf{m m}^{2}\right)\end{array}$ & $\begin{array}{c}\text { Aliq/Ab } \\
\mathbf{( \% )}\end{array}$ \\
\hline $\mathbf{6 - 1}$ & 6644 & 3570,7 & 39675,0 & 16304,0 & 41,09 \\
$\mathbf{6 - 2}$ & 6675 & 3581,9 & 39818,8 & 16365,6 & 41,10 \\
$\mathbf{6 - 3}$ & 6652 & 3578,1 & 39749,5 & 16264,0 & 40,92 \\
$\mathbf{6 - 4}$ & 6670 & 3565,1 & 39888,0 & 16428,0 & 41,19 \\
$\mathbf{6 - 5}$ & 6617 & 3558,9 & 39749,5 & 16353,5 & 41,14 \\
$\mathbf{6 - 6}$ & 6648 & 3583,0 & 39823,5 & 16259,9 & 40,83 \\
$\mathbf{6 - 7}$ & 6728 & 3566,6 & 40885,5 & 16465,6 & 40,27 \\
$\mathbf{6 - 8}$ & 6661 & 3581,0 & 40036,5 & 16426,7 & 41,03 \\
$\mathbf{6 - 9}$ & 6644 & 3567,9 & 39893,0 & 16318,8 & 40,91 \\
$\mathbf{6 - 1 0}$ & 6681 & 3575,8 & 40245,8 & 16386,3 & 40,72 \\
$\mathbf{6 - 1 1}$ & 6661 & 3572,6 & 39962,5 & 16297,6 & 40,78 \\
$\mathbf{6 - 1 2}$ & 6713 & 3557,2 & 40815,3 & 16436,5 & 40,27 \\
$\mathbf{6 - 1 3}$ & 6681 & 3566,2 & 40315,5 & 16393,7 & 40,66 \\
Média & - & - & $\mathbf{4 0 0 6 6 , 0}$ & $\mathbf{1 6 3 6 1 , 6}$ & $\mathbf{4 0 , 8 4}$ \\
$\mathbf{D P}$ & - & - & $\mathbf{3 9 5 , 2}$ & $\mathbf{6 8 , 2}$ & $\mathbf{0 , 3 0}$ \\
$\mathbf{C V}$ (\%) & - & - & $\mathbf{0 , 9 9}$ & $\mathbf{0 , 4 2}$ & $\mathbf{0 , 7 4}$ \\
\hline
\end{tabular}

Tabela A.4 - Resistência à compressão e módulo de elasticidade para blocos inteiros cerâmicos (individuais)

\begin{tabular}{ccccc}
\hline ID & $\begin{array}{c}\text { Carga } \\
\text { (kN) }\end{array}$ & $\begin{array}{c}\text { Área bruta } \\
\left(\mathbf{m m}^{2}\right)\end{array}$ & $\begin{array}{c}\text { Tensão na } \\
\text { área bruta } \\
\text { (MPa) }\end{array}$ & $\begin{array}{c}\text { Módulo de } \\
\text { elasticidade } \\
\text { estático } \\
\text { (GPa) }\end{array}$ \\
\hline $\mathbf{6 - 1}$ & 430,26 & 39675,0 & 10,84 & 3,16 \\
$\mathbf{6 - 2}$ & 417,81 & 39818,8 & 10,49 & 5,31 \\
$\mathbf{6 - 3}$ & 403,66 & 39749,5 & 10,16 & 4,66 \\
$\mathbf{6 - 4}$ & 371,57 & 39888,0 & 9,32 & 3,14 \\
$\mathbf{6 - 5}$ & 419,41 & 39749,5 & 10,55 & 3,52 \\
$\mathbf{6 - 6}$ & 399,36 & 39823,5 & 10,03 & 3,89 \\
$\mathbf{6 - 7}$ & 285,18 & 40885,5 & 6,97 & 3,53 \\
$\mathbf{6 - 8}$ & 258,26 & 40036,5 & 6,45 & 3,41 \\
$\mathbf{6 - 9}$ & 376,19 & 39893,0 & 9,43 & 5,08 \\
$\mathbf{6 - 1 0}$ & 415,15 & 40245,8 & 10,32 & 3,11 \\
$\mathbf{6 - 1 1}$ & 416,02 & 39962,5 & 10,41 & 2,95 \\
$\mathbf{6 - 1 2}$ & 219,89 & 40815,3 & 5,39 & 2,88 \\
$\mathbf{6 - 1 3}$ & 410,85 & 40315,5 & 10,19 & 2,71 \\
Média & $\mathbf{3 7 1 , 0 5}$ & $\mathbf{4 0 0 6 6 , 0}$ & $\mathbf{9 , 2 7}$ & $\mathbf{3 , 6 4}$ \\
$\mathbf{D P}$ & $\mathbf{6 9 , 7 7}$ & $\mathbf{3 9 5 , 2}$ & $\mathbf{1 , 7 9}$ & $\mathbf{0 , 8 5}$ \\
$\mathbf{C V}(\mathbf{\%})$ & $\mathbf{1 8 , 8 0}$ & $\mathbf{0 , 9 9}$ & $\mathbf{1 9 , 3 2}$ & $\mathbf{2 3 , 3 3}$ \\
$\boldsymbol{f}$ bk & - & - & $\mathbf{5 , 3 3}$ & - \\
\hline
\end{tabular}


Meio-bloco cerâmico - 14 MPa e largura nominal de $14 \mathrm{~cm}(\mathrm{M}-15)$

Tabela A.5 - Dimensões efetivas para meio-blocos cerâmicos (individuais)

\begin{tabular}{cccc}
\hline ID & $\begin{array}{c}\text { Largura } \\
(\mathbf{m m})\end{array}$ & $\begin{array}{c}\text { Altura } \\
(\mathbf{m m})\end{array}$ & $\begin{array}{c}\text { Comprimento } \\
(\mathbf{m m})\end{array}$ \\
\hline M14-1 & 137,3 & 188,3 & 140,3 \\
M14-2 & 138,8 & 188,5 & 140,5 \\
M14-3 & 138,3 & 188,5 & 139,8 \\
M14-4 & 137,8 & 188,5 & 141,0 \\
M14-5 & 138,0 & 188,5 & 140,8 \\
M14-6 & 137,3 & 187,8 & 140,3 \\
M14-7 & 138,0 & 188,5 & 140,3 \\
M14-8 & 138,0 & 187,5 & 141,0 \\
M14-9 & 137,8 & 188,0 & 140,5 \\
M14-10 & 137,5 & 187,8 & 140,5 \\
M14-11 & 138,0 & 187,8 & 140,8 \\
M14-12 & 137,8 & 188,0 & 140,3 \\
M14-13 & 137,8 & 188,0 & 140,0 \\
Média & $\mathbf{1 3 7 , 8}$ & $\mathbf{1 8 8 , 1}$ & $\mathbf{1 4 0 , 4}$ \\
DP & $\mathbf{0 , 4 0}$ & $\mathbf{0 , 3 6}$ & $\mathbf{0 , 3 7}$ \\
CV (\%) & $\mathbf{0 , 2 9}$ & $\mathbf{0 , 1 9}$ & $\mathbf{0 , 2 6}$ \\
\hline
\end{tabular}

Tolerâncias:

Largura, altura e comprimento: $\pm 3,0 \mathrm{~mm}$

Tabela A.6 - Área bruta e área líquida para meio-blocos cerâmicos (individuais)

\begin{tabular}{cccccc}
\hline ID & $\begin{array}{c}\text { Massa } \\
\text { saturada } \\
(\mathbf{g})\end{array}$ & $\begin{array}{c}\text { Massa } \\
\text { aparente } \\
\mathbf{( g )}\end{array}$ & $\begin{array}{c}\text { Área } \\
\text { bruta } \\
\left.\mathbf{( m m}^{2}\right)\end{array}$ & $\begin{array}{c}\text { Área } \\
\text { líquida } \\
\left(\mathbf{m m}^{2}\right)\end{array}$ & $\begin{array}{c}\mathbf{A}_{\text {liq }} / \mathbf{A}_{\mathbf{b}} \\
\mathbf{( \% )}\end{array}$ \\
\hline M14-1 & 4622,8 & 2500,9 & 19249,3 & 11271,7 & 58,56 \\
M14-2 & 4617,3 & 2478,7 & 19494,4 & 11345,4 & 58,20 \\
M14-3 & 4697,2 & 2538,5 & 19320,4 & 11452,0 & 59,27 \\
M14-4 & 4619,3 & 2483,9 & 19422,8 & 11328,4 & 58,33 \\
M14-5 & 4675,6 & 2535,4 & 19423,5 & 11353,8 & 58,45 \\
M14-6 & 4625,3 & 2500,9 & 19249,3 & 11315,0 & 58,78 \\
M14-7 & 4678,1 & 2535,9 & 19354,5 & 11364,5 & 58,72 \\
M14-8 & 4658,1 & 2529,5 & 19458,0 & 11352,5 & 58,34 \\
M14-9 & 4635,4 & 2504,6 & 19353,9 & 11334,0 & 58,56 \\
M14-10 & 4661,3 & 2530,1 & 19318,8 & 11351,3 & 58,76 \\
M14-11 & 4669,3 & 2531,2 & 19423,5 & 11388,0 & 58,63 \\
M14-12 & 4638,2 & 2504,6 & 19319,4 & 11348,9 & 58,74 \\
M14-13 & 4607,1 & 2491,1 & 19285,0 & 11255,3 & 58,36 \\
Média & - & - & $\mathbf{1 9 3 5 9 , 4}$ & $\mathbf{1 1 3 4 3 , 1}$ & $\mathbf{5 8 , 5 9}$ \\
DP & - & - & $\mathbf{7 8 , 9}$ & $\mathbf{4 8 , 8}$ & $\mathbf{0 , 2 8}$ \\
CV (\%) & - & - & $\mathbf{0 , 4 1}$ & $\mathbf{0 , 4 3}$ & $\mathbf{0 , 4 8}$ \\
\hline
\end{tabular}


Tabela A.7 - Resistência à compressão e módulo de elasticidade para meio-blocos cerâmicos (individuais)

\begin{tabular}{ccccc}
\hline ID & $\begin{array}{c}\text { Carga } \\
(\mathbf{k N})\end{array}$ & $\begin{array}{c}\text { Área bruta } \\
\left(\mathbf{m m}^{2}\right)\end{array}$ & $\begin{array}{c}\text { Tensão na } \\
\text { área bruta } \\
(\mathbf{M P a})\end{array}$ & $\begin{array}{c}\text { Módulo de } \\
\text { elasticidade } \\
\text { estático } \\
(\mathbf{G P a})\end{array}$ \\
\hline M14-1 & 328,99 & 19249,3 & 17,09 & 8,01 \\
M14-2 & 292,50 & 19494,4 & 15,00 & 9,39 \\
M14-3 & 397,75 & 19320,4 & 20,59 & 9,91 \\
M14-4 & 354,95 & 19422,8 & 18,27 & 7,58 \\
M14-5 & 353,99 & 19423,5 & 18,22 & 8,29 \\
M14-6 & 347,21 & 19249,3 & 18,04 & 8,19 \\
M14-7 & 422,11 & 19354,5 & 21,81 & 9,17 \\
M14-8 & 339,93 & 19458,0 & 17,47 & 9,99 \\
M14-9 & 371,89 & 19353,9 & 19,22 & 8,36 \\
M14-10 & 273,73 & 19318,8 & 14,17 & 9,62 \\
M14-11 & 316,90 & 19423,5 & 16,32 & 8,50 \\
M14-12 & 340,57 & 19319,4 & 17,63 & 9,26 \\
M14-13 & 363,97 & 19285,0 & 18,87 & 8,17 \\
Média & $\mathbf{3 4 6 , 5 0}$ & $\mathbf{1 9 3 5 9 , 4}$ & $\mathbf{1 7 , 9 0}$ & $\mathbf{8 , 8 0}$ \\
DP & $\mathbf{3 9 , 6 8}$ & $\mathbf{7 8 , 9}$ & $\mathbf{2 , 0 7}$ & $\mathbf{0 , 7 9}$ \\
CV (\%) & $\mathbf{1 1 , 4 5}$ & $\mathbf{0 , 4 1}$ & $\mathbf{1 1 , 5 4}$ & $\mathbf{8 , 9 5}$ \\
$\boldsymbol{f}_{\boldsymbol{b} \boldsymbol{k}}$ & - & - & $\mathbf{1 4 , 3 9}$ & - \\
\hline
\end{tabular}

Bloco inteiro de concreto - 10 MPa e largura nominal de $14 \mathrm{~cm}(\mathrm{M}-15)$

Tabela A.8 - Dimensões efetivas para blocos inteiros de concreto (individuais)

\begin{tabular}{cccc}
\hline ID & $\begin{array}{c}\text { Largura } \\
(\mathbf{m m})\end{array}$ & $\begin{array}{c}\text { Altura } \\
(\mathbf{m m})\end{array}$ & $\begin{array}{c}\text { Comprimento } \\
(\mathbf{m m})\end{array}$ \\
\hline $\mathbf{1 4 . 1 0 - 1}$ & 138,3 & 189,0 & 391,0 \\
$\mathbf{1 4 . 1 0 - 2}$ & 139,0 & 187,0 & 389,7 \\
$\mathbf{1 4 . 1 0 - 3}$ & 139,2 & 189,3 & 391,0 \\
$\mathbf{1 4 . 1 0 - 4}$ & 139,2 & 190,0 & 390,7 \\
$\mathbf{1 4 . 1 0 - 5}$ & 139,0 & 190,0 & 390,3 \\
$\mathbf{1 4 . 1 0 - 6}$ & 139,0 & 190,7 & 390,3 \\
Média & $\mathbf{1 3 8 , 9}$ & $\mathbf{1 8 9 , 3}$ & $\mathbf{3 9 0 , 5}$ \\
DP & $\mathbf{0 , 3 1}$ & $\mathbf{1 , 2 8}$ & $\mathbf{0 , 5 1}$ \\
CV (\%) & $\mathbf{0 , 2 2}$ & $\mathbf{0 , 6 8}$ \\
\multicolumn{4}{c}{ Tolerâncias: } \\
\multicolumn{4}{c}{ Largura: $\pm 2,0$ mm } \\
\hline \multicolumn{4}{c}{ Altura e comprimento: $\pm 3,0$ mm } \\
\hline
\end{tabular}


Tabela A.9 - Espessura das paredes, dimensões dos furos e raio das mísulas para blocos inteiros de concreto (individuais)

\begin{tabular}{ccccccc}
\hline ID & $\begin{array}{c}\text { Paredes } \\
\text { longitudinais } \\
(\mathbf{m m})\end{array}$ & $\begin{array}{c}\text { Espessura } \\
\begin{array}{c}\text { Paredes } \\
\text { transversais } \\
(\mathbf{m m})\end{array}\end{array}$ & $\begin{array}{c}\text { Transversal } \\
\text { equivalente } \\
(\mathbf{m m} / \mathbf{m})\end{array}$ & $\begin{array}{c}\text { Longitudinal } \\
(\mathbf{m m})\end{array}$ & $\begin{array}{c}\text { Transversal } \\
(\mathbf{m m})\end{array}$ & $\begin{array}{c}\text { Raio das } \\
\text { mísulas } \\
(\mathbf{m m})\end{array}$ \\
\hline $\mathbf{1 4 . 1 0 - 1}$ & 26,0 & 25,3 & 194,4 & 147,5 & 76,5 & 43,0 \\
$\mathbf{1 4 . 1 0 - 2}$ & 26,0 & 24,3 & 187,3 & 148,5 & 78,0 & 43,5 \\
$\mathbf{1 4 . 1 0 - 3}$ & 25,8 & 25,0 & 191,8 & 146,5 & 76,0 & 42,8 \\
$\mathbf{1 4 . 1 0 - 4}$ & 26,0 & 25,3 & 194,5 & 148,0 & 77,5 & 43,3 \\
$\mathbf{1 4 . 1 0 - 5}$ & 25,6 & 25,2 & 193,4 & 148,0 & 77,5 & 43,5 \\
$\mathbf{1 4 . 1 0 - 6}$ & 25,8 & 24,7 & 189,6 & 149,0 & 77,0 & 43,0 \\
Média & $\mathbf{2 5 , 9}$ & $\mathbf{2 5 , 0}$ & $\mathbf{1 9 1 , 8}$ & $\mathbf{1 4 7 , 9}$ & $\mathbf{7 7 , 1}$ & $\mathbf{4 3 , 2}$ \\
DP & $\mathbf{0 , 1 7}$ & $\mathbf{0 , 4 0}$ & $\mathbf{2 , 9}$ & $\mathbf{0 , 8 6}$ & $\mathbf{0 , 7 4}$ & $\mathbf{0 , 3 0}$ \\
CV (\%) & $\mathbf{0 , 6 4}$ & $\mathbf{1 , 6 0}$ & $\mathbf{1 , 5 1}$ & $\mathbf{0 , 5 8}$ & $\mathbf{0 , 9 5}$ & $\mathbf{0 , 7 0}$ \\
\hline
\end{tabular}

Tolerâncias e limites:

Espessura mínima das paredes longitudinais e transversais: $25 \mathrm{~mm}$, com tolerância de $-1,0 \mathrm{~mm}$ (para cada valor individual)

Espessura equivalente mínima das paredes transversais: $188 \mathrm{~mm} / \mathrm{m}$

Dimensão mínima do furo: $70 \mathrm{~mm}$

Raio mínimo das mísulas de acomodação: $40 \mathrm{~mm}$ (blocos classe A), expresso individualmente.

Tabela A.10 - Área bruta e área líquida para blocos inteiros de concreto (individuais)

\begin{tabular}{cccccc}
\hline ID & $\begin{array}{c}\text { Massa } \\
\text { saturada } \\
(\mathbf{g})\end{array}$ & $\begin{array}{c}\text { Massa } \\
\text { aparente } \\
(\mathbf{g})\end{array}$ & $\begin{array}{c}\text { Área } \\
\text { bruta } \\
\left(\mathbf{m m}^{2}\right)\end{array}$ & $\begin{array}{c}\text { Área } \\
\text { líquida } \\
\left(\mathbf{m m}^{\mathbf{2}}\right)\end{array}$ & $\begin{array}{c}\mathbf{A}_{\text {liq }} / \mathbf{A}_{\mathbf{b}} \\
(\mathbf{\%})\end{array}$ \\
\hline $\mathbf{1 4 . 1 0 - 1}$ & 11922 & 7106 & 54088,3 & 28806,3 & 53,26 \\
$\mathbf{1 4 . 1 0 - 2}$ & 12943 & 7863 & 54163,7 & 29494,1 & 54,45 \\
$\mathbf{1 4 . 1 0 - 3}$ & 12568 & 7568 & 54414,2 & 29167,6 & 53,60 \\
Média & - & - & $\mathbf{5 4 2 2 2 , 1}$ & $\mathbf{2 9 1 5 6 , 0}$ & $\mathbf{5 3 , 7 7}$ \\
DP & - & - & $\mathbf{1 7 0 , 6}$ & $\mathbf{3 4 4 , 0}$ & $\mathbf{0 , 6 2}$ \\
CV (\%) & - & - & $\mathbf{0 , 3 1}$ & $\mathbf{1 , 1 8}$ & $\mathbf{1 , 1 4}$ \\
\hline
\end{tabular}

Tabela A.11 - Resistência à compressão e módulo de elasticidade para blocos inteiros de concreto (individuais)

\begin{tabular}{ccccc}
\hline ID & $\begin{array}{c}\text { Carga } \\
(\mathbf{k N})\end{array}$ & $\begin{array}{c}\text { Área bruta } \\
\left(\mathbf{m m}^{2}\right)\end{array}$ & $\begin{array}{c}\text { Tensão na } \\
\text { área bruta } \\
(\mathbf{M P a})\end{array}$ & $\begin{array}{c}\text { Módulo de } \\
\text { elasticidade } \\
\text { estático } \\
\text { (GPa) }\end{array}$ \\
\hline $\mathbf{1 4 . 1 0 - 1}$ & 808,33 & 54088,33 & 14,94 & 15,79 \\
$\mathbf{1 4 . 1 0 - 2}$ & 971,13 & 54163,67 & 17,93 & 15,95 \\
$\mathbf{1 4 . 1 0 - 3}$ & 881,90 & 54414,17 & 16,21 & 15,44 \\
$\mathbf{1 4 . 1 0 - 4}$ & 1162,22 & 54367,78 & 21,38 & 16,86 \\
$\mathbf{1 4 . 1 0 - 5}$ & 839,87 & 54256,33 & 15,48 & 14,29 \\
$\mathbf{1 4 . 1 0 - 6}$ & 1014,30 & 54256,33 & 18,69 & 13,79 \\
Média & $\mathbf{9 4 6 , 2 9}$ & $\mathbf{5 4 2 5 7 , 8}$ & $\mathbf{1 7 , 4 4}$ & $\mathbf{1 5 , 3 5}$ \\
DP & $\mathbf{1 3 1 , 4 3}$ & $\mathbf{1 2 1 , 8}$ & $\mathbf{2 , 4 0}$ & $\mathbf{1 , 1 3}$ \\
$\mathbf{C V}(\mathbf{\%})$ & $\mathbf{1 3 , 8 9}$ & $\mathbf{0 , 2 2}$ & $\mathbf{1 3 , 7 9}$ & $\mathbf{7 , 3 7}$ \\
$\boldsymbol{f}_{b k}$ & - & - & $\mathbf{1 4 , 2 2}$ & - \\
\hline
\end{tabular}


Meio-bloco de concreto - 10 MPa e largura nominal de $19 \mathrm{~cm}(\mathrm{M}-20)$

Tabela A.12 - Dimensões efetivas para meio-blocos de concreto (individuais)

\begin{tabular}{cccc}
\hline ID & $\begin{array}{c}\text { Largura } \\
(\mathbf{m m})\end{array}$ & $\begin{array}{c}\text { Altura } \\
(\mathbf{m m})\end{array}$ & $\begin{array}{c}\text { Comprimento } \\
(\mathbf{m m})\end{array}$ \\
\hline $\mathbf{1 9 . 1 0 - 1}$ & 188,8 & 187,8 & 188,8 \\
$\mathbf{1 9 . 1 0 - 2}$ & 190,2 & 190,0 & 190,2 \\
$\mathbf{1 9 . 1 0 - 3}$ & 189,5 & 188,0 & 188,8 \\
$\mathbf{1 9 . 1 0 - 4}$ & 189,3 & 188,0 & 188,8 \\
$\mathbf{1 9 . 1 0 - 5}$ & 190,3 & 189,3 & 189,2 \\
$\mathbf{1 9 . 1 0 - 6}$ & 189,3 & 189,0 & 189,5 \\
Média & $\mathbf{1 8 9 , 6}$ & $\mathbf{1 8 8 , 7}$ & $\mathbf{1 8 9 , 2}$ \\
$\mathbf{D P}$ & $\mathbf{0 , 5 7}$ & $\mathbf{0 , 8 9}$ & $\mathbf{0 , 5 3}$ \\
$\mathbf{C V}$ (\%) & $\mathbf{0 , 3 0}$ & $\mathbf{0 , 4 7}$ & $\mathbf{0 , 2 8}$ \\
\multicolumn{4}{c}{ Tolerâncias: } \\
\multicolumn{4}{c}{ Largura: $\pm 2,0$ mm } \\
\multicolumn{4}{c}{ Altura e comprimento: $\pm 3,0$ mm } \\
\hline
\end{tabular}

Tabela A.13 - Área bruta e área líquida para meio-blocos de concreto (individuais)

\begin{tabular}{cccccc}
\hline ID & $\begin{array}{c}\text { Massa } \\
\text { saturada } \\
(\mathbf{g})\end{array}$ & $\begin{array}{c}\text { Massa } \\
\text { aparente } \\
(\mathbf{g})\end{array}$ & $\begin{array}{c}\text { Área } \\
\text { bruta } \\
\left(\mathbf{m m}^{2}\right)\end{array}$ & $\begin{array}{c}\text { Área } \\
\text { líquida } \\
\left(\mathbf{m m}^{2}\right)\end{array}$ & $\begin{array}{c}\text { Alíq/Ab } \\
(\mathbf{\%})\end{array}$ \\
\hline $\mathbf{1 9 . 1 0 - 1}$ & 8272 & 4897 & 35658,0 & 17976,0 & 50,41 \\
$\mathbf{1 9 . 1 0 - 3}$ & 8268 & 4899 & 36004,7 & 17920,2 & 49,77 \\
$\mathbf{1 9 . 1 0 - 6}$ & 8305 & 4921 & 35878,7 & 17904,8 & 49,90 \\
Média & - & - & $\mathbf{3 5 8 4 7 , 1}$ & $\mathbf{1 7 9 3 3 , 7}$ & $\mathbf{5 0 , 0 3}$ \\
DP & - & - & $\mathbf{1 7 5 , 5}$ & $\mathbf{3 7 , 5}$ & $\mathbf{0 , 3 4}$ \\
CV (\%) & - & - & $\mathbf{0 , 4 9}$ & $\mathbf{0 , 2 1}$ & $\mathbf{0 , 6 8}$ \\
\hline
\end{tabular}

Tabela A.14 - Resistência à compressão e módulo de elasticidade para meio-blocos de concreto (individuais)

\begin{tabular}{ccccc}
\hline ID & $\begin{array}{c}\text { Carga } \\
(\mathbf{k N})\end{array}$ & $\begin{array}{c}\text { Área bruta } \\
\left(\mathbf{m m}^{2}\right)\end{array}$ & $\begin{array}{c}\text { Tensão na } \\
\text { área bruta } \\
(\mathbf{M P a})\end{array}$ & $\begin{array}{c}\text { Módulo de } \\
\text { elasticidade } \\
\text { estático } \\
(\mathbf{G P a})\end{array}$ \\
\hline $\mathbf{1 9 . 1 0 - 1}$ & 917,01 & 35658,0 & 25,72 & 18,95 \\
$\mathbf{1 9 . 1 0 - 2}$ & 1110,17 & 36176,0 & 30,69 & 24,61 \\
$\mathbf{1 9 . 1 0 - 3}$ & 885,61 & 36004,7 & 24,60 & 24,28 \\
$\mathbf{1 9 . 1 0 - 4}$ & 840,24 & 35739,8 & 23,51 & 21,64 \\
$\mathbf{1 9 . 1 0 - 5}$ & 567,15 & 36004,8 & 15,75 & 23,18 \\
$\mathbf{1 9 . 1 0 - 6}$ & 830,44 & 35878,7 & 23,15 & 14,92 \\
Média & $\mathbf{8 5 8 , 4 3}$ & $\mathbf{3 5 9 1 0 , 3}$ & $\mathbf{2 3 , 9 0}$ & $\mathbf{2 1 , 2 6}$ \\
DP & $\mathbf{1 7 5 , 2 2}$ & $\mathbf{1 9 0 , 9}$ & $\mathbf{3 , 4 4}$ & $\mathbf{3 , 7 3}$ \\
$\mathbf{C V}(\mathbf{\%})$ & $\mathbf{2 0 , 4 1}$ & $\mathbf{0 , 5 3}$ & $\mathbf{2 0 , 2 4}$ & $\mathbf{1 7 , 5 5}$ \\
$\boldsymbol{f} \boldsymbol{b k}$ & - & - & $\mathbf{1 5 , 4}$ & - \\
\hline
\end{tabular}




\section{APÊNDICE B}

\section{TESTES DE HIPÓTESES: HOMOGENEIDADE DAS UNIDADES DE ALVENARIA}

A partir da observação das velocidades de propagação (ondas longitudinais e transversais) nas diferentes posições de medida e camadas ao longo da altura do espécime, foram propostos testes de hipóteses para avaliar a homogeneidade de cada unidade/material, analisada com base na variância (teste F) e na média (teste $t$ de Student) entre medições.

Inicialmente, para todas as unidades, três testes foram averiguados, sendo enunciados a seguir juntamente com as hipóteses nula $\left(\mathrm{H}_{0}\right)$ e alternativa $\left(\mathrm{H}_{\mathrm{A}}\right)$ pertinentes:

1) “A velocidade de propagação varia ao longo das quatro camadas examinadas."

$$
\begin{aligned}
& \mathrm{H}_{0}: \mu_{1}=\mu_{2}=\mu_{3}=\mu_{4} \\
& \mathrm{H}_{\mathrm{A}}: \mu_{1} \neq \mu_{2} \neq \mu_{3} \neq \mu_{4}
\end{aligned}
$$

2) “A velocidade de propagação não é equivalente nas medições que são simétricas."

$$
\begin{aligned}
& \mathrm{H}_{0}: \mu_{\mathrm{Li}}=\mu_{\mathrm{Lj}} ; \mu_{\mathrm{Ci}}=\mu_{\mathrm{Cj}} \\
& \mathrm{H}_{\mathrm{A}}: \mu_{\mathrm{Li}} \neq \mu_{\mathrm{Lj}} ; \mu_{\mathrm{Ci}} \neq \mu_{\mathrm{Cj}}
\end{aligned}
$$

3) “A velocidade de propagação é diferente ao longo das três dimensões do espécime."

$$
\begin{aligned}
& \mathrm{H}_{0}: \mu_{\mathrm{L}}=\mu_{\mathrm{C}}=\mu_{\mathrm{H}} \\
& \mathrm{H}_{\mathrm{A}}: \mu_{\mathrm{L}} \neq \mu_{\mathrm{C}} \neq \mu_{\mathrm{H}}
\end{aligned}
$$

Os resultados foram apurados considerando um nível de confiança igual a 95\%. Os Quadros B.1 a B.4 adiante detalham as conclusões de forma individual. 
Quadro B.1 - Testes de hipóteses: blocos inteiros cerâmicos

\begin{tabular}{|c|c|c|c|}
\hline & ri $\square$ & $\overbrace{}^{9}$ & \\
\hline ID & TESTE 1 & TESTE 2 & TESTE 3 \\
\hline \multirow{2}{*}{ 6-1(END) } & $\begin{array}{l}\text { ONDAS LONGITUDINAIS: } \\
\text { Não há evidência para } \\
\text { recusar a hipótese nula (as } \\
\text { velocidades nas } 4 \text { camadas } \\
\text { não são significativamente } \\
\text { diferentes). }\end{array}$ & $\begin{array}{l}\text { ONDAS LONGITUDINAIS: } \\
\text { As velocidades nas medidas } \\
\text { simétricas 0-9/3-6 e 1-8/2-7 } \\
\text { são significativamente } \\
\text { diferentes entre si. }\end{array}$ & $\begin{array}{l}\text { ONDAS LONGITUDINAIS: } \\
\text { A hipótese alternativa pode } \\
\text { ser aceita (as velocidades ao } \\
\text { longo das } 3 \text { dimensões } \\
\text { diferem significativamente). }\end{array}$ \\
\hline & $\begin{array}{l}\text { ONDAS TRANSVERSAIS: } \\
\text { Não há evidência para } \\
\text { recusar a hipótese nula (as } \\
\text { velocidades nas } 4 \text { camadas } \\
\text { não são significativamente } \\
\text { diferentes). }\end{array}$ & $\begin{array}{l}\text { ONDAS TRANSVERSAIS: } \\
\text { As velocidades nas medidas } \\
\text { simétricas 0-9/3-6 e 1-8/2-7 } \\
\text { são significativamente } \\
\text { diferentes entre si. }\end{array}$ & $\begin{array}{l}\text { ONDAS TRANSVERSAIS: } \\
\text { A velocidade ao longo do } \\
\text { comprimento difere } \\
\text { significativamente daquelas } \\
\text { nas demais dimensões. }\end{array}$ \\
\hline \multirow[t]{2}{*}{ 6-2(END) } & $\begin{array}{l}\text { ONDAS LONGITUDINAIS: } \\
\text { Não há evidência para } \\
\text { recusar a hipótese nula (as } \\
\text { velocidades nas } 4 \text { camadas } \\
\text { não são significativamente } \\
\text { diferentes). }\end{array}$ & $\begin{array}{l}\text { ONDAS LONGITUDINAIS: } \\
\text { As velocidades nas medidas } \\
\text { simétricas } 0-9 / 3-6 \text { e } 4-11 / 5- \\
10 \text { são significativamente } \\
\text { diferentes entre si. Ressalva } \\
\text { para as medidas } 1-8 / 2-7 \\
(p=0,0551) \text {. }\end{array}$ & $\begin{array}{l}\text { ONDAS LONGITUDINAIS: } \\
\text { A hipótese alternativa pode } \\
\text { ser aceita (as velocidades ao } \\
\text { longo das } 3 \text { dimensões } \\
\text { diferem significativamente). }\end{array}$ \\
\hline & $\begin{array}{l}\text { ONDAS TRANSVERSAIS: } \\
\text { Não há evidência para } \\
\text { recusar a hipótese nula (as } \\
\text { velocidades nas } 4 \text { camadas } \\
\text { não são significativamente } \\
\text { diferentes). }\end{array}$ & $\begin{array}{l}\text { ONDAS TRANSVERSAIS: } \\
\text { As velocidades nas medidas } \\
\text { simétricas 0-9/3-6 e 1-8/2-7 } \\
\text { são significativamente } \\
\text { diferentes entre si. }\end{array}$ & $\begin{array}{l}\text { ONDAS TRANSVERSAIS: } \\
\text { A velocidade ao longo do } \\
\text { comprimento difere } \\
\text { significativamente daquelas } \\
\text { nas demais dimensões. }\end{array}$ \\
\hline \multirow{2}{*}{ 6-3(END) } & $\begin{array}{l}\text { ONDAS LONGITUDINAIS: } \\
\text { Não há evidência para } \\
\text { recusar a hipótese nula (as } \\
\text { velocidades nas } 4 \text { camadas } \\
\text { não são significativamente } \\
\text { diferentes). }\end{array}$ & $\begin{array}{l}\text { ONDAS LONGITUDINAIS: } \\
\text { As velocidades nas medidas } \\
\text { simétricas 0-9/3-6 e 4-11/5- } \\
10 \text { são significativamente } \\
\text { diferentes entre si. }\end{array}$ & $\begin{array}{l}\text { ONDAS LONGITUDINAIS: } \\
\text { A velocidade ao longo da } \\
\text { altura é significativamente } \\
\text { diferente daquelas nas } \\
\text { demais dimensões. }\end{array}$ \\
\hline & $\begin{array}{l}\text { ONDAS TRANSVERSAIS: } \\
\text { Não há evidência para } \\
\text { recusar a hipótese nula (as } \\
\text { velocidades nas } 4 \text { camadas } \\
\text { não são significativamente } \\
\text { diferentes). }\end{array}$ & $\begin{array}{l}\text { ONDAS TRANSVERSAIS: } \\
\text { As velocidades nas medidas } \\
\text { simétricas } 0-9 / 3-6 \text { são } \\
\text { significativamente diferentes. }\end{array}$ & $\begin{array}{l}\text { ONDAS TRANSVERSAIS: } \\
\text { A velocidade ao longo do } \\
\text { comprimento difere } \\
\text { significativamente daquelas } \\
\text { nas demais dimensões. }\end{array}$ \\
\hline
\end{tabular}


Quadro B.2 - Testes de hipóteses: blocos inteiros de concreto

\begin{tabular}{|c|c|c|c|}
\hline & ${ }_{\omega}^{+5}$ & $\begin{array}{l}\mathrm{H} 2 \\
1 \\
1\end{array}$ & $\int_{0}^{\infty}{ }^{\infty}$ \\
\hline ID & TESTE 1 & TESTE 2 & TESTE 3 \\
\hline \multirow[t]{2}{*}{ 14.10-1(END) } & $\begin{array}{l}\text { ONDAS LONGITUDINAIS: } \\
\text { Não há evidência para } \\
\text { recusar a hipótese nula (as } \\
\text { velocidades nas } 4 \text { camadas } \\
\text { não são significativamente } \\
\text { diferentes). Ressalva entre as } \\
\text { camadas } 1 \text { e } 2(\mathrm{p}=0,0501) \text {. }\end{array}$ & $\begin{array}{l}\text { ONDAS LONGITUDINAIS: } \\
\text { As velocidades nas medidas } \\
\text { simétricas } 0-7 / 2-5 \text { são } \\
\text { significativamente diferentes. }\end{array}$ & $\begin{array}{l}\text { ONDAS LONGITUDINAIS: } \\
\text { A velocidade ao longo do } \\
\text { comprimento difere } \\
\text { significativamente daquela } \\
\text { na largura. }\end{array}$ \\
\hline & $\begin{array}{l}\text { ONDAS TRANSVERSAIS: } \\
\text { As velocidades nas camadas } \\
2 \text { e } 4 \text { são significativamente } \\
\text { diferentes. }\end{array}$ & $\begin{array}{l}\text { ONDAS TRANSVERSAIS: } \\
\text { As velocidades nas medidas } \\
\text { simétricas } 0-7 / 2-5 \text { são } \\
\text { significativamente diferentes. }\end{array}$ & $\begin{array}{l}\text { ONDAS TRANSVERSAIS: } \\
\text { Não há evidência para } \\
\text { recusar a hipótese nula (as } \\
\text { velocidades nas três } \\
\text { dimensões não diferem } \\
\text { significativamente). }\end{array}$ \\
\hline \multirow{2}{*}{ 14.10-2(END) } & $\begin{array}{l}\text { ONDAS LONGITUDINAIS: } \\
\text { A velocidade na camada } 4 \\
\text { difere significativamente } \\
\text { daquelas nas camadas } 1 \text { e } 2 \text {. }\end{array}$ & $\begin{array}{l}\text { ONDAS LONGITUDINAIS: } \\
\text { Não há evidência para } \\
\text { recusar a hipótese nula (as } \\
\text { velocidades nas medidas } \\
\text { simétricas não diferem } \\
\text { significativamente). }\end{array}$ & $\begin{array}{l}\text { ONDAS LONGITUDINAIS: } \\
\text { Não há evidência para } \\
\text { recusar a hipótese nula (as } \\
\text { velocidades nas três } \\
\text { dimensões não diferem } \\
\text { significativamente). }\end{array}$ \\
\hline & $\begin{array}{l}\text { ONDAS TRANSVERSAIS: } \\
\text { As velocidades nas camadas } \\
1 \text { e } 3 \text { são significativamente } \\
\text { diferentes. }\end{array}$ & $\begin{array}{l}\text { ONDAS TRANSVERSAIS: } \\
\text { Não há evidência para } \\
\text { recusar a hipótese nula (as } \\
\text { velocidades nas medidas } \\
\text { simétricas não diferem } \\
\text { significativamente). }\end{array}$ & $\begin{array}{l}\text { ONDAS TRANSVERSAIS: } \\
\text { Não há evidência para } \\
\text { recusar a hipótese nula (as } \\
\text { velocidades nas três } \\
\text { dimensões não diferem } \\
\text { significativamente). }\end{array}$ \\
\hline \multirow{2}{*}{ 14.10-3(END) } & $\begin{array}{l}\text { ONDAS LONGITUDINAIS: } \\
\text { A velocidade na camada } 1 \\
\text { difere significativamente } \\
\text { daquelas nas camadas } 2 \text { e } 3 \text {. }\end{array}$ & $\begin{array}{l}\text { ONDAS LONGITUDINAIS: } \\
\text { Não há evidência para } \\
\text { recusar a hipótese nula (as } \\
\text { velocidades nas medidas } \\
\text { simétricas não diferem } \\
\text { significativamente). }\end{array}$ & $\begin{array}{l}\text { ONDAS LONGITUDINAIS: } \\
\text { A velocidade ao longo da } \\
\text { largura é significativamente } \\
\text { diferente daquelas nas } \\
\text { demais dimensões. }\end{array}$ \\
\hline & $\begin{array}{l}\text { ONDAS TRANSVERSAIS: } \\
\text { Não há evidência para } \\
\text { recusar a hipótese nula (as } \\
\text { velocidades nas } 4 \text { camadas } \\
\text { não são significativamente } \\
\text { diferentes). }\end{array}$ & $\begin{array}{l}\text { ONDAS TRANSVERSAIS: } \\
\text { As velocidades nas medidas } \\
\text { simétricas } 0-7 / 2-5 \text { são } \\
\text { significativamente diferentes. }\end{array}$ & $\begin{array}{l}\text { ONDAS TRANSVERSAIS: } \\
\text { A velocidade ao longo do } \\
\text { comprimento difere } \\
\text { significativamente daquela } \\
\text { na largura. }\end{array}$ \\
\hline
\end{tabular}


Quadro B.3 - Testes de hipóteses: meio-blocos cerâmicos

\begin{tabular}{|c|c|c|c|}
\hline & $\omega^{4}$ & $\overbrace{\mathrm{H} 4}^{\mathrm{H} 1}$ & \\
\hline ID & TESTE 1 & TESTE 2 & TESTE 3 \\
\hline \multirow{2}{*}{ M14-1(END) } & $\begin{array}{l}\text { ONDAS LONGITUDINAIS: } \\
\text { Não há evidência para } \\
\text { recusar a hipótese nula (as } \\
\text { velocidades nas } 4 \text { camadas } \\
\text { não são significativamente } \\
\text { diferentes). }\end{array}$ & $\begin{array}{l}\text { ONDAS LONGITUDINAIS: } \\
\text { As velocidades nas medidas } \\
\text { simétricas } 0-5 / 1-4 \text { e } 2-7 / 3-6 \\
\text { são significativamente } \\
\text { diferentes entre si. }\end{array}$ & $\begin{array}{l}\text { ONDAS LONGITUDINAIS: } \\
\text { A hipótese alternativa pode } \\
\text { ser aceita (as velocidades ao } \\
\text { longo das } 3 \text { dimensões } \\
\text { diferem significativamente). }\end{array}$ \\
\hline & $\begin{array}{l}\text { ONDAS TRANSVERSAIS: } \\
\text { Não há evidência para } \\
\text { recusar a hipótese nula (as } \\
\text { velocidades nas } 4 \text { camadas } \\
\text { não são significativamente } \\
\text { diferentes). }\end{array}$ & $\begin{array}{l}\text { ONDAS TRANSVERSAIS: } \\
\text { As velocidades nas medidas } \\
\text { simétricas } 0-5 / 1-4 \text { são } \\
\text { significativamente diferentes. }\end{array}$ & $\begin{array}{l}\text { ONDAS TRANSVERSAIS: } \\
\text { A velocidade ao longo da } \\
\text { largura é significativamente } \\
\text { diferente daquelas nas } \\
\text { demais dimensões. }\end{array}$ \\
\hline \multirow{2}{*}{ M14-2(END) } & $\begin{array}{l}\text { ONDAS LONGITUDINAIS: } \\
\text { Não há evidência para } \\
\text { recusar a hipótese nula (as } \\
\text { velocidades nas } 4 \text { camadas } \\
\text { não são significativamente } \\
\text { diferentes). }\end{array}$ & $\begin{array}{l}\text { ONDAS LONGITUDINAIS: } \\
\text { As velocidades nas medidas } \\
\text { simétricas } 0-5 / 1-4 \text { são } \\
\text { significativamente diferentes. }\end{array}$ & $\begin{array}{l}\text { ONDAS LONGITUDINAIS: } \\
\text { A hipótese alternativa pode } \\
\text { ser aceita (as velocidades ao } \\
\text { longo das } 3 \text { dimensões } \\
\text { diferem significativamente). }\end{array}$ \\
\hline & $\begin{array}{l}\text { ONDAS TRANSVERSAIS: } \\
\text { Não há evidência para } \\
\text { recusar a hipótese nula (as } \\
\text { velocidades nas } 4 \text { camadas } \\
\text { não são significativamente } \\
\text { diferentes). }\end{array}$ & $\begin{array}{l}\text { ONDAS TRANSVERSAIS: } \\
\text { As velocidades nas medidas } \\
\text { simétricas } 0-5 / 1-4 \text { são } \\
\text { significativamente diferentes. }\end{array}$ & $\begin{array}{l}\text { ONDAS TRANSVERSAIS: } \\
\text { A velocidade ao longo da } \\
\text { largura é significativamente } \\
\text { diferente daquelas nas } \\
\text { demais dimensões. }\end{array}$ \\
\hline \multirow{2}{*}{ M14-3(END) } & $\begin{array}{l}\text { ONDAS LONGITUDINAIS: } \\
\text { Não há evidência para } \\
\text { recusar a hipótese nula (as } \\
\text { velocidades nas } 4 \text { camadas } \\
\text { não são significativamente } \\
\text { diferentes). }\end{array}$ & $\begin{array}{l}\text { ONDAS LONGITUDINAIS: } \\
\text { As velocidades nas medidas } \\
\text { simétricas } 0-5 / 1-4 \text { e } 2-7 / 3-6 \\
\text { são significativamente } \\
\text { diferentes entre si. }\end{array}$ & $\begin{array}{l}\text { ONDAS LONGITUDINAIS: } \\
\text { A hipótese alternativa pode } \\
\text { ser aceita (as velocidades ao } \\
\text { longo das } 3 \text { dimensões } \\
\text { diferem significativamente). }\end{array}$ \\
\hline & $\begin{array}{l}\text { ONDAS TRANSVERSAIS: } \\
\text { Não há evidência para } \\
\text { recusar a hipótese nula (as } \\
\text { velocidades nas } 4 \text { camadas } \\
\text { não são significativamente } \\
\text { diferentes). }\end{array}$ & $\begin{array}{l}\text { ONDAS TRANSVERSAIS: } \\
\text { As velocidades nas medidas } \\
\text { simétricas } 0-5 / 1-4 \text { são } \\
\text { significativamente diferentes. }\end{array}$ & $\begin{array}{l}\text { ONDAS TRANSVERSAIS: } \\
\text { A velocidade ao longo da } \\
\text { largura é significativamente } \\
\text { diferente daquelas nas } \\
\text { demais dimensões. }\end{array}$ \\
\hline
\end{tabular}


Quadro B.4 - Testes de hipóteses: meio-blocos de concreto

\begin{tabular}{|c|c|c|c|}
\hline & 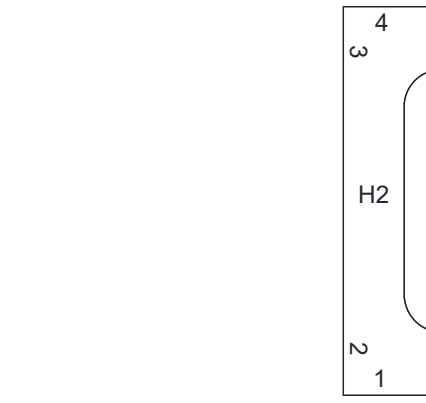 & 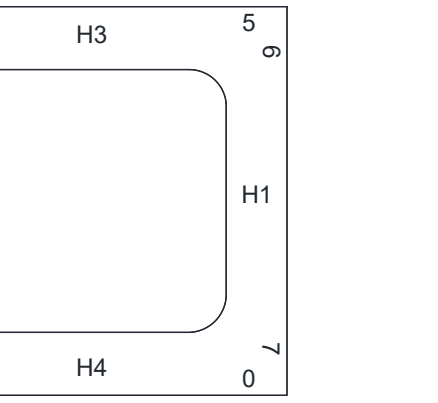 & \\
\hline ID & TESTE 1 & TESTE 2 & TESTE 3 \\
\hline \multirow{2}{*}{ 19.10-1(END) } & $\begin{array}{l}\text { ONDAS LONGITUDINAIS: } \\
\text { As velocidades nas camadas } \\
3 \text { e } 4 \text { são significativamente } \\
\text { diferentes. }\end{array}$ & $\begin{array}{l}\text { ONDAS LONGITUDINAIS: } \\
\text { Não há evidência para } \\
\text { recusar a hipótese nula (as } \\
\text { velocidades nas medidas } \\
\text { simétricas não diferem } \\
\text { significativamente). }\end{array}$ & $\begin{array}{l}\text { ONDAS LONGITUDINAIS: } \\
\text { A velocidade ao longo da } \\
\text { altura é significativamente } \\
\text { diferente daquelas nas } \\
\text { demais dimensões. }\end{array}$ \\
\hline & $\begin{array}{l}\text { ONDAS TRANSVERSAIS: } \\
\text { Não há evidência para } \\
\text { recusar a hipótese nula (as } \\
\text { velocidades nas } 4 \text { camadas } \\
\text { não são significativamente } \\
\text { diferentes). }\end{array}$ & $\begin{array}{l}\text { ONDAS TRANSVERSAIS: } \\
\text { Não há evidência para } \\
\text { recusar a hipótese nula (as } \\
\text { velocidades nas medidas } \\
\text { simétricas não diferem } \\
\text { significativamente). }\end{array}$ & $\begin{array}{l}\text { ONDAS TRANSVERSAIS: } \\
\text { A velocidade ao longo da } \\
\text { altura é significativamente } \\
\text { diferente daquela na largura. }\end{array}$ \\
\hline \multirow{2}{*}{ 19.10-2(END) } & $\begin{array}{l}\text { ONDAS LONGITUDINAIS: } \\
\text { A velocidade na camada } 1 \\
\text { difere significativamente } \\
\text { daquelas nas demais } \\
\text { camadas. }\end{array}$ & $\begin{array}{l}\text { ONDAS TRANSVERSAIS: } \\
\text { Não há evidência para } \\
\text { recusar a hipótese nula (as } \\
\text { velocidades nas medidas } \\
\text { simétricas não diferem } \\
\text { significativamente). }\end{array}$ & $\begin{array}{l}\text { ONDAS LONGITUDINAIS: } \\
\text { A velocidade ao longo da } \\
\text { altura é significativamente } \\
\text { diferente daquelas nas } \\
\text { demais dimensões. }\end{array}$ \\
\hline & $\begin{array}{l}\text { ONDAS TRANSVERSAIS: } \\
\text { As velocidades nas camadas } \\
1 \text { e } 4 \text { são significativamente } \\
\text { diferentes. }\end{array}$ & $\begin{array}{l}\text { ONDAS TRANSVERSAIS: } \\
\text { Não há evidência para } \\
\text { recusar a hipótese nula (as } \\
\text { velocidades nas medidas } \\
\text { simétricas não diferem } \\
\text { significativamente). }\end{array}$ & $\begin{array}{l}\text { ONDAS TRANSVERSAIS: } \\
\text { Não há evidência para } \\
\text { recusar a hipótese nula (as } \\
\text { velocidades nas três } \\
\text { dimensões não diferem } \\
\text { significativamente). }\end{array}$ \\
\hline \multirow{2}{*}{ 19.10-3(END) } & $\begin{array}{l}\text { ONDAS LONGITUDINAIS: } \\
\text { A velocidade na camada } 3 \\
\text { difere significativamente } \\
\text { daquelas nas camadas } 1 \text { e } 4 \text {. }\end{array}$ & $\begin{array}{l}\text { ONDAS LONGITUDINAIS: } \\
\text { Não há evidência para } \\
\text { recusar a hipótese nula (as } \\
\text { velocidades nas medidas } \\
\text { simétricas não diferem } \\
\text { significativamente). }\end{array}$ & $\begin{array}{l}\text { ONDAS LONGITUDINAIS: } \\
\text { A velocidade ao longo da } \\
\text { altura é significativamente } \\
\text { diferente daquelas nas } \\
\text { demais dimensões. }\end{array}$ \\
\hline & $\begin{array}{l}\text { ONDAS TRANSVERSAIS: } \\
\text { A velocidade na camada } 1 \\
\text { difere significativamente } \\
\text { daquelas nas demais } \\
\text { camadas. }\end{array}$ & $\begin{array}{l}\text { ONDAS TRANSVERSAIS: } \\
\text { Não há evidência para } \\
\text { recusar a hipótese nula (as } \\
\text { velocidades nas medidas } \\
\text { simétricas não diferem } \\
\text { significativamente). }\end{array}$ & $\begin{array}{l}\text { ONDAS TRANSVERSAIS: } \\
\text { Não há evidência para } \\
\text { recusar a hipótese nula (as } \\
\text { velocidades nas três } \\
\text { dimensões não diferem } \\
\text { significativamente). }\end{array}$ \\
\hline
\end{tabular}

Fonte: Autor (2020) 